\title{
SUSTENTABILIDAD Y AGROBIODIVERSIDAD
}

análisis de la conservación de semillas y conocimientos asociados en agroecosistemas familiares del Cinturón Hortícola Platense

Tesis Doctoral María Margarita Bonicatto año: 2018

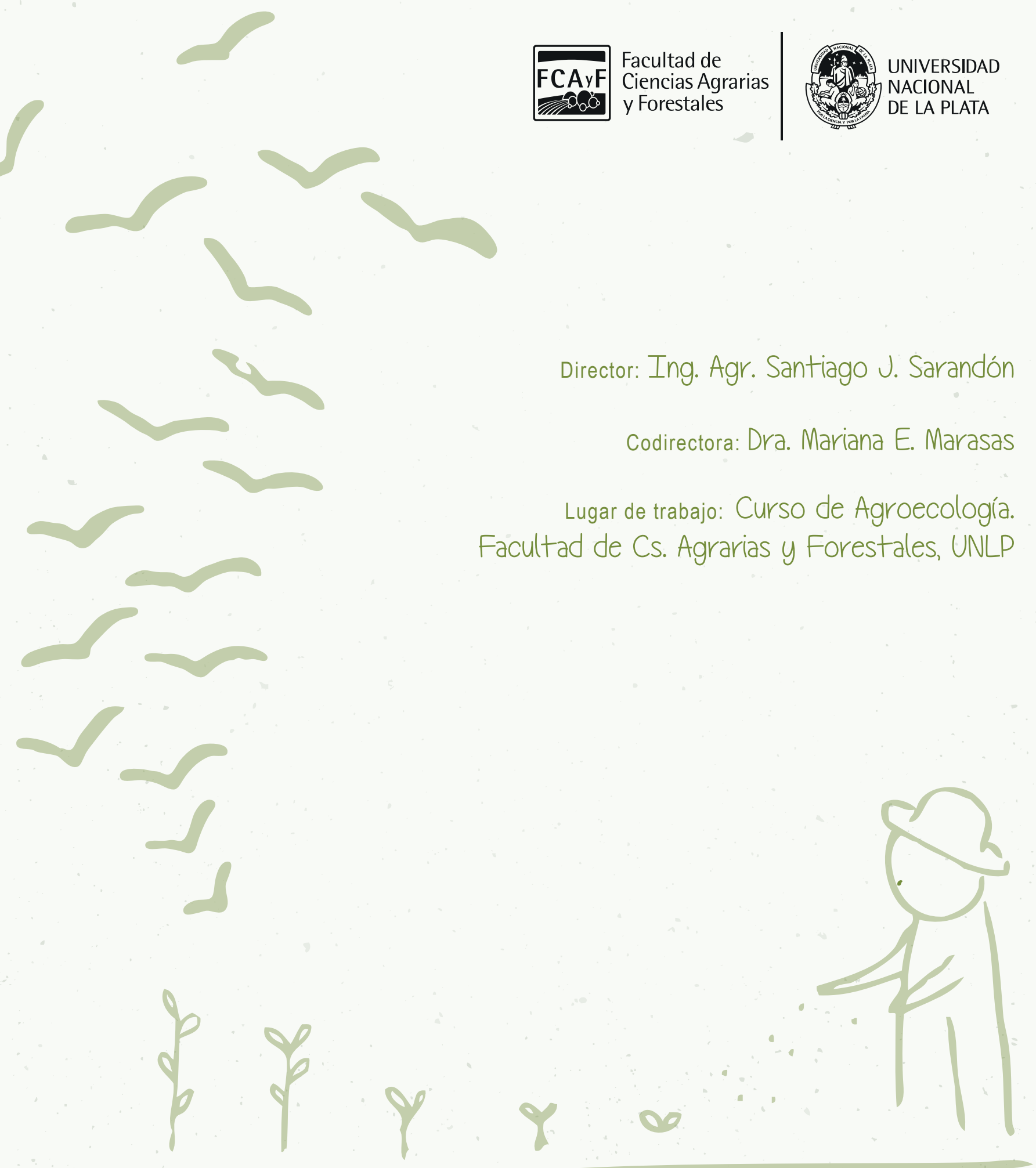




\section{Dedico este trabajo}

A los agricultores y agricultoras que custodian la diversidad biocultural de este territorio A Dante y Valentín, por y para ustedes deseo un mundo más igualitario y saludable

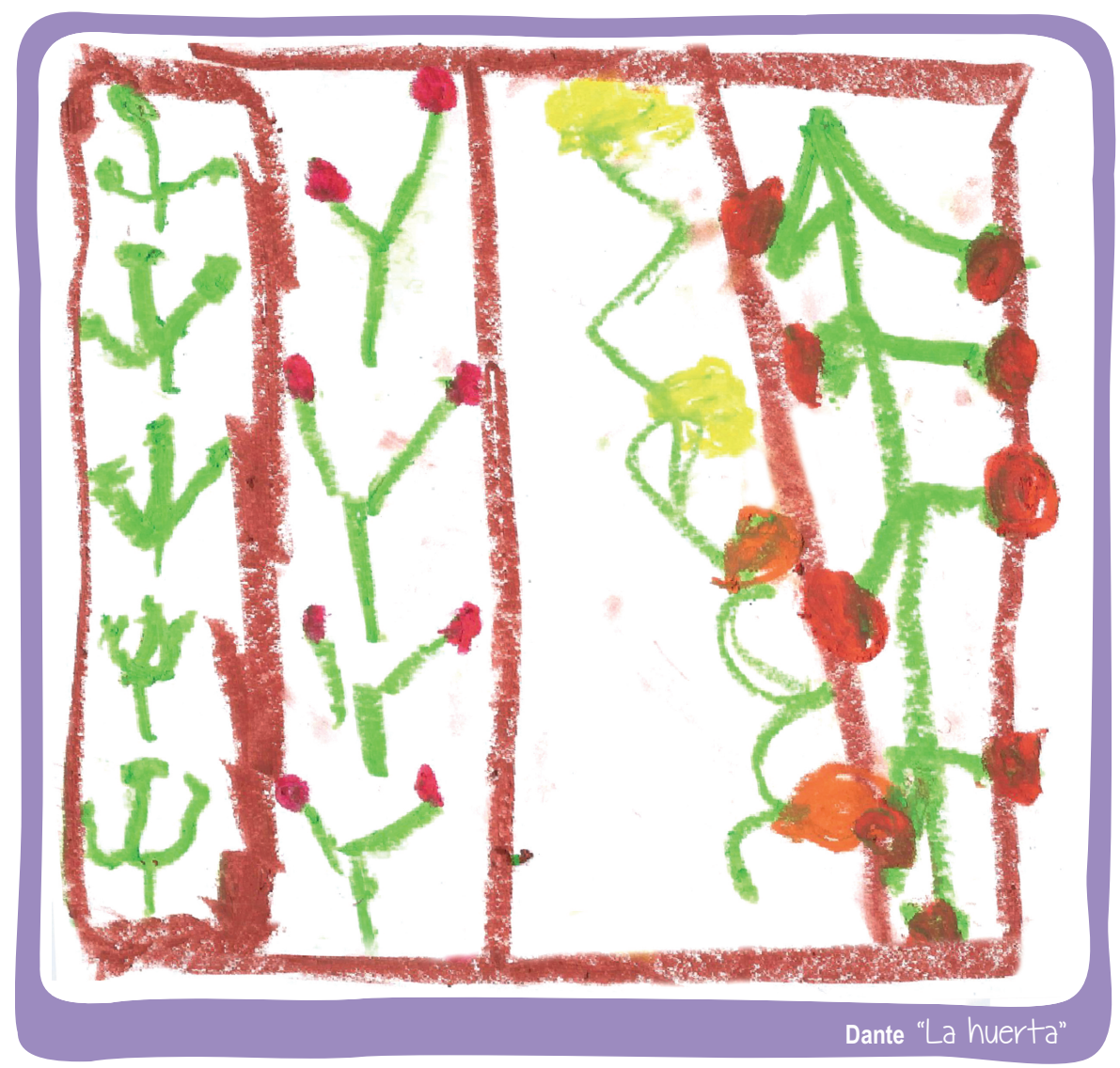




\section{AGRADECIMIENTOS}

El primer agricultor que visité cuando empecé las entrevistas de esta tesis, fue José Lizarraga, él era una persona muy integra y generosa, siempre recuerdo unas palabras que me dijo: "la vida hay que saberla vivir, no vivir porque vivo, la vida hay que aprenderla a vivir y conocer cosas que uno no conoce"

Es así que, el andar en busca de conocimientos que aporten a una horticultura familiar sustentable, transcurrió como parte de mi vida durante unos cuantos años, y por lo tanto, fue atravesado por amor, hijos, alegría, tristeza, ánimo y desánimo, vivido junto a mi familia, mis amigas y amigos, colegas, agricultores y agricultoras. De los momentos compartidos, los gestos, las miradas, de los consejos, de las críticas y los elogios, fui aprendiendo más que contenidos académicos, enriqueciendo mi manera de entender y vivir la vida.

Con los afectos que siguen por acá y los que me acompañan desde las estrellas, comparto la palabra escrita sobre el camino andado.

\section{Mi eterno agradecimiento}

A los agricultores y agricultoras que compartieron sus vidas.

A María Lelia Pochettino (Tany), una gran maestra. Por los años de codirección de beca y su ininterrumpido acompañamiento.

A Santiago Sarandón y Mariana Marasas, por tantas enseñanzas, por sus aportes y reflexiones, pero por sobre todo por transmitirme su entusiasmo por la agroecología.

A mis hermosos y amados Dante y Valentín, sus abrazos, besos y sonrisas son mi energía.

A Guido, por tu confianza en mí y tu contención, que fueron fundamentales para que pueda llegar a esta entrega. Te amo.

A mi hermana y mi mamá, por darme el ejemplo de que las mujeres podemos lograr lo que nos propongamos.

A mis abuelos Oto y Teté, por tanto... pero en especial por su mirada de amor.

A mi papá, por enseñarme a seguir adelante.

A mi tía Coca, por transmitirme su amor por las plantas.

A Julio, Javo, Keki, Ana, Gabriel, Nelba, Pascual y mis sobrinos Julia, Pedro y Alejo ¡linda familia! 
A mis amigas Fer, Agus, Majo, Marilú. Con la energía positiva de todas, el ciclo se va cerrando.

A mis compañeros y compañeras de agroecología, Esteban, Claudia, Paula, Carolina, Susana, Griselda, con ustedes aprendo cada día más.

A los compañeros de las sistematizaciones de la Feria de Semillas Nativas y Criollas, cuna de ideas.

A mis amigas de siempre Juana, Celia, Azu, Jime, Indi.

A Matilde por bajarme a tierra, donde a las plantas le gusta estar.

A Mariana Licursi por su ayuda en el diseño de la tesis y Carolina Baldini con la elaboración de imágenes satelitales.

A las Dras. Ana H. Ladio; Norma I. Hilgert y Nilda Dora Vignale por sus aportes y sugerencias, las cuales enriquecieron este trabajo.

Un agradecimiento especial a la UNLP y al Consejo Nacional de Investigaciones Científicas y Técnicas (CONICET) ya que gran parte de esta tesis fue realizada en el marco de las Becas de investigación que me fueron otorgadas. 


\section{ÍNDICE}

\section{AGRADECIMIENTOS}

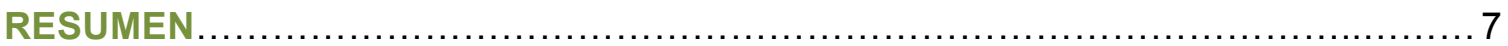

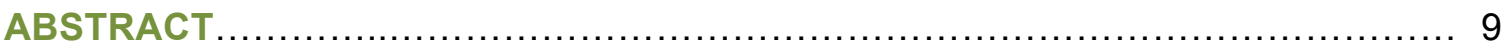

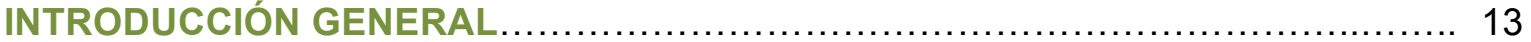

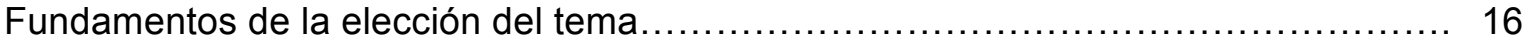

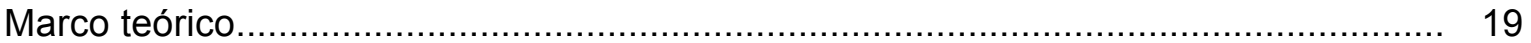

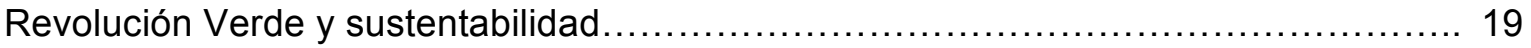

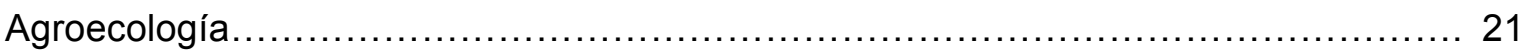

Los agricultores y agricultoras familiares.............................................. 24

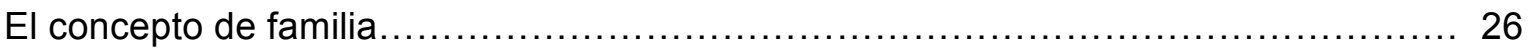

Las semillas en manos de los agricultores y agricultoras ............................ 27

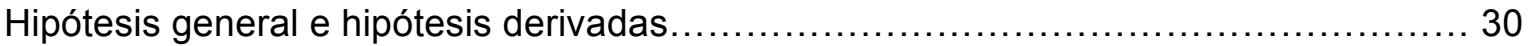

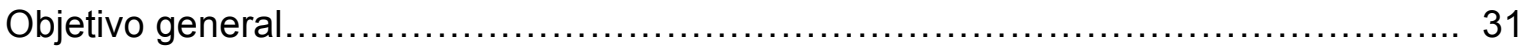

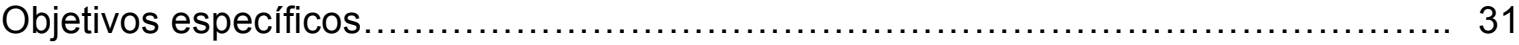

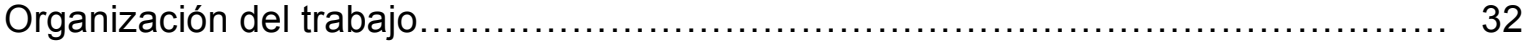

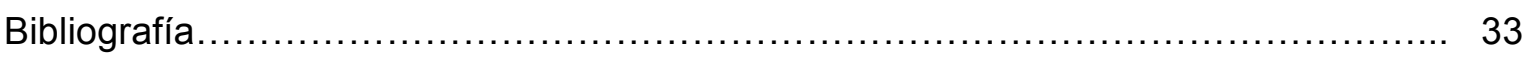

CAPÍTULO 1: Área de estudio y metodología....................................... 44

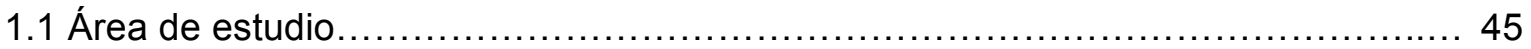

1.1.1 Breve historia de la horticultura en el Cinturón Hortícola Platense.............. 47

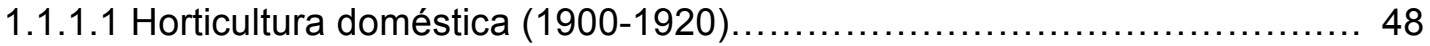

1.1.1.2 Nacimiento de la horticultura comercial $(1920-1940) \ldots \ldots \ldots \ldots \ldots \ldots \ldots \ldots . \ldots 48$

1.1.1.3 Expansión e intensificación de la producción (1940-actualidad)............ 49

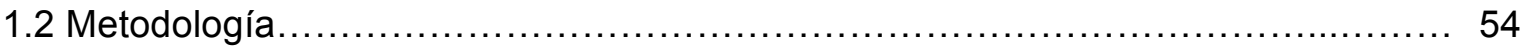

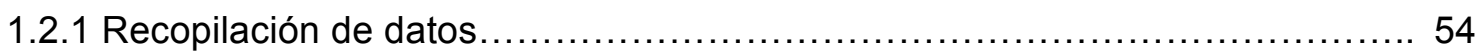

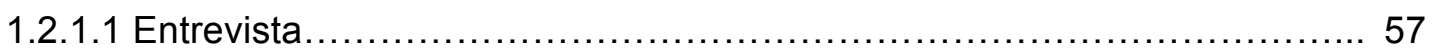

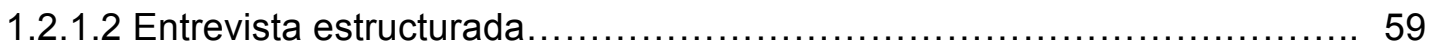

1.2.2. La organización de los datos............................................ 59

1.2.2.1 Determinación del material botánico................................... 59

1.2.2.2 Sistematización..................................................... 60

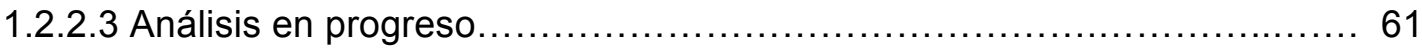

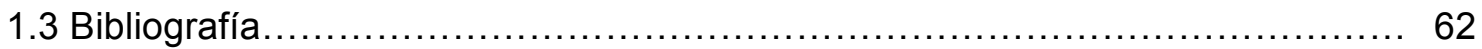


CAPÍTULO 2. La conservación de semillas: una práctica ancestral que sigue activa ... 69

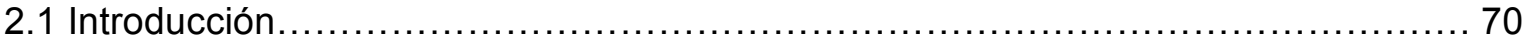

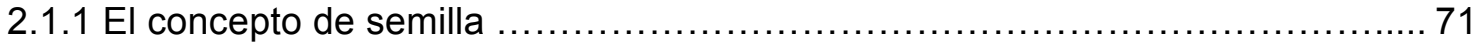

2.1.2 La importancia de los nombres locales..................................... 72

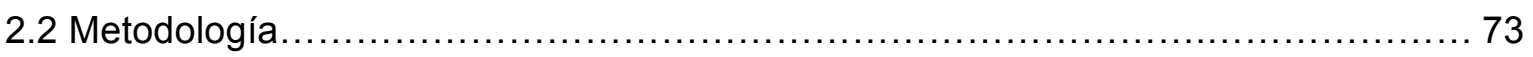

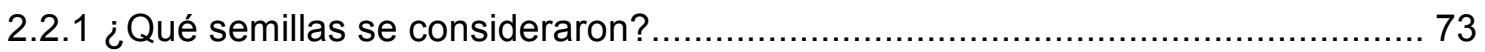

2.2.2 ¿Cómo se cuantificó la agrobiodiversidad? .................................................... 74

2.2.3 Organización y análisis de los datos......................................... 75

2.2.4 ¿De dónde vienen las semillas conservadas? .............................. 77

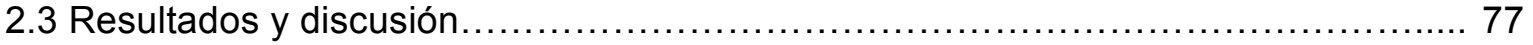

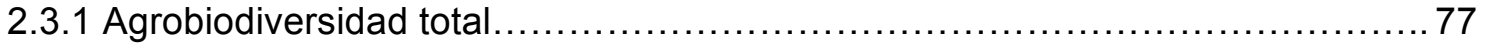

2.3.2 Agrobiodiversidad hortícola cultivada y conservada........................... 80

2.3.2.1 El significado local de los términos variedad e híbrido...................... 86

2.3.2.2 Las vías de ingreso de las semillas conservadas....................... 88

2.3.3 Agrobiodiversidad hortícola no conservada..................................... 91

2.3.4 Agrobiodiversidad rememorada....................................... 97

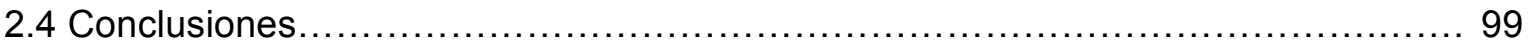

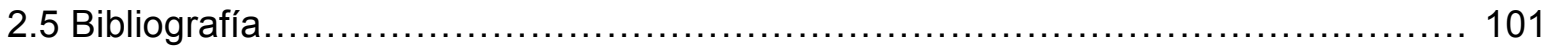

CAPÍTULO 3: Motivos de la conservación de semillas..................................... 108

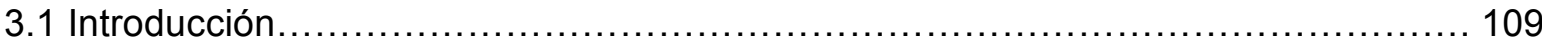

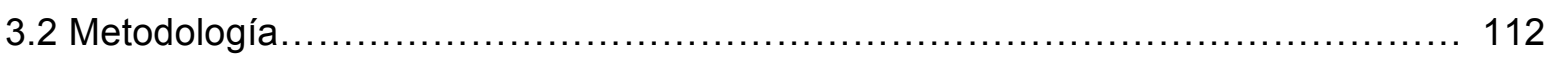

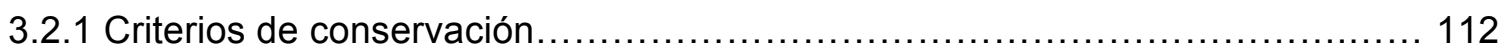

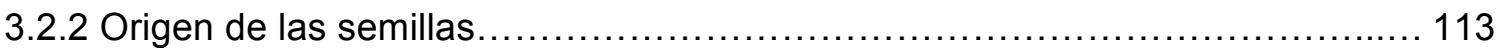

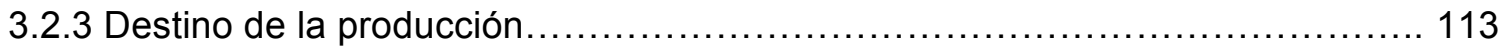

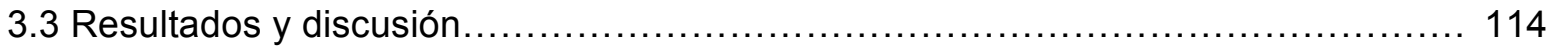

3.3.1 Motivos de los agricultores y agricultoras para conservar agrobiodiversidad in situ................................................................. 114

3.3.2 Relación entre los criterios de conservación y las vías de ingreso

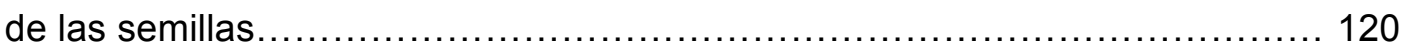

3.3.3 Pluricriterios en la conservación de semillas..................................... 123

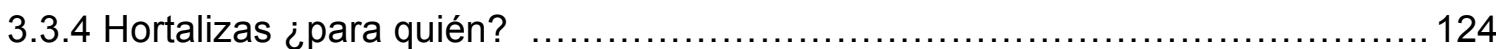

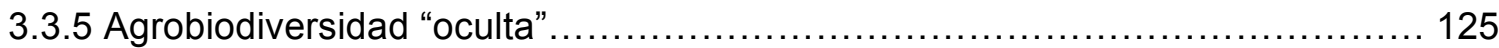

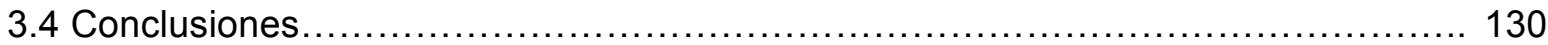

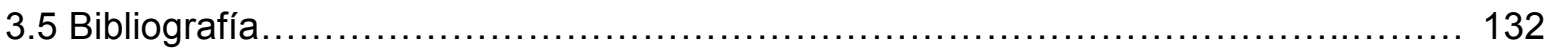


CAPÍTULO 4: Saberes y prácticas sobre conservación de semillas.

Su importancia para la resiliencia de los agroecosistemas familiares...138

4.1 Introducción. 139

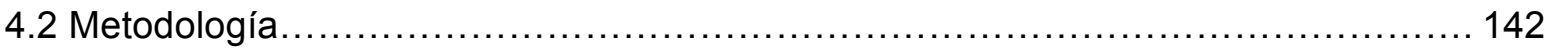

4.2.1 Saberes y prácticas sobre la conservación de semillas.......................... 142

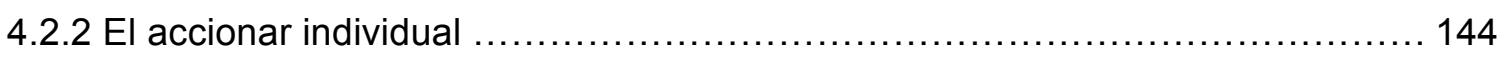

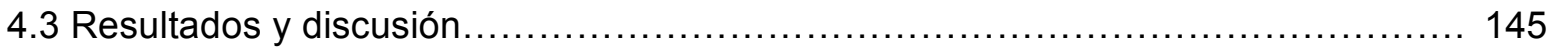

4.3.1 Saberes sobre conservación de semillas en el Cinturón Hortícola Platense..... 147

4.3.1.1 Cultivo y selección de plantas para semillar............................ 148

4.3.1.2 De la quinta a la alacena. Técnicas de recolección, limpieza, secado y guardado de semillas ........................................ 149

4.3.1.4 Dificultades para la conservación..................................... 151

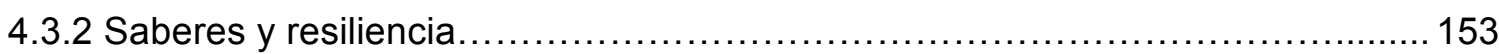

4.3.3 El accionar individual en la conservación de semillas.......................... 154

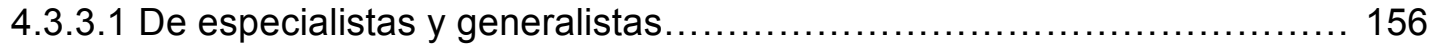

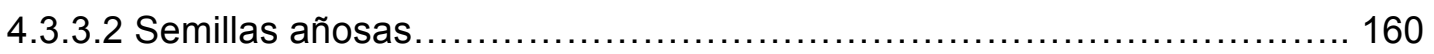

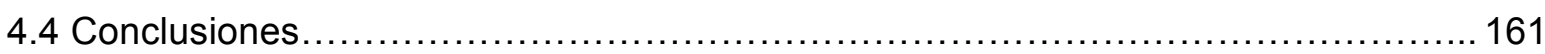

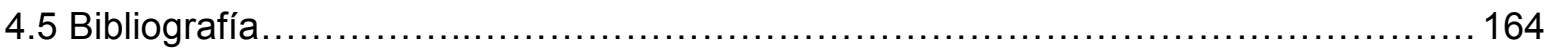

CAPÍTULO 5: La valoración de la conservación de semillas hortícolas

en actores externos al agroecosistema............................. 171

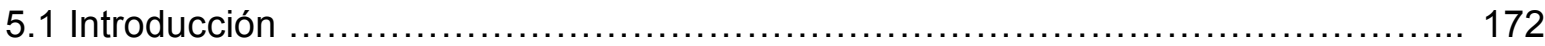

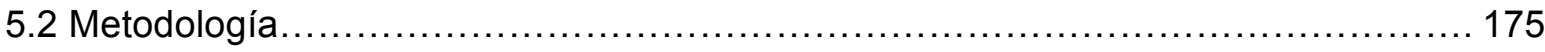

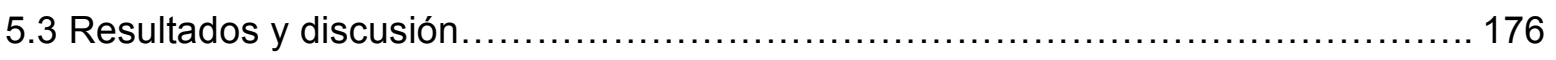

5.3.1 La percepción externa sobre la conservación in situ de semillas ................. 176

5.3.2 Valoración de las semillas producidas por los agricultores y agricultoras......... 178

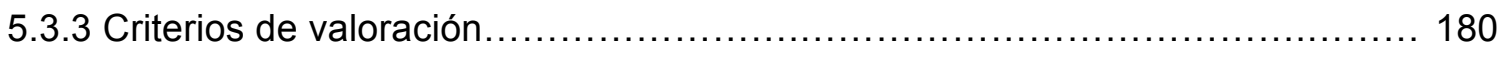

5.3.4 Investigación sobre semillas ¿hacia dónde ir? .............................................. 185

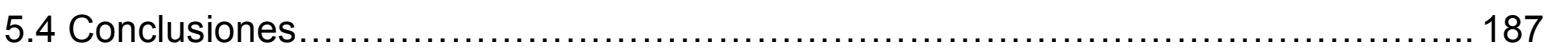

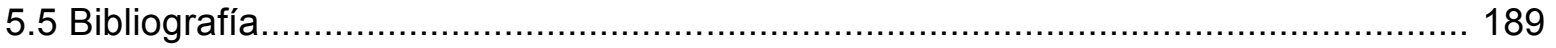

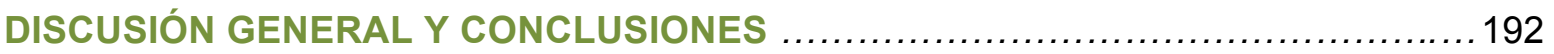

Discusión general: El rol de la conservación de semillas en la sustentabilidad de las producciones familiares del Cinturón Hortícola Platense............... 193

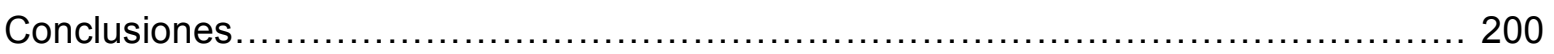

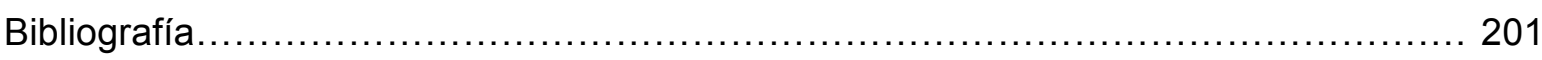




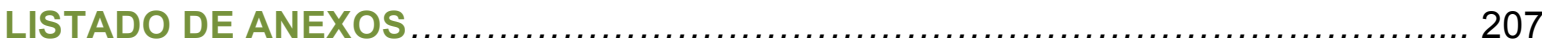

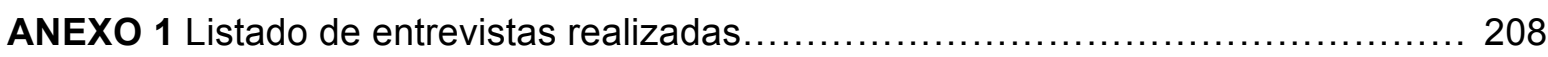

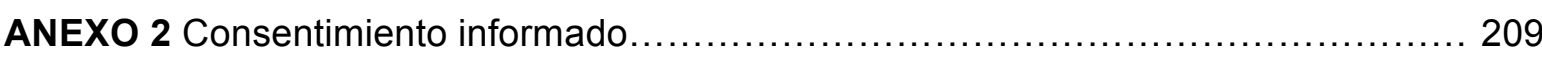

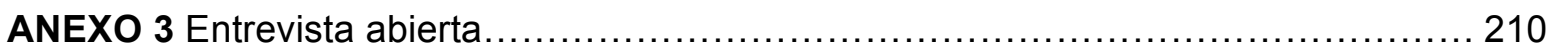

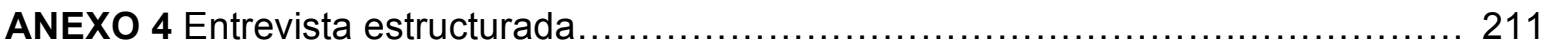

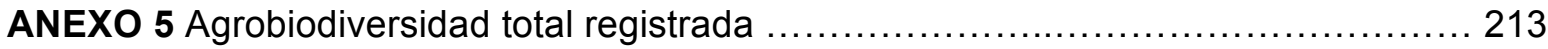

ANEXO 6 Organización de los saberes en torno a la conservación de semillas...........240

\section{LISTADO DE FIGURAS}

Figura 1: Condiciones necesarias para el mantenimiento de agroecosistemas diversificados con semillas de autoproducción. ..................................................... 16

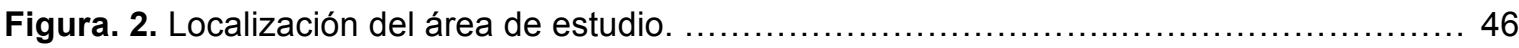

Figura 3: Producción bajo cubierta (invernáculos) en el Cinturón Hortícola Platense ................ 47

Figura 4: Quintas hortícolas a campo y bajo cubierta en el Cinturón Hortícola Platense. ...........53

Figura 5: Localización de los agroecosistemas familiares visitados el Cinturón Hortícola Platense. 56

Figura 6: Detalle de la ubicación de los agroecosistemas familiares visitados el Cinturón Hortícola Platense.

Figura 7: Total de registros de plantas cultivadas en los agroecosistemas familiares del Cinturón Hortícola Platense.

Figura 8: Rubros productivos de la agrobiodiversidad registradas en los agroecosistemas familiares del Cinturón Hortícola Platense.

Figura 9: Usos de la agrobiodiversidad registrada en los agroecosistemas familiares del Cinturón Hortícola Platense.

Figura 10: Total de registros (cultivos hortícolas) conservados y no conservados por agricultores y agricultoras del Cinturón Hortícola Platense.

Figura 11: Riqueza específica y etnoespecífica conservada por agricultores y agricultoras del Cinturón Hortícola Platense.

Figura 12: Riqueza de etnotaxa por cada especie botánica conservada en los agroecosistemas familiares del Cinturón Hortícola Platense.

Figura 13: Origen de las semillas hortícolas conservadas por agricultores y agricultoras del Cinturón Hortícola Platense.

Figura 14: Hortalizas cultivadas y conservadas por agricultores y agricultoras del Cinturón Hortícola Platense.

Figura 15: Agrobiodiversidad hortícola no conservada por agricultores y agricultoras del Cinturón Hortícola Platense.

Figura 16: Criterios de conservación utilizados por los agricultores y agricultoras familiares 
del Cinturón Hortícola Platense.

Figura 17: Criterios de conservación según las diferentes vías de ingreso de semillas agroecosistemas familiares del Cinturón Hortícola Platense.

Figura 18. Destino de los cultivos hortícolas conservados por agricultores y agricultoras del Cinturón Hortícola Platense. 125

Figura 19: Hortalizas cultivadas para autoconsumo. 126

Figura 20. Criterios de conservación de hortalizas cultivadas para autoconsumo en el Cinturón Hortícola Platense.

Figura 21. Categorías utilizadas para el análisis de los conocimientos en torno a la conservación in situ de semillas.

Figura 22: Cultivos destinados a la obtención de semillas en agroecosistemas familiares del Cinturón Hortícola Platense.

Figura 23: Estrategias de acondicionamiento y guardado de semillas en agroecosistemas familiares del Cinturón Hortícola Platense.

Figura 24. Dificultades para la conservación de semillas mencionadas por los agricultores y agricultoras del Cinturón Hortícola Platense.

Figura 25 a y b. Agrobiodiversidad cultivada y conservada por agricultores y agricultoras familiares del Cinturón Hortícola Platense. A. mayores a 50 años. b. menores a 50 años. 155

Figura 26. Origen de las semillas conservadas según el grupo etario de los agricultores y Las agricultoras familiares del Cinturón Hortícola Platense.

Figura 27: Etnoespecies cultivadas y conservadas en agroecosistemas del Cinturón Hortícola Platense.

Figura 28. La autoproducción de semillas según a. investigadores y técnicos extensionistas lasesores b. comerciantes de agroinsumos.

Figura 29: Venta de semillas en comercios de agroinsumos en el Cinturón Hortícola Platense... 180

Figura 30: Criterios de valoración de semillas de hortalizas en actores externos a las producciones.

Figura 31 a y b: Criterios de selección de cultivos hortícolas mencionados por a. investigadores y técnicos vinculados al Cinturón Hortícola Platense. b. Comerciantes de agroinsumos del Cinturón Hortícola de Platense.

\section{LISTADO DE TABLAS}

Tabla 1: Agrobiodiversidad hortícola conservada por agricultores y agricultoras del

Cinturón Hortícola Platense.

Tabla 2: Agrobiodiversidad hortícola no conservada por agricultores y agricultoras del

Cinturón Hortícola Platense.

Tabla 3: Agrobiodiversidad hortícola rememorada por agricultores y agricultoras del 
Tabla 4 Criterios que sustentan la conservación de semillas en agroecosistemas familiares

del Cinturón Hortícola Platense.

Tabla 5: Pluricriterios en la conservación de semillas. 124

Tabla 6: Criterios que sustentan la conservación de hortalizas cultivadas para autoconsumo. .. 129

Tabla 7. Conocimientos de los agricultores y agricultoras familiares del Cinturón Hortícola

Platense, sobre la conservación de semillas in situ y porcentaje de hortalizas conservadas sobre el total cultivado.

Tabla 8. Agrobiodiversidad hortícola conservada por agricultores y agricultoras familiares del Cinturón Hortícola Platense. 159

Tabla 9. Agrobiodiversidad conservada por más de 7 años en agroecosistemas del Cinturón Hortícola Platense. 161

Tabla 10. Ranking de características vinculadas a las semillas hortícolas según actores externos a los agroecosistemas familiares del Cinturón Hortícola Platense.

Tabla 11: Conservación de semillas locales y comerciales en agroecosistemas familiares del Cinturón Hortícola Platense. Similitudes y diferencias. 


\section{SUSTENTABILIDAD Y AGROBIODIVERSIDAD}

\section{análisis de la conservación de semillas y conocimientos asociados en agroecosistemas familiares del Cinturón Hortícola Platense.}

\section{RESUMEN}

La diversificación de agroecosistemas familiares permite minimizar el riesgo, estabilizar los rendimientos a largo plazo, promover la diversidad de dietas y maximizar los ingresos en situaciones de recursos limitados. Para lograr el éxito de dichas estrategias deben coexistir dos factores básicos: una alta disponibilidad de semillas y los conocimientos en torno a las prácticas de manejo, usos y conservación del material reproductivo. En el Partido de La Plata, Provincia de Buenos Aires existe uno de los cinturones hortícolas más importantes de la Argentina. Allí la producción nace con la fundación de la ciudad de La Plata a fines del siglo XIX. En estas tierras con el paso del tiempo, a través de la selección y conservación de hortalizas realizada por las familias agricultoras "quinteros", la llegada de nuevas inmigraciones y la dinámica particular de la producción hortícola, se estableció una "cultura de producción biodiversa". Desde los años 90 comenzó un proceso de avance del modelo de la Revolución Verde, el cual implicó la incorporación de formas intensivas de producción, con baja diversificación, semillas híbridas, agroquímicos y un mercado exigente en rendimiento y estética de los productos, lo cual impactó negativamente en su sustentabilidad. El propósito de este trabajo es aportar conocimiento científico sobre la diversidad biocultural conservada por agricultores y agricultoras familiares del Cinturón Hortícola Platense a partir del conocimiento y de la práctica local. La hipótesis general de esta tesis se plantea que: En los agroecosistemas familiares del Cinturón Hortícola Platense, existe agrobiodiversidad hortícola conservada in situ. A su vez, las hipótesis derivadas enuncian que: 1. Los agricultores y agricultoras familiares del Cinturón Hortícola Platense utilizan diferentes criterios que intervienen en la conservación del material reproductivo. 2. Existen recursos genéticos "ocultos" cultivados por los agricultores familiares del Cinturón Hortícola Platense. 3. Los agricultores y agricultoras familiares del Cinturón Hortícola Platense mantienen conocimientos sobre la práctica de conservación de semillas. Los conocimientos son condición necesaria para el mantenimiento in situ de agrobiodiversidad 4. En los actores externos a la producción (técnicos, investigadores y comerciantes) prevalecen criterios productivistas en la valoración del material reproductivo hortícola. Este tema multidimensional, se estudió 
desde el marco teórico de la agroecología. Para la realización de esta investigación se utilizaron herramientas metodológicas de la etnobotánica: entrevistas abiertas, semiestructuradas y estructuradas, observación participante y análisis en progreso. Se realizaron entrevistas a 26 familias agricultoras. En el total de agroecosistemas visitados se registró la agrobiodiversidad cultivada, las semillas conservadas, su origen y sus usos. Se describieron los criterios que sustentan su conservación y los conocimientos locales referidos a dicha práctica. Para profundizar en el valor que otorgan a la conservación in situ los actores externos a las producciones, se realizaron entrevistas estructuradas. Cada cultivo hortícola fue considerado un registro. Se documentaron 616 registros que corresponden a 31 familias botánicas, 120 especies botánicas y 305 etnoespecies ligadas a diferentes rubros productivos. 454 de ellos corresponden a la categoría horticultura. El 53.7\% de los registros de plantas hortícolas son conservadas in situ y corresponden a una riqueza de 10 familias botánicas, 41 especies y 152 etnoespecies. Los resultados obtenidos dan cuenta de que la conservación de semillas en el Cinturón Hortícola Platense sigue activa y dinámica. Los agricultores y agricultoras familiares aplican esta práctica y la adaptan para conservar tanto semillas locales, obtenidas por vías informales, como para conservar semillas comerciales obtenidas del circuito formal. Se describieron 10 criterios de conservación que operan de manera diferente según el origen de la semilla. La conservación de semillas locales está relacionada con criterios ligados a la experimentación y al quehacer cotidiano e historia familiar, mientras que las de origen comercial se conservan principalmente por el criterio económico y morfológico. Los resultados obtenidos revelan que los agricultores y agricultoras mantienen conocimientos sobre el conjunto de prácticas que hacen a la conservación in situ. Las diferencias en el número de hortalizas conservadas y su origen muestran divergencias en el posicionamiento sobre cuánta agrobiodiversidad y qué conservar. Por último, se discute la coexistencia de dos vertientes en la conservación de semillas, con implicancias diferentes en la sustentabilidad y resiliencia de los agroecosistemas familiares. La conservación de semillas obtenidas por vías informales, se posiciona como una estrategia contra hegemónica, más adecuada para el fortalecimiento de la sustentabilidad y conservación de la diversidad biocultural. Esta conservación genera independencia de insumos externos, mantiene diversidad de etnoespecies y acciona para la permanencia de la identidad y tradición de los agricultores y agricultoras. Los datos obtenidos sugieren que las recomendaciones y valoraciones de los comerciantes de agroinsumos, son coherentes con el modelo productivista, mientras que el sector institucional considera importante el mantenimiento de semillas locales y los aspectos sociales que se asocian a estos, pero detectan complicaciones ligadas al modelo dominante. Por lo tanto, en el 
contexto actual, pensar en la diversificación de los agroecosistemas basada exclusivamente en semillas locales de conservación in situ, no es suficiente para asegurar la autonomía y favorecer la permanencia de las familias en el territorio. Finalmente, se sugiere fortalecer el vínculo entre las instituciones estatales ligadas al sector y los agricultores y agricultoras, como estrategia para complementar las acciones que favorezcan el mejoramiento, la conservación y distribución de semillas, para promover la sustentabilidad de la producción familiar en el Cinturón Hortícola Platense.

Palabras clave: agricultura; conocimiento local; agroecología, agroecosistemas resilientes. 
Sustainability and agrobiodiversity: seed conservation analysis and its associated knowledge in family agroecosystems in La Plata's Green Belt.

Diversification of family agroecosystems allows minimizing the risk, stabilizing the longterm yields, promoting the diversity of diets and maximizing the income in situations of limited resources. To achieve the success of these strategies, two basic factors must coexist: high availability of seeds and associated knowledge about practice of selection, use and conservation of reproductive material. One of the most important green belts in Argentina is located in La Plata region. Horticultural production started during late nineteenth century with the founding of La Plata city. In these lands, through selection and conservation of vegetables grown by farmers, the arrival of new immigrants and the particular dynamics of horticultural production, a "culture of diversified production" were promoted. The model put forward by the Green Revolution was widely adopted and resulted in deep technological transformations, mainly during the 1990s. Such area, characterized by intensive forms of production, low diversification, hybrid seeds, (the use of) agrochemicals and a demanding market in terms of product performance and aesthetics, is undergoing certain changes that seriously affect the sustainability of such area. The aim of this study is to provide scientific knowledge about the biocultural diversity conserved by family farmers from La Plata's Green Belt, based on local knowledge and practice. The general hypothesis stated that: In family agroecosystems of La Plata's Green Belt, horticultural agrobiodiversity is conserved in situ. In turn, the derived hypotheses state that: 1. Family farmers of La Plata's Green Belt use different seed criteria that intervene in reproductive material conservation. 2. Family farmers of La Plata's Green Belt cultivate genetic resources that remain "hidden" 3. Family farmers of La Plata's Green Belt maintain knowledge about seed conservation practice. Knowledge is a necessary condition for agrobiodiversity in situ conservation. 4. Productivist criteria prevail in the evaluation of horticultural reproductive material from external agents (technicians, researchers and traders). This multidimensional approach was studied from the theoretical agroecology framework. Ethnobotany methodological tools were used to carry out this research: open, semistructured and structured interviews, participant observation and "working with data" process. Data collection was based on 26 semi-structured interviews. During interviews we inquired about cultivated agrobiodiversity, preserved seeds, their origin, uses, conservation criteria and local knowledge. In order to study agrobiodiversity values that commercial and institutional actors place on in situ conservation, structured interviews were conducted. 616 cultivated plants were recorded 
corresponding to 31 botanical families, 120 botanical species and 305 ethnospecies. This agrobiodiversity belong to different productive areas. 454 of them belongs to horticulture category. $53.7 \%$ of the horticultural records were conserved in situ and correspond to 10 botanical families, 41 species and 152 ethnospecies. The data presented here confirms that, the practice of seed conservation is still active and dynamic. Also show that family farmers are not only keeping local seeds obtained by the informal system but they have also made this practice extensive to commercial seeds distributed by the formal system. Their conservation is supported by 10 conservation criteria. The results of this research suggest that criteria for seed conservation are different depending on seed origin. Local seeds conservation is related to experimentation and the diversification of plants for household use, to the family day-to-day work and traditions. On the other hand, conservation of commercial seeds is mostly based on economic and morphological criteria. The results of this research also show the permanence of local knowledge about the practice of seed conservation. Differences in the number of vegetables preserved and their origin, show divergences in the positioning on how much agrobiodiversity and what to conserve. Finally, the coexistence of two positions in seed conservation with different implications in the sustainability and resilience of family agroecosystems is discussed. Local seed maintenance obtained by the informal system is suggested as a more suitable strategy for the strengthening of sustainability and the conservation of biocultural diversity.

The optimization of this diversity results in an independence from external inputs, diversity of ethnospecies and contributes with the permanence of the identity and tradition of farmers. The data obtained show that recommendations and valuations of commercial actors are consistent with the Green Revolution model. Meanwhile institutional actors, highlight the importance of local seed conservation and social aspects, however they identify complications linked to the dominant model. Therefore, in the current context, thinking about the diversification of agroecosystems based exclusively on local seeds of in situ conservation is not enough to ensure the autonomy and permanence of families in the territory. Finally, it is suggested to strengthen the link between state institutions related to agrobiodiversity conservation and family farmers. This strategy complements the actions that favor the improvement, conservation and distribution of seeds, to promote the sustainability of family production in La Plata's Green Belt.

Key words: agriculture; local knowledge; agroecology; resilient agroecosystems 
INTRODUCCIÓN GENERAL 


\section{INTRODUCCIÓN GENERAL}

"Yo soy muy curioso, usted sabrá disculpar y siempre quiero saber por qué, para qué, cuál es el motivo, la razón, los objetivos"

(Bonicatto 2013d. Entrevista a IG)

Desde la Convención sobre Diversidad Biológica (UNEP, 1992) realizada en Río de Janeiro en 1992, se generó una conciencia mundial sobre la importancia de proteger la biodiversidad como un componente clave para el desarrollo de una agricultura sustentable (Sarandón, 2009). Este Convenio define a la biodiversidad como "la variabilidad entre organismos vivientes de todo tipo u origen incluyendo, entre otros, ecosistemas terrestres, marinos y otros sistemas acuáticos y los complejos ecológicos de los cuales ellos forman parte". A partir de la firma de este convenio, y por primera vez en el derecho internacional, se reconoce que la conservación de la biodiversidad es una preocupación de la humanidad y parte integral del proceso de desarrollo (Sarandón, 2009). Por lo tanto, se establece como uno de los desafíos más importantes a nivel mundial, el lograr compatibilizar la conservación con el manejo sostenible de la misma (UNEP, 1997). En este contexto, se reconoce que la biodiversidad es un concepto complejo, que involucra varios niveles de organización biológica (genético, específico, ecosistémico y paisajístico) y que no es solamente un concepto que expresa la "variedad de vida" sino que es una construcción socio-política y una entidad ecológica medible (Gaston, 1996). Teniendo en cuenta lo anteriormente expuesto, es que de aquí en adelante se utilizará el término agrobiodiversidad por considerarse más adecuado para el abordaje propuesto, entendiendo el mismo como todos los componentes de la biodiversidad que constituyen el ecosistema agrícola, las variedades y variabilidad de animales, plantas y microorganismos a nivel genético, específico y ecosistémico, necesarios para mantener las funciones principales de los ecosistemas agrarios, su estructura y procesos (UNEP, 2000). A su vez se pondrá especial interés en el componente vegetal de la agrobiodiversidad, entendiendo que su importancia radica en que éste es el eslabón trófico que sostiene la complejidad del sistema.

La toma de conciencia sobre la importancia de la agrobiodiversidad posiciona su conservación como un tema de relevancia tanto para el ámbito académico y político como para los agricultores y la población en general (Abdelali-Martini et al., 2008; Almekinders et al., 1994; Clergue et al., 2005; Hilgert et al., 2013; Louette et al., 1997; 
Martínez-Torres \& Rosset, 2017; Nazarea, 2006; Sarandón, 2009; Silveira, 2015; Wood \& Lenné 1997). A escala internacional, la COP-5 (UNEP, 2000), reconoce que quienes administran la agrobiodiversidad son los agricultores y que los componentes de la misma, dependen de la intervención humana. De ello deriva que los agroecosistemas manejados mediante prácticas tradicionales o locales en sintonía con el ambiente, son considerados reservas de diversidad genética in-situ (Altieri, 2000). Se entiende por tradicional el corpus acumulativo de prácticas, conocimientos y creencias sobre las relaciones entre los seres vivos (incluidos los seres humanos) y de los mismos con su entorno (Berkes, 1993; Gadgil et al., 1993; Hunn, 2002). En este trabajo, si bien se toma la definición de Berkes (1993), se reemplaza el rótulo de tradicional por el de local como lo proponen ReyesGarcía \& Martí Sanz (2007), el cual implica una mayor amplitud al incorporar los saberes derivados de otros grupos, incluso el científico, tamizados a la luz de las prácticas propias. A su vez, los términos saberes y conocimientos serán utilizados indistintamente. El término diversidad biocultural se incorpora a fin de hacer referencia a la diversidad de la vida en todas sus manifestaciones -biológica, cultural y lingüística- interrelacionadas conformando un sistema adaptativo socio-ecológico (Maffi, 2005; Terralingua, 2010). Según Harwood (1979) y Nicholls (2013) la diversidad biocultural, permite a los agricultores, minimizar el riesgo de sus producciones, estabilizar los rendimientos a largo plazo, promover la diversidad de dietas y maximizar los ingresos en situaciones de recursos limitados. El mantenimiento de una producción diversificada necesaria para la subsistencia, implica la generación de toda una gama de productos que incluyen, entre otros, una gran variedad de alimentos (Toledo, 1992). La evidencia científica señala que la diversificación de cultivos representa una estrategia para los agricultores que están experimentando un clima errático, y que el uso de la diversificación al interior de los sistemas agrícolas puede reducir en gran medida la vulnerabilidad de los mismos (Altieri et al., 2015; Isbell et al., 2015; Nicholls, 2013; Nicholls et al., 2015). A su vez, se destaca que el conocimiento local sobre aquellas prácticas de manejo de recursos, entre ellos la agrobiodiversidad, que fortalezcan los procesos ecológicos, son la base de la resiliencia de los agroecosistemas tradicionales (Altieri, 2013). Se entiende por resiliencia, la capacidad de absorber un disturbio y reorganizarse ante el cambio (Berkes \& Turner, 2006; Folke et al., 2010). Estas evidencias posicionan en un lugar de suma importancia a la agrobiodiversidad conservada por los agricultores, resaltando que este componente es de vital importancia, si de resiliencia y sustentabilidad de los agroecosistemas familiares estamos hablando. 


\section{Fundamentos de la elección del tema}

Para el desarrollo y mantenimiento de agroecosistemas diversificados son necesarias dos condiciones, la disponibilidad de semillas para cultivar y los conocimientos que acompañen dichas semillas (Figura 1). Entendiendo el término semilla en sentido amplio, como todo órgano o parte vegetal que permita su propagación (Bonicatto et al., 2009).

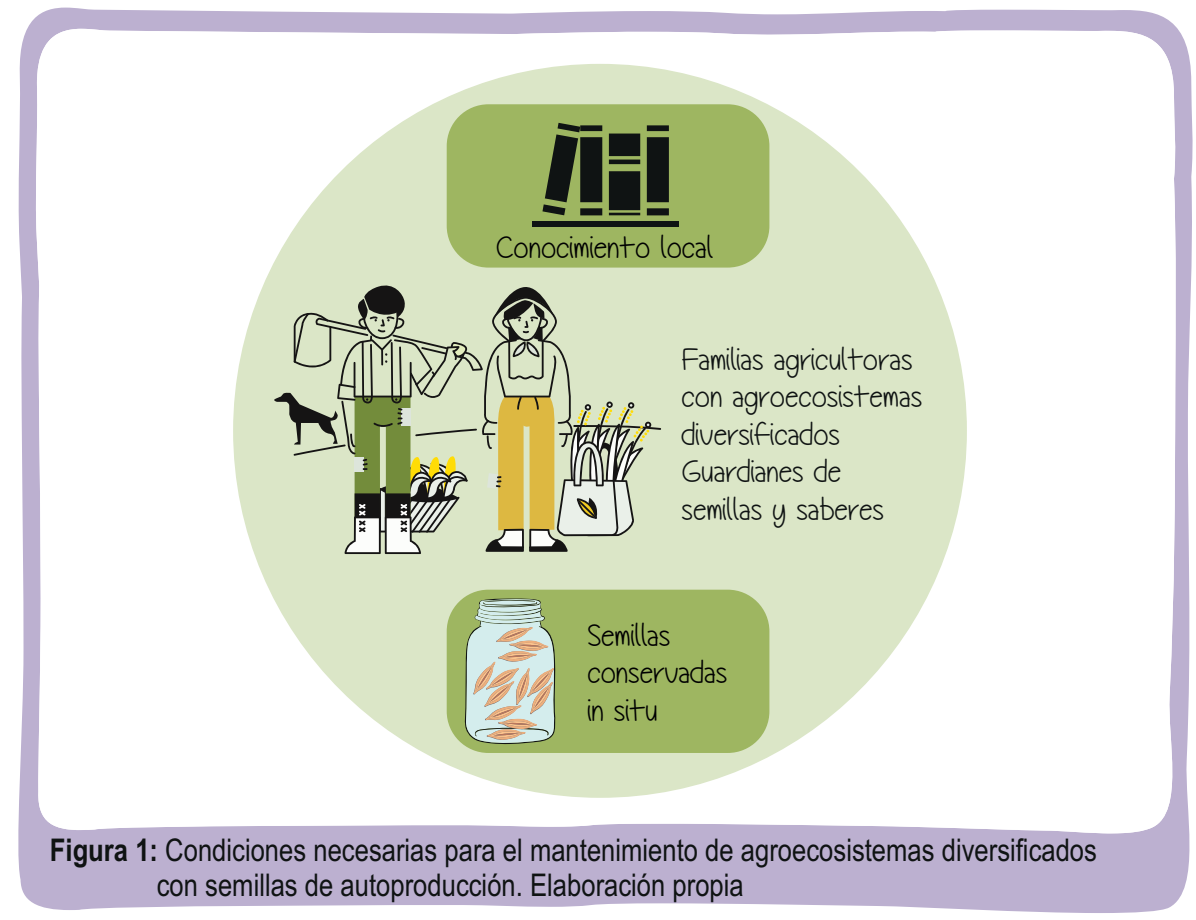

La conservación y reproducción de semillas es una práctica que se encuentra entre las actividades agrícolas más básicas y antiguas que ha realizado el ser humano y permite a los agricultores y agricultoras cultivar variedades adaptadas al ambiente local, a sus cambios y a sus necesidades y gustos, siendo un componente fundamental de los sistemas productivos, la soberanía y la autonomía alimentaria de los pueblos (Grupo Semillas, 2014). En un sentido más simbólico, las semillas han sido y siguen siendo parte de la identidad de las personas, ya que están vinculadas a las costumbres alimenticias y a los platos típicos que expresan orígenes y tradiciones, prácticas y celebraciones. En definitiva, este cuerpo simbólico, del cual las semillas forman parte, es la identidad del agricultor y, por lo tanto, de su pueblo y de su vida (Pochettino et al., 2011).

A pesar de los aspectos resaltados anteriormente, la conservación de semillas llevada a cabo por los agricultores y agricultoras, es uno de los aspectos afectados por el modelo agrícola de la Revolución Verde (de Boef, 2007). Este modelo introdujo y generalizó la idea de modificar el ambiente mediante la utilización de paquetes tecnológicos basados 
semillas comerciales de alto potencial de rendimiento (Sarandón \& Flores, 2014), en lugar de conservar una alta variabilidad genética que se adecuara a la diversidad de ambientes y costumbres. En la práctica esto se evidencia, a partir de la simplificación de los agroecosistemas a través del reemplazo de la diversidad natural y agrobiodiversidad conservada por los agricultores, por un pequeño número de plantas cultivadas organizadas en monocultivos (Altieri, 1999; Swift et al., 2004). El producto de esta simplificación es la reducción y posible pérdida de agrobiodiversidad y los conocimientos que la acompañan. El trabajo realizado por Eyssartier et al. (2011) advierte que la pérdida de diversidad genética tradicional conlleva a la pérdida de conocimientos asociados. A su vez, el trabajo de Tengö \& Belfrage (2004) resalta la importancia del aprendizaje continuo para el desarrollo y manejo sustentable de agroecosistemas complejos. En el contexto planteado surge el accionar individual como una perspectiva importante de estudiar, al ser los individuos -y no las sociedades- los que manipulan las plantas (Pochettino \& Lema, 2008; Reyes-García et al., 2007) y por lo tanto, accionan hacia la permanencia o no de los conocimientos en torno a la conservación de semillas.

Este trabajo de investigación se focaliza en agroecosistemas familiares por varias razones. La primera es la representatividad de los sistemas productivos familiares en la Argentina, los cuales corresponden al $66 \%$ de los establecimientos agropecuarios del país y ocupan el $13,5 \%$ de la superficie, siendo esto más de 23 millones de hectáreas (Fornari, 2008). Es de imaginar que dentro del $66 \%$ que representan los establecimientos familiares en la Argentina existe una gran heterogeneidad. Sin embargo, se encuentran aspectos comunes que caracterizan este sector, como la orientación de la producción para autoconsumo y para el mercado, el trabajo familiar y la integración física de la unidad doméstica y productiva. Estas características sumadas a la diversidad productiva, hacen de la agricultura familiar un tejido de contención social que permite la permanencia de las familias en el ámbito rural, evitando la migración interna y la formación de cordones urbanos de pobreza, jugando además, un rol clave en la seguridad y soberanía alimentaria familiar (Cittadini et al., 2005). El trabajo de Salcedo et al. (2014a) destaca la contribución de la agricultura familiar a la seguridad alimentaria de la población en general, mediante la generación de sistemas alimentarios de bajo impacto ambiental, que contribuyan a dietas saludables, que a la vez, sean sustentables y diversificadas, y que al ser locales y de temporada, apoyen la producción de alimentos agroecológicos, así como redes de producción-consumo de corta distancia para el comercio justo. A su vez, Silveira (2015) resalta la importancia de que las comunidades tengan control sobre sus recursos, entre ellos la agrobiodiversidad, para garantizar la soberanía alimentaria. 
La segunda razón es que este sector está transitando cambios que lo posicionan de una manera muy vulnerable en cuanto a su sustentabilidad a causa del avance de formas intensivas de producción, con baja diversificación, semillas híbridas, agroquímicos y un mercado exigente en rendimiento y estética de los productos. Por último, pero no menos importante, es que estos sistemas familiares, al ser manejados por los propios agricultores, mantienen vigente la estrecha relación entre los agricultores y el ambiente, cuya importancia se destacó anteriormente.

En el Partido de La Plata, Provincia de Buenos Aires, existe uno de los cinturones hortícolas más importantes de la Argentina. Allí la producción nace con la fundación de la ciudad a fines del Siglo XIX. En estas tierras con el paso del tiempo, a través de la selección y conservación de hortalizas realizada por las familias agricultoras "quinteros", la llegada de nuevas inmigraciones y la dinámica particular de la producción hortícola, se estableció una "cultura de producción biodiversa" (Garat et al., 2007; 2009). Posteriormente se provocó una lenta reducción y desuso de un gran número de semillas locales, a causa del avance de formas intensivas de producción, con baja diversificación, semillas híbridas, agroquímicos y un mercado exigente en rendimiento y estética de los productos. Los cambios ocurridos establecieron un territorio heterogéneo respecto al origen de los agricultores, la organización social del trabajo (familiar o asalariada), los estilos de producción (orgánico y convencional) y los niveles de incorporación tecnológica (Cieza, 2004), pero homogéneo en cuanto a la presión del modelo hegemónico. En el contexto planteado, los conocimientos propios de los agricultores y la agrobiodiversidad por ellas y ellos seleccionada y conservada ha sido desvalorizada.

El propósito de esta tesis es aportar conocimientos científicos enmarcados en las bases conceptuales de la agroecología, sobre la agrobiodiversidad hortícola conservada por los agricultores y agricultoras familiares del Cinturón Hortícola Platense y los conocimientos locales asociados a dicha práctica. En este sentido, la información de esta tesis brinda elementos de importancia para el desarrollo y fortalecimiento de estrategias que tiendan a conservar la diversidad biocultural de este territorio. A su vez los conocimientos aportan conceptos aplicables al diseño y manejo de agroecosistemas resilientes y sustentables. 


\section{MARCO TEÓRICO}

\section{Revolución Verde y sustentabilidad}

La agricultura en su sentido más amplio, constituye el vínculo central de las sociedades rurales con la naturaleza y es el eje de la vida económica, social y cultural para la mayoría de las comunidades rurales y sus habitantes (Sarandón \& Flores, 2014). Teniendo en cuenta que la agricultura es uno de los usos de la tierra predominante en el mundo, que ocupa alrededor del $40 \%$ de la superficie terrestre (FAO, 2013), es fundamental mantener la biodiversidad en los agroecosistemas (Matson et al., 1997). A su vez, la agrobiodiversidad es el componente esencial para el mantenimiento de las funciones ecológicas de los sistemas productivos y es la base de los recursos genéticos necesarios para sostener las producciones (Nicholls et al., 2016; Stupino et al., 2014). En este sentido, la agricultura necesita y utiliza la agrobiodiversidad y dependiendo de las formas de uso que se establezcan, es que la misma agricultura puede tornarse una de las mayores amenazas para la conservación de este componente. A lo largo de la historia se han desarrollado diversas formas de hacer agricultura vinculadas a las distintas regiones y culturas. Actualmente el modelo que predomina, es el que sigue las bases propuestas por la Revolución Verde, el cual se constituye como una de las principales amenazas contra la agrobiodiversidad, debido al uso intensivo de agroquímicos y la utilización de un número reducido de especies y variedades mejoradas, y de otras tecnologías, que conducen a la pérdida de especies silvestres beneficiosas por su rol ecológico en los ecosistemas naturales y modificados (Altieri \& Nicholls ,1994; Matson et al.,1997; Stupino et al., 2014).

Es sabido que uno de los pilares fundamentales de los paquetes tecnológicos propuestos por la Revolución Verde son las semillas de alto rendimiento, y que esta propuesta se dirige a poner el ambiente al servicio de las variedades cultivadas, es decir, generar las condiciones necesarias para que los cultivos expresen su mayor potencial de rendimiento. Según Shiva (1991 en Sarandón \& Flores 2014), ha prevalecido en este modelo una mirada reduccionista, llevando a comparaciones inequitativas y erróneas. En este sentido, la autora argumenta que el término variedades de alto rendimiento, corresponde a una categoría reduccionista que usa como vara de medición el rendimiento de una parte de uno o unos pocos cultivos (la parte económica: grano), cuando la comparación correcta debería hacerse a nivel del sistema. Es decir: ¿cuál sistema, como un todo, es más productivo? De alguna manera, el redescubrimiento y 
difusión actual de los sistemas de policultivos o cultivos consociados (Flores \& Sarandón, 2014), retoma esta idea de una visión más global. En las agriculturas desplazadas, los sistemas de cultivos incluían una relación simbiótica entre suelo, agua, animales y plantas (Sarandón \& Flores 2014), siendo una de sus principales fortalezas la capacidad de compatibilizar la producción con la conservación de la diversidad biocultural.

Actualmente se reconoce que el paradigma de la Revolución Verde está en crisis y que no se tuvieron en cuenta las externalidades socio ambientales negativas generadas por el mismo (IICA, 2012). En este escenario, surgen avances vinculados a la agricultura sustentable. La definición propuesta por Sarandón et al. (2006), entiende que una agricultura sustentable es aquella que mantiene en el tiempo un flujo de bienes y servicios que satisfagan las necesidades alimenticias, socioeconómicas y culturales de la población, dentro de los límites biofísicos que establece el correcto funcionamiento de los sistemas naturales (agroecosistemas) que lo soportan". En palabras de Berkes et al. (2003), la sustentabilidad implica mantener la capacidad de los ecosistemas para sostener los sistemas ecológicos, sociales y económicos. Conservar esta capacidad conlleva comprender las interacciones entre los componentes ecológicos y sociales de un sistema.

Por lo tanto, para cumplir con la sustentabilidad y satisfacer las necesidades de las actuales y futuras generaciones, el estilo de agricultura debe poder mantenerse en el tiempo. Para ello deben cumplirse una serie de requisitos. La falta de cumplimiento de los mismos pone en duda, en el corto o largo plazo, la sustentabilidad. Esta agricultura debería ser:

- Suficientemente productiva (dependiendo del nivel de análisis).

- Económicamente viable (a largo plazo y contabilizando todos los costos).

- Ecológicamente adecuada (que conserve la base de recursos naturales y que preserve la integridad del ambiente en el ámbito local, regional y global).

- Cultural y socialmente aceptable.

Se busca entonces un sistema que pueda producir suficiente alimento, para satisfacer la demanda del agricultor y su familia en primer lugar y de la humanidad en segundo lugar. Esto depende del nivel de análisis: muchos sistemas agropecuarios no tienen por fin producir para alimentarse sino para obtener dinero para luego comprar estos alimentos. Para aquellos sistemas de autosuficiencia es fundamental que los niveles de producción sean suficientes 
para satisfacer la demanda del agricultor y su familia. Si esto no se consigue, el sistema no puede continuar en el tiempo. Por otro lado, debe ser económicamente viable, sin dudas, para permitir al agricultor y su familia satisfacer sus necesidades, reconociendo que no todas son meramente económicas ya que hay aspectos socioculturales importantísimos para lograr la satisfacción del agricultor que no deben dejarse de lado. Asimismo, es importante reconocer que la valoración económica debe ser hecha teniendo en cuenta todos los costos, incluyendo los costos ocultos y a largo plazo. Claramente, la idea de solidaridad con las futuras generaciones implica conservar la capacidad productiva del sistema y esto incluye mantener o mejorar los recursos (agua, biodiversidad, suelo) que constituyen el capital natural y preservar el ambiente a nivel local, regional o global, como la calidad del agua, el aire, la atmósfera, entre otros. Finalmente, el modelo de agricultura debe ser social y culturalmente aceptable, tanto para el agricultor, de acuerdo a sus intereses, creencias y valores, como para el resto de la sociedad. La sustentabilidad es un concepto multidimensional complejo porque incluye el cumplimiento simultáneo de varios objetivos o dimensiones: productivo, ecológico, temporal, económico y sociocultural. La importancia de esta mirada multidimensional, radica en la sinergia entre sus dimensiones. Un ejemplo de esto, es la idea de que los alimentos generados, deben estar relacionados a los deseos, hábitos culinarios y tradiciones de quienes cultivan y de la sociedad que los consume. Por tanto, los objetivos planteados, son igualmente importantes, de cumplimiento simultáneo y no son reemplazables los unos con los otros (Sarandón \& Flores, 2014). Está claro que se entiende a la sustentabilidad como un proceso y no como un producto terminado, este proceso es dinámico y requiere principalmente que las sociedades tengan capacidad adaptativa para hacer frente a los cambios (Berkes et al., 2003). Al ser la sustentabilidad un concepto complejo y multidimensional, no puede ser abordado desde el enfoque simplista y reduccionista. Se requiere un nuevo paradigma de las ciencias agrarias que permita abordar la complejidad implicada de una manera holística.

\section{Agroecología}

La agroecología parte de una serie de premisas metodológicas para desarrollar, integrar y mejorar las prácticas que respondan a sus principios (Guzmán Casado et al., 2000):

- Un enfoque holístico y sistémico. 
- Una mirada multidisciplinaria, entendiendo que los sistemas sólo pueden entenderse a través de las perspectivas que aportan diferentes áreas del conocimiento.

- Una investigación-acción participativa, en que los agricultores son sujetos y no sólo objetos del proceso de investigación.

La agroecología debe entenderse como un nuevo enfoque más amplio, que reemplaza la concepción exclusivamente técnica por una que incorpora la relación entre la agricultura y el ambiente global y las dimensiones sociales, económicas, políticas, éticas y culturales. La sustentabilidad debe ser vista como una búsqueda permanente de nuevos puntos de equilibrio entre estas diferentes dimensiones que pueden ser conflictivas entre sí en realidades concretas (Caporal \& Costabeber, 2004). De acuerdo con Altieri (2010) la agroecología es la disciplina científica que enfoca el estudio de la agricultura desde una perspectiva ecológica y proporciona un marco teórico cuyo fin es analizar los procesos agrícolas de una manera más amplia. Al decir de Sarandón (2002) la agroecología puede definirse como un nuevo campo de conocimientos, un enfoque, una disciplina científica que reúne, sintetiza y aplica conocimientos de la agronomía, la ecología, la sociología, la etnobotánica y otros campos afines, con una óptica holística y sistémica y un fuerte componente ético, para generar conocimientos y validar y aplicar estrategias adecuadas para diseñar, manejar y evaluar agroecosistemas sustentables En este sentido, la agroecología se posiciona como un nuevo paradigma de las ciencias agrarias. Este enfoque considera el agroecosistema como la unidad fundamental de estudio y como parte de éstos los ciclos minerales, las transformaciones de la energía, los procesos biológicos y las relaciones socioeconómicas son investigadas y analizadas como un todo. De este modo a la investigación agroecológica le interesa no solo la maximización de la producción de un componente particular, sino la optimización del agroecosistema en su conjunto. Esto tiende a reenfocar el énfasis de la investigación agrícola más allá de las consideraciones disciplinarias, hacia interacciones complejas entre personas, cultivos, suelos y animales (Altieri, 1995). Como uno de sus objetivos la agroecología promueve la producción local/nacional en agroecosistemas basados en innovaciones y recursos locales. Esto implica que los agricultores tengan acceso a tierra, semillas, agua, créditos y mercados locales, en parte a través de la creación de políticas públicas que favorezcan estos aspectos (Altieri \& Toledo, 2011).

Sin embargo, esto no podría lograrse en tanto la agroecología transcurriese sólo como disciplina científica. Hoy en día, la propuesta agroecológica es tomada desde distintos 
ámbitos y bajo distintas concepciones. Es pensada como práctica productiva (Altieri \& Toledo, 2011), entendiendo el hacer campesino tradicional que teniendo o no un origen campesino o indígena, se vinculan con la naturaleza de manera armónica y sustentable, a través de prácticas de manejo basadas en bajos insumos externos, el no uso de agrotóxicos y el desarrollo de tecnologías de procesos. A su vez, es entendida por algunos movimientos sociales como una herramienta política en la defensa de la soberanía alimentaria (Martínez-Torres \& Rosset, 2017). Este concepto, se define como el derecho de los pueblos a alimentos nutritivos y culturalmente adecuados, accesibles, producidos de forma sostenible y ecológica, y el derecho a decidir su propio sistema alimentario y productivo (Declaración de Nyéléni, 2007) y supera al concepto de seguridad alimentaria entendido como el derecho humano a la alimentación-cada niño, mujer, y hombre debe tener la certeza de contar con el alimento suficiente cada día (Martínez-Torres \& Rosset, 2017). La Vía Campesina y el MAELA (Movimiento Agroecológico de América Latina y el Caribe) ambos colectivos internacionales que nuclean organizaciones de productores familiares y campesinos, han ratificado el enfoque agroecológico para lograr la soberanía alimentaria. En el ámbito argentino la Mesa Provincial de Productores Familiares de Buenos Aires, el Movimiento Agroecológico Chaqueño, el Movimiento Nacional Campesino Indígena, el Movimiento Campesino de Liberación, el Foro Nacional de la Agricultura Familiar, entre otros, consideran a la agroecología como el encuadre apropiado, no sólo para que el desarrollo de sus actividades alcance mejores niveles de sustentabilidad, sino también, como una herramienta más en la disputa por la soberanía alimentaria. De esta diversa forma de entender y relacionarse con la agroecología, surge una compleja trama de relaciones entre personas, que hace viable la construcción de estrategias locales, que permiten a los productores poner en marcha prácticas y conocimientos para fortalecer la sustentabilidad y resiliencia de los agroecosistemas (Cap et al., 2012). El trabajo de Castro \& Pérez (2017) sostiene que las prácticas agroecológicas son una "opción política", una "bandera", cuando existe una convicción de los productores y sus organizaciones. Inclusive, hay autores que incluyen otros actores en el desarrollo de la agroecología, como, por ejemplo, a aquellos que están interesados en consumir alimentos sanos en un ambiente limpio, con justicia social y con relaciones equilibradas entre el campo y la ciudad (van der Ploeg, 2012). Ejemplos locales de construcción colectiva que fortalece la soberanía alimentaria son las ferias de venta directa del productor al consumidor (Fingermann, 2017) o encuentros anuales como las Ferias de Semillas Nativas y Criollas de la Provincia de Buenos Aires (Ahumada et al., 2009; Bonicatto et al., 2010; Pochettino et al., 2011). Para la realización de estos trabajos se articuló entre organizaciones de 
productores familiares, organizaciones no gubernamentales y diversas entidades estatales. Entre ellas se contaban aquellas vinculadas a la investigación, con el fin de abordar una demanda del sector vinculada a la obtención de un registro que diera cuenta de las semillas conservadas e intercambiadas durante estos encuentros.

La agroecología reconoce entre sus raíces fundacionales la práctica agrícola realizada por las comunidades rurales y registra en la coevolución social y ecológica las formas de manejo de los agroecosistemas que permiten el equilibrio en el uso de los recursos naturales (Nicholls et al., 2016). Todo ello lleva a la agroecología a otorgarle un papel central al conocimiento de los agricultores como un elemento básico del potencial endógeno y como punto de partida y componente de las estrategias de agricultura sustentable (Morales Hernández, 2011). De acuerdo con Reijntjes et al. (1999) el conocimiento local va más allá de técnicas e incluye nociones, percepciones e intuiciones relacionadas con el medio ambiente y se encuentra integrado a creencias, valores, tradiciones, mitos y a las formas de organización y cooperación social.

Entonces la agroecología en tanto es entendida como ciencia, como práctica productiva y como herramienta política, implica el abordaje de temas como la conservación de semillas realizada por los agricultores, desde una óptica holística, sistémica y multidimensional. Según Sarandón \& Marasas (2015) aunque la agroecología no es aún el enfoque predominante de las ciencias agrarias en la República Argentina, donde el sistema de producción y comercialización (instituciones técnicas, organismos de control, empresas y universidades), aun está orientado hacia el monocultivo y el mercado de commodities internacional, los avances de la agroecología en diversos campos han sido y son muy alentadores $y$, sin dudas, permiten abrigar un gran optimismo.

\section{Los agricultores y agricultoras familiares}

Al decir de García (2011) antes de definir la agricultura familiar vamos a detallar el rol de los agricultores y agricultoras familiares, para luego establecer la caracterización y las variables que definen al sujeto. En este sentido, la agricultura familiar engloba a los sujetos cuya función en el sistema actual, sería el de preservar o potenciar una serie de características que se entienden como positivas, a saber: proteger al productor directo; reducir el éxodo rural y favorecer el poblamiento rural; evitar o, por lo menos, moderar la concentración del capital y, por qué no, el importante rol de preservar la diversidad 
biocultural a través de agroecosistemas diversificados que permitan reducir o eliminar el uso de agroquímicos.

La decisión de tomar como sector en estudio a la agricultura familiar está relacionada tanto con su representación a escala nacional y local, como a la posible vulnerabilidad en cuanto a su sustentabilidad (Blandi et al., 2009; 2015) y principalmente a la particularidad que emerge del vivir donde se produce, que genera la permanencia de un estrecho vínculo con el componente ecológico de los sistemas productivos. En cuanto a la caracterización tomada para direccionar las hipótesis y objetivos de este trabajo, el Programa Nacional de Investigación y Desarrollo Tecnológico para la Pequeña Agricultura Familiar del Instituto Nacional de Tecnología Agropecuaria (INTA), en el texto publicado por Elverdín et al. (2005) definen a la agricultura familiar como: "un tipo de producción donde la unidad doméstica y la unidad productiva están físicamente integradas, la agricultura es un recurso significativo en la estrategia de vida de la familia, la cual aporta la fracción predominante de la fuerza de trabajo utilizada en la explotación, y la producción se dirige tanto al autoconsumo como al mercado ". Al decir de van der Ploeg (2014) el predio no es sólo un lugar de producción, es un espacio en donde las/os niñas/os crecen en contacto con la actividad agrícola y las dinámicas ecológicas que posibilitan el dominio productivo y conocimiento de cultivos y animales: todo un laboratorio natural de gran importancia para comprender y entender la relación con el medioambiente. Además, la agricultura familiar forma parte y contribuye al mantenimiento del entorno rural, dado que ayuda a la preservación de la biodiversidad y su trabajo implica una relación directa con la naturaleza viva.

Es interesante considerar la definición propuesta por la FAO (Salcedo et al., 2014b) en el año internacional de la agricultura familiar, durante el cual se concentraron esfuerzos para elaborar un concepto que unifique las definiciones nacionales, muchas veces vinculadas a contextos sociales, históricos y políticos particulares. La definición consensuada fue: "La agricultura familiar (incluyendo todas las actividades agrícolas basadas en la familia), es una forma de organizar la agricultura, ganadería, silvicultura, pesca, acuicultura y pastoreo, que es administrada y operada por una familia y, sobre todo, que depende preponderantemente del trabajo familiar, tanto de mujeres como hombres. La familia y la granja están vinculados, co-evolucionan y combinan funciones económicas, ambientales, sociales y culturales."

Las características planteadas hacen de la agricultura familiar un tejido de contención social que permite la permanencia de las familias en el ámbito rural, evitando la migración 
interna y la formación de cordones urbanos de pobreza, jugando, además, un rol clave en la seguridad y soberanía alimentaria familiar (Cittadini et al., 2005). Según datos de la FAO, en Argentina del total de explotaciones agrícolas (333.477), 218.868 son unidades agrícolas familiares, lo cual representa el 65,6 \% (Leporati et al., 2014).

\section{concepto de familia}

Las variables tales como la fuerza de trabajo familiar, la producción para autoconsumo y venta, las tareas domésticas, el trabajo dentro y fuera del predio, hacen referencia a tareas repartidas entre los integrantes de una familia. Pero ¿qué entendemos como familia cuando pensamos en agricultores familiares? ¿Logramos romper los preconceptos de la familia basada en el matrimonio monógamo?

Durham (1983) plantea, que las sociedades conciben y combinan de forma variable el matrimonio, el parentesco, la residencia y la vida doméstica, privilegiando muchas veces combinaciones diferentes a las de la organización familiar basada en el matrimonio monógamo. Propone que lo fundamental para desnaturalizar las formas organizativas a las que diferentes sociedades definen como familia, es entender que la relación que conocemos entre un grupo conyugal, familia, parentesco y división sexual del trabajo puede ser disociada, dando origen a instituciones diferentes. Asimismo esta autora plantea que la familia referencia a un grupo social concreto, que existe como tal en las representaciones de sus miembros y que se organiza en función de la reproducción (biológica y social) y por la manipulación, por un lado, de los principios formales de la alianza, de la descendencia y de la consanguineidad, y por el otro, por las prácticas de la división sexual del trabajo. En este sentido ella, explica la superposición y separación de este concepto con los de grupo doméstico y unidad residencial. Las familias tienden por lo menos en una fase de su ciclo, a confundirse con grupos domésticos y unidades residenciales. En tanto grupos domésticos, y siendo unidades residenciales, pueden restringirse a los miembros de una familia o ampliarse por la inclusión de personas no relacionadas por parentesco o afinidad.

Lo que las familias producen y reproducen todos los días -según señala Vázquez Laba (2005) es la energía humana que luego puede alquilarse al mercado de trabajo: el trabajo doméstico, la crianza de los hijos, la preservación de la vida. Lo que la autora percibe en relación a las trabajadoras del limón en Tucumán, es que las personas en función del género "arreglan" en la repartición de posiciones y división de tareas al interior de cada 
hogar en su vida cotidiana. Estos arreglos familiares modifican tanto la composición o estructura familiar como así también, hacen variar las funciones y los roles desempeñados por cada miembro al interior de la familia (Aguirre \& Fassler, 1994 en Vázquez Laba, 2005). Así encuentra diferentes formas de familias, algunas monoparentales nucleares o extensas, otras familias completas nucleares o completas extensas. Estas diferentes formas implican, en algunos casos, la convivencia de varias generaciones en un mismo hogar, donde hay un núcleo conyugal primario y a su vez núcleos conyugales secundarios, es así como entre estas personas se modifican los roles y las tareas al interior del hogar. La bibliografía analizada deja en evidencia: la multiplicidad de definiciones de familia y de grupos humanos que se definen en términos de familia; una base común en todas las conceptualizaciones que alude a la presencia de al menos un adulto que cumpla la función de cuidar, formar y contener a una generación menor. En cuanto a trabajos de investigación realizados en el ámbito de la producción hortícola Platense, Salva et al. (2009) y Ferroni (2010) observan en la organización familiar del trabajo, una división de tareas en el espacio productivo y en el reproductivo según el género del trabajador. Tanto los varones como las mujeres participan en la preparación de la tierra, la siembra o el trasplante de plantines, el riego y la cosecha, pero la fumigación con agroquímicos es tarea sólo de los varones. Las mujeres se encargan además de las tareas del hogar y del cuidado de los hijos. Si bien los niños y niñas también colaboran en las tareas más livianas de la quinta, sus padres marcan la importancia que tiene para ellos el hecho de que sus hijos asistan al colegio.

Estas reflexiones son centrales al momento de cuestionar el imaginario sobre el cual el investigador trabaja. Replantear conceptos o palabras que parecen hablar por si solos, como lo es el término familia, permite abordar una investigación de manera muy diferente. En este trabajo, la interpelación de este término, por el cual se identifica al grupo en estudio (agricultores familiares) permitió ampliar la mirada hacia todos aquellos grupos de personas, diversos entre sí en su conformación, que llevan adelante una producción familiar en los agroecosistemas visitados.

\section{Las semillas en manos de los agricultores y agricultoras}

Desde el punto de vista botánico la semilla constituye el reservorio de la vida, transmitiendo los caracteres que darán continuidad a la especie. Sin embargo, si incorporamos una mirada más amplia, vemos que las semillas reflejan milenios de interacción con el hombre, 
permitiendo fijar aquellas características (forma, tamaño, sabor) que resulten particularmente útiles o deseables (Ahumada et al., 2009). Al hablar de vínculo entendemos que más de un componente es necesario para su existencia. Por esto, cuando pensamos en conservación de semillas, no podemos dejar de hablar tanto de material genético, como de los agricultores y agricultoras que llevan a cabo la práctica de conservación. A lo largo de la historia, cada adaptación particular, cada semilla conservada, cada acierto y cada error, acompañó la existencia de variabilidad y de conocimientos acerca de las condiciones locales, usos y prácticas ligadas a la agrobiodiversidad. El producto final de este proceso ha sido, tras 10.000 años de diversificación agrícola y pecuaria, miles de diseños genéticos originales, que a su vez son la consecuencia de creaciones de innumerables culturas locales a lo largo del espacio y tiempo (Toledo \& Barrera-Bassols, 2008). Los conocimientos que acompañan estas semillas son comúnmente transmitidos a través del lenguaje, para lo cual la memoria es el recurso intelectual más importante (Toledo, 2005). En este sentido el "accionar individual" de los agricultores en la manipulación de las plantas y por ende en la conservación de recursos genéticos, debe ser también comprendido (Pochettino \& Lema 2008).

Otro suceso importante que ha ocurrido durante esta historia es de carácter solidario, y tiene que ver con la libre circulación de las semillas. Esta idea está ligada a concebir la agrobiodiversidad como un patrimonio de todos los agricultores y agricultoras. Por lo tanto, a la vez que la agrobiodiversidad es mejorada y conservada en los agroecosistemas (in situ), también circula, se intercambia y continúa su transformación en manos de nuevos agricultores y agricultoras. Los nexos de la agrobiodiversidad conservada in situ son los sistemas informales de intercambio de semillas. Estos sistemas también llamados locales (Almekinders et al., 1994), funcionan en el ámbito comunal a través de mecanismos de trueque o regalo con vecinos, amigos y parientes, involucra cantidades limitadas de semillas y constituyen una producción de semillas no especializada, integrada dentro de la producción de granos, raíces y tubérculos para consumo y para el mercado (Mekbib, 2000). En este sistema de conservación son los agricultores y agricultoras quienes controlan los recursos genéticos de las plantas de una manera integrada y con finalidades diferentes (de Boef, 2007). Según Almekinders \& de Boef (2000) las fuentes más importantes de semillas en los países en desarrollo, son las semillas provenientes de sistemas llamados informales, donde destacan la producción propia en las fincas, los intercambios con vecinos y parientes y las ferias de semillas o jornadas de intercambio organizadas a distinta escala. Estos autores estiman que el $80 \%$ de las semillas en los países "en desarrollo" se produce en las fincas, variando el 
porcentaje según el cultivo. Según Calvet-Mir et al. (2012) los intercambios de semillas promueven la creación y preservación de diversidad genética. Los trabajos de sistematización de las Ferias de Semillas Nativas y Criollas Sembrando Esperanza, realizadas en la provincia de Buenos Aires (Ahumada et al., 2009; Bonicatto et al., 2010; Pochettino et al., 2011), dan cuenta de la gran agrobiodiversidad y conocimientos que constituye un patrimonio actual de la Argentina. A su vez, el trabajo realizado por Cababié et al. (2015) con agricultores que participaron de estos encuentros, expone la importancia que tienen estas ferias en la diversificación de los agroecosistemas familiares, al comprobar que el $93 \%$ de las semillas intercambiadas fueron sembradas, y el $79 \%$ lograron ser cultivadas con éxito.

En el contexto internacional el Convenio sobre la Diversidad Biológica (UNEP, 1992), establece que la exigencia fundamental para la conservación de diversidad biológica es la conservación in situ, siendo la conservación ex situ (fuera de sus lugares de origen) un complemento importante. Estas aclaraciones son necesarias, ya que históricamente, el mejoramiento de semillas realizado por los agricultores y agricultoras ha sido ignorado y desvalorizado (Almekinders et al., 1994; de Boef, 2007). En tanto, el sistema formal realizado por el sector público y privado instala la idea de "seriedad", de ser aquel que guarda las formas estipuladas para el mejoramiento y conservación de semillas, ligado al mantenimiento ex situ de agrobiodiversidad. Esta conservación es realizada en bancos genéticos, programas de mejoramiento y sistema de recursos genéticos vegetales, que tienen una función paralela al sistema de los agricultores (FAO, 2000). La gran diferencia entre ambos sistemas radica en que, las semillas que permanecen en manos de los agricultores y agricultoras, al tiempo que preserva vida también preservan saberes, esos saberes que intervinieron en su reproducción y selección, y a su vez preserva la gran diversidad de usos y simbolismos creados a partir de ellas. Por lo tanto, las semillas conservadas por los agricultores y agricultoras merecen una mirada holística entendiendo que una semilla no constituye únicamente la fuente de futuras plantas y alimentos, sino que es el lugar en sentido simbólico, en el que se almacena la cultura y la historia (Pochettino et al., 2011). Una mirada holística de la agrobiodiversidad conservada por los agricultores familiares necesariamente debe incluir los cultivos destinados exclusivamente al consumo de la familia. Cada vez surgen más estudios que destacan la gran agrobiodiversidad e importancia de los cultivos destinados a la esfera familiar (Bisht et al., 2014; May et al., 2017; Montañez-Escalante et al., 2014; Nuñez \& Traglia, 2015; Salazar-Barrientos et al., 2016) y que están "ocultos" ante la mirada mercantil y productivista del modelo hegemónico. Según la Real Academia Española, el adjetivo 
"oculto" se aplica a aquello que está escondido, ignorado, que no se da a conocer, ni se deja ver, ni sentir. En definitiva la agrobiodiversidad que se conserva circunscripta al autoconsumo, resulta ser tanto un reservorio de saberes, simbolismos y prácticas como de material genético per se.

Ante lo expuesto no que quedan dudas de la importancia de que el proceso de mejoramiento y conservación de agrobiodiversidad sea en los agroecosistemas y en conjunto a los agricultores y agricultoras. Los trabajos de Wood \& Lenné (1997) y de Boef (2007) reflexionan sobre los puntos de encuentro entre el sistema formal e informal de conservación de agrobiodiversidad, incorporando la idea de una posible combinación o entre las estrategias utilizadas, para asegurar una mayor disponibilidad de recursos genéticos para la agricultura familiar. En definitiva, lograr comprender la situación en torno a la presencia de conocimientos sobre conservación in situ y las semillas que se están conservando, es un aporte fundamental para avanzar en estrategias para la conservación de la agrobiodiversidad del Cinturón Hortícola Platense.

\section{HIPÓTESIS GENERAL E HIPÓTESIS DERIVADAS}

\section{Hipótesis general}

En los agroecosistemas familiares del Cinturón Hortícola Platense, existe agrobiodiversidad hortícola conservada in situ.

\section{Hipótesis derivadas}

1. Los agricultores y agricultoras familiares del Cinturón Hortícola Platense utilizan diferentes criterios que intervienen en la conservación del material reproductivo.

2. Existen recursos genéticos "ocultos" cultivados por los agricultores familiares del Cinturón Hortícola Platense.

3. Los agricultores y agricultoras familiares del Cinturón Hortícola Platense mantienen conocimientos sobre la práctica de conservación de semillas. Los conocimientos son condición necesaria para el mantenimiento in situ de agrobiodiversidad. 
4. En los actores externos a la producción (técnicos, investigadores y comerciantes) prevalecen criterios productivistas en la valoración del material reproductivo hortícola.

\section{OBJETIVO GENERAL}

Relevar la agrobiodiversidad hortícola cultivada y conservada en agroecosistemas familiares del Cinturón Hortícola Platense y los conocimientos y criterios asociados a su conservación, uso y manejo, incluyendo el accionar individual, como base para aportar al diseño de estrategias sustentables.

\section{Objetivos específicos}

1. Relevar y organizar la agrobiodiversidad cultivada según su clasificación botánica y local, uso/s, rubro productivo, conservación de material reproductivo.

2. Analizar la agrobiodiversidad hortícola conservada y no conservada según su clasificación botánica y local, uso/s, origen y destino.

3. Identificar y describir los criterios locales de conservación de semillas.

4. Relacionar los criterios de conservación de semillas con el origen y destino de las mismas.

5. Identificar el cultivo de hortalizas para autoconsumo y los criterios que sustentan su conservación.

6. Registrar y analizar los conocimientos de los agricultores y agricultoras familiares del Cinturón Hortícola Platense sobre la conservación de semillas.

7. Analizar el "accionar individual" de los agricultores en la conservación de la diversidad biocultural (recurso y saberes asociados).

8. Registrar y categorizar impedimentos para la conservación de semillas manifestados por los agricultores y agricultoras familiares del Cinturón Hortícola Platense.

9. Registrar criterios de valoración del material reproductivo en los actores externos a la producción (técnicos, investigadores y comerciantes).

10. Ordenar los criterios de valoración de los actores externos.

11. Analizar la presencia de criterios productivistas en los actores externos.

12. Interpretar la conservación de semillas en el cinturón Hortícola Platense desde la perspectiva agroecológica. 


\section{Organización del trabajo}

La tesis consta de cinco capítulos, una discusión general y conclusiones. En el primer capítulo se presenta la ubicación y caracterización del territorio en estudio y aquellos conceptos centrales para el desarrollo del trabajo, tales como el marco teórico de la agroecología y sustentabilidad, sistemas resilientes, diversidad biocultural, el concepto de familia y su relación con la agricultura familiar, así como los puntos de encuentro entre la etnobotánica y la agroecología. A su vez se plantea la metodología utilizada en términos generales para luego en cada capítulo desarrollar las estrategias particulares empleadas. El segundo capítulo da cuenta de la situación actual en torno a la conservación de semillas en los agroecosistemas familiares del Cinturón Hortícola Platense, estableciendo un perspectiva de la agrobiodiversidad cultivada, y aquella conservada, sus usos y origen. En el tercer capítulo se abordan los criterios por los cuales los agricultores familiares conservan semillas, las diferentes vías de ingreso de las mismas, el destino de los productos hortícolas obtenidos y la relación entre las variables mencionadas. El cuarto capítulo aborda el análisis de los conocimientos en torno a las diferentes instancias que hacen a la producción y conservación de agrobiodiversidad in situ, resaltando el accionar de los individuos en la conservación de misma y la importancia de este enfoque para la agroecología. A partir de las preguntas sobre si los agricultores familiares aún conservan semillas, qué conservan, por qué y quienes, el quinto capítulo reflexiona sobre la valoración de la agrobiodiversidad de otros actores (investigadores, técnicos y comerciantes) que dialogan en el territorio en estudio, para analizar si las valoraciones confrontan o no, según el objetivo de fortalecer la sustentabilidad de los agroecosistemas familiares.

Las conclusiones de dichos capítulos son vinculadas en una discusión general que busca no solo aportar conocimiento científico sobre el tema estudiado, sino también generar interrogantes y propuestas para futuras investigaciones. Por último se presentan las conclusiones del trabajo. 


\section{BIBLIOGRAFÍA}

Abdelali-Martini, M.; A. Ahmed; M. Ajlouni; R. Assi; Y. Sbiehand \& A. Khnifes. 2008. Gender dimension in the conservation and sustainable use of agro-biodiversity in West Asia. The Journal of Socio-Economics 37: 365-383.

Aguirre, R. \& C. Fassler. 1994. ¿Qué hombres? ¿Qué mujeres? ¿Qué familias? Familias Siglo XXI. Ediciones de las Mujeres, $N^{\circ} 20$, Santiago de Chile, Conjunto Integrado de Sistemas de Información (ISIS).

Ahumada, A.; F. Mainella, M.M. Bonicatto, M.L. Pérez, M.L.; Pochettino, M. Marasas, M. Moricz, M. Pérez, N. Anglese, P. Domínguez \& V. Parmigiani. 2009. Segunda Feria Provincial de Semillas Nativas y Criollas "Sembrando Esperanza". Editor responsable CYTED- Programa Iberoamericano Ciencia y tecnología para el Desarrollo. Jujuy, Argentina.

Almekinders, C.J.M \& W.S. de Boef. 2000. El reto de la colaboración en el manejo de la diversidad genética de los cultivos. LEISA 15: 5-7.

Almekinders, C.J.M.; N.P. Louwaars \& G.H. de Bruijn. 1994. Local seed systems and their importance for an improved seed supply in developing countries. Euphytica 78: 207-216.

Altieri, M. \& C.I. Nicholls. 1994. Biodiversity and pest management in agroecosystems. Haworth. Press, New York.

Altieri, M.; C.I. Nicholls, A. Henao \& M.A. Lana. 2015. Agroecology and the design of climate change-resilient farming systems. Agronomy for Sustainable Development 35:869-890.

Altieri, M.A. \& V.M. Toledo. 2011. The agroecological revolution in Latin America: rescuing nature, ensuring food sovereignty and empowering peasants. The Journal of Peasant Studies 38(3):587-612. http://dx.doi.org/10.1080/03066150.2011.582947

Altieri, M.A. 1995. Agroecology: the science of sustainable agriculture. Westview Press, Boulder, CO.

Altieri, M.A. 1999. The ecological role of biodiversity in agroecosystems. Agriculture, Ecosystems and Enviromnment 74: 19-31. 
Altieri, M.A. 2000. Biodiversidad multifuncional en la agricultura tradicional latinoamericana. Boletín de ILEIA Pp.14.

Altieri, M.A. 2010. El estado del arte de la agroecología: revisando avances y desafíos, en T.L. Sicard \& M.A. Altieri (editores.) Vertientes del pensamiento agroecológico: fundamentos y aplicaciones. Pp77-104. Bogotá. Opciones Gráficas Editores.

Altieri, M.A. 2013. Construyendo resiliencia socio-ecológica en agroecosistemas: algunas consideraciones conceptuales y metodológicas, en: C.I. Nicholls Estrada.; L.A. Ríos Osorio \& M.A. Altieri (editores.) Agroecología y resiliencia socioecológica: adaptándose al cambio climático, pp. 94-104. Medellín, Colombia: REDAGRESCYTED.

Berkes, F.; J. Colding \& C. Folke. 2003. Introduction, en F. Berkes. ; J. Colding \& C. Folke (editores). Navigating Social-ecological Systems. Building resilience for complexity and change. Cambridge University Press. Pp 1-30.

Berkes, F. \& N.J. Turner. 2006. Knowledge, learning and the Evolution of Conservation Practice for Socia-Ecological System Resilience. Human Ecology 34 (4): 479-494.

Berkes, F. 1993. Traditional ecological knowledge in perspective, en: J.T. Inglis (editor). Traditional ecological knowledge: Concepts and cases. Pp. 1-9. International Development Research Centre, Ottawa, Canadá

Bisht, I.S.; S.R. Pandravada, J.C. Rana, S.K. Malik, Archna Singh, P.B. Singh, Firoz Ahmed \& K.C. Bansal. 2014. Subsistence farming, Agrobiodiversity, and Sustainable Agriculture: A case Study. Agroecology and Sustainable Food Systems 38: 890-912.

Blandi, M.L.; N.A. Gargoloff, C.C. Flores \& S.J. Sarandón. 2009. Análisis de la sustentabilidad de la producción hortícola bajo invernáculo en la zona de La Plata, Argentina. Revista Brasilera de Agroecología 4 (2): 1635-1638.

Blandi, M.L.; S.J. Sarandón, C.C. Flores \& I. Veiga. 2015. Evaluación de la sustentabilidad de la incorporación del cultivo bajo cubierta en la horticultura platense. Revista de la Facultad de Agronomía, La Plata 114 (2): 251-264.

Bonicatto, M.M.; V. Fernández, N.G. Gargoloff, M. Marasas, L. Muscio, M. Pérez \& M.L. Pochettino. 2010. Sembrando Esperanza. III Feria Provincial de Semillas Nativas y Criollas. En defensa de la vida de la soberanía alimentaria. Por una 
economía solidaria, construyendo la casa de todos. Ediciones INTA. Publicaciones IPAF- Región Pampeana. La Plata, Argentina.

Bonicatto, M.M.; S.J. Sarandón \& M.L. Pochettino. 2009. El concepto de "semilla" y su relación con la agrobiodiversidad en una zona hortícola (Buenos Aires, Argentina). Actas del $\mathrm{V}^{\text {th }}$ Internacional Congress of Ethnobotany. 21 al 24 de septiembre de 2009. Bariloche.

Cababié, J.; M.M. Bonicatto \& E.A. Abbona. 2015. Semillas y saberes de los agricultores familiares. ¿Cuál es el rol de las ferias de intercambio en su reproducción y conservación? Revista Facultad de Agronomía La Plata 114 (Núm. Esp.1) Agricultura Familiar, Agroecología y Territorio: 122-128.

Calvet-Mir, L.; M. Calvet-Mir, J.L. Molina \& V. Reyes-García. 2012. Seed Exchange as an Agrobiodiversity Conservation Mechanism. A case Study in Vall Fosca, Catalan Pyrenees, Iberian Peninsula. Ecology and Society 17(1): 29.

Cap, G.; L. De Luca, M.E. Marasas, M. Pérez \& R. Pérez. 2012. El Camino de la Transición Agroecológica. Ediciones INTA, Argentina.

Caporal, F.R. \& J.A. Costabeber 2004. Agroecologia e extensâo rural. Contribuiçoes para a promoçâo do desenvolvimiento rural sustentável. MDA/SAF/DATER-IICA. Brasilia DF. 119 pp.

Castro, A. S. \& M. Pérez. 2017. Cambios en las prácticas productivas y de comercialización de horticultores del Sur del Área Metropolitana de Buenos Aires. Reflexiones en el marco de un espacio de formación en Agroecología. Actas de las $X$ Jornadas Interdisciplinarias de Estudios Agrarios y Agroindustriales Argentinos y Latinoamericanos. 7 al 10 de noviembre de 2017. Buenos Aires.

Cieza, R.I. 2004. Asesoramiento profesional y manejo de nuevas tecnologías en unidades de producción hortícolas del gran La Plata, Argentina. Scientia Agraria 5 (12): $79-85$.

Cittadini, RJ; P. Catalano, J. Gómez, D. Catullo, D. Díaz \& J. Elverdín. 2005. Programa Nacional de Investigación y Desarrollo Tecnológico para la Pequeña Agricultura Familiar. Documento base. Disponible en: http://www.inta.gov.ar/cipaf/inst/doc/documentobase.pdf [consulta diciembre de 2010]. 
Clergue, B.; F.P. Amiaud, F. Lasserre-Joulin \& S. Plantureux. 2005. Biodiversity: function and assessment in agricultural areas. A review. Agronomy for Sustainable Development 25: 1-15.

de Boef, W.S., 2007. Biodiversidade e agrobiodiversidade, en: W.S. de Boef.; M.H. Thijssen, J. Bernardi Ogliari \& B.R. Sthapit (organizadores) Biodiversidade $e$ Agricultores. Fortalecendo o manejo comunitário. L\&PM Editores. Brasil. 1: 15-34.

Declaración de Nyéléni. 2007. Disponible en: http://www.nyeleni.org/spip.php?article291 (consulta octubre de 2017).

Durham, E.R. 1983. Família e reprodução humana, en: B. Franchetto.; M.L. Cavalcanti \& M.Z. Heilborn (organizadores). Perspectiva antropológica da mulher. 3: 13-34. Zahar. Rio de Janeiro.

Elverdín, J.; J. Catalano, F. Cardozo, D. Ramilo, G. Tito, R. Cittadini, G. Giordano, M. Gómez, C. Paulizzi, D. Alcoba, M.E. Aradas, J. Braña, L. Bilbao, G. Cap, S. Dumrauf, C. Golsberg, A. López, A. Maggio, M. Marasas, V. Mazacotte, G. Prividera, M. Quiroga Mendiola, D. Setta, N. Sosa Rolón \& F. Videla. 2005. La Pequeña Agricultura Familiar en Argentina: Problemas, oportunidades y líneas de acción. Programa Nacional de Investigación y Desarrollo Tecnológico para la Pequeña Agricultura Familiar (PNPAF) del INTA. Disponible en: http://agro.unc.edu.ar/ extrural/Elverdin.pdf [consulta noviembre de 2015].

Eyssartier, C.; A.H. Ladio \& M. Lozada. 2011. Traditional horticultural knowledge change in rural population of the Patagonian steppe. Journal of Arid Environments 75: 78-86.

FAO. 2000. Políticas y programas de semillas en América latina y el Caribe. Estudio FAO producción y protección vegetal. Disponible en http://www.fao.org/docrep/018/x9459s/x9459s.pdf [consulta marzo 2017].

FAO. 2013. Statistical yearbook 2013. World Food and Agriculture, FAO, 289 pp. Roma. Disponible en http://www.fao.org/docrep/018/i3107e/i3107e00.htm [consulta diciembre de 2013].

Ferroni, P.G. 2010. De la mediería al arrendamiento. Un abordaje de las prácticas y significaciones de los trabajadores hortícolas del Cinturón Verde del partido de La Plata en el marco de una nueva posición en el espacio socio-productivo [en línea]. 
Trabajo final de grado. Universidad Nacional de La Plata. Facultad de Humanidades y Ciencias de la Educación. Disponible en:

http://www.memoria.fahce.unlp.edu.ar/tesis/te.597/te.597.pdf.

Fingermann, L. 2017. Representaciones de los productores/feriantes de la Feria de Pequeños Productores Familiares Manos de la Tierra, del productor al consumidor, en torno a la construcción de mercados de la economía social y solidaria. (Trabajo final integrador). Universidad Nacional de Quilmes, Bernal, Argentina. Disponible en RIDAA Repositorio Institucional de Acceso Abierto http://ridaa.unq.edu.ar/handle/20.500.11807/258.

Flores C.C. \& S.J. Sarandón. 2014. Manejo de la biodiversidad en agroecosistemas en: S.J. Sarandón \& C.C. Flores (editores). Agroecología: Bases teóricas para el diseño y manejo de agroecosistemas sustentables. Colección de libros Cátedra. Universidad Nacional de La Plata (EDULP). 13:342-373.

Folke, C.; S.R. Carpenter, B. Walker, M. Scheffer, T. Chapin \& J. Rockström. 2010. Resilience thinking: integrating resilience, adaptability and transformability. Ecology and Society 15(4): 20.

Fornari, R. 2008. El rol de la Agricultura Familiar. Disponible en: http://es.scribd.com/doc/56027202/EI-Rol-de-La-Agricultura-Familiar\#scribd. [consulta agosto 2015].

Gadgil, M.; F. Berkes \& C. Folke. 1993. Indigenous knowledge for biodiversity conservation. Ambio 22 (2/3):151-156.

Garat, J.J.; A. Ahumada, J. Otero, L. Terminiello, G. Bello \& M.L. Ciampagna. 2009. Las Hortalizas típicas locales en el Cinturón verde de La Plata: Su localización, preservación y valorización. Horticultura Argentina 28 (66) 32-39.

Garat, J.J.; A. Castro, S. Gramuglia, A. Nico \& A. Ahumada. 2007. El rescate de la biodiversidad local y la acción colectiva: una estrategia de desarrollo a través de la revalorización de hortalizas locales en el cinturón verde de La Plata, Buenos Aires, Argentina. Revista Brasilera de Agroecología 2 (1): 430-434.

García, M. 2011. Agricultura familiar en el sector hortícola. Un tipo social que se resiste a desaparecer en: N. López Castro \& G. Prividera (compiladores), Repensar la 
agricultura familiar. Aportes para desentrañar la complejidad agraria pampeana. Pp.: 167-184. Argentina: Ediciones CICCUS.

Gaston, K.J. 1996. Biodiversity: a biology of numbers and difference. Blackwell Science. Cambridge.

Grupo Semillas. 2014. Las leyes de semillas aniquilan la soberanía y autonomía alimentaria de los pueblos, en: Leyes de Semillas y otros pesares (Los pueblos de América Latina las cuestionan e impugnan). Alianza Biodiversidad. Buenos Aires 2: 38-44.

Guzmán Casado, G.M.; N. González de Molina \& E. Sevilla Guzmán. 2000. Métodos y técnicas en Agroecología, en: G.M. Guzmán Casado.; N. González de Molina \& E. Sevilla Guzmán (coordinadores). Introducción a la Agroecología como desarrollo rural sostenible. Mundi Prensa. Madrid. 5: 149-195.

Harwood, R.R. 1979. Small farm development-understanding and improving farming systems in the humid tropics. Westview Press, Boulder, CO.

Hilgert, N.I.; F. Zamudio, V. Furlan \& L. Cariola. 2013. The Key Role of Cultural preservation in Maize Diversity Conservation in the Argentine Yungas. Evidence-Based Complementary and Alternative Medicine. Article ID 732760, 10 pages. Doi: $10.1155 / 2013 / 732760$.

Hunn, E.S. 2002. Evidence for the precocious acquisition of plant knowledge by Zapotec children, en: J.R. Stepp, F.S. Wyndham and R. Zarger (editores). Ethnobiology and biocultural diversity. Pp. 604-613. University of Georgia Press.

IICA. 2012. Situación y desempeño de la agricultura en ALC, desde la perspectiva tecnológica. San José, C.R.: IICA.

Isbell, F; D. Craven, J. Connolly, M. Loreau, B. Schmid, C. Beierkuhnlein, T.M. Bezemer, C. Bonin, H. Bruelheide, E. De Luca, A. Ebeling, J.N. Griffin, Q. Guo, Y. Hautier, A. Hector, A. Jentsch, J. Kreyling, V. Lanta, P. Manning, S.T. Meyer, A.S. Mori, S. Naeem, P.A. Niklaus, H.W. Polley, P.B. Reich, C. Roscher, E.W. Seabloom, M.D. Smith, M.P. Thakur, D. Tilman, B.F. Tracy, W.H. van der Putten, J. van Ruijven, A. Weigelt, W.W. Weisser, B. Wilsey \& N. Eisenhauer. 2015. Biodiversity increases the resistance of ecosystem productivity to climate extremes. Nature 526 (7574): 574-7 
Leporati, M.; S. Salcedo, B. Jara, V. Boero \& M. Muñoz. 2014. La agricultura familiar en cifras, en S. Salcedo \& L. Guzmán (editores). Agricultura Familiar en América Latina y el Caribe: Recomendaciones de Política 2: 35-56.

Louette, D.; A. Charrier \& J. Berthaud. 1997. In Situ Conservation of Maize in Mexico: Genetic Diversity and Maize seed Management in a Traditional Community. Economic Botany 51 (1): 20-38.

Maffi, L. 2005. Linguistic, Cultural, and Biological Diversity. Annual Review of Anthropology 29:599-617

Martínez-Torres, M.A. \& P.M. Roset. 2017. Diálogo de saberes: la construcción colectiva de la soberanía alimentaria y la agroecología en La Vía Campesina, en: Soberanía alimentaria un diálogo crítico. Apuntes sobre su recorrido intelectual en los estudios agrarios críticos, la construcción de conocimiento campesino y la incorporación de la perspectiva de género a la propuesta política de la Soberanía Alimentaria. EHNEBizkaia, ETXALDE, ICAS, ISS, Hands on the land for Food Sovereignty. PP. 147-159. Disponible en: https://www.researchgate.net/publication/316604964 [consulta octubre de 2017]

Matson, P.A., W.J. Parton, A.G. Power \& M.J. Swift. 1997. Agricultural intensification and ecosystem properties. Science 277: 504-509.

May, M.P.; S.G Fauret; I. Ciocchini; A. Ahumada \& M.M. Bonicatto. 2017. Cultivos tradicionales y saberes culinarios en el cinturón hortícola de La Plata, Argentina. Su rol en la conservación de agrobiodiversidad. Actas del VI Congreso Latinoamericano de Agroecología X Congreso Brasileiro de Agroecología y V Seminario de Agroecología del Distrito Federal y Región. 10 al 15 de septiembre de 2015. Brasilia. Brasil.

Mekbib, F. 2000. Sistemas informales de semillas. LEISA 15: 15.

Montañez-Escalante, P.I.; M.d.R., Ruenes-Morales; M. Monserrat Ferrer-Ortega \& H. Estrada-Medina. 2014. Los huertos familiares Maya-Yucatecos: Situación actual y perspectivas en México. Revista ambienta 107: 100-109.

Morales Hernández, J. 2011. Agricultura sustentable y Agroecología, en: J. Morales Hernández (coordinador), La Agroecología en la construcción de alternativas hacia la sustentabilidad rural, pp79-108. México: Grupo Editorial Siglo XXI. 
Nazarea, V.D. 2006. Local Knowledge and Memory in Biodiversity Conservation. Annual Review of Anthropology 35(1):317-335.

Nicholls, C.I. 2013. Enfoques agroecológicos para incrementar la resiliencia de los sistemas agrícolas al cambio climático, en: C.I. Nicholls Estrada.; L.A. Ríos Osorio, \& M.A. Altieri (editores.) Agroecología y resiliencia socioecológica: adaptándose al cambio climático, pp. 18-29. Medellín, Colombia: REDAGRES-CYTED.

Nicholls, C.I.; M.A. Altieri, A. Henao, R. Montalba \& E. Talavera. 2015. Agroecología y el diseño de sistemas agrícolas resilientes al cambio climático. REDAGRES-SOCLACYTED. Perú.

Nicholls, C.I.; M.A. Altieri \& L. Vázquez. 2016. Agroecology: Principles for the Conversion and redesign of Farming Systems. Journal of Ecosystems \& Ecography S5: 010. doi:10.4172/2157-7625.S5-010.

Nuñez, M.G. \& C. Traglia. 2015. Saberes y prácticas locales relacionadas a cultivos de autoconsumo entre pequeños productores tabacaleros de Colonia San Miguel, El Soberbio. Actas de las Jornadas de Investigadores 2015. Secretaría de Investigación y Postgrado. FHyCS-UNaM.

Pochettino, M.L. \& V. Lema. 2008. La variable tiempo en la caracterización del conocimiento botánico tradicional. Darwiniana 46(2): 227-239.

Pochettino, M.L.; V. Fernández, N.A. Gargoloff, L. Muscio, L. Pérez, L. González Espinosa, M.M. Bonicatto, M. Pérez, A. Cremaschi, E. Barreto, M.P. May, J. Cababié \& M.E. Marasas 2011. I Feria Nacional, IV Feria Provincial de Semillas Nativas y Criollas. "Sembrando Esperanza". Editorial INTA.

Reijntjes, C.; B. Haverkort \& A. Waters Bayer. 1999. Agricultura para o futuro. Uma introdução a agricultura sustentável e de baixo uso de insumos externos. AS-PTA/ ILEIA, Rio de Janeiro.

Reyes-García, V. \& N. Marti Sanz. 2007. Etnoecología: punto de encuentro entre naturaleza y cultura. Ecosistemas 16 (3): 46-55.

Reyes-García, V.; N. Martí, T. McDade, S. Tanner \& V. Vadez. 2007. Concepts and methods in studies measuring individual ethnobotanical knowledge. Journal of Ethnobiology 27(2):182-203. 
Salazar-Barrientos, L.d.L.; M.A. Magaña-Magaña, A.N. Aguilar-Jiménez \& M.F. Ricalde-Pérez. 2016. Factores socio económicos asociados al aprovechamiento de la agrobiodiversidad de la milpa en Yucatán. Ecosistemas y Recursos Agropecuarios 3 (9): $391-400$.

Salcedo, S.; A. Sánchez \& M.J. Coloma. 2014a. Agricultura familiar y seguridad alimentaria. El exitoso caso del proyecto Forsandino, en: S. Salcedo \& L. Guzmán (editores). La Agricultura Familiar en América Latina y El Caribe. Recomendaciones de Políticas. FAO 3:57-78.

Salcedo, S.; A.P. De la O \& L. Guzmán. 2014b. El concepto de Agricultura Familiar en América Latina y el Caribe, en: S. Salcedo \& L. Guzmán (editores). La Agricultura Familiar en América Latina y El Caribe. Recomendaciones de Políticas. FAO 1:17-34.

Salva, M.C.; M.B. Leguizamón \& L.R. Salva. 2009. Dinámica laboral y relaciones de género en la horticultura del partido de la plata. II Congreso Internacional de Investigación de la Facultad de Psicología de la Universidad Nacional de La Plata.

Sarandón, S.J. \& C.C. Flores. 2014. La insustentabilidad del modelo agrícola actual, en: S.J. Sarandón \& C.C. Flores (editores). Agroecología: Bases teóricas para el diseño y manejo de agroecosistemas sustentables. Colección de libros Cátedra. Universidad Nacional de La Plata (EDULP) 1:13-41

Sarandón, S.J. \& M.E. Marasas. 2015. Breve historia de La Agroecología en la Argentina: orígenes, evolución y perspectivas futuras. Agroecología 10 (2): 93-102.

Sarandón, S.J.; M.S. Zuluaga, R. Cieza, C. Gómez, L. Janjetic \& E. Negrete. 2006. Evaluación de la sustentabilidad de sistemas agrícolas de fincas en Misiones, Argentina, mediante el uso de indicadores. Revista Agroecología 1: 19-28.

Sarandón, S.J. 2002. La agricultura como actividad transformadora del ambiente. El Impacto de la Agricultura intensiva de la Revolución Verde, en SJ Sarandón (editor) Agroecología: El camino hacia una agricultura sustentable. Ediciones Científicas Americanas, La Plata1: 23-48.

Sarandón, S.J. 2009. Biodiversidad, agrobiodiversidad y agricultura sustentable: Análisis del Convenio sobre Diversidad Biológica, en: T.L. Siccard \& M.A. Altieri (editores). Vertientes del pensamiento agroecológico: fundamentos y aplicaciones. IDEAS 21, 
Sociedad Científica Latinoamericana de Agroecología (SOCLA), Bogotá, Colombia. 4:105-130.

Shiva, V. 1991. The violence of the green revolution. Third World Agriculture, Ecology and Politics. Third World Network, Pennang, Malaysia.

Silveira, R.P. 2015. Diversidade de variedades crioulas de tomates conservadas por camponeses no Municipio de Anchieta, oeste de Santa Catarina. Universidade Federal de Santa Catarina. Programa de posgraduaçao en agroecosistemas. 197 pp. Disponible en: https://repositorio.ufsc.br/handle/123456789/156749.

Stupino, S.A.; M.J. lermanó, N.A. Gargoloff \& M.M. Bonicatto. 2014. La biodiversidad en los agroecosistemas, en: Sarandón SJ \& CC Flores (editores). Agroecología: Bases teóricas para el diseño y manejo de agroecosistemas sustentables. Colección de libros Cátedra. Universidad Nacional de La Plata (EDULP) 5:131-158

Swift, M.J.; M.N. Izac \& M. van Noordwijk. 2004. Biodiversity and ecosystem services in agricultural landscapes-are we asking the right questions? Agriculture, Ecosystems and Environment 104: 113-134.

Tengö, M. \& K. Belfrage. 2004. Local Management Practices for dealing with Change and Uncertainty: A Cross-scale comparison of cases in Sweden and Tanzania. Ecology and Society 9 (3):4.

Terralingua. 2010. Published on the Internet: http://www.terralingua.org/basics/intro.html [consulta noviembre de 2016].

Toledo, V. M. \& N. Barrera-Bassols. 2008. La memoria biocultural. La importancia ecológica de las sabidurías tradicionales. Serie Perspectivas Agroecológicas. Ícara. Barcelona.

Toledo, V.M. 1992. La racionalidad ecológica de la producción campesina, en: E. Sevilla Guzmán \& M. González de Molina (editores). Ecología, campesinado e historia. La Piqueta. Madrid. España 5:197-218.

Toledo, V. M. 2005. La memoria tradicional: la importancia agroecológica de los saberes locales. LEISA Revista de Agroecología 20 (4): 16-19.

UNEP 1992. Convention on Biological Diversity. UNEP - Environmental Law and Institutions. Disponible en https://www.cbd.int/doc/legal/cbd-es.pdf [consulta octubre de 2017] 
UNEP 1997. The Biodiversity Agenda. Decisions from the third Meeting of the Conference of the Parties to the Convention on Biological Diversity. $2^{\mathrm{a}} \mathrm{Ed}$, Buenos Aires, Argentina.

UNEP/CDB/COP/5. 2000. The Biodiversity Agenda. Decisiones adoptadas por la conferencia de las partes en el convenio sobre la diversidad biológica en su quinta reunión. Apéndice. Nairobi. Disponible en: http: www.cdb.int [consulta noviembre de 2016].

van der Ploeg, J.D. 2012. The drivers of change: the role of peasants in the creation of an agro-ecological agriculture. Agroecología 6: 47-54.

van Der Ploeg, J.D. 2014. Diez Cualidades de la Agricultura Familiar. LEISA Revista de Agroecología 29 (4): 6-8.

Vázquez Laba, V. 2005. Imágenes de familias: un estudio sobre tipos de familias de las trabajadoras del limón en la provincia de Tucumán. Actas de las Primeras Jornadas de Antropología Rural, Facultad de Filosofía y letras. Universidad Nacional de Tucumán.

Wood, D. \& J.M. Lenné. 1997. The conservation of agrobiodiversity on-farm: questioning the emerging paradigm. Biodiversity and Conservation 6: 109-129. 
CAPÍTULO :

Área de estidio y metodología

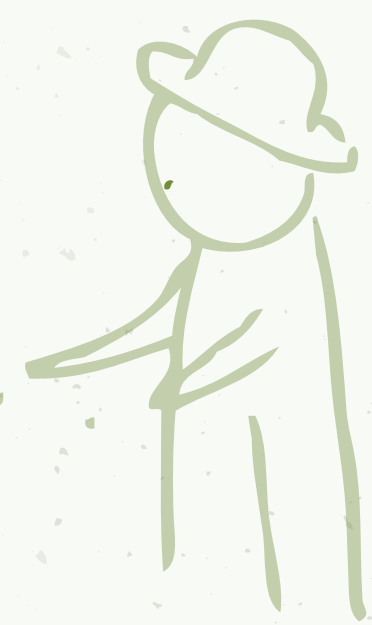




\section{CAPÍTULO I Área de estudio y metodología}

"Yo de verdura aprendí todo aquí, lo que es maíz y maní aprendí en Bolivia, mi papá solía tener. Como que te queda algo que te lleva a hacer esto"

(Bonicatto 2013a. Entrevista a BIS)

\section{l. Área de estudio}

Ubicado al nordeste de la provincia de Buenos Aires ( $34^{\circ} 54^{\prime} 24^{\prime \prime}$ de latitud sur y $57^{\circ} 55^{\prime}$ 56 " de longitud oeste) se ubica uno de los cinturones verdes más importantes de la Argentina (Figura 2), el Cinturón Hortícola Platense (CHP). La ciudad de La Plata es la capital de la provincia de Buenos Aires y está localizada a $55 \mathrm{Km}$ de la Capital Federal. Esta ciudad limita al noreste con los partidos de Ensenada y Berisso, al noroeste con los partidos de Berazategui y Florencio Varela, al suroeste y sur, con San Vicente y Coronel Brandsen y al sureste con el partido de Magdalena, ocupando una superficie de $893 \mathrm{~km}^{2}$. El partido de La Plata se compone por el casco fundacional y las siguientes localidades: Abasto, Arturo Seguí, City Bell, Etcheverry, El Peligro, Gonnet, Gorina, Hernández, Lisandro Olmos, Los Hornos, Melchor Romero, Ringuelet, San Carlos, San Lorenzo, Tolosa, Villa Elisa, Villa Elvira. El Cinturón Hortícola de La Plata, inserto en el Cinturón Hortícola Bonaerense, comprende una franja de territorio de 5 a $12 \mathrm{Km}$ de ancho que se extiende entre el suburbio de la ciudad y el medio agropecuario extensivo (Bozzano, 2003). El clima es templado semi húmedo sin estación seca. La temperatura media anual es de $16,3{ }^{\circ} \mathrm{C}$, con un promedio de $26,3{ }^{\circ} \mathrm{C}$ en enero y $10,5{ }^{\circ} \mathrm{C}$ en julio. La precipitación anual promedio es de $1023 \mathrm{~mm}$.

Según Barsky (2005) se puede entender el "cinturón verde" como el espacio periurbano conformado por una trama de quintas o huertas familiares -y otras de características más empresariales que rodean a las grandes ciudades, cuya producción se destina especialmente a verduras de hoja y hortalizas de estación. La lógica de localización de estas actividades altamente intensivas en el uso de los factores de la producción (tierra, trabajo y capital) responde a su cercanía geográfica con respecto a los grandes centros urbanos, aprovechando intersticios o zonas de vacancia para establecerse. Desde un punto de vista ecológico, este territorio es abordado como una zona de transición o ecotono entre el campo y la ciudad, en el que coexisten sistemas productivos o agroecosistemas que explotan el suelo fósil, los ecosistemas consumidores o aglomeraciones urbanas y los cada vez más reducidos ecosistemas naturales (Barsky, 2005). Estas particularidades le otorgan a dichos espacios características transicionales 
tanto desde los aspectos ambientales, productivos, como en cuanto a la posesión y transmisión de conocimientos sobre el entorno.

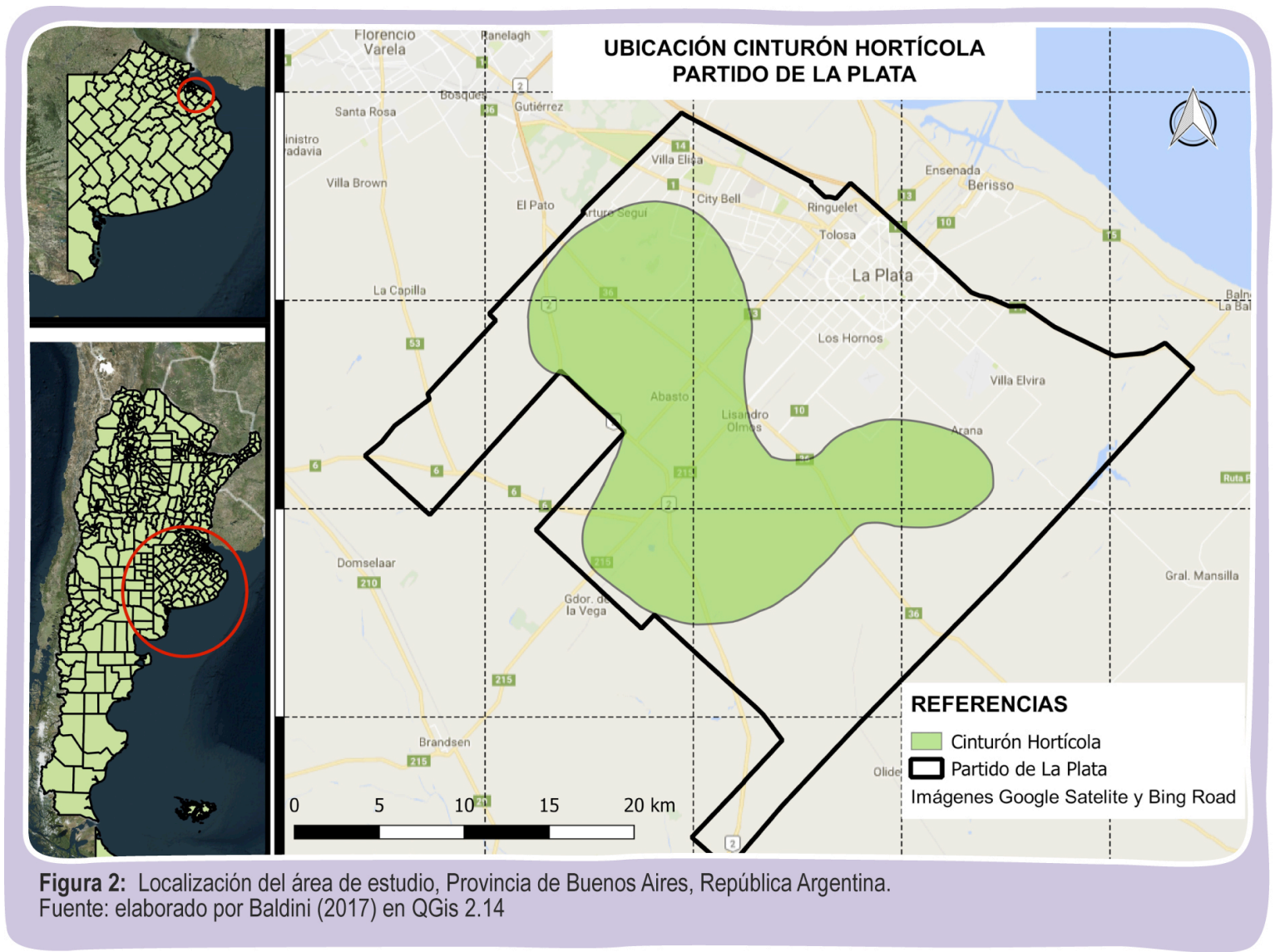

El municipio de La Plata es la región hortícola más importante del Cinturón Verde de Buenos Aires por poseer la mayor producción hortícola de la región, la mayor superficie hortícola y el $49 \%$ de las explotaciones del Cinturón Hortícola Bonaerense (Dirección Provincial de Estadística, 2005). Según el Censo Hortiflorícola (Dirección Provincial de Estadística, 2005), La Plata cuenta con 761 unidades productivas que ocupan 4184 has, representando una superficie promedio de 5,5 has por unidad. Sin embargo, desde distintos ámbitos, se coincide en que el incremento del número de productores es superior al cuádruple del registro realizado en el último Censo Hortiflorícola (Cieza et al., 2015).

En cuanto a la producción el Cinturón Hortícola Platense es responsable, de más de la mitad de la superficie implantada en el Cinturón verde de Buenos Aires, y participa con casi el $60 \%$ de la producción regional (Dirección Provincial de Estadística, 2005). Según estimaciones de García (2012) para el año 2010, la actividad hortícola de la capital bonaerense pasó a ser responsable del $72 \%$ de la producción regional. Para el año 2010 los sistemas exclusivamente bajo cubierta son los que predominaban en el Partido, con unas 2500 
hectáreas bajo invernadero para el Gran La Plata (Staviski, 2010) (Figura 3). Esta mayor superficie bajo cubierta ha provocado un incremento de la producción de hortalizas, siendo La Plata en la actualidad la responsable de la provisión del $82 \%$ de hortalizas que se comercializan en el Mercado Central de Buenos Aires (Cieza et al., 2015)

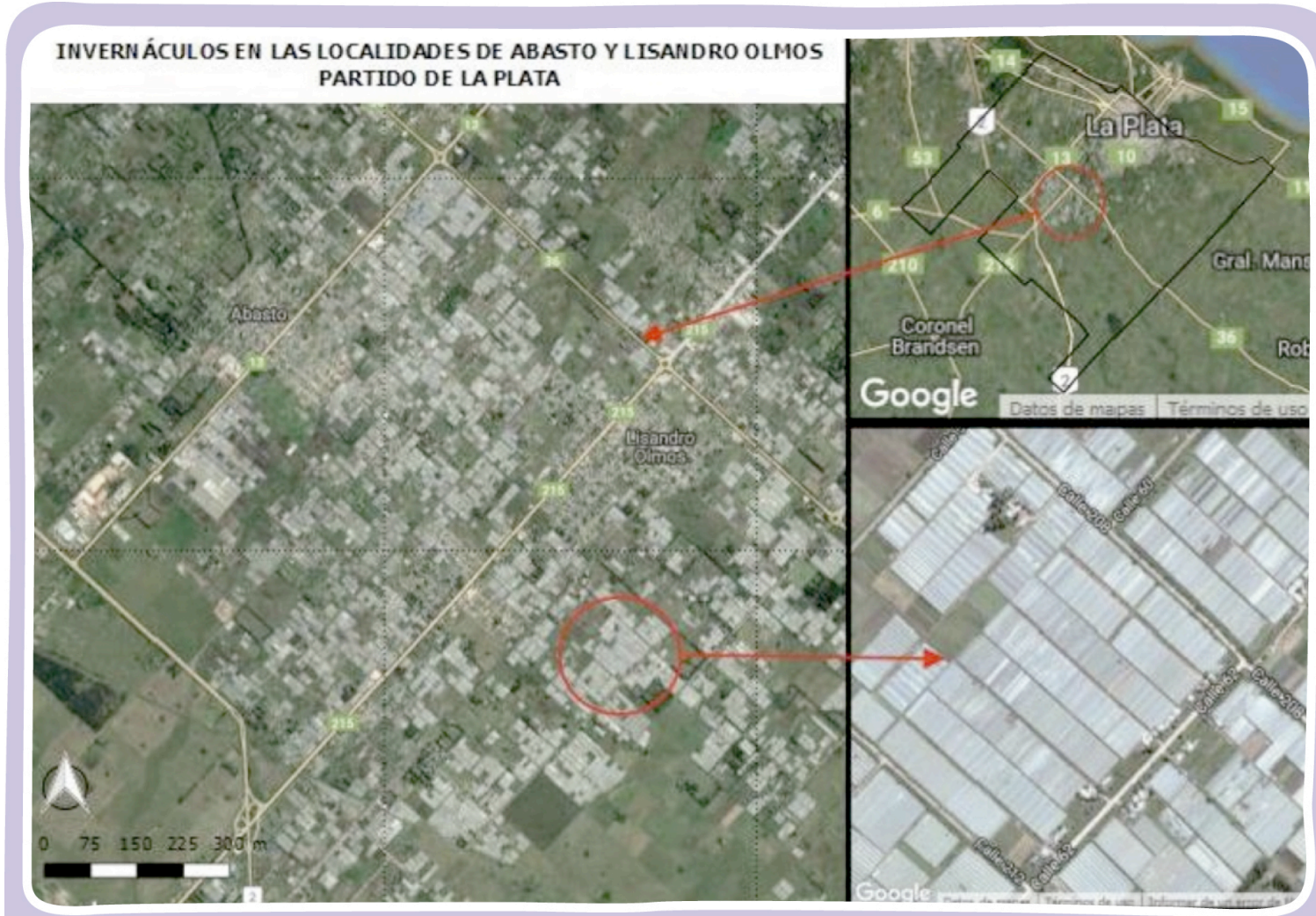

Figura 3 : Producción bajo cubierta (invernáculos) en el Cinturón Hortícola Platense.

Fuente: elaborado por Baldini (2017) en QGis 2.14

\section{1..I. Breve historia de la horticultura en el Cinturón Hortícola Platense}

Si consideramos el territorio como un producto social e histórico constituido por recursos naturales, ciertas formas de producción, consumo e intercambio, redes institucionales, formas de organización (Sepúlveda et al., 2003) y actores, es necesario conocer como fue el proceso histórico de ese territorio no sólo espacial sino también temporalmente para poder comprender los sucesos ocurridos en la horticultura platense en los últimos 20 años. En este sentido y siguiendo el análisis de García \& Lemmi (2011) se presenta la historia de la horticultura platense dividida en tres grandes períodos, que serían un primer momento llamado de horticultura doméstica (1900-1920), un segundo momento de nacimiento de la horticultura comercial (1920-1940), un tercer momento de expansión e intensificación de la producción (desde 1940 hasta la actualidad). 


\subsubsection{Horticultura doméstica (1900-1920)}

Las quintas donde se producían las hortalizas para abastecer a los primeros habitantes de la ciudad de La Plata (fundada en 1882) se ubicaban dentro del espacio urbano. Estas quintas eran de muy pequeñas superficies, ubicadas sobre los fondos de las casas, con una muy amplia variedad de cultivos a campo, teniendo como fin autoabastecer al núcleo familiar y comercializar los excedentes obtenidos. Algunos sujetos que obtenían sus ingresos principalmente del trabajo asalariado complementaban sus ingresos con la venta de sus excedentes de hortalizas. En muchos casos eran las mujeres las que se quedaban al cuidado del hogar y las encargadas de producir estos alimentos mientras los hombres trabajaban fuera (Lemmi, 2011). Estas prácticas de complemento del ingreso con producciones propias en el hogar tienen antecedentes inmemoriales. Tanto los pueblos originarios americanos que mantuvieron parte de sus tierras como los migrantes de ultramar de origen campesino realizaban junto a sus actividades asalariadas producciones de subsistencia. Los conocimientos básicos sobre la producción de alimentos, fueron transmitidos de generación en generación, y de región en región. Estos saberes se trasladaron junto con las personas y se aplicaron en cada nuevo destino. En la medida que la ciudad fue creciendo tanto urbanística como económicamente, esta producción de hortalizas que puede denominarse doméstica, fue resultando insuficiente. Las pequeñas huertas en los fondos de las casas fueron desapareciendo con el crecimiento urbano y el cambio en el ritmo de vida. El censo agropecuario de 1914 da cuenta de la existencia de 165 explotaciones dedicadas específicamente a la producción de frutas y hortalizas en La Plata, abarcando una superficie de 518 hectáreas. La mayoría de las explotaciones se encontraban dirigidas por migrantes italianos (78 \%), en segundo lugar argentinos (10\%) y españoles (8\%), en las cuales prima la utilización del trabajo familiar. El $92 \%$ de las explotaciones no superaba las 25 hectáreas de superficie (García \& Lemi, 2011).

\subsubsection{Nacimiento de la horticultura comercial (1920-1940)}

Las pequeñas huertas en los fondos de las casas junto a la cría de aves fue una práctica que se extendió hasta principios del siglo XX. Las explotaciones comerciales cercanas al ejido urbano con producción de hortalizas y leche cobraron importancia con una segunda llegada de inmigrantes de larga tradición en esas tareas (Gutman et al., 1987). La mayor demanda de hortalizas, consecuencia del incremento de la población, convirtió a esta 
producción en un nicho económico rentable, viable como producto mercantil, disminuyendo sus rasgos prioritarios de producción para autoabastecimiento. Estos inmigrantes arribaron a la ciudad en el período de entreguerras, provenientes en su gran mayoría de Italia en situación de pauperización, con saberes acumulados en el trabajo de la tierra. Vinieron a instalarse directamente a las quintas, convocados por algún familiar o paisano de su lugar de origen. Así, la producción de hortalizas comenzó a concentrarse en las zonas contiguas a Los Hornos y Gorina, llegando a Abasto, Olmos, Romero y Etcheverry. La producción hortícola si bien aun reducida, se elevó del autoabastecimiento a la producción mercantil (Lemmi, 2011). El trabajo de Garat et al. (2007) da cuenta de que era habitual que los inmigrantes trajeran consigo semillas que luego incorporaban a sus quintas. Es el caso del alcaucil (Cynara cardunculus L.) del cual hay registro del ingreso desde Europa de los primeros brotos por los años '30; o del tomate platense (Solanum lycopersicum L.), que a pesar del origen americano de esta especie, se cuenta que la variedad platense, ingresó a la zona desde Italia en 1935 de la mano de un quintero famoso en la zona. Algunas de estas variedades, entre otras, siguen cultivándose hoy en día (Garat et al., 2009).

\section{1..1.3 Expansión e intensificación de la producción (1940-actualidad).}

Fue entre fines de los años 40 y mediados de los años 60 que muchos de los trabajadores migrantes hortícolas lograron comprar la tierra y según el nivel de capitalización alcanzado se transformaron en medianos o pequeños productores. A partir de 1960 comenzaron a afluir a las quintas locales, trabajadores provenientes de las provincias del norte del país, principalmente santiagueños, seguidos por salteños y jujeños. Eran en un principio jornaleros con pago diario, semanal o quincenal, dedicándose a tareas de encañe, desbrote, cosecha y embalaje. Al igual que los migrantes de ultramar, en sus lugares de origen practicaban la agricultura de subsistencia. Estos trabajadores fueron contratados por los primeros inmigrantes y sus descendientes, ahora devenidos en patrones propietarios (Lemmi, 2011).

Hasta mediados de 1960 en la mayoría de las quintas prevalecía la tracción animal, el riego por gravitación, la fertilización con cama de pollo y el deshierbe manual. El nivel técnico evolucionó con retraso en relación con el promedio pampeano, la tractorización se expandió recién hacia 1965-1967 y la difusión de agroquímicos es de los años 1970-1973 (Benencia, 2006). En este sentido, se puede establecer que entre las décadas $70^{\prime}$ y 80', 
surge la denominada Revolución Verde. Los agricultores que podían invertir realizaron una serie de transformaciones tecnológicas complejas, algunas de ellas fueron la utilización de semillas híbridas o variedades comerciales, que reemplazaron las variedades tradicionales en gran medida (Garat et al., 2009), la instalación de sistemas de riego y la incorporación de tractores de mayor potencia (Benencia, 2006). Un aspecto interesante a distinguir en cuanto a la organización del trabajo es el carácter familiar de las quintas, es decir, donde el quintero junto a su familia, se hacía cargo de la mayoría de las actividades. En ciertos momentos del año donde había más trabajo, se contrataban peones temporarios, generalmente migrantes del norte del país. En las explotaciones de mayor tamaño, que eran más escasas, había peones permanentes, encargados y/o capataces.

Durante 1990 el sector hortícola platense profundiza la incorporación tecnológica con la adopción del invernáculo, que fue el símbolo del progreso técnico del periodo, transformando a esta región, en el cinturón hortícola más tecnificado del país. Es así que se modificaron radicalmente los sistemas productivos, a partir de la incorporación del cultivo bajo cobertura plástica y un paquete tecnológico asociado al mismo, que incluyó semillas de alto potencial de rendimiento y mayor uso de insumos de síntesis química (Archenti et al., 1993; Selis, 2000). El trabajo de Gallardo (2012) recupera el ejemplo del tomate y describe que en los años '80, aparecieron los híbridos, y en especial uno de ellos, carmelo, el cual representó para los productores una opción tecnológica ventajosa, fundamentalmente por el alto rendimiento, resultado, básicamente, del poco descarte y la firmeza de los frutos. De este modo, las cultivares y planes de trabajo del Instituto Nacional de Tecnología Agropecuaria (INTA), perdieron relevancia, más aún cuando desde los grandes centros de investigación y aplicación de los conocimientos, dieron paso a los tomates larga vida. Estas transformaciones repercutieron de varias formas: EI invernáculo y las semillas mejoradas tuvieron grandes efectos en los rendimientos, la calidad de la producción, la demanda de insumos, la comercialización y en el uso y remuneración de los distintos factores de producción, así como produjo una aceleración de los ritmos y de las inversiones. Esta adopción fue posible por una relación favorable insumo/producto permitida por el momento económico del país (Selis, 2000). Sin embargo, este nuevo hito provocó un aumento de la brecha tecnológica, una mayor diferenciación entre quienes estaban en condiciones de arriesgar capital en los nuevos paquetes tecnológicos y quienes ni siquiera podían llegar al simple invernáculo con postes de madera. Es por ello, que los establecimientos hortícolas que se encontraban dentro del segundo grupo, se redujeron hacia finales de la década del '90 (García, 2010; Ringuelet, 2008). Para este entonces, la población boliviana ya representaba una gran 
proporción de la mano de obra mediera, y gracias a su autoexplotación del trabajo y ahorro, se convirtieron en productores arrendatarios e invirtieron en invernáculos.

Las políticas nacionales de desarrollo rural se incrementaron, entre ellas se implementó el Programa Nacional de Reconversión Productiva para la Pequeña y Mediana Empresa Agropecuaria (Cambio Rural), con la formación de grupos que con el acompañamiento de un técnico, pudieron solucionar algunos problemas técnicos y organizacionales. La ampliación del asociativismo y la presencia institucional fue decayendo. En este contexto avanzó el sector privado, mediante empresas de agroinsumos, agencias de asesoramiento y servicios profesionales agronómicos, económicos, financieros y legales (Ringuelet, 2008).

A partir del 2001 con la finalización de la convertibilidad, la horticultura platense, al igual que el país, se vio afectada. El sistema de producción bajo invernáculo altamente dependiente y demandante de insumos, en su mayoría importados y rigiéndose entonces a valor dólar (agroquímicos, fertilizantes, plásticos y semillas híbridas) prácticamente triplicó su valor en pesos, en concordancia con el nuevo tipo de cambio de 3:1. A esto se sumó, el corte de la cadena de pago y la desaparición de la financiación. Además, los productos hortícolas se generalizan como de consumo interno. A diferencia del resto del sector agrícola al cual el cambio de política económica benefició, el sub-sector hortícola posee un ínfimo volumen de productos que se exportan, debiéndose producir de esta manera con insumos en dólares y ventas en pesos (García \& Hang, 2007). Ante esta situación, los productores desarrollan diversas estrategias tecnológicas. Se observan retrocesos, como los usos de insecticidas de amplio espectro y de contacto, la toma de decisiones sin planificación y la baja en la oferta, entre otros. Pero también surgieron estrategias de subsistencia. El incremento de la productividad en un contexto adverso, el uso más eficaz de insumos a través de determinados manejos llevados a cabo por algunos productores (monitoreo de plagas), el uso más racional de algunos insumos (fertilizantes) y la sustitución de otros (Bromuro por el Vapam) (García \& Hang, 2007). Los cambios económicos acentuaron el proceso de diferenciación social, marcando un sector de medianos y grandes productores los cuales implementan los avances técnicos, de gestión y comerciales. Hay otro sector de productores medios y pequeños que entró en un proceso de retracción, muchos dan en arriendo su tierra o parte de ella, re direccionan sus capitales y ahorros, o aceleran los traspasos generacionales (Ringuelet, 2008).

En la actualidad, los sistemas de producción hortícolas son altamente intensivos en el uso de capital y mano de obra, y conviven diversas formas de producción como sistemas al aire 
libre, aquellos que combinan producción al aire libre con invernáculo y sistemas productivos que sólo utilizan invernáculo. Según datos del Censo Hortiflorícola de Buenos Aires (Dirección Provincial de Estadística, 2005), del total de 2.608,386 hectáreas bajo producción hortícola, $1.842,830$ ha se realizan a campo y 765,556 ha bajo invernáculo (Figura 4). Datos más actuales aportados por García (2015) dan cuenta del avance de la superficie bajo cubierta. Este autor sostiene que entre el año 2005 y la actualidad, se estima la incorporación de 1500 has de invernáculo. Esta tecnología posibilita una disponibilidad de hortalizas en cantidad y continuidad más amplia, casi sin baches a lo largo del año o bien de ciclo completo (García, 2015), a su vez, esta tecnología implica que el productor de hortalizas localizado en zonas de primicias o cinturones hortícolas de los centros urbanos, requiera cultivares específicos en cada especie. La demanda de cultivares híbridos en tomate, pimiento, zapallo, espinaca y maíz dulce va en aumento por la gran presión de las empresas y por las ventajas productivas que las mismas ofertan (Gaviola, 2003). Este proceso de intensificación ha ido de la mano de la expansión de plantineras en el territorio, las cuales según García (2016a) pasaron de una o dos plantineras en 1995, a más de veinte en 2016. Según Castro (2016) nuevos saberes y prácticas fueron necesarios para que los agricultores pudiesen adaptarse a esta forma intensiva de producción. Esta autora sostiene que el modelo hegemónico penetró en los actores desde la esfera económica, a través de la demanda del mercado y desde la simbólica, a través de un paradigma que extendieron las agroquímicas, ingenieros, medios de comunicación y productores exitosos. Por un lado, el mercado demanda un cultivo convencional y si no se hace de esta manera, la producción es muy difícil ubicar en el mercado. Distintos autores como Blandi et al. (2009, 2015) y García (2015) analizan las consecuencias sociales, económicas y ecológicas del avance del cultivo bajo cubierta en la horticultura platense. Parte de esta coyuntura es la actual preocupación en torno al uso de agroquímicos. El relevamiento sobre el uso de agroquímicos realizado en la Provincia de Buenos Aires por investigadores de la Universidad Nacional de La Plata para la Defensoría del Pueblo de la Provincia (DPBA, 2015) da cuenta de esto, arrojando datos alarmantes. 


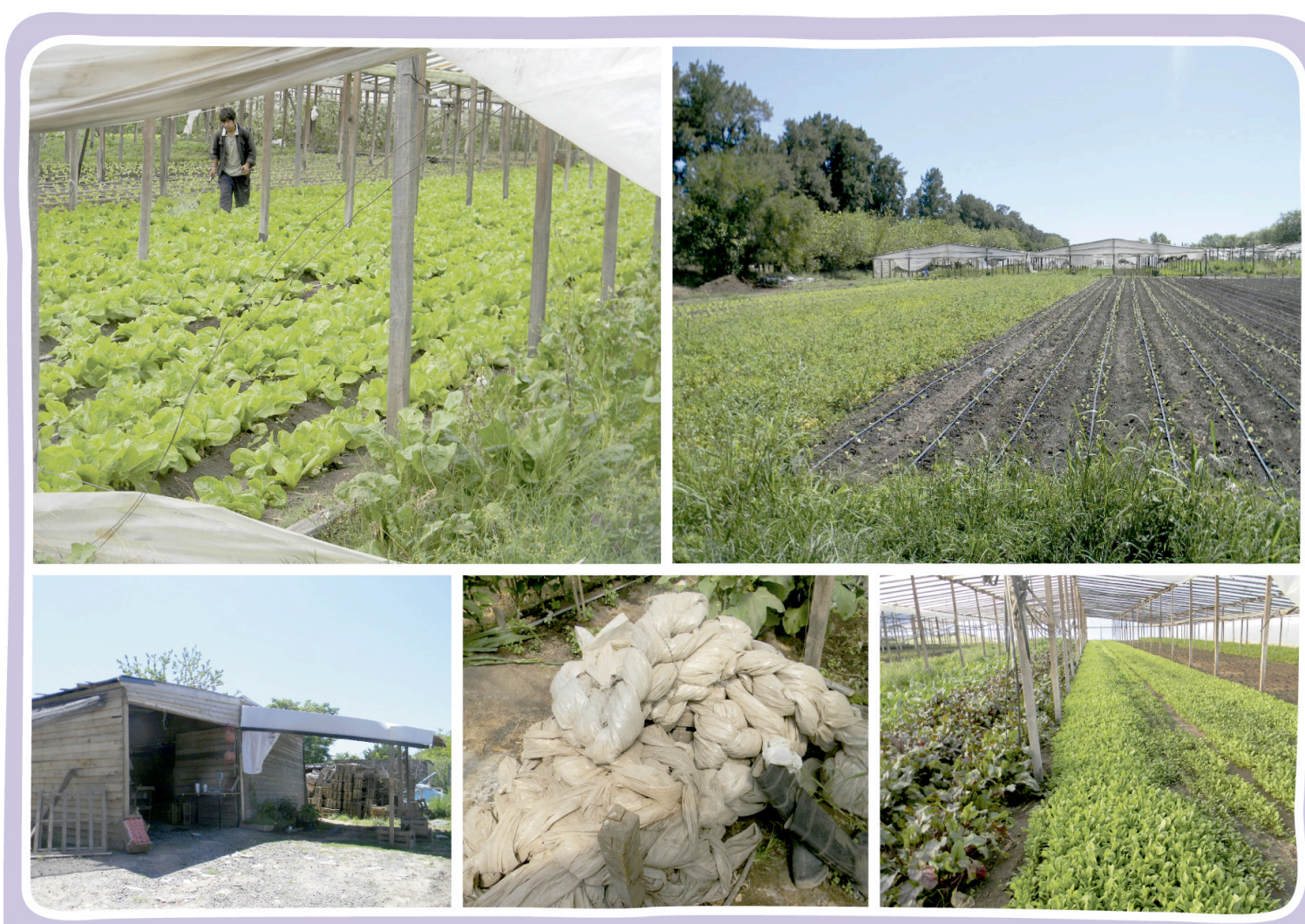

Figura 4: Quintas hortícolas a campo y bajo cubierta en el Cinturón Hortícola Platense. Fuente: fotos de la autora.

Los cambios sociales y económicos de la Argentina han tenido su influencia en diversas dimensiones de la actividad productiva, entre ellas en la propiedad de la tierra. En tal sentido, el Censo Hortiflorícola de la Provincia de Buenos Aires (Dirección Provincial de Estadística, 2005) señala que en la región bajo estudio, el $34.6 \%$ de los productores son propietarios, mientras que el $61.2 \%$ son arrendatarios y el restante $4.2 \%$ está bajo la forma de propietario, arrendatario, contratos accidentales, sucesión (Seibane et al., 2014). Según García (2016b), los establecimientos hortícolas siguen siendo de pequeña superficie pero su cuantía ha reducido drásticamente. Según el último Censo Hortiflorícola realizado en el año 2005 , la quinta promedio platense posee 5,5 hectáreas, siendo que una mirada más profunda señala que 2 de cada 3 quintas no superan las 2 hectáreas de superficie.

Actualmente la presión competitiva y la puja por el valor generado resulta mayor sobre las quintas más pequeñas, cuestión que genera a su vez, menores ingresos y una mayor explotación de la mano de obra y desaparición de las quintas menos competitivas (García, 2015). En este contexto, la práctica de conservación de semillas, al ser una actividad que demanda espacio físico, disponibilidad de recursos económicos y mano de obra, a su vez de implicar el riesgo de la obtención de un producto menos homogéneo que no cumpla con los estándares del mercado, se encuentra amenazada. 


\subsection{Metodología}

La agroecología representa un enfoque transdisciplinario en sí mismo, que ilustra la fusión de los conjuntos integrados de abordajes disciplinares que conforman esta nueva orientación (Bowling, 2011). Para la realización de esta investigación se tomaron herramientas metodológicas de la etnobotánica. En dicha interdisciplina los "datos" se refieren a la amplia gama de información, que se obtiene acerca de cómo se relaciona la gente local con el medio ambiente (Crivos, 2009; Martin, 1995). La etnobotánica está situada en el interés por estudiar el conocimiento de un grupo humano acerca de los diversos componentes vegetales del ecosistema al que pertenecen, así como las razones que motivan su actitud con respecto al entorno vegetal (Arenas, 2012). El interés por brindar soluciones frente a temas como la seguridad alimentaria, el deterioro de la calidad de vida, la pérdida de conocimientos tradicionales (Ladio, 2010) representa un punto de encuentro entre la etnobotánica y la agroecología. A su vez la mirada sobre los conocimientos relacionados a las plantas que son el principal componente de la agrobiodiversidad, resulta un aporte fundamental para la agroecología.

\subsection{Recopilación de datos}

Para diseñar el muestreo se utilizó la técnica llamada "bola de nieve" (Bailey, 1994 en Albuquerque et al., 2010; Bernard, 2000; Furlán et al., 2011; Veteto, 2008), para la cual se seleccionó un grupo de interlocutores iniciales. Se entiende que un interlocutor inicial es aquella persona informada, reflexiva y dispuesta a hablar con el investigador. Estos informantes fueron contactados a partir de su participación en espacios de intercambio de semillas locales y/o del vínculo con extensionistas e investigadores que se encuentran trabajando con este sector. Posteriormente, dichos informantes recomendaron a otros posibles participantes, entendiendo que la presentación que hace el sujeto ya incluido en el proyecto, establece una relación de confianza con los nuevos participantes. En tal sentido, el muestreo no es aleatorio, bajo el supuesto de que aquellos/as agricultores/as familiares que conserven semillas, proporcionarán información más específica sobre el tema (Martín-Crespo Blanco \& Salamanca Castro, 2007). Se seleccionaron 11 interlocutores iniciales a fin de comenzar el proceso de muestreo en diferentes localidades del Cinturón Hortícola Platense (Los Hornos, Etcheverry, Hernández, Parque Pereyra Iraola, Gorina, Colonia Urquiza, Abasto, Florencio Varela, Arana) y tomando más de un informante inicial en algunas localidades en función de los contactos obtenidos. La 
propuesta de seleccionar diversos informantes iniciales, se realizó buscando ampliar la red de contactos, a fin de adaptar la metodología de bola de nieve a las dimensiones del área en estudio. El muestreo se completó con la selección de casos al azar (4), teniendo en cuenta que la técnica de muestreo de bola de nieve no permite registrar datos independientes entre sí. Como se describió en el capítulo 1.1, el Cinturón Hortícola Platense se encuentra inserto en el Cinturón Hortícola Bonaerense. Algunos agroecosistemas sugeridos por los informantes sobrepasaron las barreras teóricas que delimitan las localidades que comprende el CHP. A pesar de este punto, estos agroecosistemas fueron visitados e incorporados al estudio ya que se consideró que estas barreras no interfieren en los circuitos de intercambio y circulación de semillas. Al decir de García (2012) el área hortícola Bonaerense en función de la expansión urbana, sufre desplazamientos, contracciones, cambios y continuidades en el uso del suelo. Por ende, la delimitación y composición de la misma varía en función del tiempo.

Cada quinta de producción familiar visitada fue considerada una unidad de muestreo (Girard et al., 2014; Henao Salazar, 2013; Mitchell 1983; Turner et al., 2003; Yacuzzi 2005). Trabajos realizados en el área de la agroecología y conservación de agrobiodiversidad, han utilizado la técnica de "bola de nieve" y han obtenido tamaños de muestras muy variables, entre 6 (Saldaña Gazzaneo et al., 2005), 26 informantes (Veteto, 2008) y 91 informantes (Cerdán Cabrera, 2007). Considerando que no hay criterios firmemente establecidos respecto al tamaño de la muestra, se definió el principio de saturación de datos, donde se muestrea hasta el punto en que la información comienza a ser redundante (Martín-Crespo Blanco \& Salamanca Castro, 2007). En este sentido, las entrevistas se realizaron hasta cubrir los informantes derivados por los iniciales (11) y a su vez que la información comenzara a reiterarse sistemáticamente, siendo 26 el número final de informantes (Figuras 5 y 6 ) y 33 entrevistas realizadas, ya que alguna familias fueron visitadas en más de una oportunidad. Las derivaciones fueron diversas: algunos interlocutores derivaron un máximo a de 3 informantes y otros a ninguno. Algunos contactos no pudieron establecerse ya sea por falta de precisión sobre la ubicación de la quinta/ familia, o por no disponer de un contacto telefónico. Las visitas fueron realizadas durante los años 2009 (4 entrevistas), 2010 (3 entrevistas), 2011 (10 entrevistas), 2013 (5 entrevistas) y 2014 (11 entrevistas). En el Anexo 1 se presenta el listado de las entrevistas realizadas, la sigla del/la interlocutor/ra, la localidad en el Cinturón Hortícola Platense y el año de realización de la entrevista. En referencia a este anexo y a fin de facilitar la identificación de las entrevistas a lo largo de la tesis, cada una es nombrada 
con el apellido de quien escribe, el año de realización, una letra indicando la secuencia cronológica y la sigla del/la interlocutor/ra; ejemplo: (Bonicatto 2011a. Entrevista a BV).

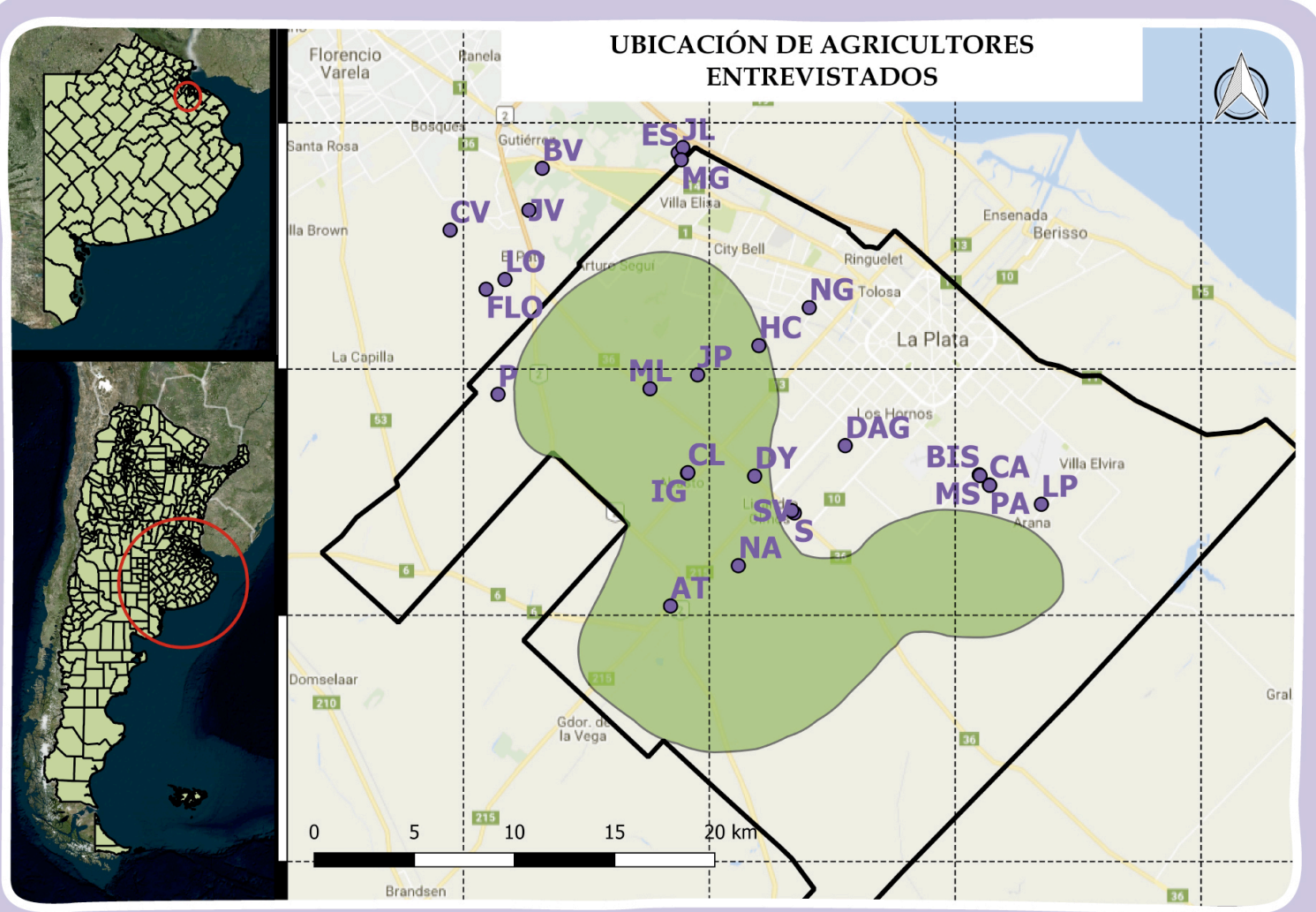

Figura 5: Localización de los agroecosistemas familiares visitados en el Cinturón Hortícola Platense. Fuente: elaborado por Baldini (2017) en QGis 2.14 


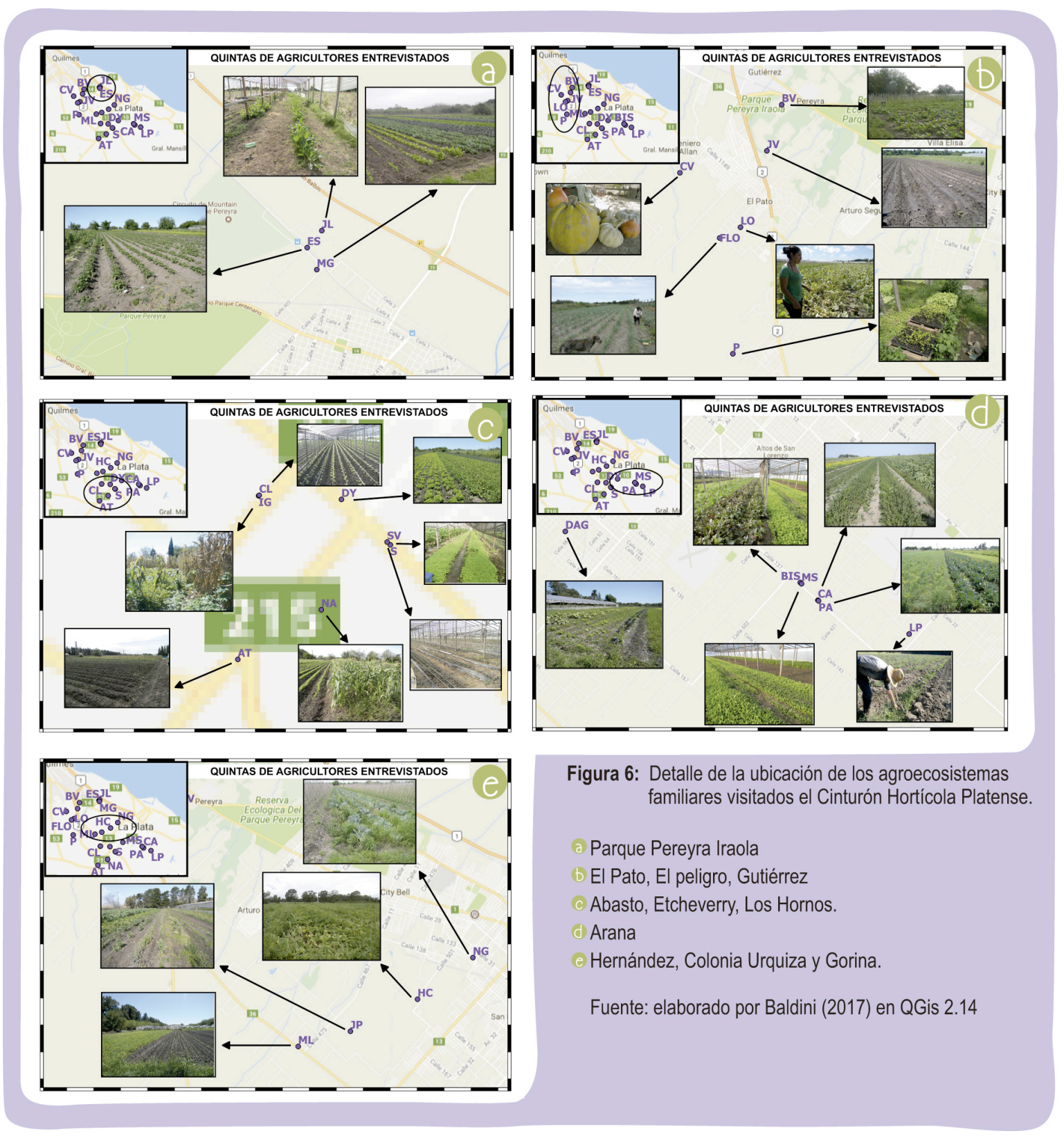

\section{I.2.I. Entrevista}

El primer momento de las entrevistas se dedicó a explicar a los interlocutores, en lenguaje apropiado y divulgativo, los fundamentos, objetivos, implicancias y alcances de la investigación (Alexiades \& Laird, 2002), acordando con los interlocutores, distintos ítems de consentimiento incluyendo fotografías, grabaciones, identidad, toma de muestras vegetales y difusión de la información. Se elaboraron dos documentos, uno quedando en mano de los miembros de la comunidad y otro en manos de quien escribe (Anexo 2). En algunos casos se realizó el consentimiento de forma oral quedando registrado en la grabación. 
Se realizaron entrevistas abiertas (charla informal sobre los tópicos de interés) y semiestructuradas, donde los interlocutores dan respuesta extensa a una serie de preguntas generales, en secuencia estipulada previamente (Anexo 3). Las mismas son herramientas interesantes cuando se busca dar una idea de la forma en la cual la gente describe su vida y su entorno natural (Martin, 1995). Esta variable metodológica es una interesante opción en situaciones donde no se tiene más de una oportunidad para entrevistar a alguien, además de la flexibilidad que presenta este tipo de entrevista para abordar los temas presentados y poder profundizar en aquellos puntos surgidos durante la misma (Albuquerque et al., 2010). A su vez se utilizó la observación participante que consiste en compartir con la gente los distintos aspectos de su actividad diaria (Amorozo \& Viertler, 2010), en este caso, los momentos de siembra, cosecha, selección y mantenimiento de las semillas, a fin de documentar el conocimiento en el mismo momento en que se realiza la práctica. En aquellos casos donde surgieron temas de interés, se realizaron a posteriori entrevistas en profundidad. Según Taylor \& Bogdan (1987) la entrevista en profundidad implica reiterados encuentros cara a cara entre el investigador y los informantes, encuentros éstos dirigidos hacia la comprensión de las perspectivas que tienen los informantes respectos de sus vidas, experiencias o situaciones, tal como las expresan con sus propias palabras. Las entrevistas en profundidad siguen el modelo de una conversación entre iguales, y no de un intercambio formal de preguntas y respuestas. El registro se realizó mediante grabaciones para asegurar no perder información y poder dar libertad a la conversación (Albuquerque et al., 2010). Para las situaciones donde los interlocutores manifestaron no querer ser grabados, se utilizó un diario de campo para registrar la entrevista. El registro se completó con fotografías y filmaciones.

Luego de explicar a cada familia el sentido del trabajo se entrevistó a quien estaba dispuesto a dedicar tiempo a esta propuesta, independientemente de variables como género y edad. A fin de preservar la identidad de los interlocutores se los denomina con siglas. Los ejes de la entrevista se basaron en el vínculo del/la entrevistado/a con la producción hortícola, la diversidad hortícola cultivada, las semillas conservadas, su origen y destino, los usos, y motivos de la conservación de dichas semillas, las técnicas de conservación y los posibles impedimentos para la conservación. Cada cultivo fue considerado un registro.

En cuanto al relevamiento de material botánico para su determinación, se recorrieron las quintas, focalizando el interés en el área denominada unidad productiva. En estas recorridas se solicitó a los agricultores una muestra de las semillas conservadas. En 
aquellos casos en que ya habían sido sembradas, se colectó aquella parte de la planta cultivada que permitía su determinación. Todas las colectas de material fueron realizadas en presencia de los informantes y bajo su supervisión y autorización. Las muestras de semillas se conservaron en sobres de papel madera y posteriormente en frascos de vidrio en heladera, etiquetados con la información correspondiente: nombre local, especie, familia botánica, origen de la semilla, lugar, sigla del interlocutor y fecha de colección, En el caso de ser muestras de cultivos sembrados a campo, se realizaron colectas y su posterior acondicionamiento para ejemplares de herbario (Lima dos Santos et al., 2010) montados en cartulinas etiquetados, indicando: especie, familia botánica, lugar y fecha de colección.

\subsubsection{Entrevista estructurada}

Se utilizaron preguntas abiertas y cerradas previamente establecidas en la misma secuencia (Albuquerque, et al., 2010) para entrevistar a personas externas a la producción pero influyentes en el contexto territorial como comerciantes de agroinsumos y técnicos extensionistas e investigadores (Anexo 4). El número de entrevistas no se determinó previamente, sino que se trabajó en el área de influencia y en función de la disposición a ser entrevistado. Para el caso de los comercios se realizaron 10 encuestas. Para el caso de técnicos extensionistas/investigadores se envió el cuestionario de forma digital obteniendo 13 respuestas. El listado de entrevistas realizadas se presenta en el Anexo 1.

\subsubsection{La organización de los datos}

Las entrevistas fueron transcriptas en su totalidad. Todos los registros tomados (grabaciones, fotografías, filmaciones, notas de campo y material botánico colectado) en cada visita realizada, se identificó con la sigla del interlocutor, fecha y número de entrevista.

\subsubsection{Determinación del material botánico}

Cada muestra vegetal colectada fue montada en cartulinas y etiquetadas, indicando: especie, familia botánica, nombre local, lugar y fecha de colección para la realización de un herbario (Katinas, 2001). En el caso de las semillas se conservaron en frascos de vidrio, en un lugar oscuro y libre de humedad y los frutos u órganos vegetales carnosos 
se conservaron en frascos de vidrio con conservante para color de muestras vegetales (por litro: $540 \mathrm{ml}$ de alcohol $96^{\circ}, 250 \mathrm{ml}$ de glicerina líquida, $210 \mathrm{ml}$ de agua y formol).

La determinación botánica se realizó con el empleo de lupa binocular estereoscópica, en base a consulta bibliográfica (Cabrera, 1965; Cabrera \& Zardini, 1978; Dimitri, 1987; 2004), el apoyo de material de referencia del Herbario LP- FCNyM- UNLP, consulta a especialistas del Jardín Botánico y Arboretum Carlos Spegazzini de la FCAyF-UNLP. Para la nomenclatura de las plantas cultivadas se utilizó Hurrell et al. (2008; 2009; 2010; 2011) y el Catálogo de las Plantas vasculares del Conosur (IBODA, 2017) para nativas. Esta selección se realizó sobre la base de su amplia difusión en el ámbito de la agronomía.

\subsubsection{Sistematización}

La sistematización es un proceso metodológico que se basa en poner en orden o dar organización a un conjunto de elementos (prácticas, conocimientos, ideas, datos) que hasta ese momento estaban desorganizados (Berdegué et al., 2004). La información recabada, se ordenó, codificó y capturó en una base de datos diseñada en una hoja de cálculo en Microsoft Excel. En dicha tabla cada cultivo fue considerado un registro asiciado al agroecosistema donde fue registrado.

La información fue codificada a fin de identificar cada extracto de las entrevista. Este código se construyó con: Las iniciales del interlocutor/ra + el número de la visita, ya que en algunos casos se visitó más de una vez la producción + el renglón según la transcripción de la entrevista. Ejemplo MG E2-21. Para el análisis de los datos se elaboró una tabla dinámica, la cual permitió hacer un cruzamiento de información, obtener tablas y gráficas para la interpretación de los resultados. Estos datos se organizaron para cada sitio de muestreo (cada agroecosistema) y luego se conformó una planilla general. Para cada planta mencionada (nombrada de aquí en adelante como "registro" de planta cultivada), se detalló el nombre científico, nombre local, familia botánica, la conservación o no semillas, el tiempo que hace que conservan la variedad/especie botánica, el motivo por el/los cual/es se conserva, el origen de la misma, el destino y uso/s de ese cultivo. A partir de estos datos se realizaron cuantificaciones que permitieron analizar los datos según los diferentes aspectos mencionados. Para el análisis de los datos se describieron categorías en base al relato local, en tanto, los rótulos de las mismas fueron puestos por la autora. A través de esta metodología se intentó rescatar las categorías descriptas por 
los interlocutores sin imponer el orden del investigador. De esta manera se pretende dar lugar al imprevisto, a aquello que va más allá de lo esperado por el investigador (Furlán et al., 2011). Con la información recopilada se realizó un "banco de memoria" (Nazarea 1998; Veteto 2008) entendido como la documentación del conocimiento local y las tecnologías incluyendo los usos, preferencias y criterios de evaluación asociados a la agrobiodiversidad hortícola cultivada y conservada.

\subsubsection{Análisis en progreso}

Para abordar el análisis de los saberes vinculados a las prácticas de conservación de semillas se realizó el análisis en progreso propuesto por Taylor \& Bogdan (1987), entendiendo que el análisis cualitativo de los datos es un proceso continuo durante el progreso de la investigación. Hacia el final de la misma, el investigador se concentra en el análisis e interpretación de los datos. Las observaciones realizadas, imágenes y notas de campo se conjugan con las transcripciones de las grabaciones, para avanzar en el desarrollo de conceptos y proposiciones, que dan sentido a los datos. A lo largo del análisis, se busca lograr una comprensión más profunda del escenario estudiado, que permita comprender los datos en el contexto en el que fueron recogidos. 


\subsection{BIBLIOGRAFÍA}

Albuquerque, U.P.; R.F.P. Lucena \& N.L. Alencar. 2010. Métodos e técnicas para coleta de dados etnobiológicos, en: U.P. Albuquerque.; R.F.P. Lucena \& L.V.F. Cruz da Cunha (editores.), Métodos e técnicas na pesquisa Etnobiológica e Etnoecológica 1: 41-64. Editorial NUPEEA. Brasil.

Alexiades, M.N. \& S.A. Laird. 2002. Estableciendo los fundamentos: relaciones equitativas de la investigación sobre biodiversidad, en: S.A. Laird (editor), Biodiversidad y conocimiento tradicional. Participación equitativa en práctica. Montevideo: Nordan Comunidad, p. 41-52.

Amorozo, M.C.M \& R.B. Viertler. 2010. A abordagem qualitativa na coleta e análise de dados em etnobiologia e etnoecologia, en: U.P. de Albuquerque, R.F.P. Lucena \& L.V.F. Cruz da Cunha (editores.), Métodos e técnicas na pesquisa Etnobiológica e Etnoecológica 1: 67-82. Editorial NUPEEA. Brasil.

Archenti, A.; R. Ringuelet \& M. Salva. 1993. Los procesos de diferenciación de los productores hortícolas de La Plata. Continuidad y Cambio. Revista ETNIA. Olavarría 38-39: 57-83.

Arenas, P. 2012. Etnobotánica en zonas áridas y semiáridas del Cono Sur de Sudamérica. Edición del CEFYBO-CONICET. Buenos Aires. Argentina.

Bailey, K. 1994. Methods of social research. $4^{\mathrm{a}}$ ed. New York: The Free Press.

Barsky, A. 2005. El periurbano productivo, un espacio en constante transformación. Introducción al estado del debate, con referencias al caso de Buenos Aires. Scripta Nova 9(194):36.

Benencia, R. 2006. Transformaciones de la horticultura periurbana bonaerense en los últimos cincuenta años. El papel de la tecnología y la mano de obra. Disponible en: https://periferiaactiva.files.wordpress.com/2012/08/roberto-benecencia.pdf [consulta octubre de 2015].

Berdegué, J.A.; A. Ocampo \& G. Escobar. 2004. Sistematización de experiencias locales de desarrollo agrícola y rural. Guía metodológica. Versión 3. Preval Fidamerica. 
Bernard, H.R. 2000. Social research methods: qualitative and quantitative approaches. Sage Publications, London.

Blandi, M.L.; N.A. Gargoloff, C.C. Flores \& S.J. Sarandón. 2009. Análisis de la sustentabilidad de la producción hortícola bajo invernáculo en la zona de La Plata, Argentina. Revista Brasilera de Agroecología 4 (2): 1635-1638.

Blandi, M.L.; S.J. Sarandón, C.C. Flores \& I. Veiga. 2015. Evaluación de la sustentabilidad de la incorporación del cultivo bajo cubierta en la horticultura platense. Revista Facultad de Agronomía 114 (2): 251-264.

Bowling, P.M. 2011. Agroecología, complejidad, transdisciplinariedad y multidimensionalidad, en: J. Morales Hernández (coordinador) La Agroecología en la construcción de alternativas hacia la sustentabilidad rural. ITESO-Siglo XXI editores. Pp 111-128.

Bozzano, H. 2003. La Plata, sistemas de objetos, sistemas de acciones. Propuesta de territorialización, en: Pensar La Plata. Políticas públicas, sociedad y territorio en la década de los noventa. Contribuciones desde la geografía, ed. P. Pintos, 173-201. La Plata, Argentina: Ediciones Al Margen.

Cabrera, A.L. \& E.M. Zardini. 1978. Manual de la flora de los alrededores de Buenos Aires. Editorial ACME.

Cabrera, A.L. 1965. Flora de la Provincia de Buenos Aires. Tomo I-VI. Colección científica del INTA, Buenos Aires.

Castro, A. S. 2016. Saberes migrantes. Trayectorias de productores bolivianos del periurbano platense (Tesis de grado). Presentada en Universidad Nacional de La Plata. Facultad de Humanidades y Ciencias de la Educación para optar al grado de Licenciada en Sociología. Disponible en:

http://www.memoria.fahce.unlp.edu.ar/tesis/te.1295/te.1295.pdf

Cerdán Cabrera, C.R. 2007. Conocimiento local sobre servicios ecosistémicos de cafeticultores del Corredor Biológico Volcánica Central Talamanca, Costa Rica. Tesis Magíster Scientiae en Agricultura Ecológica. Costa Rica: Centro Agronómico Tropical de Investigación y Enseñanza (CATIE). 
Cieza, R.I.; G. Ferraris, C. Seibane, G. Larrañaga \& L. Mendicino. 2015. Aportes a la caracterización de la agricultura familiar en el Partido de La Plata. Revista Facultad de Agronomía La Plata. 114 (Núm. Esp.1) Agricultura Familiar, Agroecología y Territorio: 129-142.

Crivos, M. 2009. Implicancias teóricas y epistemológicas de las estrategias de investigación etnobotánica, en. M.L.Pochettino; A.H. Ladio \& P.A. Arenas (editoras). Tradiciones y transformaciones en etnobotánica. CYTED-RISAPRET. Pp 5-10.

Dimitri, M. 1987. Enciclopedia Argentina de Agricultura y Jardinería. Tomo I. Vol I. Editorial Acme S.A.C.I. Buenos Aires.

Dimitri, M. 2004. Enciclopedia Argentina de Agricultura y Jardinería. Tomo I. Vol II. Acme Agency S.A.C.I.y F. Buenos Aires.

Dirección Provincial de Estadística. 2005. Censo Hortiflorícola de la Provincia de Buenos Aires. La Plata, Ministerio de Asuntos Agrarios, Dirección Provincial de Economía Rural, Gobierno de la Provincia de Buenos Aires, Ministerio de Economía.

DPBA (Defensoría del Pueblo de la Provincia de Buenos Aires). 2015. Relevamiento de la utilización de Agroquímicos en la Provincia de Buenos Aires - Mapa de Situación e incidencias sobre la salud. Informe técnico.

Furlán, V.; C. Torres \& L. Galleto. 2011. Conocimiento y utilización de plantas medicinales por pobladores rurales del bosque chaqueño serrano de Córdoba (Argentina). Bonplandia 20 (2): 285-307.

Gallardo, G.S. 2012. Desarrollo institucional y política científica: el caso de la producción nacional de semilla hortícola. Tesis de Maestría en Gestión de la Ciencia, Tecnología e Innovación. Universidad Nacional de general Sarmiento.

Garat, J.J.; A. Ahumada, J. Otero, L. Terminiello, G. Bello, \& M.L. Ciampagna. 2009. Las hortalizas típicas locales en el cinturón verde de La Plata: su localización, preservación y valorización. Horticultura Argentina 28(66):32-39.

Garat, J.J.; A. Castro, S. Gramuglia, A. Nico \& A. Ahumada. 2007. El rescate de la biodiversidad local y la acción colectiva: una estrategia de desarrollo a través de la revalorización de hortalizas locales en el cinturón verde de La Plata, Buenos Aires, Argentina. Revista Brasilera de Agroecologia 2 (1): 430:434. 
García, M. \& G. Hang. 2007. Impacto de la devaluación de principios de 2002 en el Cinturón Hortícola Platense. Estrategias tecnológicas adoptadas, sus resultados y consecuencias. Mundo Agrario 15: 1-12.

García, M. \& S. Lemmi. 2011. Territorios pensados, territorios migrados. Una historia de la formación del territorio hortícola platense. Ponencia presentada en las VIII Jornadas Patagónicas de Geografía. Comodoro Rivadavia, Facultad de Humanidades y Ciencias Sociales, Universidad Nacional de la Patagonia San Juan Bosco.

García, M. 2010. Reestructuraciones de las periferias hortícolas de Buenos Aires y modelos espaciales ¿Un archipiélago verde? EchoGéo №11. Disponible en: http://echogeo.revues.org/11539. [Consulta: noviembre de 2015].

García, M. 2012. Análisis de las transformaciones de la estructura agraria hortícola platense en los últimos 20 años. El rol de los horticultores bolivianos. Tesis doctoral. Facultad de Ciencias Agrarias y Forestales, UNLP. 432pp. Disponible en: http://hdl.handle.net/10915/18122

García, M. 2015. Horticultura de La Plata (Buenos Aires). Modelo productivo irracionalmente exitoso. Revista Facultad de Agronomía La Plata 114 (Núm. Esp.1) Agricultura Familiar, Agroecología y Territorio: 190-201.

García, M. 2016a. Surgimiento, dinámica y rol de las plantineras en el aglomerado hortícola de La Plata. Revista Geografía 20:84-102.

García, M. 2016b. Capacidad competitiva y dinamismo en la horticultura de La Plata interpretada desde el enfoque basado en los aglomerados de empresas. Revista Huellas 20: 100-124.

Gaviola, J.C. 2003. Producción de semillas hortícolas en la Argentina. Idia XXI. Ediciones INTA 3 (4):19-24.

Girard, N.; D. Magda, C. Noseda \& S. Sarandón. 2014. Practicing agroecology: Management principles drawn from small farming in Misiones (Argentina): Communication au congrès IFSA. Berlin.

Gutman, P.; G. Gutman \& F. Dascal. 1987. El campo en la ciudad. La producción agrícola en el Gran Buenos Aires, en: Informes de investigación del CEUR 6CONICET. 
Henao Salazar, A. 2013. Propuesta metodológica de medición de la resiliencia agroecológica en sistemas socio-ecológicos: un estudio de caso en los andes colombianos. Agroecología 8 (1): 85-91.

Hurrell, J.A.; E.A. Ulibarri; P.M. Arenas \& M.L. Pochettino. 2011. Plantas de herboristería. Editorial LOLA, Buenos Aires.

Hurrell, J.A.; E.A. Ulibarri; G. Delucchi \& M.L. Pochettino. 2008. Plantas aromáticas condimenticias. Biota Rioplatense XIII, Editorial L.O.L.A., Buenos Aires.

Hurrell, J.A.; E.A. Ulibarri; G. Delucchi \& M.L. Pochettino. 2009. Hortalizas, verduras y legumbres -Biota Rioplatense XIV, Editorial L.O.L.A., Buenos Aires.

Hurrell, J.A.; E.A. Ulibarri; G. Delucchi \& M.L. Pochettino. 2010. Frutas frescas, secas y preservadas. Biota rioplatense XV. Editorial L.O.L.A, Buenos Aires.

IBODA. 2017. Catálogo de las Plantas vasculares del Conosur. Disponible en: http://www.darwin.edu.ar/Proyectos/FloraArgentina/fa.htm [Consulta septiembre 2017].

Katinas, L. 2001. El Herbario. Significado, valor y uso. Serie Técnica y Didáctica №1. PROBIOTA. 3-7.

Ladio, A.H. 2010. Apresentação, en: U.P. de Albuquerque.; R.F.P. Lucena \& L.V.F. Cruz da Cunha (editores.), Métodos e técnicas na pesquisa Etnobiológica e Etnoecológica, 19-20. Editorial NUPEEA. Brasil,

Lemmi, S. 2011. Las clases sociales en la horticultura platense. Ejercicio de teorización, historización y análisis empírico. Mundo Agrario 12 (23):1-27.

Lima dos Santos, L.; F.J. Vieira, L. Gomos de Sousa Nascimento, A.C., Olivera da Silva \& G.M. de Sousa. 2010. Técnicas para coleta e processamento de material botânico e suas aplicações na pesquisa etnobotánica, en: U.P. de Albuquerque.; R.F.P. Lucena \& L.V.F. Cruz da Cunha (editores.), Métodos e técnicas na pesquisa Etnobiológica e Etnoecológica, 279-295. Editorial NUPEEA. Brasil.

Martin, G.J. 1995. Etnobotánica. Manual de métodos. Editorial Nordan Comunidad. Montevideo, Uruguay. 
Martín-Crespo Blanco, M.C. \& A.B. Salamanca Castro. 2007. El muestreo en la investigación cualitativa. Nure Investigación, 27.

http://www.nureinvestigacion.es/OJS/index.php/nure/article/view/340

Mitchell, J. C. 1983. Case and situational analysis. Sociological Review 31(2):187-211.

Nazarea, V. 1998. Cultural Memory and Biodiversity. The University of Arizona Press. Estados Unidos de América.

Ringuelet, R. 2008. La complejidad de un campo social periurbano centrado en las zonas rurales de La Plata. Mundo Agrario, 9 (17).

Saldaña Gazzaneo, R.L.; R.F. Paiva de Lucena \& U.P. Albuquerque. 2005. El conocimiento y la utilización de las plantas medicinales por especialistas locales en una región de Bosque Atlántico, en el estado de Pernambuco (Nordeste de Brasil). Journal of Ethnobiology and Ethnomedicine 1: 9-9.

Seibane, C.; G. Larrañaga; C. Kebat; G. Hang, G. Ferraris \& M.L. Bravo. 2014. Redes para la promoción del desarrollo territorial en el cinturón hortícola platense. Mundo Agrario 15 (28):19.

Selis, D. 2000. Efectos del cambio tecnológico sobre las condiciones de producción y reproducción del sector hortícola de La Plata. Serie Estudios/Investigación. Facultad de Humanidades y Ciencias de la Educación. UNLP.

Sepúlveda, S.; A. Rodríguez; R. Echeverri \& M. Portilla. 2003. El Enfoque Territorial del Desarrollo Rural. Instituto Interamericano de Cooperación para la Agricultura. Dirección de Desarrollo Rural Sostenible San José, Costa Rica.

Staviski, A. 2010. Situación de la plasticultura en Argentina. Actas XXXIII Congreso Argentino de Horticultura. Rosario. Santa Fe. ASAHO.

Taylor, SJ \& R. Bogdan. 1987. Introducción a los métodos cualitativos de investigación. La búsqueda de significados. Barcelona, Paidós.

Turner, B. L.; P. A. Matson, J. J. McCarthy, R. W. Corell, L. Christensen, N. Eckley, G. K. Hovelsrud-Broda, J. X. Kasperson, R. E. Kasperson, A. Luers, M. L. Martello, S. Mathiesen, R. Naylor, C. Polsky, A. Pulsipher, A. Schiller, H. Selin, \& N. Tyler. 2003. Illustrating the coupled human-environment system for vulnerability analysis: three case studies. Proceedings of the National Academy of Sciences 100:8080-8085. 
Veteto, J.R. 2008. The history and survival of traditional heirloom vegetable varieties in the southern Appalachian Mountains of western North Carolina. Agriculture and Human Values 25:121-134

Yacuzzi, E. 2005. El estudio de caso como metodología de investigación: Teoría, mecanismos causales, validación (Serie Documentos de Trabajo, Universidad del CEMA). http://www.econstor.eu/handle/10419/84390 
una práctica ancestral que sigue activa

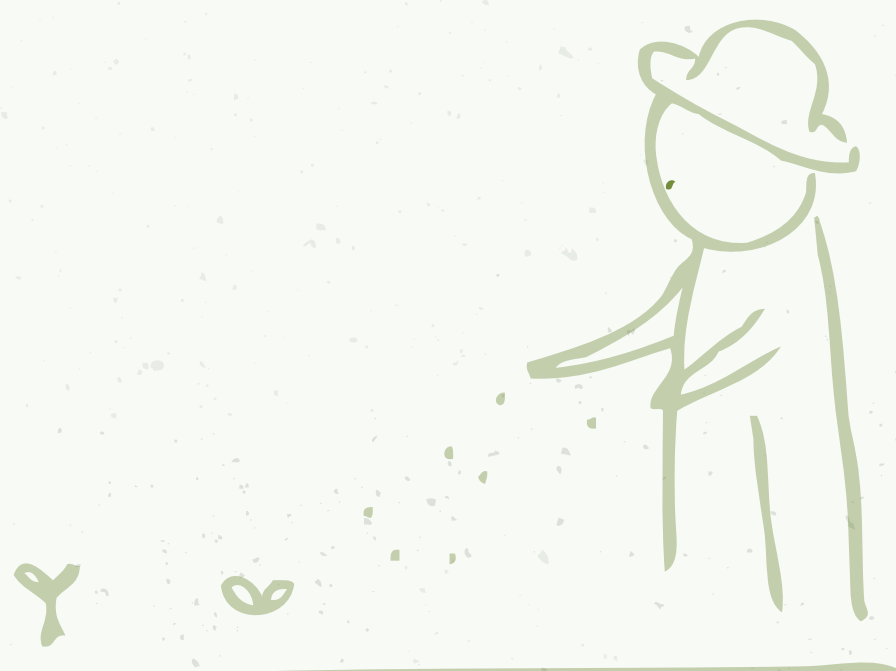




\section{CAPÍTULO 2 La conservación de semillas: una práctica ancestral que sigue activa}

"Ellos (refiriéndose a sus padres) no estaban tranquilos si no sacaban la semilla [...] entonces me decía: siempre hay que guardar la semilla. Me acuerdo que me lo decía"

(Bonicatto 2013c. Entrevista a MG)

\section{I Introducción}

El reciente informe del IPCC (2014) reafirma con autoridad que el cambio y la variabilidad del clima impactarán sobre la producción de alimentos y fibra a nivel global (Nicholls et al., 2015). En el escenario descripto, la creciente simplificación de la agrobiodiversidad a escala mundial, es un problema analizado por diversas investigaciones (Altieri \& Nicholls, 1994; Altieri \& Nicholls 2000; Bojar et al., 2012; de Boef 2007; Loreau et al., 2001; Nicholls et al., 2016; Pochettino, 2015). La simplificación y homogeneización de los agroecosistemas, conduce al deterioro y debilitamiento de sus funciones $y$, por ende, a una menor resiliencia ante el cambio climático (Altieri et al., 2015; Belloni, 2017; Isbell et al., 2015; Nicholls, 2013; Pérez \& Marasas, 2013). A su vez, surgen trabajos que analizan la erosión genética de la mano de procesos de desnutrición y malnutrición de las poblaciones (Chappell \& La Valle, 2011; Salcedo et al., 2014). En resistencia al avance de este proceso erosivo, existen numerosas experiencias de agroecosistemas familiares que manejan la agrobiodiversidad de manera tal de optimizar los servicios que provee la misma, y que minimizan tanto el uso de insumos externos, como el impacto socio ambiental sobre otros sistemas (Altieri 1999; Gargoloff et al., 2007; Nicholls et al., 2016; Salcedo et al., 2014; van der Ploeg 2012). Las estrategias de diversificación utilizadas por los agricultores son numerosas e implican variedad genética y diversidad de especies, así como las mezclas y diseños de la misma en rotaciones de cultivos, policultivos, abonos verdes o cultivos de cobertura, sistemas agroforestales, bordes, cercas y manejo de la vegetación espontánea (Marasas et al., 2010; Nicholls et al., 2016; Pérez \& Marasas 2013). Según Del Valle Isla (2014) la existencia de un contexto socioambiental diverso y heterogéneo en sus elementos y funciones, es la base para el desarrollo de diferentes opciones de manejo de recursos naturales por individuos y sociedades. El incremento de la agrobiodiversidad basado en estrategias múltiples, ha demostrado muchas ventajas, entre ellas asegurar una mejor polinización, una mayor regulación de plagas, enfermedades y malezas, mejorar el reciclaje de nutrientes, la captación de energía e 
inclusive lograr tener una mayor productividad total (Altieri \& Nicholls, 2000; Del Valle Isla, 2014; Marasas et al., 2014; Sarandón \& Flores, 2014). Para el desarrollo de estas estrategias, los agricultores y agricultoras, necesitan disponer de un abanico amplio de recursos genéticos, que les permitan experimentar y poner en práctica sus ideas. En este contexto, las semillas conservadas in situ y seleccionadas según criterios locales, son un pilar fundamental (Almekinders et al., 1994). Por lo expuesto, la diversificación de los agroecosistemas basada en semillas conservadas por los agricultores, permite mantener vivas, no solo las formas locales de producción y de vida, sino también asegurar el mantenimiento de las funciones ecológicas básicas para el correcto funcionamiento de los agroecosistemas.

El presente capítulo aborda la hipótesis general de esta tesis la cual enuncia que "En los agroecosistemas familiares del Cinturón Hortícola Platense, existe agrobiodiversidad hortícola conservada in situ".

Los objetivos de este capítulo fueron:

- Relevar y organizar la agrobiodiversidad cultivada según su clasificación botánica y local, uso/s, rubro productivo, conservación de material reproductivo.

- Analizar la agrobiodiversidad hortícola conservada y no conservada según su clasificación botánica y local, uso/s, origen y destino.

\section{2...I El concepto de semilla}

Al hablar de conservación in situ de la agrobiodiversidad, surge la importancia de analizar la utilización que hacen los agricultores del término semilla. Los trabajos de Ahumada et al. (2009), Bonicatto et al. (2009) y Pochettino et al. (2011) indican que los agricultores designan semilla a toda parte que permita la reproducción de la planta (tubérculos, bulbos, rizomas, semillas "per se", estacas) e incluso plantas jóvenes (plantines), dando cuenta de una representación de este concepto más amplia que lo estrictamente botánico. En este sentido, diversas estructuras de reproducción vegetativa (tubérculos o rizomas) son nombradas por los agricultores como semillas, dando cuenta del vínculo entre el término y el concepto de reproducción. Así aquellos tubérculos de papa (Solanum tuberosum L. subsp. tuberosum) y papa andina (Solanum tuberosum subsp. andigenum (Juz. et Bukasov) Hawkes) (Solanaceae) utilizados para la nueva siembra son nombrados como "papa semilla", al igual que los bulbos de cebolla o cebolla colorada (Allium cepa L. var. cepa) (Alliaceae) llamados cebolla semilla. En esta Tesis se toma 
este uso del término, entendiendo que es el adecuado para dar cuenta del material genético conservado por los agricultores familiares. Por lo tanto, lejos de ser simplemente un término técnico o botánico, semilla es una designación con un gran valor simbólico, el cual representa la posibilidad de reproducción y conservación de vida, los años de interacción entre las personas y su medio, historia e identidad.

\subsubsection{La importancia de los nombre locales}

Al decir de Hilgert (2007) las investigaciones que incorporan los criterios propios del sector estudiado incluyen dos modalidades: una mirada desde la sociedad estudiada (perspectiva émica) y otra desde la ciencia (perspectiva ética). En ambos casos son posibles las descripciones científicas y objetivas de los campos mental y conductual (Harris, 2004). Estas formas de abordar, se basan en criterios de la lingüística; la fonética estudia los sonidos del lenguaje sin analizar los sentimientos que los mismos contienen, es decir constituye una perspectiva externa. En tanto que la fonemática, de fonemic, trata la lengua desde dentro, y considera su significado emocional o simbólico y para eso necesita ponerse en la situación de la persona que es el objeto observado por la ciencia. Esta perspectiva permite ir más allá de la mirada científica sobre la conservación de taxones botánicos. Según Harris (2004) al llevar a cabo la investigación en el modo emic, los científicos tratan de adquirir un conocimiento de las categorías y reglas necesarias para pensar y actuar como la sociedad estudiada.

Berlin (1992) sostiene que si bien las plantas y los animales se presentan al observador humano como grupos o conjuntos cuya estructura y contenido pueden ser percibidos por todos los seres humanos esencialmente del mismo modo, cualquier sistema clasificatorio sólo reconoce ciertas porciones de la realidad biológica reconocidas por quienes las comparten. Dado que el lenguaje permite rotular (dar nombre) a esas categorías que se han separado, resulta de suma utilidad pensar en etnoespecies o etnotaxas, es decir los grupos de plantas percibidos y agrupados por los agricultores como entidades botánicas diferentes (Pochettino, 2015). Desde esta perspectiva, los rótulos utilizados por los agricultores dan cuenta de una importante información que de otra manera quedaría invisibilizada, ya que se entiende que el nombrar de manera diferente está vinculado a diferentes valoraciones, prácticas de manejo y usos (Altieri \& Nicholls, 2000; Bellon \& Risopoulos 2001; Bonicatto et al., 2010; Garat et al., 2009; Hilgert et al., 2013; Kraft et al., 2010; Lambaré \& Pochettino, 2012; Peroni \& Hanazaki, 2002; Pochettino et al., 2011; Scarpa, 2012; Veteto 2014; Zamudio \& Hilgert, 2012). En definitiva, al ser los agricultores quienes administran la 
agrobiodiversidad, son dichos conjuntos de plantas, las que constituyen la fuente de diversidad, al brindar caracteres valiosos según los distintitos criterios. Esta perspectiva es central para la agroecología, la cual se nutre y dialoga con los conocimientos y practicas locales, a fin de acompañar y fortalecer la sustentabilidad de las producciones.

\subsection{Metodología}

Se analizaron los principales resultados producto de las entrevistas realizadas a los 26 interlocutores, así como los datos provenientes de las recorridas a campo. La metodología para la realización de las mismas, así como sus principales ejes y sistematización fue descripta en el capítulo 1.2. Los datos sobre la agrobiodiversidad cultivada y conservada, se obtuvieron en base al total de plantas cultivadas registradas, donde cada mención se corresponde con un registro. Dada la convivencia entre unidad productiva y doméstica de los agroecosistemas familiares, el listado general incluye además de plantas hortícolas otras categorías como frutales, ornamentales, aromáticas y medicinales, que fueron mencionadas por los interlocutores. Una vez obtenido un registro total de la agrobiodiversidad cultivada, se trabajó con aquellas plantas de la categoría horticultura. Las plantas mencionadas durante las entrevistas que actualmente no se están cultivando se incorporaron al estudio destacando dicha salvedad. En estos casos se registró como no cultivada actualmente.

\subsection{1 ¿Qué semillas se consideraron?}

Se tuvieron en cuenta todos aquellos materiales reproductivos conservados, tanto aquellos provenientes de material genético comercial, como las semillas locales, nativas o criollas. Se entiende por semillas comerciales a aquellas que han paso por el sistema de control nacional establecido por el Instituto Nacional de Semillas (INASE), y que posteriormente salen a la venta al mercado (Instituto Nacional de Semillas, 2017). Se entiende por semillas local, también utilizados los rótulos de criolla, o tradicional, a aquellas cuyo proceso de reproducción fue realizado por los agricultores y agricultores en sus agroecosistemas (in situ). Se entiende por semillas nativas a aquellas que pertenecen a una región o ecosistema determinados y que su presencia en esa región es el resultado de fenómenos naturales sin intervención humana. Algunas de estas semillas, han sido mejoradas y conservadas por mucho tiempo pudiendo establecerse como poblaciones diferenciadas, tanto geográfica como ecológicamente, visiblemente diferentes de las demás poblaciones (González, 2007), 
mientras que otras llevan pocos años de conservación. Según Almekinders et al. (1994) las semillas locales permiten la interacción continua de las variedades cultivadas, entre ellas así como con el ambiente ecológico y socioeconómico.

Para analizar las semillas comerciales se incorporaron los términos variedad cultivada con la salvedad de que sean de condición genética híbrida o no. Para las especies cultivadas se ha desarrollado el término especial cultivar que designa esas poblaciones (León, 1987). Según este autor, en la práctica, cultivar y variedad cultivada son lo mismo. En tanto, el INASE (Instituto Nacional de Semillas, 2017), utiliza la categoría condición genética, para establecer si se trata de un híbrido o una variedad cultivada de polinización abierta (Adlercreutz et al., 2014). Al hablar de híbrido se hace referencia a una semilla obtenida de la combinación de dos padres (dos líneas parentales puras), estas dos líneas puras se cruzan entre sí para obtener el híbrido F1 cuyas semillas son las que se venden en el mercado (Doneland, 2009). Las características que ofrecen los híbridos desde el punto de vista productivo son homogeneidad y vigor de la primera generación, posicionando la promesa de rentabilidad como el principal objetivo.

\subsection{2 ¿Cómo se cuantificó la agrobiodiversidad?}

Existen diferentes maneras de analizar y cuantificar la agrobiodiversidad (Duelli \& Obrist 2003). Una de ellas es la propuesta por Noss (1990) quien caracteriza la misma subdividiéndola en tres aspectos: la composición, la estructura y la función. La composición tiene que ver con la identidad y variedad de los elementos que constituyen la biodiversidad, como los genes y las especies. Un listado de especies de los cultivos presentes en un campo da idea de la composición y, el número de especies diferentes da idea de la diversidad específica. La estructura se refiere a la disposición física de los elementos. Son ejemplos de estructura, la distribución espacial de las plantas cultivadas o espontáneas en el plano horizontal (patrón de asociación) y/o vertical (en un perfil con diferentes capas o estratos) y, la estructura trófica determinada por las relaciones alimentarias entre las especies. La función surge de los procesos ecológicos que ocurren en el sistema, como por ejemplo la regulación biótica (Stupino et al., 2014). Otra propuesta es la realizada por Gliessman (2002) quien sugiere diferentes dimensiones que permiten analizar la agrobiodiversidad, incluyendo cambios temporales y una dimensión funcional.

Lo interesante de rescatar de estas propuestas radica en la utilidad de las mismas para la agroecología. Las interpretaciones mencionadas permiten estudiar la agrobiodiversidad 
de un sistema productivo, lo cual resulta un elemento básico para la generación de alternativas de manejo basadas en procesos ecológicos. A fin de dar cuenta de la composición vegetal cultivada en los agroecosistemas familiares de la zona en estudio, se tomó la riqueza taxonómica entendida como el número de taxa (familias, géneros, especies, etnoespecies) por unidad de área. Para el caso de las etnoespecies, se consideró como una unidad cada nombre diferente otorgado por los agricultores.

\subsubsection{Organización y análisis de los datos}

Se registraron las plantas cultivadas, mencionadas por los interlocutores y relevadas a campo, siendo ésta la unidad de variabilidad de cada agroecosistema analizado. Cada cultivo se corresponde a un registro. La información recabada se ordenó, codificó y capturó en una base de datos diseñada en una hoja de cálculo en Microsoft Excel. Los detalles metodológicos se describen en el capítulo 1.2.2. Se calculó el total de registros de plantas cultivadas, incluyendo tanto aquellos cultivos mencionados por los interlocutores, como los registrados durante la recorrida a campo. Cada planta cultivada se describió por su nombre local, nombre científico, familia botánica, rubro productivo, uso/s, situación de cultivo (si se cultiva o no), situación sobre la conservación de material reproductivo (si se conserva o no) y origen del mismo. Se calculó la riqueza de familias botánicas, riqueza específica y riqueza de etnoespecies.

Al ser los agroecosistemas familiares unidades de producción que exceden la horticultura, las plantas cultivadas registradas se clasificaron según el rubro productivo al que fueron vinculadas por los interlocutores. Cada registro de planta cultivada se ubicó en un rubro productivo. Se describieron 9 categorías: horticultura (incluye todas aquellas plantas cultivadas en la parcela hortícola), fruticultura (incluye todas aquellas plantas cultivadas para producir fruta), floricultura (incluye todas aquellas plantas cultivadas para producir flores), cultivos forrajeros (incluye todas aquellas plantas cultivadas para la alimentación animal), cultivos aromáticos y/o medicinales (incluye todas aquellas plantas cultivadas por su aroma y/o usos para la salud), cultivos forestales (incluye todos aquellos árboles cultivados), cultivos ornamentales (incluye todas aquellas plantas cultivadas con propósitos decorativos), cultivos proveedores de servicios ecológicos (incluye todas aquellas plantas cultivadas para cumplir funciones ecológicas en vida -como repeler insectos- 0 elaborar biopreparados), crecimiento espontáneo (incluye todas aquellas plantas de crecimiento espontáneo), cultivos regionales (incluye todas aquellas plantas consideradas producciones agrícolas y agroindustriales de zonas extrapampeanas). Esta clasificación permitió seleccionar el conjunto de plantas destinadas al rubro horticultura lo cual es el objetivo principal de esta tesis. 
Cada registro de planta cultivada se ubicó en una categoría en función de su situación al momento de la entrevista. Se diferenció entre aquellas plantas que se cultivan actualmente y no se cultivan actualmente. Estas dos categorías se definieron en función del relato de los entrevistados. Por lo expresado, el lapso temporal de la categoría se cultiva actualmente, implica que la planta estaba sembrada o que se disponía de semillas para sembrar. En el caso de la categoría no se cultiva actualmente, incluye situaciones donde las plantas se dejaron de cultivar desde hace varios ciclos productivos, hasta plantas que no fueron sembradas durante el año del registro. Posteriormente y en función del relato de los interlocutores se organizó la información en plantas de las cuales se conserva material reproductivo, no conserva material reproductivo, plantas de crecimiento espontáneo y material reproductivo perdido. Cada registro, fue ubicado en una categoría en función del relato de los interlocutores. La categoría crecimiento espontáneo incluye plantas mencionadas por los interlocutores como parte del componente cultivado del agroecosistema, con la salvedad de que su reproducción se da a través de la resiembra natural. La categoría material reproductivo perdido incluye plantas cultivadas cuyo material reproductivo no se encuentra en manos de los agricultores y agricultoras.

Se calculó la riqueza de familias botánicas, riqueza específica y etnoespecífica para los cultivos hortícolas conservados y los no conservados. En base a la riqueza específica conservada, se estimó el Índice de Consenso (IC) de conservación de cada especie hortícola registrada en el conjunto de 26 interocutores, dado que se entiende que un acuerdo en este sentido sería indicativo de la frecuencia en que cada especie hortícola es conservada (Eyssartier et al., 2011; Richeri et al., 2013). Para esto se calculó la cantidad de agricultores que conservan cada especie botánica, con respecto al total de interlocutores (por ejemplo en el caso de Brassica napus L., 6 de 26 personas mencionaron conservar semillas de esta especie, IC 23.07\%).

Por último se trabajó con el conjunto de datos correspondientes a las especies hortícolas cuyas semillas se perdieron (material reproductivo perdido). La inclusión de estos datos en este capítulo se debe a que se entiende que, aunque fallida o interrumpida su conservación, la intención de conservar las semillas implica la ejecución de dicha práctica, con lo cual los saberes en torno a la misma son puestos en juego, y por ende forman parte del universo de la diversidad biocultural. 


\subsection{4 ¿De dónde vienen las semillas conservadas?}

Para analizar las vías de ingreso de las semillas que se están conservando y en función de los datos obtenidos, se determinaron las siguientes categorías de ingreso: A: compradas en comercios. B: vínculos interpersonales (incluye las semillas obtenidas por herencia, regalo de otros agricultores, de consumidores, intercambio entre vecinos, agricultores, familiares, en ferias de intercambio o intercambio casuales). C: instituciones (incluye semillas obtenidas a través de Instituciones estatales Universidad/INTA). D: oportunista (incluye semillas obtenidas aprovechando la oportunidad de hortalizas descartadas del mercado, verdulerías, recolectadas de espacios públicos y privados. E: resiembra espontánea (incluye semillas que se siembran espontáneamente en el agroecosistema, mediadas por la decisión de los agricultores y agricultoras). F: origen no especificado. Para cada planta cultivada registrada se describió su vía de ingreso al agroecosistema.

\subsection{Resultados y discusión}

\subsection{Agrobiodiversidad total}

Los resultados se basan en 616 registros de plantas cultivadas los cuales corresponden a 31 familias botánicas, 120 especies botánicas y 305 etnoespecies (Anexo 5). Los 616 registros representan plantas de las cuales se conserva material reproductivo (326), no se conserva material reproductivo (217), son de crecimiento espontáneo (11), otras de material reproductivo perdido (29), y un conjunto de plantas cuyo estado de conservación fue no especificado (33)- Estos registros corresponden a plantas perennes como frutales y aromáticas. Se destaca en la Figura 7 , el alto porcentaje de agrobiodiversidad conservada registrado $(52.9 \%)$. 


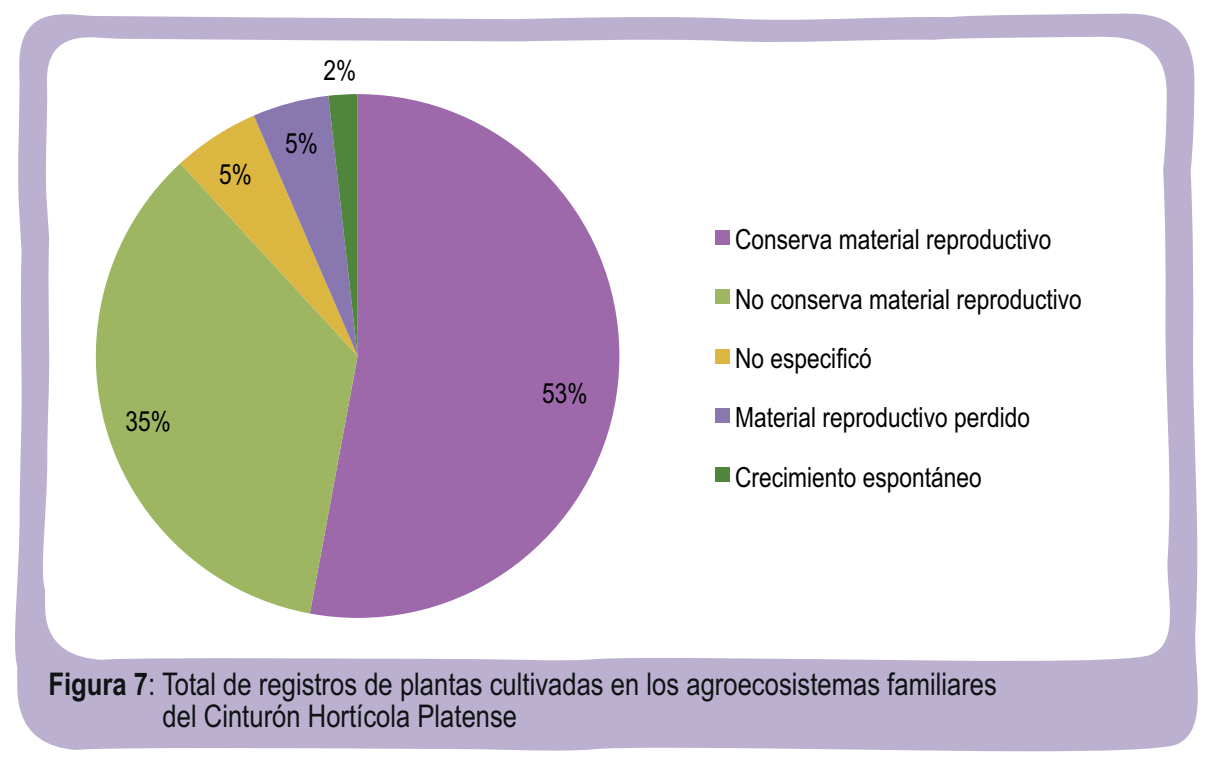

La Figura 8, expone el total de registros de plantas cultivadas, organizadas según los 10 rubros productivos registrados. La categoría horticultura con 479 registros es la más representada. Las siguientes 9 categorías en orden decreciente, incluyen 57 registros para aromáticas y medicinales, 46 para fruticultura y entre 11 y 1 registros para cultivos ornamentales, cultivos proveedores de servicios, floricultura, crecimiento espontáneo, cultivos regionales, cultivos forrajeros y cultivos forestales. Aunque representada por un menor número de registros la presencia de otras categorías productivas habla de la complejidad del componente vegetal de los agroecosistemas familiares. Esta complejidad vegetal registrada, acompaña al componente hortícola estableciendo la presencia de mayor diversidad en las unidades productivas.

"yo no pongo allá en vidriera las flores porque se me llena el trip, a las flores lo atrae mucho trip.[...] Y allá hay caña de azúcar, lo pelamos y todo lo que queda adentro lo chupamos, lo comemos, es caña dulce". (Bonicatto 2014j entrevista a SV) 


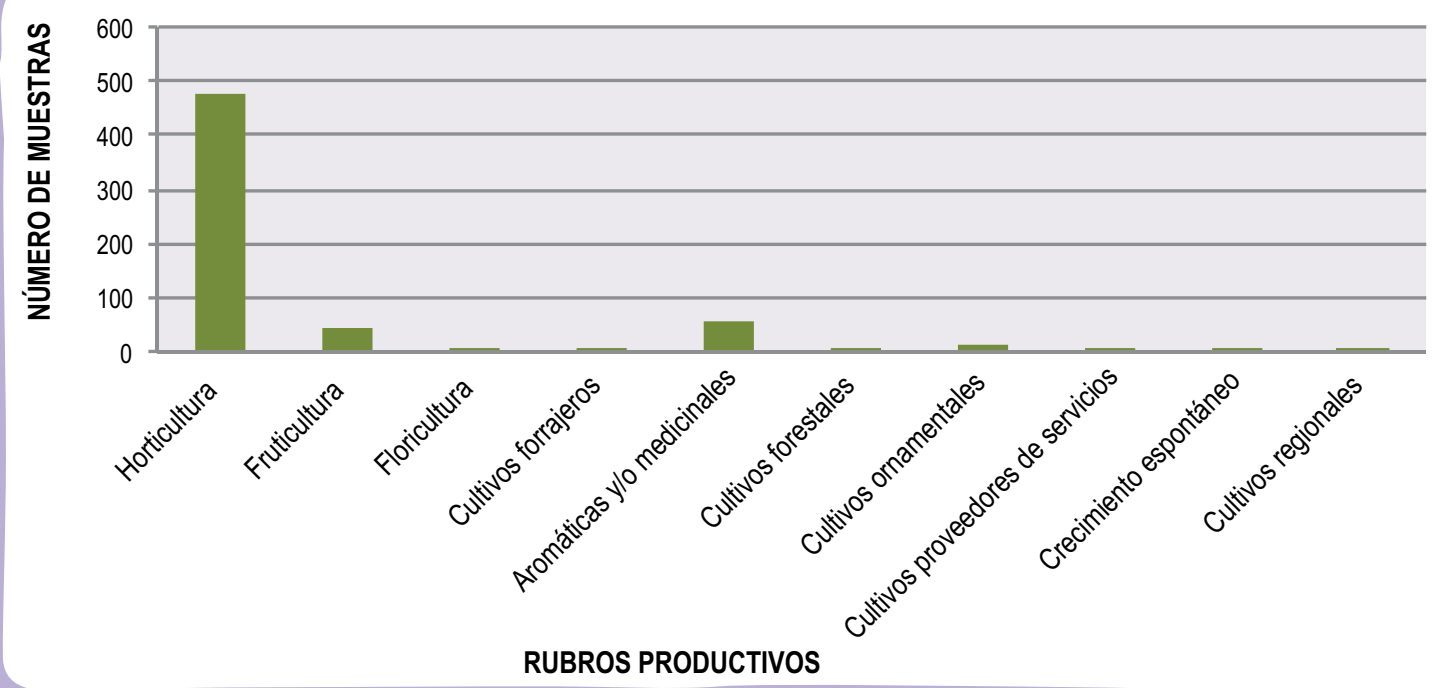

Figura 8: Rubros productivos de la agrobiodiversidad registradas en los agroecosistemas familiares del Cinturón Hortícola Platense.

Al analizar los usos de la agrobiodiversidad registrada se determinaron 9 categorías medicinal, aromático y condimenticio, consumo alimenticio, artesanal, alimento para animales, ornamental, producción de semillas e injertos, función ecológical biopreparados, cosmético. La representatividad de cada categoría se expone en la (Figura 9). Dado que la cuantificación de los usos se realizó en base al relato de los interlocutores, cada planta registrada se asoció a una o más menciones de uso. La categoría consumo alimenticio fue la más representada, dado el objetivo productor de bienes alimenticios de los agroecosistemas analizados. La importancia de los múltiples usos de la biodiversidad ha sido señalada en estudios previos. Hilgert et al. (2013) relacionan la riqueza a escala regional con la diversidad de usos. Cababié et al. (2015) reflexionan sobre el rol de los usos de la biodiversidad en los intercambios de semillas. Furlán et al. (2011), vincula los usos y conocimientos sobre la biodiversidad como elementos que permiten alimentar la memoria colectiva. La presencia de cultivos ligados a la atención de la salud, la alimentación de los animales, e incluso la elaboración de artesanías (Figura 9), son un vivo ejemplo de las múltiples manifestaciones y aplicaciones que tiene la agrobiodiversidad en los agroecosistemas familiares de este territorio, a la vez que reafirman la importancia de que estas familias vivan donde trabajan a fin de mantener activo el vinculo directo con la naturaleza. 


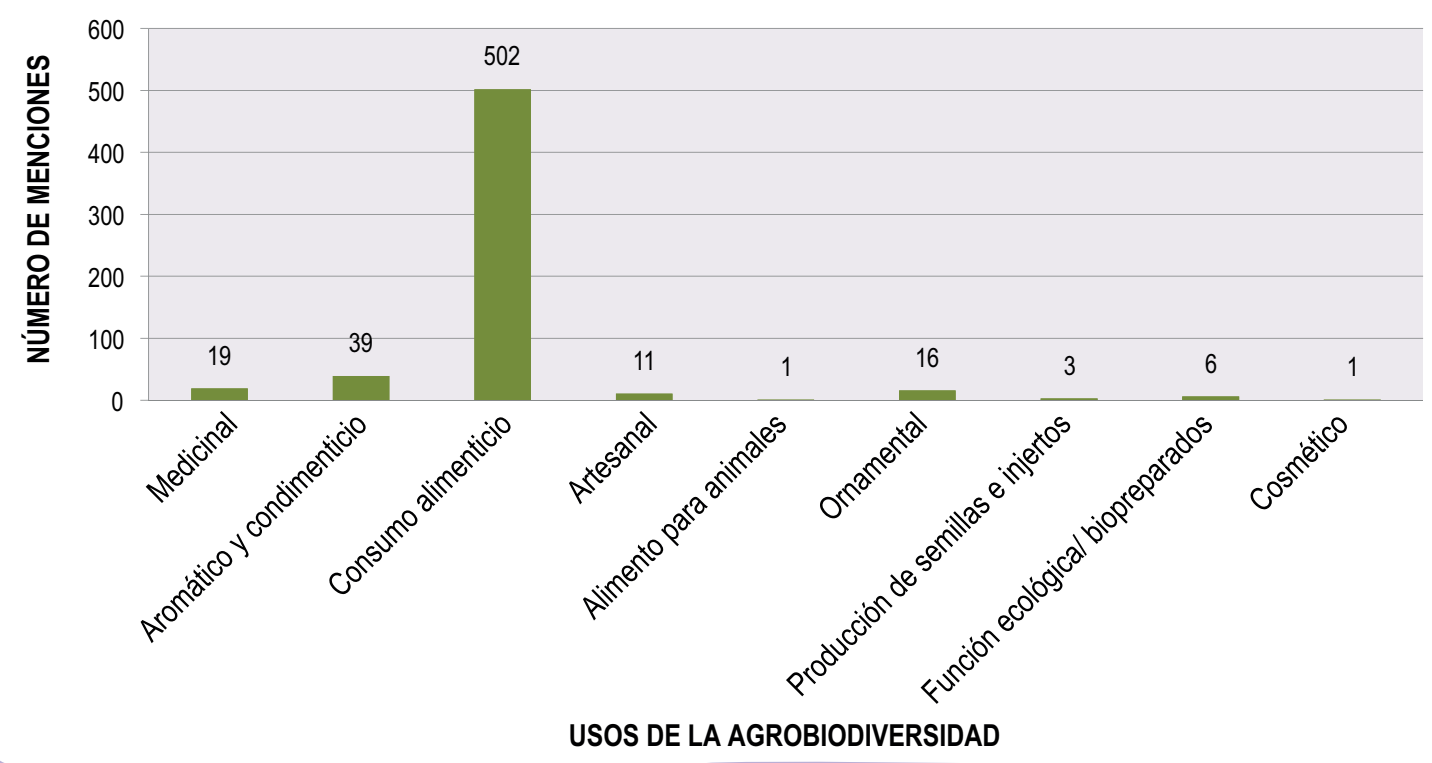

Figura 9: Usos de la agrobiodiversidad registrada en los agroecosistemas familiares del Cinturón Hortícola Platense.

\subsubsection{Agrobiodiversidad hortícola cultivada y conservada}

El total de registros de plantas cultivadas para la categoría horticultura, obtenido a partir de los 26 agroecosistemas visitados, fue de 479. Cada cultivo registrado durante las entrevistas, fue la unidad de variabilidad utilizada para el ordenamiento de los datos. El $94.8 \%$ del total de registros, estaba siendo cultivado al momento de las entrevistas o se disponía de las semillas para sembrar. Por tanto, sobre un total de 454 registros de plantas cultivadas, $244(53.7 \%)$ eran conservadas in situ (Figura 10). El promedio de cultivos hortícolas por agroecosistema fue de 18, y 10 el de cultivos hortícolas conservados. El trabajo de Calvet-Mir et al. (2014) realizado en el Pirineo catalán (España), registra un promedio de 32 plantas por huerto; el trabajo de Peroni \& Hanazaki (2002) registra 263 variedades correspondientes a 43 cultivos en la mata atlántica de Brasil. Trabajos realizados en el Cinturón Hortícola Platense, sugieren valores entre 6 y 35 especies (Stupino et al., 2008), y 1 y 19 cultivos por hectárea según Blandi et al., (2016). Los resultados obtenidos se mantienen en concordancia con lo descripto por estos autores.

Según Almekinders et al. (1994) y Almekinders \& de Boef (2000) las fuentes más importantes de semillas en los países en desarrollo, son las semillas provenientes de sistemas informales, donde destacan la producción propia en las fincas, los intercambios 
con vecinos y parientes y las ferias de semillas o jornadas de intercambio organizadas a distinta escala. Estiman que el $80 \%$ de las semillas en los países en desarrollo se produce en las fincas, variando el porcentaje según el cultivo. Los datos obtenidos para el Cinturón Hortícola Platense indican que del total de 454 registros para la categoría horticultura, el $60 \%$ proviene de semillas compradas en comercios (sistema formal) y que el restante $40 \%$ esta ligado a otras vías de ingreso.

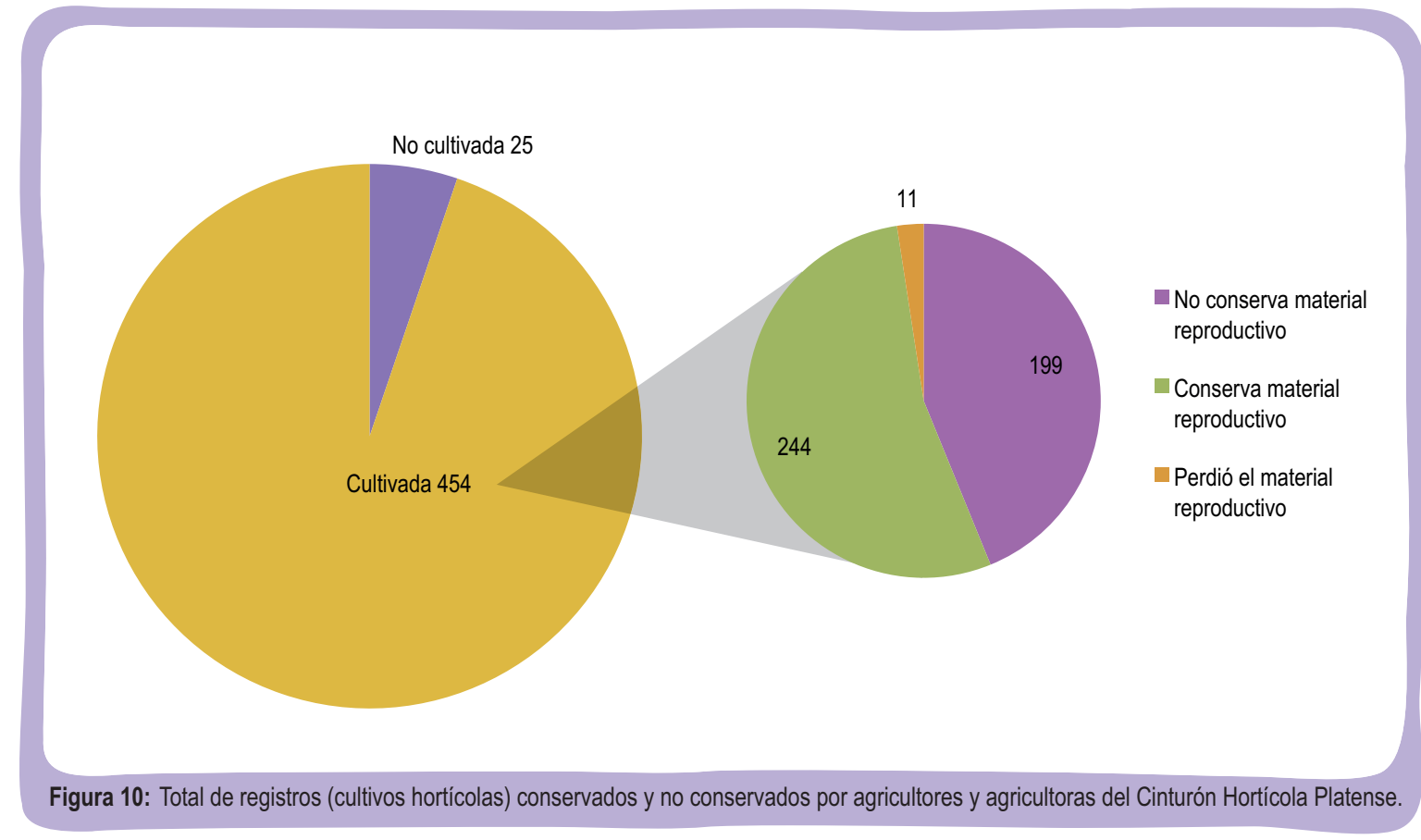

Los 244 registros conservados in situ corresponden a una riqueza de 10 familias botánicas, 41 especies y 152 etnoespecies. Se registraron semillas conservadas en 25 de los 26 agroecosistemas familiares, dando cuenta de la persistencia de dicha práctica.

La Figura 11, muestra que la familia Cucurbitaceae fue la más representada considerando la riqueza de especies botánicas (10), siendo el género Cucurbita el que concentra la mayor diversidad de etnoepecies. Las familias Solanaceae, Fabaceae, Asteraceae, Alliaceae y Brassicaceae no presentaron grandes diferencias en cuanto a su riqueza específica. Sin embargo, y en concordancia con lo expuesto por Garat et al. (2007); Hilgert et al. (2013); Veteto (2007); Zamudio \& Hilgert (2012), al observar los datos sobre la riqueza de etnoespecies se vislumbran otros resultados. La gran riqueza etnoespecífica de la familia Poaceae, vinculada a una única especie botánica Zea mays y 15 etnoespecies (maíz enanito, choclo, maíz puro blanco, maíz puro negro, maíz rojo, choclito, maíz colorado, maíz turco, maizón, maíz choclo, maizón amarillo, maíz blanco, maíz morado chiquito, maíz de colores, maíz perla blanca), es un claro ejemplo de la diversidad que se pone en evidencia al considerar la taxonomía local (emic). A su vez pueden verse los calificadores utilizados en algunas denominaciones, tales como maíz 
colorado, maíz blanco o maizón amarillo que permiten diferenciar a estas etnoespecies según su fruto; o las partículas utilizadas como es el caso del diminutivo choclito o maíz enanito. Al decir de Scarpa (2012) los calificadores o partículas que acompañan a los nombres genéricos, hacen alusión a diferentes aspectos con el fin de distinguir las etnoespecies de un mismo nombre genérico. Al analizar los usos de esta especie encontramos una diversidad que excede el esperado uso alimenticio (Tabla 1) dando cuenta de otros modos de aprovechamiento vinculados a lo artesanal y ornamental.

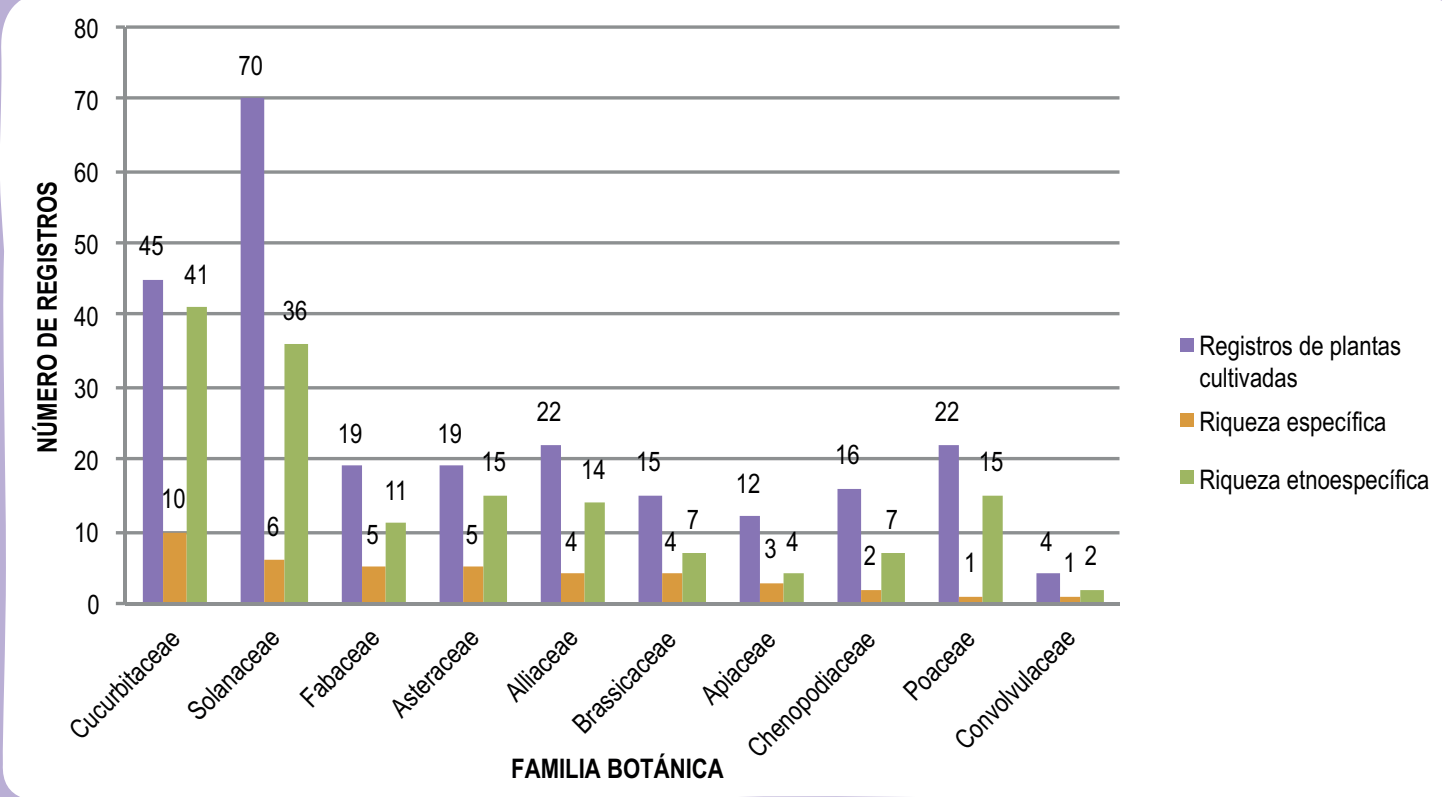

Figura 11: Riqueza especifica y etnoespecífica conservada por agricultores y agricultoras del Cinturón Hortícola Platense.

La familia Solanaceae en la cual también hay una gran diversidad de etnoespecies (Figura 11) principalmente vinculadas a la especie botánica Solanum lycopersicum (Figura 12) ampliamente cultivada en la zona de estudio, la cual incluye etnoespecies como el tomate cherry variedad 1, tomate cherry variedad 2, tomate platense, tomate, tomate 110, y al género Capsicum (morrón calahorra, morrón chiquito picante, ají vinagre, aji de la mala palabra, entre otros). 


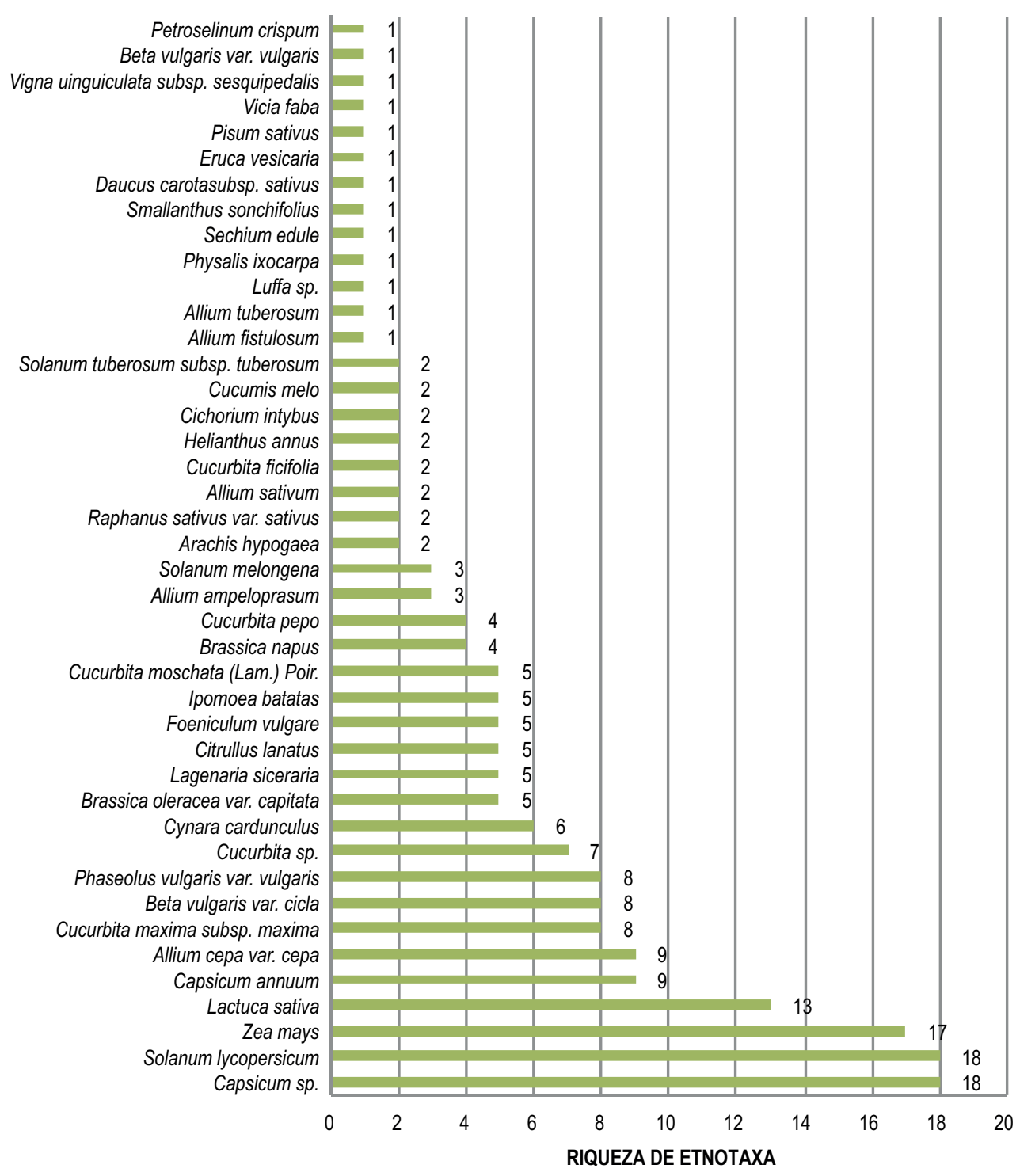

Figura 12: Riqueza de etnotaxa por cada especie botánica conservada en los agroecosistemas familiares del Cinturón Hortícola Platense 
Tabla 1: Agrobiodiversidad hortícola conservada por agricultores y agricultoras familiares del cinturón Hortícola Platense. Nombre científico, nombre local, familia botánica, uso/s medicinal (A), aromático y condimenticio (B), consumo alimenticio (C), artesanal $(E)$, ornamental $(G)$, producción de semillas/injertos $(H)$; e índice de consenso (IC)

\begin{tabular}{|c|c|c|c|c|}
\hline NOMBRE CIENTÍFICO & NOMBRE LOCAL & FLIA. BOTANICA & USO/S & IC \\
\hline Solanum lycopersicum & $\begin{array}{l}\text { tomate cherry variedad } 1 \text {, tomate cherry variedad } 2 \text {, tomate platense, } \\
\text { tomate, tomate } 110 \text {, tomate cherry perita, tomate perita, tomate perita } \\
\text { amarillo, tomate perita largo, tomate tardío, tomate col } 45 \text {, tomate } \\
\text { perita zorzal, tomate perita zorzal }\end{array}$ & Solanaceae & C & 69,23 \\
\hline Zea mays & $\begin{array}{l}\text { maíz enanito, choclo, maíz puro blanco, maíz puro negro, maíz rojo, } \\
\text { choclito, maíz colorado, maíz turco, maizón, maíz choclo, maizón } \\
\text { amarillo, maíz blanco, maíz morado chiquito, maíz de colores, maíz } \\
\text { perla blanca }\end{array}$ & Poaceae & C-E-G & 57,69 \\
\hline Cucurbita maxima subsp. maxima & $\begin{array}{l}\text { zapallo plomo, zapallo variedad 1, zapallo variedad 2, zapallo } \\
\text { variedad 3, zapallito de tronco, zapallito }\end{array}$ & Cucurbitaceae & C & 53,8 \\
\hline Phaseolus vulgaris var. vulgaris & $\begin{array}{l}\text { chaucha fina, chaucha balina, chaucha, chaucha lengua de dragón, } \\
\text { chaucha cronos, poroto lengua de dragón, poroto }\end{array}$ & & C & 34,61 \\
\hline Cucurbita moschata (Lam.) Poir & anco, zapallo anco batata, anquito, calabaza batata & Cucurbitaceae & C & 34,6 \\
\hline Beta vulgaris var. cicla & $\begin{array}{l}\text { acelga, acelga de penca verde, acelga de palo blanco, acelga de palo } \\
\text { verde, acelga de penca blanca nacional, acelga de penca verde } \\
\text { nacional }\end{array}$ & Chenopodiaceae & C & 34,6 \\
\hline Allium cepa var. cepa & $\begin{array}{l}\text { cebolla morada, verdeo, cebolla, cebolla balanceana, cebolla de } \\
\text { verdeo morada, cebolla morada, cebolla blanca, Cebolla colorada, } \\
\text { Cebolla roja }\end{array}$ & Alliaceae & C & 30,7 \\
\hline Cucurbita pepo & zucchini, zapallo de angola, angolita, zapallo turco & Cucurbitaceae & C & 26,9 \\
\hline Capsicum annuum & $\begin{array}{l}\text { morrón calahorra, morrón, pimiento calahorra, morrón chiquito } \\
\text { picante, aji de la mala palabra }\end{array}$ & Solanaceae & C & 26,9 \\
\hline Capsicum sp. & $\begin{array}{l}\text { ají vinagre, aji variedad 1, aji variedad 2, ají variedad 3, aji variedad } \\
4 \text {, ají variedad } 5 \text {, aji variedad } 6 \text {, aji variedad } 7 \text {, ají variedad } 8 \text {, ají } \\
\text { variedad 9, aji campanita, aji redondito picante, aji vinagre el } \\
\text { tradicional, ají picante, ají verde, ají miracielo. }\end{array}$ & Solanaceae & B-C & 26,9 \\
\hline Cucurbita sp. & zapallo, calabaza, calabaza verde, zapallo okaido & Cucurbitaceae & C & 23,07 \\
\hline Brassica napus & nabiza, grilo, grilo nabo, & Brassicaceae & $\mathrm{C}-\mathrm{H}$ & 23,07 \\
\hline Cynara cardunculus & $\begin{array}{l}\text { alcaucil gringo INTA, alcaucil francés, alcaucil violeta, alcaucil, } \\
\text { alcaucil ñato }\end{array}$ & Asteraceae & A-C-E & 23,07 \\
\hline Petroselinum crispum & perejil & Apiaceae & B-C & 19,23 \\
\hline Solanum melongena & berenjena & Solanaceae & C & 19,23 \\
\hline Allium ampeloprasum & puerro, puerro francés de Caterá & Alliaceae & $\mathrm{C}$ & 15,4 \\
\hline Beta vulgaris var. vulgaris & remolacha & Chenopodiaceae & $\mathrm{C}$ & 15,4 \\
\hline Citrullus lanatus & sandía amarilla, sandía enana, sandía cuarentina & Cucurbitaceae & C & 15,4 \\
\hline Foeniculum vulgare & hinojo platense, hinojo & Apiaceae & C & 15,4 \\
\hline Ipomoea batatas & batata, batata pata de rana & Convolvulaceae & C & 15,4 \\
\hline $\begin{array}{l}\text { Solanum tuberosum subsp. } \\
\text { tuberosum }\end{array}$ & papa & Solanaceae & C & 15,4 \\
\hline Brassica oleracea var. capitata & repollo blanco, brócoli & Brassicaceae & C & 11,5 \\
\hline Cichorium intybus & radicheta, achicoria & Asteraceae & C & 11,5 \\
\hline Cucumis melo & melón, melón amarillo & Cucurbitaceae & C & 11,5 \\
\hline Lactuca sativa & $\begin{array}{l}\text { lechuga escarola fina, lechuga moradita, lechuga, lechuga otra, } \\
\text { lechuga }\end{array}$ & Asteraceae & C & 11,5 \\
\hline Lagenaria siceraria & cucuza longa, calabaza de mate, cucuza & Cucurbitaceae & C-E & 11,5 \\
\hline Vicia faba & haba & Fabaceae & C & 11,5 \\
\hline $\begin{array}{l}\text { Vigna uinguiculata subsp. } \\
\text { sesquipedalis }\end{array}$ & chaucha metro & Fabaceae & C & 11,5 \\
\hline Allium sativum & ajo orgánico, ajo & Alliaceae & $\mathrm{B}-\mathrm{C}$ & 7,7 \\
\hline Cucurbita ficifolia & cayote, acayote & Cucurbitaceae & $\mathrm{C}$ & 7,7 \\
\hline Daucus carota subsp. sativus & zanahoria & Apiaceae & C & 7,7 \\
\hline Eruca vesicaria & rúcula & Brassicaceae & C & 7,7 \\
\hline Helianthus annus & girasol rojo, girasol & Asteraceae & C & 7,7 \\
\hline Pisum sativum & arveja & Fabaceae & C & 7,7 \\
\hline Allium fistulosum & cebolla de verdeo & Alliaceae & C & 3,84 \\
\hline Allium tuberosum & tare o puerro japonés & Alliaceae & C & 3,84 \\
\hline Arachis hypogaea & maní colorado & Fabaceae & C & 3,84 \\
\hline Luffa sp. & esponja vegetal & Cucurbitaceae & G & 3,84 \\
\hline Physalis ixocarpa & tomate verde vestido & Solanaceae & C & 3,84 \\
\hline Raphanus sativus var. sativus & nabo daikon & Brassicaceae & C & 3,84 \\
\hline Sechium edule & papa del aire & Cucurbitaceae & $\mathrm{C}$ & 3,84 \\
\hline Smallanthus sonchifolius & yacón & Asteraceae & C & 3,84 \\
\hline
\end{tabular}


El relato del entrevistado CA de la localidad de Arana, describe las diferencias que percibe entre el grilo, la nabiza, el grilo-nabo y el grilo comercial, todas etnoespecies de la especie (Brassica napus) (IC 23.07). Los relatos de CA y CV dan cuenta de las diferencias utilizadas por los agricultores y agricultoras para diferenciar entre etnoespecies de Brassica napus y Zea mays. Utilizando la inflorescencia en el primer caso y el color de la mazorca en el segundo. Estos relatos a su vez, describen de manera implícita o explícita, estrategias de manejo, uso y comercialización:

"y bueno esta es una semilla no es nabiza, ni grilo, es grilo- nabo (señalando un cultivo en el campo en etapa de cosecha). Yo te voy a mostrar la planta de grilo, la comercial, la que nosotros compramos. Bueno es diferente a esto. Te da directamente el grilo, no crece tan alto. El grilo es la florcita. Por ejemplo la nabiza, te da esto (mostrando el pimpollo), pero tira la vara y tarda bastante, en cambio el grilo tira bastantes hojas, pero no crece tanto la vara y te da esto, pero te da un poco más grande. [...] Esta nabiza la podemos vender como grilo pero ya son más finitos, no es como el otro. A este le dicen grilo nabo y yo lo veo el mismo que la nabiza. Yo a la nabiza la arranco de planta y se vende como paquete con raíz y todo. De la nabiza se come todas las hojas, pero yo después se me paso y tiro esta vara y la corte como grilo, pero yo veo que el grilo es como más, como más chiquito pero parecido al brócoli. Aquel amarillo es grilo, yo vi que tiene unas pequeñas espinitas y es lo que no tiene el comercial es más suave el grilo. Es mucho más grandecito el grilo, es parecido pero es mucho más grande. Yo veo que este (el grilo nabo) es más frágil que esto (grilo) esto es más compacto. Hay diferencia, el grilo comercial con la nabiza, el grilo tarda un poco más digamos, el grilo comercial sale más rápido, sale mucho más rápido. Por ejemplo la nabiza acá cuesta salir, la nabiza, la planta, y yo lo mando al mercado y me piden todos los días, me piden y ahora ya no porque ahora ya se termina la época" (Bonicatto 2011d. Entrevista a CA)

"este es así de este color y no quiere cruzarse, pero porque le erramos en el ciclo no conocíamos el ciclo de este (señalando otro cultivo de maíz Zea mays), tienen que quedar de este color, con blanco, así queda bonito (haciendo referencia a un maíz de grano color rojo). Pero ves que podes mantener a la línea pura, pero lo tenés que sacar de ciclo, si lo dejas ahí (en la parcela cultivada) chau" (Bonicatto 2011j. Entrevista a CV) 
Estos relatos incorporan diferentes dimensiones en los nombres otorgados a los cultivos, incluyendo variables morfológicas, comerciales, y productivas entre otras. En definitiva, el análisis de la agrobiodiversidad a partir de los nombres otorgados por los agricultores y agricultoras, permite visualizar un amplio universo de particularidades, ligadas a prácticas y usos, que acompañan a los materiales genéticos cultivados y conservados por los agricultores y agricultoras.

"está el redondito (refiriéndose a Solanum lycopersicum) también que todavía no lo cosechamos, y acá el tomate que también hicimos un pedacito del tomate perita largo. Después estaba el perita amarillo y también estaba del cherry el alargadito, el cherry perita" (Bonicatto 2014d. Entrevista a NA)

Estos resultados, en sintonía con lo expuesto por (Veteto, 2014) sostienen la necesidad de incorporar las clasificaciones locales de la agrobiodiversidad para comprender la conservación in situ. Según Scarpa (2012) es previsible el obtener una mayor riqueza de nombres locales, en comparación con la nomenclatura botánica, por el hecho de que el número de nombres locales es mayor que el de taxones. Sin embargo, aun ante su previsibilidad, la diversidad de nombres locales, se posiciona como un elemento sumamente interesante para la perspectiva agroecológica, en tanto, introduce diversidad de prácticas y saberes ligados a las dimensiones ecológico-productiva, económica y sociocultural.

En tanto, los datos obtenidos a partir del índice de consenso (IC) (Tabla 1) dan idea de aquellas especies más difundidas y conservadas entre los interlocutores. El cultivo y conservación de Solanum lycopersicum y Zea mays resaltan por sobre los otros cultivos, dejando ver la amplia incorporación tanto del tomate y del maíz entre los agricultores familiares. Un motivo de esta amplia incorporación, está ligado al hecho de la diversidad y versatilidad que estas especies tienen. Siendo que son cultivos de amplia aceptación en la zona, y ligados a los hábitos culinarios. Por tanto, se utilizan tanto para autoconsumo como para la venta, estando estos objetivos ligados a las diferentes etnoespecies registradas.

\subsection{2.l El significado local de los términos variedad e híbrido}

Como se dijo en el capítulo 2.2.1, se tuvieron en cuenta todos aquellos materiales reproductivos conservados, tanto aquellos provenientes de material genético comercial, como las semillas locales. Al profundizar en este capítulo sobre las semillas que se están conservando, surge en el relato de los agricultores y agricultoras la incorporación de 
vocabulario técnico, tamizado a través de la valoración local. Es así que las palabras variedad e híbrido, son utilizadas frecuentemente por los interlocutores con fines algo diferentes a su definición técnica, establecida previamente en este capítulo. En este sentido, toman como bifurcación entre estos términos, el hecho puntual de su posible reproducción in situ. Es así que utilizan la palabra variedad para hacer referencia a aquellos cultivos de los cuales pueden conservar semillas ya que las características buscadas se mantienen durante los ciclos de cultivo y conservación: "las semillas de variedad son más rústicas, ya están adaptadas acá a la zona" (Bonicatto 2011d. Entrevista a CA). En tanto, el término híbrido es empleado para aquellas variedades comerciales de condición híbrida cuyas características se pierden o merman luego de su cultivo y por tanto pierde el sentido su conservación: "si es híbrido no podes guardar" (Bonicatto 2014d. Entrevista a NA); "lo que pasa es que si es semilla hibrida no se puede hacer muchos años, dos años nomás, después se va como degenerando. Ahora el tomate platense ¡no! El tomate platense es siempre igual” (Bonicatto 2014k. Entrevista a LP); "semilla de descendencia hibrida no conviene guardarla, semilla de descendencia casera y de buena calidad la hago guardar" (Bonicatto 2011e. Entrevista a NG)

Esta incorporación local de términos derivados de tecnologías que responden al modelo productivista, permite comprender una dicotomía establecida por los agricultores en base a la práctica de conservación in situ. La utilización emic de estos términos divide en dos el gran universo de semillas que circulan por las manos de las familias agricultoras. Lo que "se puede guardar" (variedades) y lo que "no se puede guardar" (híbridos). Esta dualidad, producto del modelo hegemónico, inaugura un nuevo simbolismo sobre semillas hortícolas que "no se pueden" conservar in situ. Estas semillas, ingresan desde el mercado, con promesas de aptitud, aumento de la producción y rentabilidad. Los datos analizados a continuación buscar aclarar, si esta percepción en cuanto a la conservación, está realmente limitando la conservación.

Hasta este punto, los datos analizados sugieren que en los agroecosistemas familiares del territorio en estudio, se conservan semillas de hortalizas. Dado el contexto territorial estudiado, donde prima una lógica mercantil surge preguntarse ¿cuál es el origen de las semillas que están conservando los agricultores y agricultoras familiares? 


\subsubsection{Las vías de ingreso de las semillas conservadas}

En la Figura 13 se observa la distribución de las plantas cultivadas según el origen de las semillas conservadas expresadas en porcentajes. Estos resultados dan cuenta de que las principales vías de ingreso de las semillas conservadas están comprendidas tanto por el sistema de circulación de semillas informal y formal. Las vías informales, agrupadas bajo la categoría vínculos interpersonales están representadas por el mayor número de registros de cultivos conservados (115). Estos vínculos representan intercambios con vecinos, o semillas regaladas tanto de vecinos como feriantes. A su vez, se incluye el ingreso de semillas por consumidores que se acercan con semillas durante los encuentros en canales cortos de comercialización (venta directa, ferias, reparto a domicilio), e intercambio realizados durante ferias de semillas locales o a las que han viajado para participar. Los datos obtenidos dejan ver que esta vía de ingreso de semillas, junto con aquellas compradas en comercios (80 registros), representan las vías de adquisición más importantes.

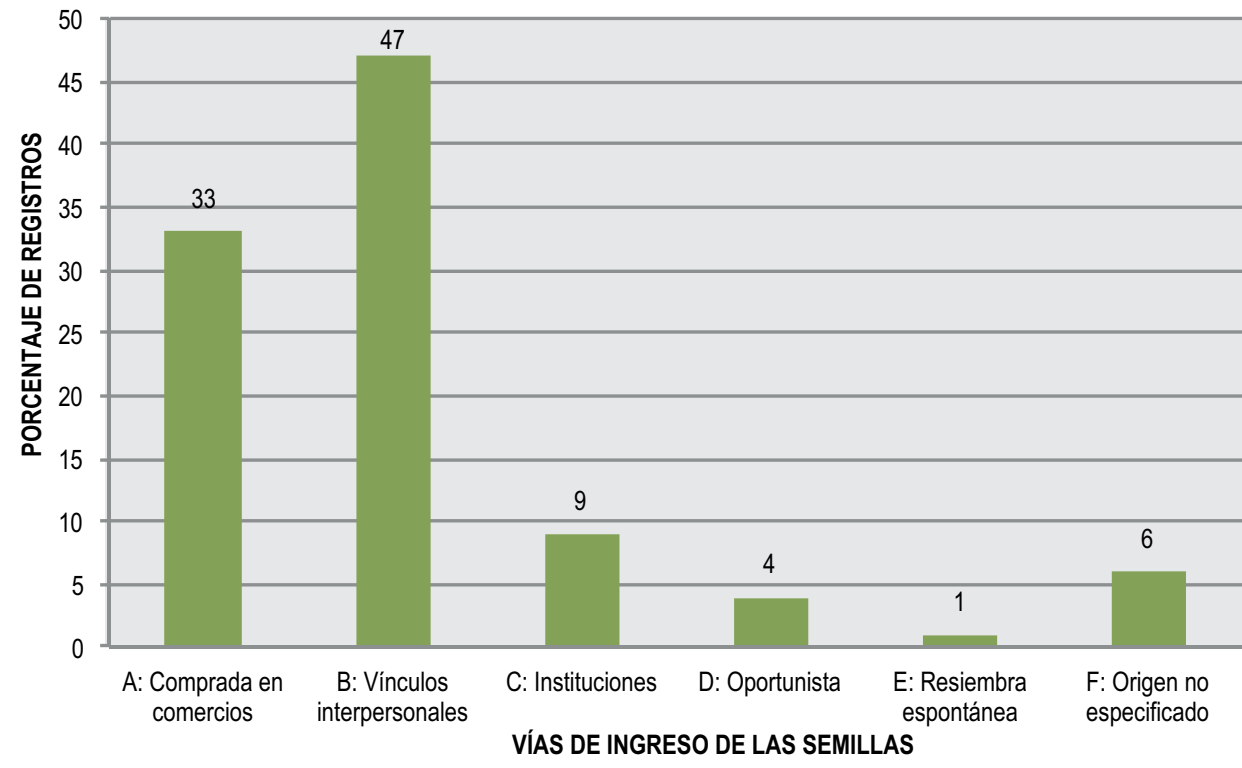

Figura 13: Origen de las semillas hortícolas conservadas por agricultores y agricultoras del Cinturón Hortícola Platense.

A este escenario complejo de circulación de semillas, se suman otros actores, y son los consumidores, quienes se acercan a los espacios de compra directa como ferias locales, venta por "bolsones de verdura", y suelen traer consigo semillas para los agricultores y agricultoras, que luego son incorporadas a las producciones. Las ferias de intercambio, destacadas previamente como canales de ingreso de semillas, fueron destacadas durante las entrevistas, como medio para obtener semillas y saberes: "el intercambio se 
da ahí [...] vos fijate, si no hay intercambio va a pasar lo que pasó con una cantidad de semillas que desaparecieron" (Bonicatto 2011j. Entrevista a CV), "ya fui a varias ferias pero mucho más chicas, antes fui a la de bolívar, el anteaño a intercambiar semilla, ideas, opiniones y todas esas cosas" (Bonicatto 2011d. Entrevista a CA).

A su vez surge con una gran presencia otra vía de ingreso, representada por semillas originalmente compradas en comercios (80) de agroinsumos, que una vez cultivadas, son conservadas por los agricultores y agricultoras. Esta situación habla de la iniciativa de los agricultores y agricultoras familiares por desarrollar estrategias que les permitan incluirse a la lógica productiva de un territorio con alta influencia del mercado hortícola. En tanto la categoría oportunista, implica una estrategia para obtener material reproductivo sin costo alguno. Esta categoría, se podría describir como ligada a una actitud de subsistencia, ya que implica el acomodarse a la circunstancia, a lo que se encuentra descartado y recogerlo para su incorporación a la producción.

En tanto la categoría instituciones vinculada a la incorporación de semillas distribuidas por instituciones estatales como el Pro Huerta, o la Unidad Promocional de Investigación y Desarrollo (UPID) de la Facultad de Ciencias Agrarias y Forestales (UNLP), expone la presencia del estado en la agrobiodiversidad que circula en el territorio. Estas semillas, aunque en un número bajo de menciones (Figura 13), diversifican las vías de ingreso accesibles para los agricultores familiares de este territorio. A su vez, expresan la predisposición de los agricultores y agricultoras para incorporarlas. Por último, se detalla una categoría que concentra aquellos cultivos a los cuales los agricultores refieren como que "aparecieron solos" o "están ahí", o que "los puso alguien de la familia hace mucho tiempo" y que ellos y ellas deciden conservarlos. Esta agrobiodiversidad refleja el pasaje generacional de la tierra, y cómo, con ella, se traspasa la agrobiodiversidad. Es así que surge como otra vía de "ingreso" la resiembra espontánea (Figura 13), siendo éstos, los cultivos incorporados porque se encontraban en la quinta, tal vez por haber sido sembrados por propietarios anteriores o familiares que ya no están. No obstante, la decisión de mantener con vida esas plantas es pura y exclusivamente decisión de quienes hoy están en esas tierras, resaltando la capacidad de observación de los agricultores y agricultoras en cuanto a la agrobiodiversidad que crece en sus producciones.

"acá el tomate que también hicimos un pedacito, semilla que venimos guardando también empezaron a aparecer plantas, se ve que eran de los anteriores quinteros, 
está el tomate largo, ¿lo conoces vos al perita largo? Aquel mirá, apareció una planta acá y apareció ese tomate" (Bonicatto 2009d. Entrevista a NA)

Los datos presentados comprueban la incorporación de semillas de diferentes orígenes y su conservación (Figura 14). Por un lado, la conservación de semillas obtenidas de redes informales, el conservar lo tradicional, las variedades locales, las semillas con historia familiar o semillas novedosas obtenidas en intercambios y por otro lado, la conservación ligada a semillas incorporadas del sistema formal. Estableciendose el conservar semillas comerciales ya sean variedades de condición híbrida, o no, que cumplan con las exigencias del mercado. Esta segunda estrategia mencionada, se posiciona como una alternativa de permanencia en el territorio ante los estándares de un modelo productivista que impone materiales genéticos a las producciones.

Es así, que el éxito en la conservación de semillas comerciales es ejemplo de que los agricultores y agricultoras familiares resignifican una práctica antes ligada exclusivamente a la conservación de semillas locales, y la aplican con el objetivo de conservar semillas de origen comercial. Según Wood \& Lenné (1997) los agricultores y agricultoras han demostrado la habilidad de generar diversidad de variedades, y manejarla dinámicamente. Estos autores sostienen que el amplio acceso a la agrobiodiversidad del sistema formal, lejos de generar conflicto, se posiciona como una oportunidad de complementariedad. El trabajo de Richeri et al. (2013) describe en relación a la incorporación de plantas exóticas, la flexibilidad del conocimiento y cómo este atributo ayuda a afrontar las nuevas condiciones del entorno. Lo que queda claro, es que para cada nuevo desafío, en este caso la conservación de semillas producidas por el sistema formal, debe ser necesario adaptar la práctica. Esta nueva aplicación conlleva experimentación, aprendizaje, incorporación de conocimientos técnico-científicos, en definitiva, generación de nuevos conocimientos locales. El dinamismo de los conocimientos implicados en la conservación in situ, será analizado en el capítulo 4. Retomando los resultados obtenidos, es interesante destacar la incorporación y apropiación de agrobiodiversidad, y la heterogeneidad en las vías de ingreso, lo cual se posiciona como otro factor de diversificación en la conservación in situ del territorio en estudio. 


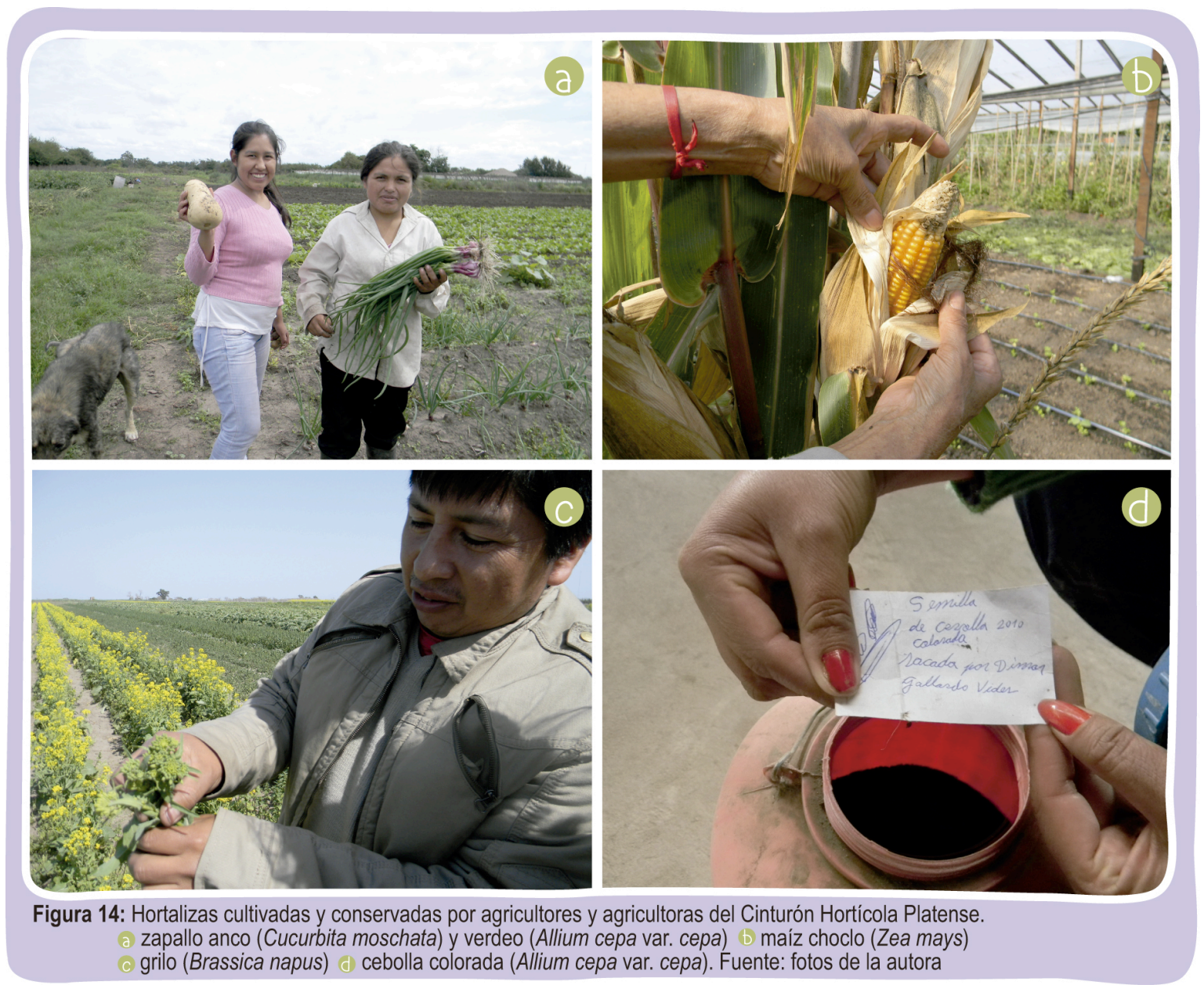

\subsubsection{Agrobiodiversidad hortícola no conservada}

Esta agrobiodiversidad constituye la contracara de la conservación. Lo no conservado, implica aquellos cultivos cuyas semillas se compran cada vez que van a ser sembradas. Del total de cultivos hortícolas registrados, 199 corresponden a la categoría no conserva material reproductivo (Figura 10). Desde el punto de vista botánico, estos cultivos representan 12 familias (Figura 15). Las familias Brassicaceae está representada por el cultivo de 6 especies botánicas (Tabla 2), entre ellas Brassica oleracea y sus 4 variedades italica, botrytis, capitata y gemmifera, las cuales constituyen un conjunto de cultivos hortícolas (brócoli, coliflor, repollo y repollito de Bruselas respectivamente), de amplia incorporación en el Cinturón Hortícola Platense, basados en materiales genéticos de condición híbrida.

Algunos relatos dan cuenta de los reemplazos de material genético de la Familia Brassicaceae que han transcurrido en la zona, así como de la práctica y planificación 
productiva que implicaba la conservación de las semillas. A su vez, estos relatos llevan consigo la presión que ejerce el mercado sobre la agrobiodiversidad cultivada:

"esa semilla ellos (sus padres) la hacían, hacían un año repollo, otro año coliflor, porque si la dejas se cruza, y si no ¿sabe que hacían? la tapaban toda cuando la hacían, pero la semilla la hacían ellos, ese repollo que digo yo que duraban 3,4 meses en el mismo cuadro" (Bonicatto 2014K. Entrevista a LP).

"nosotros teníamos semilla de repollo blanco, que era semilla casera también, era un repollo que era dulce como la miel Bueno, después cuando salieron los híbridos que son éstos (señalando la parcela cultivada), no lo quisieron más en el mercado a ese repollo blanco" (Bonicatto 2011E. Entrevista a NG).

Una situación similar se relaciona con la familia Solanaceae, representada principalmente por el cultivo de tomate, berenjena y morrón (rojo, verde, amarillo). Estos cultivos son los más representativos de la zona y los que tienen mejor precio y salida en el mercado mayorista. Estos cultivos cuando sus semillas son de origen comercial y su producción bajo invernáculo, son sugeridos para cumplir con objetivos que impliquen lograr aumentar la producción, calidad y la precocidad y la rentabilidad (Adlercreutz et al., 2014). A su vez, algunos de estos cultivos, debido a su perecibilidad, se realizan generalmente cerca de los centros urbanos, con acceso rápido al mercado, y pueden cultivarse en terrenos más pequeños (Instituto Nacional de Educación Tecnológica, 2010).

Una especie botánica exclusiva de la categoría no conserva material reproductivo, es la albahaca (Ocimum basilicum) de la familia Lamiaceae, comúnmente utilizada en invernáculos como cultivo secundario.

En cuanto al origen de los cultivos hortícolas que no son conservados, el $89.94 \%$ fueron comprados en comercios de agroinsumos y el $10.05 \%$ incluye otras vías de ingreso, como, instituciones u oportunista. Las semillas obtenidas en comercios son un eslabón del "paquete hortícola" que se comercializa junto a otros insumos externos, asociados al invernáculo. El trabajo de Blandi et al., (2016) sostiene, que el sistema de producción bajo invernáculo en el Cinturón Hortícola Platense corresponde con manejos y visiones que tienden a disminuir la agrobiodiversidad tanto cultivada como espontánea. En tanto el porcentaje de semillas provenientes de instituciones u oportunista que no son conservadas, expone el no cumplimiento de las expectativas de agricultores y agricultoras por parte del material genético incorporado. 
"nosotros nos habían dado una vez la semilla de haba del INTA, pero viene la vainita es así cortita, te vienen dos habitas tres por cada vaina, o en alguno uno, para comercializar, nosotros...como que no lo quieren." (Bonicatto 2011h. Entrevista a PA).

A través de algunos nombre locales de los cultivos no conservados, puede verse expresada la incorporación del modelo productivo hegemónico a través de semillas híbridas de alto rendimiento. El alcaucil híbrido, hinojo hibrido, tomate híbrido, zapallo híbrido son ejemplo de la situación descripta. Estos resultados, ligados al punto 2.3.2.1 de este capítulo, dan cuenta de la incorporación al nombre local, el calificador híbrido, y como éste, se vincula, en los ejemplos nombrados a la no conservación del cultivo.

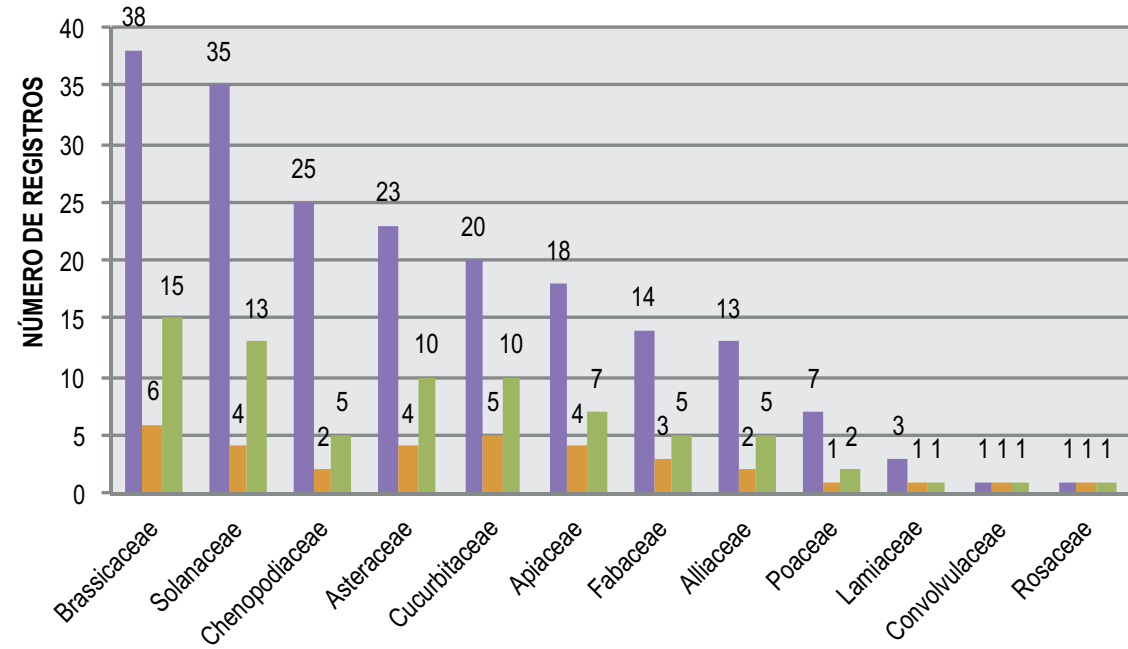

Registros de plantas cultivadas Riqueza especifica Riqueza etnoespecífica

FAMILIA BOTÁNICA 
Tabla 2: Agrobiodiversidad hortícola no conservada por agricultores y agricultoras del Cinturón Hortícola Platense

\begin{tabular}{|c|c|c|c|}
\hline FAMILIA BOTÁNICA & I NOMBRE CIENTÍFICO & NOMBRE LOCAL & SIGLA \\
\hline & Allium ampeloprasum & Puerro & BIS \\
\hline & & Ajo puerro & $\mathrm{CA}$ \\
\hline & & & $\mathrm{CL}$ \\
\hline & & Puerro & DY \\
\hline & & & PA \\
\hline & & & SV \\
\hline & Allium cepa var. cepa & & BIS \\
\hline & & & $\mathrm{CA}$ \\
\hline & & Verdeo & DAG \\
\hline & & & DY \\
\hline & & & $\mathrm{ML}$ \\
\hline & & $\begin{array}{l}\text { Cebolla colorada } \\
\text { var. cometa }\end{array}$ & NG \\
\hline & & Cebolla & S \\
\hline & & Verdeo & SV \\
\hline & & & MG \\
\hline & Apium graveolens var. graveolens & Apio & $\mathrm{ML}$ \\
\hline & & & $\mathrm{JL}$ \\
\hline & & & BIS \\
\hline & Daucus carota subsp. sativus & Zanahoria & $\mathrm{JL}$ \\
\hline & & & MG \\
\hline & & & NA \\
\hline & & Hinojo & MG \\
\hline & Feeniculum uulaare & Hinojo híbrido & CA \\
\hline & roeniculum vulgare & Hinojo importado & PA \\
\hline & & Hinojo nacional & PA \\
\hline & & & $\mathrm{CA}$ \\
\hline & & & DY \\
\hline & & & FLO \\
\hline & Petroselinum crispum & Perejil & LO \\
\hline & & & MG \\
\hline & & & $\mathrm{ML}$ \\
\hline & & & SV \\
\hline & & Radicheta & BV \\
\hline & & Achicoria & MG \\
\hline & Cichorium intybus & & NA \\
\hline & & Radicheta & $\mathrm{P}$ \\
\hline & Cynara cardunculus & Alcaucil híbrido & $\mathrm{CA}$ \\
\hline & & Lechuga capuchina & BIS \\
\hline & & Lechuga manteca & $P$ \\
\hline & & Lechuga criolla & $\mathrm{CA}$ \\
\hline & & Lechuga capuchina & $\mathrm{CL}$ \\
\hline & & Lechuga crespa & $\mathrm{CL}$ \\
\hline & & Crespa & DY \\
\hline & & Lechuga manteca & DY \\
\hline & & Lechuga crespa & JV \\
\hline & Lactuca sativa & Leguga manteca & JV \\
\hline & & Lechuga & LO \\
\hline & & Lechuga & MG \\
\hline & & Escarola fina & $\mathrm{ML}$ \\
\hline & & Escarola morada & $\mathrm{ML}$ \\
\hline & & Lechuga crespita & $\mathrm{ML}$ \\
\hline & & Lechuga manteca & $\mathrm{ML}$ \\
\hline & & Lechuga & NA \\
\hline & & Lechuga capuchina & $\mathrm{P}$ \\
\hline & & Lechuga morada & $P$ \\
\hline
\end{tabular}




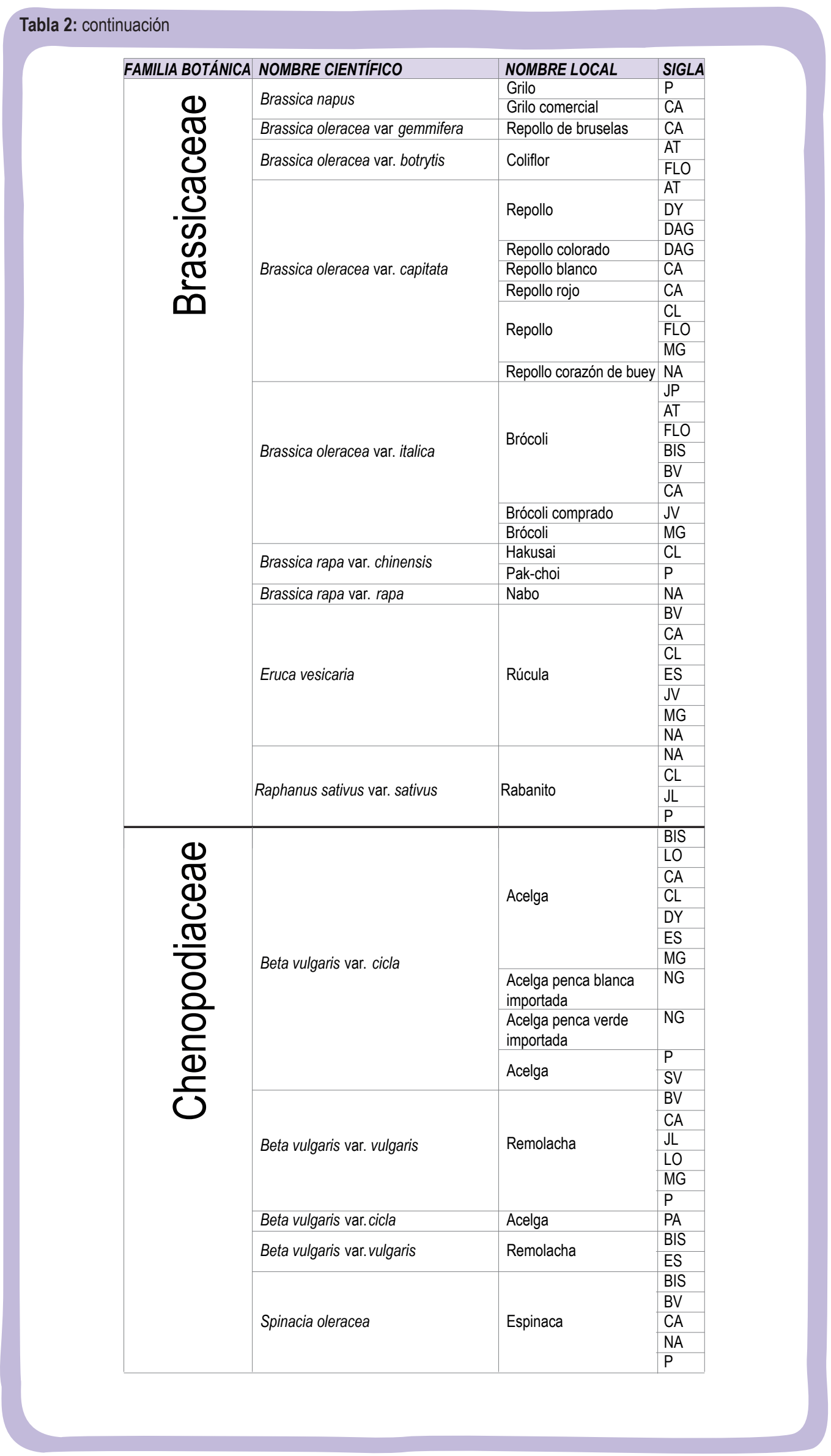

CAPÍTULO 2 Conservación de semillas, una practica ansestral que sigue activa 95 
Tabla 2: continuación

\begin{tabular}{|c|c|c|c|}
\hline FAMILIA BOTÁNICA & NOMBRE CIENTÍFICO & NOMBRE LOCAL & SIGLA \\
\hline Convolvulaceae & Ipomoea batatas & Batata boregas & AT \\
\hline & Cucumis melo & Melón & BIS \\
\hline & & Pepinito & BIS \\
\hline & Cucumis sativus & & BIS \\
\hline & vicumins salivis & Pepino & SV \\
\hline & & & DY \\
\hline & Cucurbita maxima subsp. maxima & Zapallito de tronco & LP \\
\hline & & Zapallito redondo & LP \\
\hline & $\begin{array}{l}\text { Cucurbita maxima Duchesne subsp. } \\
\text { maxima }\end{array}$ & Zapallito & DY \\
\hline & & Zapallito & CA \\
\hline & Cucurbita maxima subsp. maxima & Zapallito de tronco & FLO \\
\hline & & Zapallito & BIS \\
\hline & Cucurbita moschata & Anquito & AT \\
\hline & & & JP \\
\hline & & & BIS \\
\hline & & & $\mathrm{CA}$ \\
\hline & Cucurbita pepo & Zucchini & BV \\
\hline & & & LP \\
\hline & & & PA \\
\hline & Cucurbita sp. & Zapallo hibrido & MG \\
\hline & & Calabaza & PA \\
\hline & & Chaucha & BIS \\
\hline & & Chaucha rolliza & SV \\
\hline & & Chaucha larga & BV \\
\hline & & Chaucha & CA \\
\hline & Pnaseorus vulgaris var. vulgaris & Chaucha rolliza & MS \\
\hline & & & $\begin{array}{l}\text { BIS } \\
\text { DY }\end{array}$ \\
\hline & & Chaucha & LO \\
\hline & & & NG \\
\hline & & & SV \\
\hline & Pisum sativum & Arveja & CA \\
\hline & & & $\mathrm{ML}$ \\
\hline & Vicia faba & Habas & $\mathrm{ML}$ \\
\hline & & & BV \\
\hline I amiaceae & Ocimum basilicum & Albahaca & LO \\
\hline & & & SV \\
\hline & & Choclo & AT \\
\hline & & Maíz & $\mathrm{CL}$ \\
\hline & Zea mavs & & $\begin{array}{l}\text { DY } \\
\text { LP }\end{array}$ \\
\hline$C$ & & Choclo & $\mathrm{P}$ \\
\hline & & & PA \\
\hline & & & PA \\
\hline Rosaceae & Fragaria $\mathrm{x}$ ananassa & Frutilla & $S$ \\
\hline Monom & & Morrón rojo & $\mathrm{BIS}$ \\
\hline & & Morrón amarillo & BIS \\
\hline & & Morrón rojo & BV \\
\hline & & Morrón verde & BV \\
\hline & Capsicum annuum & & DY \\
\hline & & Morrón & LO \\
\hline & & & MS \\
\hline & & Morrón no orgánico & NA \\
\hline & & Morrón & $\mathrm{S}$ \\
\hline $\mathbf{C}$ & Capsicum sp. & Ajís & MG \\
\hline & & Tomate & BIS \\
\hline & & Tomate & DY \\
\hline & & Tomate híbrido & MG \\
\hline & & Tomate perita & $\mathrm{JL}$ \\
\hline & Solanum lycopersicum & Tomate & LO \\
\hline & & Tomate cherry & LO \\
\hline & & Tomate redondo & LP \\
\hline & & Tomate & MS \\
\hline & & Tomate & SV \\
\hline
\end{tabular}


Tabla 2: continuación

\begin{tabular}{|c|c|c|c|}
\hline \multicolumn{2}{|c|}{ FAMILIA BOTÁNICA NOMBRE CIENTÍFICO } & \multirow{4}{*}{$\begin{array}{l}\text { NOMBRE LOCAL } \\
\text { Berenjena } \\
\text { Berenjena } \\
\text { Berenjena negra }\end{array}$} & \multirow{3}{*}{$\begin{array}{l}\text { SIGLA } \\
\text { AT } \\
\end{array}$} \\
\hline & & \\
\hline \multirow{15}{*}{ 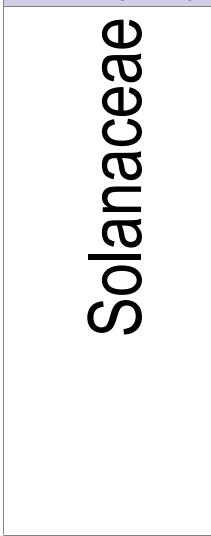 } & \multirow{12}{*}{ Solanum melongena } & & \\
\hline & & & BIS \\
\hline & & Berenjena rayada & BIS \\
\hline & & \multirow{9}{*}{ Berenjena } & BV \\
\hline & & & DY \\
\hline & & & ES \\
\hline & & & LO \\
\hline & & & LP \\
\hline & & & MG \\
\hline & & & MS \\
\hline & & & PA \\
\hline & & & SV \\
\hline & \multirow{3}{*}{ Solanum tuberosum subsp. tuberosum } & Papa & $\mathrm{CL}$ \\
\hline & & Papa colorada & LO \\
\hline & & Рара & $\mathrm{P}$ \\
\hline
\end{tabular}

\subsubsection{Agrobiodiversidad rememorada}

Al utilizar el término rememorada se hace referencia a la agrobiodiversidad que existe a través de los recuerdos. Esta agrobiodiversidad evocada del pasado, que no cuenta con el material genético para expresarse, forma parte de los relatos de los interlocutores cuando describen la agrobiodiversidad de sus producciones. El total de registros de plantas cultivadas para la categoría perdió el material reproductivo, fue de 25 (Tabla 3). La familia Brassicaceae es la más representada, con menciones al brócoli italiano (Brassica oleracea var. itálica) y repollo (Brassica oleracea var. capitata). Los relatos que acompañan estas especies remarcan la pérdida de estas variedades a causa de su desplazamiento por el ingreso de híbridos al mercado hortícola. Estas semillas suelen estar vinculadas a un sentimiento de añoranza, la pena o ausencia, y forman parte de la impronta del relato acerca de aquellas semillas ligadas al afecto:

"nosotros teníamos semilla de repollo blanco, que era semilla casera también, era un repollo que era jdulce como la miel! después cuando salieron los híbridos que son éstos, no lo quisieron más en el mercado a ese repollo blanco, eran unos repollos así (hace señas con las maños refiriéndose al tamaño) y bueno, lo dejé de plantar y perdí la semilla" (Bonicatto 2011e. Entrevista a NG).

A su vez, estas semillas cuentan acerca de la historia de los interlocutores. Ellas representan en algunos casos, intentos aunque fallidos, de cultivar aquellas plantas ligadas a sus lugares de origen. El norte argentino, Bolivia, hasta inclusive Europa, fueron 
cuna de muchos de los agricultores y agricultoras del Cinturón Hortícola Platense. Ellos y ellas son quienes hoy en día traen en viajes ocasionales, semillas para incorporar en sus quintas, en el intento de recuperar las semillas que completen sus recuerdos: " $Y$ no es como el maizón que digamos que había antes que uno lo hacía la semilla, no digamos ahora que el choclo es híbrido" (Bonicatto 2011h. Entrevista a PA). Nazarea (2006) reflexiona sobre la importancia de la memoria en la conservación de la agrobiodiversidad, sosteniendo que la memoria es necesaria para reconstruir procesos. Según Furlan et al. (2011) aunque la planta no se encuentre en la zona, los conocimientos se mantienen y se enriquecen constantemente. En este sentido, el recuerdo sobre cultivos hortícolas perdidos o abandonados, mantiene conocimiento como los expresados sobre NG, en relación al momento de siembra y por tanto, ofrece herramientas para realizar y adaptar la práctica de conservación de semillas a situaciones del presente. 
Tabla 3: Agrobiodiversidad hortícola rememorada por agricultores y agricultoras del Cinturón Hortícola Platense.

\begin{tabular}{|c|c|c|c|}
\hline Sigla & Nombre científico & Nombre local & Familia botánica \\
\hline NG & Allium cepa var. cepa & Cebolla variedad Purea & Alliaceae \\
\hline$J P$ & Brassica napus & Grilo & Brassciaceae \\
\hline$J L$ & Brassica oleracea var. italica & Brócoli italiano & Brassicaceae \\
\hline LP & Brassica oleracea var. capitata & Repollo & Brassicaceae \\
\hline NG & Brassica oleracea var. capitata & Repollo blanco & Brassicaceae \\
\hline MG & Beta vulgaris var. cicla & Acelga de penca verde & Chenopodiaceae \\
\hline BV & Ipomoea batatas & Camote & Convolvulaceae \\
\hline LP & Ipomoea batatas & Batata blanca & Convolvulaceae \\
\hline ES & Cucurbita ficifolia & Cayote & Cucurbitaceae \\
\hline FLO & Cucurbita sp. & Zapallo grande redondo verde & Cucurbitaceae \\
\hline CV & Arachis hypogaea & Maní & Fabaceae \\
\hline BV & Arachis hypogaea & Maní & Fabaceae \\
\hline PA & Vicia faba & Haba & Fabaceae \\
\hline FLO & Zea mays & Maizón & Poaceae \\
\hline BV & Zea mays & Maíz para humita & Poaceae \\
\hline PA & Zea mays & Maizón & Poaceae \\
\hline BV & Solanum tuberosum subsp. tuberosum & Papa & Solanaceae \\
\hline JV & Solanum lycopersicum & Tomate cherry amarillo & Solanaceae \\
\hline JV & Solanum lycopersicum & Tomate cherry amarillo perita & Solanaceae \\
\hline ES & Solanum tuberosum subsp. andigenum & Papa andina & Solanaceae \\
\hline JV & Solanum lycopersicum & Tomate cherry grande & Solanaceae \\
\hline JV & Solanum lycopersicum & Tomate platense & Solanaceae \\
\hline MS & Capsicum annuum & Calahorra & Solanaceae \\
\hline MS & Solanum lycopersicum & Tomate bonanza & Solanaceae \\
\hline NG & Capsicum sp. & Ají vinagre el tradicional & Solanaceae \\
\hline
\end{tabular}

\subsection{Conclusiones}

Los datos obtenidos ponen en evidencia la diversidad cultivada por los agricultores y agricultoras familiares del Cinturón Hortícola Platense. En función de la agrobiodiversidad registrada (31 familias botánicas, 120 especies y 305 etnoespecies vinculadas a 10 rubros productivos), se concluye que en los agroecosistemas familiares del Cinturón Hortícola Platense el componente cultivado mantiene diversidad genética y específica, 
necesaria para la implementación de diseños biodiversos basados en policultivos, rotaciones y abonos verdes. A su vez, los múltiples usos registrados (9 categorías) relacionados al cuidado de la salud, la ornamentación, la realización de artesanías, la producción de alimento para animales y la obtención de productos condimenticios para la elaboración de comidas, hablan de que la agrobiodiversidad cultivada, excede lo meramente hortícola. Estos datos invitan a reflexionar, sobre una de las variables descriptivas de la agricultura familiar, ligada a la importancia de vivir donde se produce, y el rol de esta variable en el mantenimiento de agrobiodiversidad in situ.

Por su parte la agrobiodiversidad documentada en la categoría horticultura, respaldaría la hipótesis general de esta tesis "En los agroecosistemas familiares del Cinturón Hortícola Platense, existe agrobiodiversidad hortícola conservada in situ", destacando el registro de 10 familias botánicas, 41 especies y 152 etnoespecies conservadas in situ.

A través del análisis de las vías de ingreso de las semillas conservadas, se pone en evidencia que los agricultores familiares de este territorio no solo conservan semillas de obtenidas por vínculos interpersonales, sino que hacen extensiva dicha práctica, a semillas de origen comercial. La conservación de estas semillas sugiere una estrategia emergente y novedosa de un territorio complejo y mercantilizado.

Desde la perspectiva agroecológica, el registro presentado sobre la agrobiodiversidad vegetal cultivada y conservada en los agroecosistemas familiares del Cinturón Hortícola Platense, tanto en términos de riqueza de familias, especies botánicas y etnoespecies, ofrece un abanico amplio de recursos genéticos, que representan un potencial para avanzar en estrategias de diseño de agroecosistemas familiares diversificados. Por este motivo, los datos presentados son fundamentales para comprender qué semillas (cultivos hortícolas) se están conservando, y es a partir de los resultados obtenidos, que se propone indagar en los motivos que tienen los agricultores y agricultoras familiares para decidir qué conservar y porqué hacerlo, a fin de avanzar en estrategias que fortalezcan la conservación in situ. 


\subsection{Bibliografía}

Adlercreutz E.; R.D. Huarte, A. López Camelo, E. Manzo, A. Szczesny \& L. Viglianchino. 2014. Producción Hortícola bajo cubierta. Ediciones INTA. Disponible en: https://inta.gob.ar/sites/default/files/script-tmp-inta-_prod_hort_bc.pdf

Ahumada, A.; F. Mainella, M.M. Bonicatto, M. Pérez, M.L. Pochettino, M.E. Marasas, M. Moricz, M. Pérez, N. Anglese, P. Domínguez \& V. Parmigiani. 2009. Segunda Feria Provincial de Semillas Nativas y Criollas "Sembrando Esperanza". Editor responsable CYTED- Programa Iberoamericano Ciencia y tecnología para el Desarrollo. Jujuy, Argentina.

Almekinders, C. \& W.S. de Boef. 2000. El reto de la colaboración en el manejo de la diversidad genética de los cultivos. LEISA 15: 5-7.

Almekinders, C.J.M.; N.P. Louwaars \& G.H. de Bruijn. 1994. Local seed systems and their importance for an improved seed supply in developing countries. Euphytica 78: 207-216.

Altieri, M.A. 1999. The ecological role of biodiversity in agroecosystems. Agriculture, Ecosystems and Environment 74: 19-31.

Altieri, M. \& C.I. Nicholls. 1994. Biodiversity and pest management in agroecosystems. Haworth Press, New York.

Altieri, M. \& C.I. Nicholls. 2000. Agroecología. Teoría y práctica para una agricultura sustentable. Programa de las Naciones Unidas para el Medio Ambiente. $1^{\circ}$ Edición. México 8: 167-180.

Altieri, M.; C.I. Nicholls, A. Henao \& M.A. Lana. 2015. Agroecology and the design of climate change-resilient farming systems. Agronomy for Sustainable Development 35:869-890.

Bellon, M.R. \& J. Risopoulos. 2001. Small-Scale Farmers Expand the Benefits of Improved Maize Germplasm: A Case Study from Chiapas, Mexico. World Development 29 (5): 799-811. 
Belloni, M.C. 2017. Resiliencia de los sistemas agroecológicos ante el cambio climático. Trabajo integrador final. Posgrado de Especialización en Agroecología Escuela de Posgrado UNLAM (Argentina).

Berlin, B. 1992. Ethnobiological Classification. Principles of categorization of plants and animals in traditional societies. Princeton University Press, New Jersey

Bojar, H.; T. Klapec \& A. Cholewa. 2012. The influence of the preservation of biological diversity on human health, en: W. Bojar.; F. Diniz \& A. Junkuszew. Biodiversity and regional development. Editorial Torun. Polonia 5 (1): 261-272.

Bonicatto M.M.; S.J. Sarandón\& M.L. Pochettino. 2009. El concepto de "semilla" y su relación con la agrobiodiversidad en una zona hortícola (Buenos Aires, Argentina). V Congreso Internacional de Etnobotánica. Bariloche. Argentina.

Bonicatto, M.M.; V. Fernández, N.A. Gargoloff, M. Marasas, L. Muscio, M. Pérez \& M.L. Pochettino. 2010. Sembrando Esperanza. III Feria Provincial de Semillas Nativas y Criollas. En defensa de la vida y de la soberanía alimentaria. Por una economía solidaria, construyendo la casa de todos. Ediciones INTA. Publicaciones IPAF- Región Pampeana. La Plata, Argentina.

Cababié, J.; M.M. Bonicatto \& E.A. Abbona. 2015. Semillas y saberes de los agricultores familiares. ¿Cuál es el rol de las ferias de intercambio en su reproducción y conservación? Revista Facultad de Agronomía La Plata 114 (Núm. Esp.1) Agricultura Familiar, Agroecología y Territorio: 122-128.

Calvet-Mir, L. T.; Garnatje, M. parada, J. Vallés \& V. Reyes-García. 2014. Más allá de la producción de alimentos: Los huertos familiares como reservorio de diversidad biocultural. Ambienta 107:40-53.

Chappell, M.J. \& L. La Valle. 2011. Food security and biodiversity: can we have both? An agroecological analysis. Agriculture and Human Values 28(1) 3-26

de Boef, W.S. 2007. Biodiversidade e agrobiodiversidade, en: W.S. de Boef.; M.H. Thijssen, J. Bernardi Ogliari \& B.R. Sthapit (organizadores) Biodiversidade E Agricultores. Fortalecendo o manejo comunitário. L\&PM Editores. Brasil. 1: 15-34.

Del Valle Isla, A.E. 2014. Al mal tiempo, Buena resiliencia. Ciencias 111-112.

Doneland, P. 2009. Cultivo de semillas. Ecology Action. Tercera edición en español. USA. 
Duelli, P. \& M.K. Obrist. 2003. Biodiversity indicators: the choice of values and measures. Agriculture, Ecosystems and Environment 98: 87-98.

Eyssartier, C.; A.H. Ladio \& M. Lozada. 2011. Traditional horticultural knowledge change in rural population of the Patagonian steppe. Journal of Arid Environments 75: 78-86.

Furlan, V., C. Torres \& L. Galetto. 2011. Conocimiento y utilización de plantas medicinales por pobladores rurales del Bosque Chaqueño Serrano de Córdoba (Argentina). Bonplandia 20 (2): 285-307.

Garat, J.J.; A. Ahumada, J. Otero, L. Terminiello, G. Bello \& ML. Ciampagna. 2009. Las hortalizas típicas locales en el cinturón verde de La Plata: su localización, preservación y valorización. Horticultura Argentina 28(66): 32-39.

Garat, J.J.; A. Castro, S. Gramuglia, A. Nico \& A. Ahumada. 2007. El rescate de la biodiversidad local y la acción colectiva: una estrategia de desarrollo a través de la revalorización de hortalizas locales en el cinturón verde de La Plata, Buenos Aires, Argentina. Revista Brasilera de Agroecología 2 (1): 430-434.

Gargoloff, N.A.; P. Riat, E.A. Abbona \& S.J. Sarandón. 2007. Análisis de la Racionalidad Ecológica en 3 grupos de horticultores en La Plata, Argentina. Revista Brasileira de Agroecología 2 (2): 468-471.

Gliessman, S.R. 2002. Agroecología: procesos ecológicos en la agricultura sostenible. CATIE: Turrialba, Costa Rica.

González, J. 2007. ¿Por qué las variedades locales? en: Red Andaluza de Semillas (edición y coordinación). Manual para la utilización y conservación de variedades locales de cultivo. Sevilla, España. Pp: 11-20 Disponible en: http://www.redandaluzadesemillas.org/libreria-virtual/materiales-libres/article/manualpara-la-utilizacion-y-676 [consulta septiembre de 2016].

Harris, M. 2004. Antropología cultural. Madrid, Alianza Ed.

Hilgert, N. 2007. La Etnobotánica como herramienta para el estudio de los sistemas de clasificación tradicionales, en: A. Contreras-Ramos.; C. Cuevas Cardona.; I. Goyenechea \& U. Iturbe (editores). La sistemática, base del conocimiento de la biodiversidad. México: Universidad Autónoma del Estado de Hidalgo. 
Hilgert, N.I.; F. Zamundio, V. Furlan \& L. Cariola. 2013. The key role of cultural preservation in the Argentine Yungas. Evidence-Based Complementary and Alternative Medicine. Article ID 732760.

Instituto Nacional de Educación Tecnológica. 2010. La Horticultura en la Argentina. Informe final. http://catalogo.inet.edu.ar/files/pdfs/info_sectorial/horticultura-informe-sectorial.pdf [consulta noviembre de 2017].

Instituto Nacional de Semillas. Argentina. https://www.inase.gov.ar [consulta julio de 2017].

IPCC. 2014. Climate change 2014: Impacts, adaptation and vulnerability. IPCC Special Report, WGII.

Isbell, F; D. Craven, J. Connolly, M. Loreau, B. Schmid, C. Beierkuhnlein, T.M. Bezemer, C. Bonin, H. Bruelheide, E. De Luca, A. Ebeling, J.N. Griffin, Q. Guo, Y. Hautier, A. Hector, A. Jentsch, J. Kreyling, V. Lanta, P. Manning, S.T. Meyer, A.S. Mori, S. Naeem, P.A. Niklaus, H.W. Polley, P.B. Reich, C. Roscher, E.W. Seabloom, M.D. Smith, M.P. Thakur, D. Tilman, B.F. Tracy, W.H. van der Putten, J.van Ruijven, A. Weigelt, W.W. Weisser, B. Wilsey \& N. Eisenhauer,. 2015. Biodiversity increases the resistance of ecosystem productivity to climate extremes. Nature 526 (7574): 574-7

Kraft, K.H.; J.J. Luna-Ruíz \& P. Gepts. 2010. Different Seed Selection and Conservation Practices for Fresh Market and Dried Chile Farmers in Aguascalientes, México. Economic Botany 64 (4): 318-328.

Lambaré, D. A., \& M.L. Pochettino. 2012. Diversidad local y prácticas agrícolas asociadas al cultivo tradicional de duraznos: Prunus persica (Rosaceae), en el Noroeste de Argentina. Darwiniana, nueva serie, 50(2), 174-186.

León, J. 1987. Botánica de los cultivos tropicales. Segunda Edición. Instituto Interamericano de Cooperación para la Agricultura. Colección Libros y Materiales Educativos N84. Costa Rica.

Loreau,M.; S. Naeem, P. Inchausti, J. Bengtsson, J.P. Grime, A. Hector, D.U. Hooper, M.A. Huston, D. Raffaelli, B. Schmid, D. Tilman \& D.A Wardle. 2001. Biodiversity and ecosystem Functioning: Current knowledge and future challenges. Science 294: 804-808. 
Marasas, M.; S.J. Sarandón, A. Cicchino. 2010. Semi-Natural Habitats and Field Margins in a Typical Agroecosystem of the Argentinean Pampas as a Reservoir of Carabid Beetles. Journal of Sustainable Agriculture, 34:153-168.

Marasas, M.; M.L. Blandi, N. Dubrovsky Berensztein \& V. Fernández. 2014. Transición agroecológica de sistemas convencionales de producción a sistemas de base ecológica. Características, criterios y estrategias en: S.J. Sarandón \& C.C. Flores (editores) Agroecología: bases teóricas para el diseño y manejo de agroecosistemas sustentables. La Plata: Editorial de la Universidad de La Plata. 15: 411-436.

Nazarea, V.D. 2006. Local Knowledge and Memory in Biodiversity Conservation. Annual Review of Anthropology 35(1):317-335.

Nicholls, C.I. 2013. Enfoques agroecológicos para incrementar la resiliencia de los sistemas agrícolas al cambio climático en: C.I. Nicholls.; L.A. Ríos Osorio, \& M.A. Altieri (editores.) Agroecología y resiliencia socioecológica: adaptándose al cambio climático, 18-29. Medellín, Colombia: REDAGRES-CYTED.

Nicholls, C.I.; M.A. Altieri, A. Henao, R. Montalba \& E. Talavera. (2015). Agroecología y el diseño de sistemas agrícolas resilientes al cambio climático. REDAGRES-SOCLACYTED. Perú.

Nicholls, C.I.; M.A. Altieri \& L. Vázquez. 2016. Agroecology: Principles for the Conversion and redesign of Farming Systems. Journal of Ecosystems \& Ecography S5: 010. doi:10.4172/2157-7625.S5-010.

Noss, R.F. 1990. Indicators for Monitoring Biodiversity: a hierarchical approach Conservation Biology 4 (4) 355-364.

Pérez, M. \& M.E. Marasas. 2013. Servicios de regulación y prácticas de manejo: aportes para una horticultura de base agroecológica. Ecosistemas 22 (1): 36-43.

Peroni, N. \& N. Hanazaki. 2002. Current and lost diversity of cultivated varieties, especially cassava, under swidden cultivation systems in the Brazilian Atlantic Forest. Agriculture, Ecosystems and Environment 92: 171-183.

Pochettino, M.L. 2015. Botánica Económica. Las plantas interpretadas según tiempo, espacio y cultura. Sociedad Argentina de Botánica. Buenos Aires, Argentina. 
Pochettino, M.L.; V. Fernández, N.A. Gargoloff, L. Muscio, L. Pérez, L. González Espinosa, M.M. Bonicatto, M. Pérez, A. Cremaschi, E. Barreto, M.P. May, J. Cababié\& M.E. Marasas. 2011. I Feria Nacional, IV Feria Provincial de Semillas Nativas y Criollas. "Sembrando Esperanza". Editorial INTA.

Richeri, M.; Cardoso, M.B. \& A.H. Ladio. 2013. Soluciones locales y flexibilidad en el conocimiento ecológico tradicional frente a procesos de cambio ambiental: estudios de caso en Patagonia. Ecología Austral 23:184-193.

Salcedo, S.; A. Sánchez \& M.J. Coloma. 2014. Agricultura familiar y seguridad alimentaria. El exitoso caso del proyecto Forsandino, en: S. Salcedo \& L. Guzmán (editores). La Agricultura Familiar en América Latina y El Caribe. Recomendaciones de Políticas. FAO, Santiago, Chile 3: 57-78.

Sarandón, S.J. \& C.C. Flores 2014. La insustentabilidad del modelo agrícola actual, en: S.J. Sarandón \& C.C. Flores (editores). Agroecología: Bases teóricas para el diseño y manejo de agroecosistemas sustentables. Colección de libros Cátedra. Universidad Nacional de La Plata (EDULP) 1:13-41.

Scarpa, G.F. 2012. "Palos, yuyos, pencas, bejucos y pastos": Los nombres de las plantas y su clasificación etnobotánica por los criollos del Chaco semiárido norte (NE Salta-W Formosa, Argentina), en P. Arenas (editor). Etnobotánica en zonas áridas y semiáridas del conosur de Sudamérica. CEFYBO-CONICET-UBA, Buenos Aires, Argentina 117-144.

Stupino, S.A.; J.L. Frangi, S.J. Sarandón M.F. Arturi \& A.C. Ferreira. 2008. Plant diversity in two farms under organic and conventional management in La Plata, Argentina. A case study. Revista Brasilera de Agroecología, Asociación Brasilera de Agroecología, 3 (3): 24-35.

Stupino, S.A.; M.J. lermanó, N.A. Gargoloff \& M.M. Bonicatto. 2014. La biodiversidad en los agroecosistemas, S.J. Sarandón \& C.C. Flores (editores). Agroecología: Bases teóricas para el diseño y manejo de agroecosistemas sustentables. Colección de libros Cátedra. Universidad Nacional de La Plata (EDULP) 5:131-158.

van der Ploeg, J.D., 2012. The drivers of change: the role of peasants in the creation of an agro-ecological agriculture. Agroecología 6: 47-54.

Veteto, J.R. 2014. Seeds of Persistence. Agrobiodiversity in the American Mountain South. Culture, Agriculture, Food and Environment 36 (1) 17-27. 
Wood, D. \& J.M. Lenné. 1997. The conservation of agrobiodiversity on-farm: questioning the emerging paradigm. Biodiversity and Conservation 6: 109-129.

Zamudio, F. \& N.I. Hilgert. 2012. Descriptive attributes used in the characterization of stingless bees (Apidae: Meliponini) in rural populations of the Atlantic forest (MisionesArgentina). Journal of Ethnobiology and Ethnomedicine 8:9. 
CAPÍTUlO 3:

Motivos de la conservación de semillas

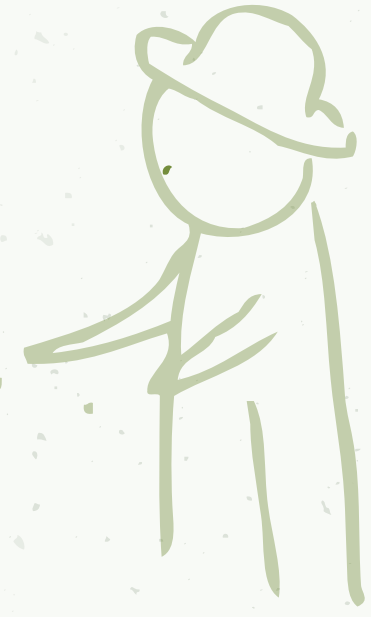




\section{CAPÍTULO 3 Motivos de la conservación de semillas}

"A mí me gusta, guardar, veo una semilla que a mí me gusta, la calidad y digo bueno, de esta semilla vamos a sacarle, de esta verdura vamos a sacar semilla, y ahí la saco, me doy el trabajo viste, y la hago"

(Bonicatto 2013c. Entrevista a MG)

\section{3.l Introducción}

La diversidad encontrada en un sistema productivo no es estática, como tampoco lo es el proceso de experimentación, que de manera voluntaria o involuntaria, genera simultáneamente la perdida y adquisición de variedades (Elias et al., 2000). Los caminos o redes a través de los cuales se incorpora variedad y variabilidad a los agroecosistemas juegan un rol preponderante en la diversidad expresada en los mismos (Bellon \& Risopoulos, 2001; Eyssartier et al., 2011, Jiménez-Escobar et al., 2011; Thomas et al., 2009; Tripp, 1996; Peroni \& Hanazaki, 2002; Pochettino et al., 2011; Veteto, 2008). Los años de interacción entre los agricultores y el entorno, son expresados en la diversidad de variedades conservadas, cultivadas y utilizadas por agricultores y agricultoras del mundo (Carpenter, 2005; Hilgert, et al., 2013; Kraft et al., 2010; Silveira 2015; Tsegaye, 1997; Veteto, 2008). Un ejemplo local de esto son las más de 1000 etnovariedades intercambiadas durante la I Feria Nacional de Semillas Nativas y Criollas y las Ferias Provinciales realizadas en Buenos Aires (Bonicatto et al., 2010; Pochettino et al., 2011). Desde el punto de vista del funcionamiento del agroecosistema, la importancia de contar con una alta disponibilidad de diversidad cultivada, radica en que junto con la agrobiodiversidad vegetal espontánea, constituyen la base para la presencia de otros eslabones tróficos, que a través de sus sinergias, establecen el correcto funcionamiento de los procesos ecológicos necesarios para avanzar en el diseño de agroecosistemas resilientes (Nicholls 2013a; Paleologos et al., 2017; Tomkins \& Adger, 2004).

Los trabajos de Altieri \& Koohafkan (2008); Henao (2013); Ladio (2011), Richeri et al. (2013), presentan estudios donde diferentes comunidades articulan conocimientos tradicionales con nuevas circunstancias socioambientales para adaptarse a los cambios. A diferencia del conocimiento científico, el conocimiento de los agricultores y agricultoras, es local, holístico y portador de una cosmovisión que integra aspectos físicos y espirituales (Toledo, 1992). Las prácticas agrícolas asociadas a la conservación de 
semillas forman parte de este conocimiento. Entre ellas se encuentran los motivos y momentos de selección de las plantas a conservar, las técnicas de cultivo y las estrategias de recolección, secado y guardado (Bellon \& Risopoulos, 2001; Garat, 2002; Garat et al., 2007; Garat et al., 2009; Kraft et al., 2010; Vernooy, 2003). Según Almekinders et al. (1994), los pequeños agricultores interactúan con un ambiente cambiante y por tanto, tienen múltiples objetivos que afectan sus elecciones acerca de los cultivos y semillas que utilizan.

El trabajo de Swift et al. (2004) establece la necesidad de contemplar diferentes valores de la biodiversidad, tales como un valor intrínseco, que contempla la valoración que tiene la biodiversidad por sí misma; un valor utilitario vinculado a los diversos usos de la biodiversidad; un valor incierto vinculado al posible descubrimiento de usos de la biodiversidad, y por último, un valor funcional vinculado a las funciones ecológicas que cumple la misma. Dicho trabajo propone incorporar diversidad a los motivos por los cuales se conserva la biodiversidad, entendiendo que existen diferentes percepciones sobre su conservación. Los motivos (criterios) que impulsan a los agricultores y agricultoras a destinar tiempo, trabajo y recursos, en la conservación de determinadas semillas, forman parte del cuerpo de conocimientos. Estos criterios ligados al cultivo y conservación, han sido objeto de diversos estudios (Díaz-Bautista et al., 2008; Hilgert et al., 2013; McGuire et al., 2003; Silveira, 2015) y son dinámicos y diferentes para cada grupo familiar y para cada semilla conservada. Es así que la decisión de los agricultores y agricultoras, en torno a qué conservar, puede vincularse a diferentes variables (Hilgert et al., 2013). Entre ellas, cualidades organolépticas, aptitudes para la comercialización, a variables económicas, a lazos familiares, a aspectos simbólicos o al origen de la semilla y destino de la producción. Estos criterios representan las razones por las cuales los agricultores y agricultoras deciden qué agrobiodiversidad conservar in situ. Por lo tanto, en ellos convergen las dimensiones ecológico-productiva; económica, política y sociocultural; posicionándose como parte esencial para el análisis y diseño de agroecosistemas sustentables.

En la Introducción general de esta tesis se caracterizó a los agricultores familiares como un tipo social donde la unidad productiva y doméstica se encuentran integradas, y cuya producción se destina tanto al autoconsumo como al mercado (Elverdín et al., 2005). En este sentido la agrobiodiversidad que cultivan y los motivos que sustentan su conservación, puede diferir según su destino. La articulación que se da entre el espacio productivo y el hogar, entiende la necesidad de una mirada más amplia de la alimentación. Según Aguirre (2010) la alimentación es un proceso complejo, más amplio que simplemente nutrirnos, visto no solo como un hecho biológico sino, al mismo tiempo 
socio-cultural, ya no es válido aislar factores biológicos de factores sociales, ya que se ponen en juego variables de orden diferente: el recorte de lo que es alimento según identidad cultural y preferencias personales (Kiple \& Ornelas, 2000). La disponibilidad, la composición y las características de los alimentos, son parte de esta concepción (Muchnik, 2006). Numerosos estudios resaltan el rol de los cultivos para autoconsumo en el mantenimiento de saberes y prácticas (Bisht et al., 2014; Kraft et al., 2010; May et al., 2017; Montañez-Escalante et al., 2014; Nuñez \& Traglia, 2015; Peroni \& Hanazaki, 2002; Pirachicán Avila, 2015; Salazar-Barrientos et al., 2016). A su vez, el trabajo de May et al. (2017) reflexiona sobre cómo el sistema mercantil invisibiliza la agrobiodiversidad que los agricultores y agricultoras cultivan para su consumo y que no encuentra lugar en el mercado ya que no suelen cumplir con los códigos establecidos y ni ser parte de "las hortalizas demandadas". Según la Real Academia Española, el adjetivo "oculto" se aplica a aquello que está escondido, ignorado, que no se da a conocer, ni se deja ver, ni sentir. Tomando este sentido, se emplea dicho adjetivo para describir aquellas hortalizas que "no se ven" o "no se sabe" que están siendo cultivadas por los agricultores y agricultoras, ya que se circunscriben a la esfera familiar del autoconsumo. Por tanto, indagar en los motivos que sustentan la conservación de semillas y sus variaciones según el origen de la semilla y el destino de la producción es de suma importancia para establecer planes de rescate y difusión de la diversidad hortícola, como base para el mantenimiento de la diversidad biocultural.

Es así que durante el presente capítulo se abordan las siguientes hipótesis

"Los agricultores y agricultoras familiares del Cinturón Hortícola Platense utilizan diferentes criterios que intervienen en la conservación del material reproductivo". Hipótesis particulares

- Los criterios de conservación varían según el origen de la semilla.

- Existen criterios afectivos y culinarios en la conservación de semillas en agroecosistemas familiares del Cinturón Hortícola Platense.

"Existen recursos genéticos "ocultos" cultivados por los agricultores familiares del Cinturón Hortícola Platense".

Los objetivos de este capítulo fueron:

- Identificar y describir los criterios locales de conservación de semillas.

- Relacionar los criterios de conservación de semillas con el origen y destino de las mismas. 
- Identificar el cultivo de hortalizas para autoconsumo y los criterios que sustentan su conservación.

En definitiva ¿Qué motiva a los agricultores a conservar semillas? ¿Existen criterios diferentes? ¿Hay diferencias entre los criterios por los que conservan semillas locales y aquellas de origen comercial? ¿Qué motiva la conservación de hortalizas restringidas al autoconsumo? En el presente capítulo se profundiza en la conservación de semillas, buscando aquellos motivos que explican la continuidad de esta práctica en un contexto territorial que presiona para su abandono, así como los motivos que sustentan el cultivo y conservación de hortalizas que se mantienen exclusivamente en la esfera familiar. En este sentido se entiende que para poder comprender por qué los agricultores familiares del Cinturón Hortícola Platense conservan semillas, es necesario profundizar en los motivos que ellos mismos otorgan a la conservación de dicha agrobiodiversidad.

\subsection{Metodología}

Se utilizó la base de datos y tabla de Excel producto de la información registrada en las 26 entrevistas y las recorridas a campo. Los ejes de la entrevista se basaron en la historia familiar y su vínculo con la producción hortícola, conocer la agrobiodiversidad cultivada, y los motivos de su conservación, así como conocer el origen de las semillas conservadas. Las entrevistas se complementaron con recorridas de la quintas junto a los agricultores y observación participante, para registrar momentos de selección y limpieza de semillas. Cada cultivo hortícola fue considerado un registro. Como se dijo en el capítulo precedente, cada cultivo hortícola fue considerado un registro. Se trabajó con los 244 registros de plantas hortícolas conservadas in situ. Para cada registro se estableció uno o más criterios que sustentan su conservación.

\subsection{Criterios de conservación}

A partir del análisis de las entrevistas se describieron los motivos por los cuales se conservan semillas para conformar el conjunto de criterios que sustentan dicha práctica. Por lo tanto, los criterios de conservación descriptos surgen de la fundamentación de los informantes. Sin embargo, los rótulos fueron puestos por la autora a posteriori del relevamiento. Posteriormente se detalló para cada registro (planta hortícola cultivada) el/los criterios que sustentan su conservación. Cada criterio se cuantificó a partir del número 
veces (citas) que fue utilizado por los interlocutores para justificar la conservación de una semilla. Debido a que para algunas semillas opera más de un criterio de conservación (pluricausalidad) y que para otras semillas conservadas los criterios de conservación no fueron explicitados, el número total de citas, difiere del número total de registros de plantas hortícolas cuyas semillas son conservadas. Teniendo en cuenta que el trabajo se enfoca en sistemas productivos familiares situados en un periurbano donde la lógica es la comercialización del producto y opera para toda la diversidad cultivada, el criterio comercial no fue cuantificado pero sí descripto, ya que se consideró subyacente a la conservación de todo el material reproductivo.

A fin de analizar la aplicación de diversos criterios (pluricriterios) por cada registro, se calculó para cada registro de planta cultivada, el número de criterios de conservación manifestados por cada interlocutor.

\subsubsection{Origen de las semillas}

Se utilizó la clasificación descripta en el capítulo 2.2.4 sobre el origen de las semillas conservadas I: comprada en comercio. II: vínculos interpersonales (incluye las semillas obtenidas por herencia, regalo de otros agricultores, de consumidores, intercambio entre vecinos, agricultores, familiares, en ferias de intercambio o intercambio casuales). III: instituciones (incluye semillas obtenidas a través de Instituciones estatales Universidad/INTA). IV: oportunista (incluye semillas obtenidas aprovechando la oportunidad de hortalizas descartadas del mercado, verdulerías, recolectadas de espacios públicos y privados. V: resiembra espontánea (incluye semillas que se siembran espontáneamente en el agroecosistema mediadas por la decisión de los agricultores y agricultoras). Se analizaron los criterios de conservación que operan sobre los cultivos hortícolas según su origen.

\subsubsection{Destino de la producción}

A fin de analizar la presencia de cultivos hortícolas que permanecen en la esfera del autoconsumo, por tanto "ocultos" ante la mirada productivista del sistema hegemónico y considerando que la caracterización de agricultura familiar implica la producción para autoconsumo y venta, la agrobiodiversidad conservada fue agrupada en 3 categorías según el destino de la producción: 1. autoconsumo y comercialización, 2. autoconsumo 
exclusivamente y 3. comercialización exclusivamente. Entendiendo la categoría de autoconsumo exclusivamente como aquella que representa los cultivos obtenidos para la esfera familiar. Se analizó desde el punto de vista botánico, la agrobiodiversidad perteneciente a dicha categoría. Posteriormente se vinculó dicha agrobiodiversidad con los criterios que sustentan la conservación de la misma.

\subsection{Resultados y discusión}

\section{3.l Motivos de los agricultores y agricultoras para conservar agrobiodiversidad} in situ.

Se describieron 10 criterios que operan sobre la conservación de los cultivos hortícolas (Tabla 4). En dicha tabla se citan algunos de los párrafos a partir de los cuales se construyó la clasificación de los criterios de conservación. La referencia de cada entrevista se presenta en el (Anexo 1). El número de criterios establecidos, expone la diversidad de motivos que los agricultores y agricultoras implican en la decisión de qué agrobiodiversidad conservar. En el apartado 3.2.1, se explicitó que dado el objetivo productivo de los agroecosistemas analizados, el criterio comercial no fue cuantificado, ya que incluiría el total de los registros de plantas conservadas. Este criterio, representa la voluntad de comercializar la agrobiodiversidad que se cultiva y se encuentra íntimamente relacionado a la lógica comercial del territorio en estudio, y por tanto, subyace a la conservación de todo el material reproductivo. Este criterio se encuentra explícito en los cultivos cuyo destino es la comercialización, e implícito en aquellos destinados al autoconsumo, los cuales son comercializados ante el surgimiento de un canal de venta. En este sentido, el criterio comercial, simboliza la unión entre conservar para el hogar y para la venta. 
Tabla 4: Criterios que sustentan la conservación de semillas en agroecosistemas familiares del Cinturón Hortícola Platense.

\begin{tabular}{|c|c|c|}
\hline $\begin{array}{l}\text { CRITERIO DE } \\
\text { CONSERVACIÓN }\end{array}$ & DESCRIPCIÓN & EJEMPLO \\
\hline Afectivo (A) & $\begin{array}{l}\text { Cultivos conservados por su vínculo con la historia } \\
\text { familiar, a personas por las cuales se siente afecto, } \\
\text { a semillas que se les perdieron o, simplemente, al } \\
\text { tiempo que hace que se las conserva. }\end{array}$ & $\begin{array}{l}\text { "la acelga la traje desde Gorina para acá y si, está conmigo } \\
\text { desde unos } 35 \text { años, o un poco más" (Bonicatto 2011a. } \\
\text { Entrevista a JV) }\end{array}$ \\
\hline Culinario (B) & $\begin{array}{l}\text { Cultivos conservados por tradición culinaria } \\
\text { familiar o alimentos regionales. }\end{array}$ & $\begin{array}{l}\text { "el alcaucil 7, } 8 \text { comidas diferentes seguro...porque está, } \\
\text { vamos a decir... así hecho milanesa, escabeche, eh...tortilla, } \\
\text { relleno, para hacer relleno con carne". (Bonicatto 2014k. } \\
\text { Entrevista a LP) }\end{array}$ \\
\hline Innovador (C) & $\begin{array}{l}\text { Innovar y experimentar en la incorporación de } \\
\text { cultivos "raros", desconocidos o reencontrados. }\end{array}$ & $\begin{array}{l}\text { "lo recuperamos porque esa semilla hacía rato que se había } \\
\text { perdido, y entonces este hombre nos trajo viste...consiguió, } \\
\text { por allá por Berisso, no sé de dónde pero me trajo un } \\
\text { poquito y yo la seguí sacando incluso este año la tenemos } \\
\text { la del platense". (Bonicatto } 2013 c \text {. Entrevista a MG } \\
\text { hablando del tomate platense (Solanum lycopersicum) } \\
\text { Solanaceae) }\end{array}$ \\
\hline Independencia (D) & $\begin{array}{l}\text { Vinculado a la posibilidad de independizarse } \\
\text { de la compra de semillas. }\end{array}$ & $\begin{array}{l}\text { "dejamos el fruto para hacer semilla porque otra no queda, } \\
\text { porque vos lees, escuchas...y decís tenemos que hacer la } \\
\text { semilla, lleva su tiempo hacer la semilla digamos hay que } \\
\text { regar la planta cuidarla, que no se te caiga la semilla, } \\
\text { cosechar cuando hay que cosechar". (Bonicatto } 2009 \mathrm{~d} \text {. } \\
\text { Entrevista a NA) }\end{array}$ \\
\hline Medicinal (E) & $\begin{array}{l}\text { Cultivos conservados por sus propiedades } \\
\text { para la salud }\end{array}$ & $\begin{array}{l}\text { "otra cosa sobre el alcaucil que tiene propiedades que } \\
\text { curan". (Bonicatto 2014k. Entrevista a LP) }\end{array}$ \\
\hline Diversificador (F) & $\begin{array}{l}\text { Cultivos conservados con el objetivo de } \\
\text { incrementar la diversidad en la quinta. }\end{array}$ & $\begin{array}{l}\text { "la idea es tener bastante variedad de verdura } \\
\text { entonces...para atraer a la gente... y que no esté yéndose a } \\
\text { otros lugares que ahí lo puede tener...entonces también por } \\
\text { eso intercambio de semillas, traje otras variedades de } \\
\text { semilla, otras variedades de zapallo". (Bonicatto 2011d. } \\
\text { Entrevista a CA) }\end{array}$ \\
\hline Morfológico (G) & $\begin{array}{l}\text { Cultivos conservados en busca de características } \\
\text { morfológicas u organolépticas (color, sabor, olor, } \\
\text { aspereza). Estas características pueden ser } \\
\text { buscadas tanto por deseos personales como por } \\
\text { estándares impuestos por el mercado. }\end{array}$ & $\begin{array}{l}\text { "vos lo ves esta así de alto y unos troncos jasí tienel". } \\
\text { (Bonicatto } 2013 \mathrm{c} \text {. Entrevista a MG refiriéndose al verdeo } \\
\text { (Allium cepa var. cepa) Alliaceae). }\end{array}$ \\
\hline Productivo (H) & $\begin{array}{l}\text { Cultivos conservados por su rol en el } \\
\text { fortalecimiento de servicios ecológicos. }\end{array}$ & $\begin{array}{l}\text { "la manzanilla para el zapallito, le ponía una infusión para } \\
\text { los hongos, [...] ají picante, que ponés unas 6-7 en } 20 \text { litros } \\
\text { y lo usas para la arañuela o para el "estrip" (Bonicatto } 2011 \text { f. } \\
\text { Entrevista a JV) }\end{array}$ \\
\hline Económico (I) & $\begin{array}{l}\text { Cultivos conservados por su vínculo con la } \\
\text { posibilidad de ahorrar el dinero que implica la } \\
\text { compra de semillas. }\end{array}$ & $\begin{array}{l}\text { "ahora lo que tengo que probar es la semilla de repollo, } \\
\text { porque de repollo están encareciendo mucho". (Bonicatto } \\
\text { 2011h. Entrevista a PA) }\end{array}$ \\
\hline Comercial $(\mathrm{J})$ & $\begin{array}{l}\text { Cultivos conservados por su posibilidad de } \\
\text { comercializarse, subyace a todos los criterios } \\
\text { descriptos ya que la venta de las plantas } \\
\text { cultivadas es parte de la lógica de las familias. }\end{array}$ & $\begin{array}{l}\text { "la chaucha lengua de dragón se llama [...] esa la sacamos } \\
\text { porque no se consigue en ningún lado, es una semilla que } \\
\text { no sé dónde la trajieron, no sé si italiana de donde es un día } \\
\text { arriba del camión venia con esa y la sacamos, entonces la } \\
\text { tenemos para sacar...esa si se vende! La gente le encanta, } \\
\text { porque como se hace el poroto, no se come la chaucha } \\
\text { viste, se come el poroto". (Bonicatto } 2013 c \text {. Entrevista a MG } \\
\text { hablando de la chaucha lengua de dragón (Phaseolus } \\
\text { vulgaris var. vulgaris) Fabaceae). }\end{array}$ \\
\hline
\end{tabular}


ocasiones $(105$ citas $=26 \%$ ) resulta ser el innovador $(C)$. Este criterio da cuenta de la actitud experimentadora de los agricultores y agricultoras, manifestada en su predisposición e inquietud por incorporar a sus agroecosistemas variedades "raras", desconocidas o reencontradas y, a su vez, a experimentar en la conservación de semillas comerciales, inclusive siendo de condición genética híbrida. En palabras de un agricultor de la localidad de Arana, hablando del tomate zorzal (Solanum lycopersicum) Solanaceae:

"ahora lo plantamos este año. Esta es semilla comprada. 1000 semillas. Pero sé que el zorzal si uno le saca la semilla no da lo mismo, lo mismo que una semilla comprada. No es la misma calidad, viene un poco más chico, deforme y ahora de esto, yo lo que quiero hacer es como te contaba del zuquini, de cómo puedo hacer para mantener la semilla, buscarle la vuelta. Algunos me dicen que hay que dejarle pasar dos años y seguirle. Por ahí se adapta al clima, por ahí a lo mejor que se yo, por ahí para el año, este año que viene no creo, si saco, como te digo, veo, si salen como 100 semillas, 1 o 2 te va a nacer, las otras no te nacen" (Bonicatto 2011h. Entrevista a PA)

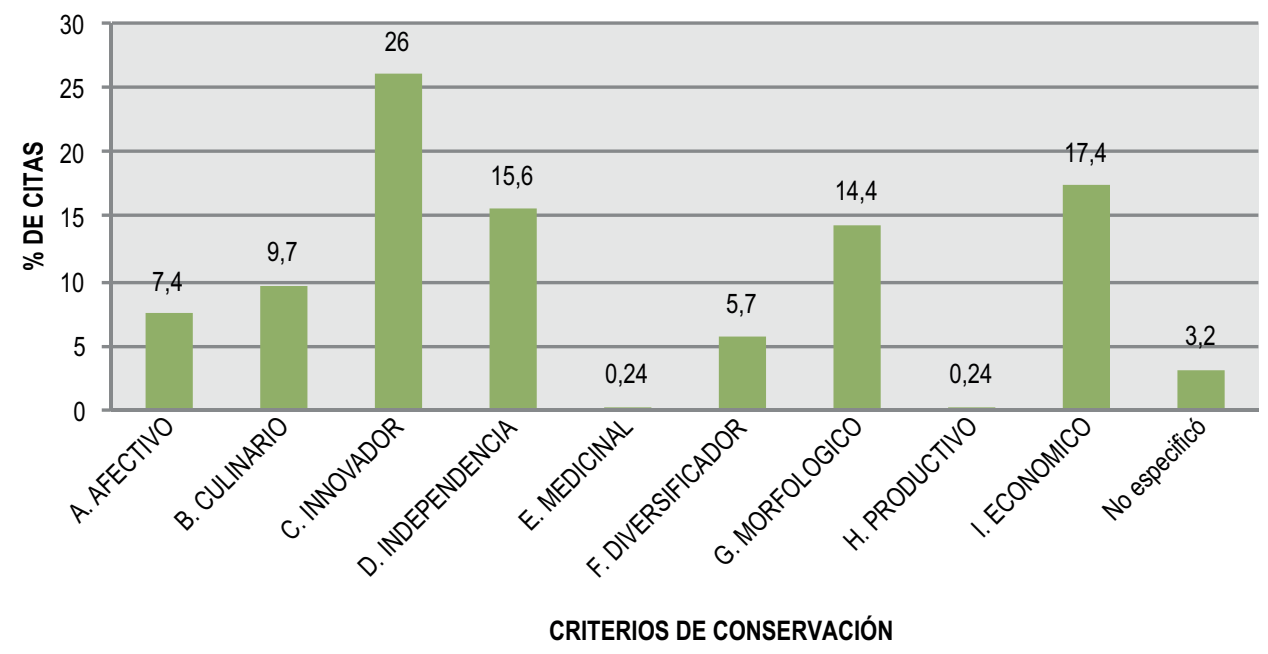

Figura 16: Criterios de conservación utilizados por los agricultores y agricultoras familiares del Cinturón Hortícola Platense.

El trabajos de Kraft et al. (2010) describe la actitud de constante experimentación de los agricultores y agricultoras ligada a la conservación de semillas criollas y comerciales. A su vez, Veteto (2014) resalta la importancia de la creatividad para la generación de nuevas variedades. Mientras que Wood \& Lenné (1997) posicionan la habilidad de los agricultores y agricultoras para generar nuevas variedades, como un elemento esencial 
de la conservación in situ. Esta actitud positiva en pos de la experimentación, expresada por los agricultores y agricultoras del Cinturón Hortícola Platense, resulta un pilar fundamental para la innovación de conocimientos producto de la interacción del agricultor con la naturaleza y con otras personas. En este punto el criterio innovador representa lo propuesto por Amorozo et al. (2008), Berkes et al. (2000) y Berkes \& Turner (2006), la unión temporal entre pasado y futuro. Implica innovar en la conservación de material genético para el futuro, en función del conocimiento del pasado, donde los saberes tradicionales se movilizan a favor de desarrollar los conocimientos necesarios para conservar la nueva semilla incorporada. El criterio innovador refleja también la voluntad de cambio y adaptación del conocimiento de los agricultores y agricultoras, en un marco de reafirmación de su capacidad individual y de reponerse ante situaciones adversas. En concordancia con lo propuesto por Pochettino \& Lema (2008), este cambio transcurre a través de los saberes hortícolas que se implementan en la zona en ese tiempo y espacio, reflejando la proyección hacia el futuro desde un anclaje en una práctica tradicional.

Esta práctica mediada por la voluntad de innovación, es uno de los ejes que sostienen el dinamismo del conocimiento en relación a la conservación de semillas. Sin embargo, el conocimiento no necesariamente implica la conservación en el tiempo, del material genético a partir del cual se pone en práctica. Este punto se vincula al hecho de que el cultivo y conservación de hortalizas actúa como canalizador del conocimiento, como escena de aprendizaje en sí misma, aun en los casos en los que no se completa el ciclo productivo. El trabajo de Cababié et al. (2015), analiza el porcentaje de éxito obtenido por los agricultores familiares luego de la siembra de las semillas intercambiadas durante la I Feria Nacional de Semillas Nativas y Criollas, arrojando valores cercanos al $80 \%$. De esta manera, el accionar de este criterio puede resultar, contradictorio, ya que por un lado moviliza los conocimientos en torno a la conservación, pero, por el otro, puede generar discontinuidad en cuanto a la conservación del material reproductivo per se. En sintonía con lo propuesto por Elias et al. (2000), este criterio condensa en sí mismo la historia de la agricultura a lo largo del tiempo, habiendo resultado en la diversidad hortícola propia de la época. A su vez, la actitud innovadora manifestada a través de este criterio, va de la mano del criterio diversificador $(F)(23$ citas $=5,7 \%$ ) vinculado en especial a la intención de agregar agrobiodiversidad a las producciones.

El segundo criterio en importancia es el económico (I) $(70$ citas $=17,4 \%)$ vinculado a la intención de conservar semillas a modo de ahorrar el dinero que implica su compra. El surgimiento de este criterio caracteriza el territorio en estudio, ya que da cuenta de la 
presión que ejerce el modelo productivista sobre la economía de las familias, las cuales ponen en juego diversas estrategias para afrontar los costos de los insumos externos, entre ellos las semillas comerciales:

"más que todo guardar la semilla es para gastar menos, al menos yo por eso lo saco, la semilla, para no estar gastando mucho porque la verdura cada vez sube más, pero el precio también sube más el alquiler, la semilla que tenés que comprarla, el abono como sea la bosta, esta como mil pesos como que ya te da miedo de invertir, la quinta porque para preparar la verdura no más tenés pagar es al tractorista, 200 pesos o más cobran la hora, te imaginas preparar diez claros? ¿cuánto vas a gastar? y más la bosta que tenés que poner y embostar la tierra, vos tenés que comprar la semilla, hacer los plantines que para hacer los plantines tenés que comprar maples de plantines, tierra y más la semilla como dije, y de ahí tenés que invertir en otra cosa más que es en telas para que no le joda....es todo inversión, inversión, inversión...eso es como que te arrugas de poner cosas grandes porque como ser el morrón o el tomate es muy propenso al frío, entonces como que nos da miedo ponerle más temprano, si no perdes toda la cosecha, es eso más que todo es comprar más y cuando no vale perdes en vez de, ahora cuando vale si, rescatas y ganas pero la tenés que saber administrar también porque si no la sabes guardar la plata, administrar bien, viene un ventarrón y de nuevo el nylon se jode, entonces otra vez ya tenés que invertir otra vez, en nylon, en madera, en clavos, en alambre, así que a veces ganamos, es para volver a invertir, por eso hay otros que ponen por cantidad y a veces lo agarran en buen precio y si, ahí ganan, esos sí, es riesgoso, pero es asi" (Bonicatto 2013a. Entrevista a BIS)

Según Cieza et al. (2015), los productores familiares elaboran sus estrategias productivas de acuerdo a sus posibilidades, buscando una diversificación de productos que les permita continuar en el circuito productivo ante dificultades de mercado o climáticas. Se realizan cultivos de ciclo más corto (como las hortalizas de hoja) y de bajo costo de implantación o cultivos de ciclo largo y con altas costos (tomate, pimiento), según las capacidades económico financieras de cada productor. En tanto el criterio independencia (D) (63 citas=15,6\%), vinculado a la posibilidad de mejorar la autonomía en la conservación in situ de semillas, es un factor de suma importancia para el fortalecimiento de los agroecosistemas familiares. Este criterio en algunos casos, ligado a una dimensión política e ideológica, da cuenta de la búsqueda por independizase del mercado, tanto convencional como orgánico, en la compra de semillas. A su vez habla 
de una búsqueda personal ligada a la independencia de insumos externos: "te da la tranquilidad de decir tengo la semilla" (Bonicatto 2013c. Entrevista a MG)

Se vincula con lo antedicho la presencia del criterio productivo $(H)(1 \mathrm{cita}=0.24 \%)$, ligado al mantenimiento de agrobiodiversidad para fortalecer servicios ecológicos. Este criterio establece un salto entre el componente vegetal espontáneo comúnmente vinculado al mantenimiento de procesos ecológicos como la regulación biótica y el componente vegetal cultivado, el cual aparece en este caso abocado a dicho objetivo. En definitiva este criterio incorpora la decisión de cultivar y conservar agrobiodiversidad en pos de procesos ecológicos. La presencia de este criterio es una fortaleza para el mantenimiento de agroecosistemas sustentables, ya que el fortalecimiento de los procesos internos y la independencia de insumos externos son objetivos centrales de la agroecología. Ante dicha importancia, la presencia de solo una cita de este criterio sugiere dos sucesos. La utilización de agroquímicos para reemplazar las funciones ecológicas y/o, la baja valoración de las funciones ecológicas de la agrobiodiversidad cultivada.

En tanto, el criterio morfológico (G) (58 citas=14,4\%), opera al conservar cultivos hortícolas por características deseadas tanto por los agricultores o agricultoras, como por características buscadas por el mercado que condiciona el criterio local. Los dos relatos que siguen a este párrafo dan cuenta de esto al hacer referencia al cultivo de zapallo anco batata (Cucurbita moschata) del cual se resalta su sabor y al cultivo de una variedad de cebolla (Allium cepa var. cepa) elegida principalmente para cumplir con un estándar de calidad demandado por el mercado: "ahí lo estás viendo, porque todo grande es, es una variedad de anquito muy lindo, jtiene un gusto! mira, mira este está bien maduro". (Bonicatto 2014b. Entrevista a HC). Otro relato dice: "esta la dejamos para semilla, es una variedad de cebolla colorada que tiene la hoja bien parada, que no se quiebra la hoja porque en el mercado si quiebra la hoja no la quieren" (Bonicatto 2011e. Entrevista a NG).

Por último, tres criterios de suma importancia para la agricultura familiar: afectivo (A) (30 citas= $7,4 \%)$, culinario $(C)$ (39 citas=9,7\%), y medicinal $(E)(1$ citas= $0,24 \%)$. Es a través de la presencia de estos criterios que se evidencia como la conservación se semillas sigue ligada a la historia y tradiciones de las familias agricultoras: "y ñato (hablando sobre la variedad local alcaucil ñato (Cynara cardunculus) debe hacer 60 años fácil que viene siempre ese alcaucil, porque era ya de la época del abuelo que se plantaba" (Bonicatto 2014k. Entrevista a LP). Los relatos sobre el tiempo que hace que se cultiva una hortaliza, el valor afectivo que tienen los cultivos, la posibilidad de elaborar platos típicos a través de la disponibilidad de los ingredientes necesarios, el uso de las plantas para la atención de la salud, son valores ligados a la esfera 
familiar: "me hace bien tener (hablando del maizón (Zea mays)), porque no es lo mismo, no es el mismo maíz de allá" (Bonicatto 2014i. Entrevista a S). Estos criterios exceden la conservación de semilla como material reproductivo, ya que en ellos, se encuentra implícita la historia, costumbres y valoraciones de quienes los expresan. Por lo tanto, la agrobiodiversidad conservada a partir a estos criterios, mantiene un estrecho vínculo con la soberanía alimentaria.

\subsubsection{Relación entre los criterios de conservación y las vías de ingreso de las semillas}

Una de las preguntas planteadas previamente invita a reflexionar acerca de los criterios que sustentan la conservación de semillas dependiendo de su origen. Al analizar los resultados, se ve que los criterios que motivan la conservación de semillas se modifican en relación al origen de las mismas (Figura 17). La conservación de semillas compradas en comercios está sustentada 7 criterios, entre los cuales el criterio económico (47 citas $=41,2 \%$ ) es el más representado, seguido por el criterio morfológico (22 citas= 19,3\%) e independencia (19 citas $=16,6 \%$ ) (Figura 17). La presencia de agrobiodiversidad conservada por estos criterios encuadra la realidad que transitan los agricultores familiares en torno a la incorporación del modelo de la Revolución Verde. El trabajo de Bellon \& Risopoulos (2001) reflexiona acerca de la incorporación y conservación de variedades mejoradas en una comunidad de Chiapas, México, documentando el proceso de hibridación entre variedades locales y comerciales que ocurre en los agroecosistemas campesinos. Mientras que el trabajo de Brush (1992), discute la pérdida de diversidad producto de la incorporación de material genético comercial. Los datos aquí presentados, permiten comenzar a entender los motivos por los cuales los agricultores y agricultoras conservan material genético comercial e instalan preguntas para futuros estudios. ¿Qué impacto sobre las semillas tradicionales tendrá la incorporación de material genético comercial si es sostenida a lo largo de los años?

Retomando la actualidad y los motivos que sostienen la conservación de semillas comerciales, se visualiza el intento por incorporar el paquete tecnológico que este modelo propone. Esta conservación permite a los agricultores y agricultoras, reducir el costo en insumos, siendo la conservación de variedades comerciales, una posibilidad factible de llevar adelante, inclusive ante las dificultades implícitas en las semillas de condición híbrida: "esta es una chaucha larga así y ancha se llama cronos, es re- re buena, pero que pasa, vale $100 \$$ ¡el kilo! y con un kilo plantas un surco, o sea que yo este año, la primer plantada 40 kilos planté y si la hago yo la semilla me ahorro 4000 pesos" (Bonicatto 2011e. Entrevista a NG). El siguiente relato expone la acción de estos criterios en relación a los cultivos de condición híbrida, en este caso referido a la berenjena (Solanum melongena): 
"lo que pasa es que cuando va pasando el año, es igual como el tomate, se va cambiando el fruto, cuando yo lo compré era un fruto más parejo, y después se hace como una especie de pera, y bueno, ya tenés que ir eligiendo la semilla de vuelta para rescatarla" (Bonicatto 2011f. Entrevista a JV).

Por lo tanto, la conservación in situ de agrobiodiversidad de origen comercial, se posiciona hoy en día como una estrategia que permite cumplir con las expectativas del mercado y ahorrar (momentáneamente), el dinero que implica la compra de las semillas.

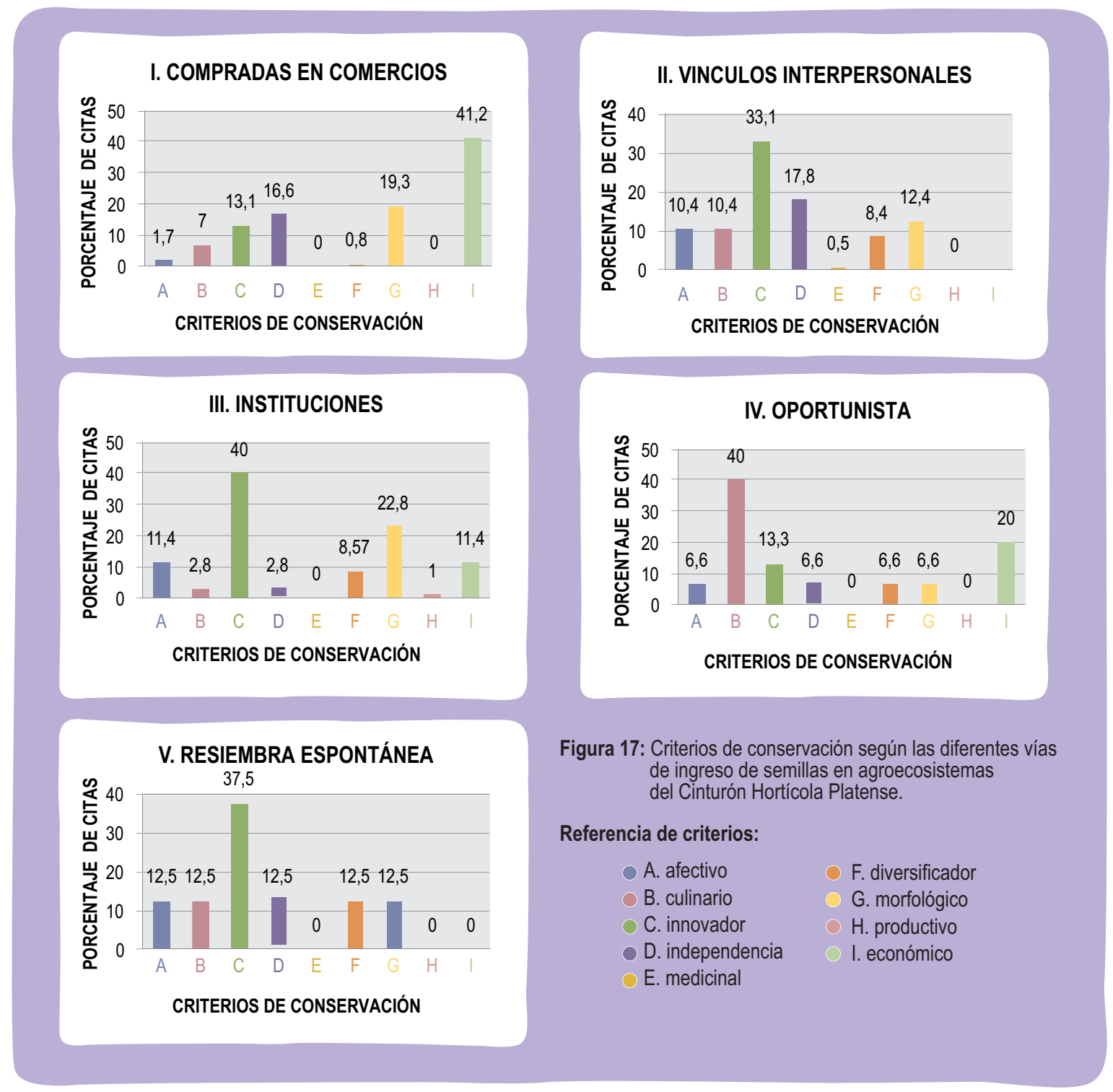

Un escenario diferente se plantea alrededor de la conservación de semillas obtenidas por vínculos interpersonales, tales como intercambios, herencias, regalos. Esta conservación está ligada a 8 criterios. En concordancia con lo propuesto por Pochettino et al. (2011) los criterios 
afectivo (21 citas= 10,4\%), culinario (21 citas $=10,4 \%$ ) y medicinal ( 1 cita $=0,5 \%$ ), con mayor o exclusiva presencia en la conservación de estas semillas, tienen la particularidad de relacionarse a la diversificación para la casa, al hacer cotidiano de las familias en torno a la preparación de alimentos, atención de la salud y al mantenimiento de la historia familiar. En sintonía con la heterogeneidad cultural del territorio en estudio y de las diferentes corrientes migratorias que ocurrieron, surge el cultivo de variedades de hortalizas ligadas a diferentes regiones. En cuanto a tradiciones italianas, o portuguesas el cultivo y conservación de grilo (Brassica napus), cardella (Sonchus oleraceus), o alcaucil (Cynara cardunculus) se vinculan con su uso culinario:

"e' un poco más amargo, esto cocinado son...esto límpielo un poco, lo hiervo un poco, le corta lo que no sirve, y hace con harina una milanesa, o sino relleno, le saca, lo corta sí y después le pone algo de una albóndiga de carne, lo pone en un cosa chica con un poco de aceite y listo. Nosotros comimos el otro día fideos con alcaucil, lo limpia y después lo corta donde está tierno, lo saca y fideos con alcaucil." (Bonicatto 2011c. Entrevista a JP).

Al igual que en el caso antes descripto, a partir de la incorporación en el CHP de agricultores y agricultoras bolivianos, se establecen nuevos cultivos hortícolas o nuevas etnovariedades conservadas para el mantenimiento de sus tradiciones y hábitos culinarios:

"hago los tamales, son la mazorca de maíz que ya esta duro, le pasa un tipo de proceso para pelarle y sacar la cáscara, fino y lo que queda afuera la chalita la hace secar y cuando le muelen, le hace la preparación con la chalita le envuelve redondito" (Bonicatto 2014i. Entrevista a S)

El trabajo de Domínguez (2008) reflexiona sobre la "erosión cultural" que viven los agricultores que inmigraron desde Bolivia. Esta autora sostiene que esta fue acentuada por la necesidad de incorporar valores de la sociedad moderna y urbana. En este contexto, los migrantes encontraron diferencias respecto de la forma de producción de sus lugares de origen que habían abandonado por las nuevas formas propuestas por patrones y vendedores de insumos. En tanto el trabajo de Castro (2016) habla de que las actividades, prácticas y saberes de los agricultores y agricultoras bolivianos, cuando eran realizados en su tierra natal, estaban vinculados a una concepción holística de la agricultura, como un complejo donde se tenía una comprensión del proceso completo. En el contexto descripto, la conservación de cultivos vinculados a las tradiciones y lugares de origen, se posicionan como resistencias frente a la homogeneización del modelo 
preponderante. Estos criterios, son comúnmente aquellos que perduran más en el tiempo, ya que inclusive continúan en la familia a través de los recuerdos y relatos, aún en ausencia del material genético necesario para su concreción. Este saber guardado en la memoria, permite que ante la recuperación del material reproductivo, se ponga en juego el conocimiento, para sembrar la semilla deseada y reactivar el saber y la práctica.

En tanto, las semillas obtenidas de instituciones, así como aquellas de resiembra espontánea, están ligadas principalmente al criterio innovador (C) (14 citas $=40 \%$ ) y (3 citas $=37,5 \%$ ) respectivamente. Este motivo representa la inquietud o curiosidad por probar el cultivo de nuevas semillas hortícolas, lo cual es una actitud fundamental para el ingreso de agrobiodiversidad a través de estas vías alternativas. Por último, las semillas conservadas cuyo ingreso se dio a través de la vía oportunista, recolección en el mercado, verdulerías, espacios públicos, sustentada por el criterio culinario (B) (6 citas= 40\%), y económico (I) (3 citas $=20 \%$ ), expone una práctica de subsistencia ligada al ahorro de dinero para la alimentación diaria.

Las variaciones en los criterios que sustentan la conservación de semillas de diferentes orígenes, expresan el complejo trasfondo de la conservación llevada adelante por los agricultores familiares. Se establece la variable del origen de las semillas como necesaria para la planificación de estrategias que permitan avanzar hacia una conservación de semillas in situ que promueva la soberanía alimentaria de los agricultores y agricultoras.

\subsubsection{Pluricriterios en la conservación de semillas}

El análisis previo evidenció que para algunos registros, los agricultores y agricultoras utilizan más de un criterio de conservación. Por lo tanto, en este apartado, se propuso indagar en la utilización de pluricriterios según el origen de la semilla.

Al analizar la cantidad de criterios que sustentan la conservación de semillas de acuerdo al origen de las mismas (Tabla 5), surgen datos interesantes. Por un lado, que los mayores porcentajes (I: 50\%; II: 41,7\%; III: 47,6\%; IV: 70\%), se encuentran en la presencia de un criterio por cada registro de planta cultivada conservadas, salvo en la categoría $\mathrm{V}$ : 0 . la existencia del uso de más de un criterio en todas las categorías de ingreso y otro, que aquellas semillas obtenidas por vínculos informales, son las únicas, aunque con un bajo porcentaje, que presentan 4 criterios de conservación (5,2\%), por lo tanto el 5,2\% de los registros de plantas conservadas en esta categoría son conservadas mediante 4 criterios. Ejemplo de las hortalizas conservadas por 4 criterios son, el alcaucil ñato (Cynara cardunculus) conservado por LP por los criterios afectivo, morfológico, culinario y medicinal. 
Esta característica puede estar relacionada al tiempo que hace que estas semillas son parte de la vida e historia de las familias agricultoras. Tiempo que implica un vínculo entre los agricultores y la naturaleza. Otro ejemplo, es la chaucha metro (Vigna unguiculata subsp. sesquipedalis) conservada por los criterios innovador, económico, culinario y morfológico. Este cultivo es conservado por diversos integrantes de una misma familia. Estos ejemplos dan cuenta de las diversas fusiones entre los criterios, tan particulares como cada interlocutor.

Estos resultados, describen la utilización de criterios ligados a difentes dimensiones (económica, sociocultural y ecológica) en relación a la conservación de un mismo cultivo. Desde la perspectiva agroecológica, el empleo de pluricriterios se entiende como un facilitador de la permanencia de la conservación in situ, dado que cada criterio empleado resulta en un motivo que acciona para la conservación.

\begin{tabular}{l} 
Tabla 5: Pluricriterios en la conservación de semillas expresada en porcentajes \\
según las diferentes vías de ingreso. \\
\begin{tabular}{|l|c|c|c|c|c|}
\hline $\begin{array}{l}\text { Criterios de conservación } \\
\text { empleados }\end{array}$ & I & II & III & IV & V \\
\hline 1 criterio & 50 & 41,7 & 47,6 & 70 & 0 \\
\hline 2 criterios & 38,7 & 40 & 19 & 10 & 100 \\
\hline 3 criterios & 5 & 11,3 & 28,6 & 20 & 0 \\
\hline 4 criterios & 0 & 5,2 & 0 & 0 & 0 \\
\hline I: Compradas en comercios. & III: Instituciones & V: Resiembra espontánea \\
II: Vínculos interpersonales & IV: Oportunista & &
\end{tabular} \\
\hline
\end{tabular}

\subsubsection{Hortalizas ¿para quién?}

Según la definición de agricultura familiar propuesta por el Elverdín et al., (2005) en el capítulo 1.1.4, la producción obtenida se dirige tanto al autoconsumo como al mercado. Esta particularidad se ve reflejada en los datos obtenidos en la Figura 18 donde el mayor porcentaje $(75 \%)$ pertenece a la conservación de semillas de cultivos hortícolas que se destinan tanto al consumo de la familia como a la venta. Esta información no llama demasiado la atención dada la propia caracterización de los actores involucrados, sin embargo las siguientes dos categorías, minoritarias en su cuantificación, ponen en discusión dos aspectos importantes. Por un lado que los agricultores familiares cultivan hortalizas solo para autoconsumo (17\%) las cuales provienen de semillas locales. El objetivo del cultivo y conservación de estas hortalizas, es satisfacer los gustos y demandas internas de la familia. Estos cultivos están directamente ligados a la soberanía alimentaria ya que son la plena expresión de sus deseos y tradiciones. 
Por otro lado, se ve que hay agricultores que cultivan hortalizas para satisfacer los gustos y demandas externas (8\%), hortalizas que no son incluidas en sus hábitos de uso y consumo, pero que al tener un mercado definido son incluidos en las producciones.

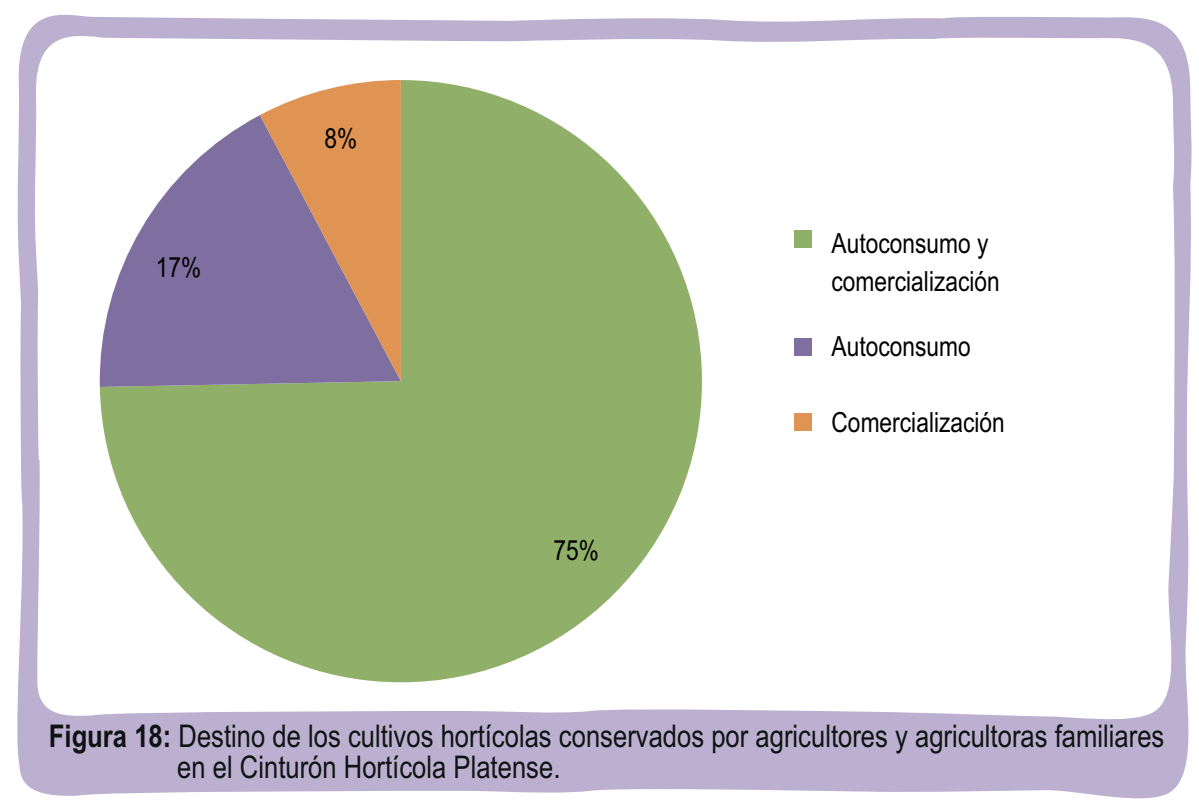

\subsubsection{Agrobiodiversidad "oculta"}

Para el análisis de este punto se consideró la agrobiodiversidad conservada destinada al autoconsumo. Es así que 16 de los 26 interlocutores mencionaron mantener algunos cultivos con este fin (Figura 19). Los 43 cultivos hortícolas mencionados corresponden a 18 géneros, 21 especies y 38 etnotaxa (Tabla 6). Cultivos tales como el maní (Arachis hypogaea), el yacón (Smallanthus sonchifolius); el tomate verde vestido (Physalis ixocarpa), el zapallo plomo (Cucurbita maxima subsp. máxima), la cucuza (Lagenaria siceraria); el tomate platense (Solanum lycopersicum) entre otros, son ejemplo de la diversidad que conservan los agricultores y agricultoras para su consumo familiar. Esta diversidad, al no incorporarse a la esfera de producción para el mercado, está en muchos casos invisibilizada. En el caso de otros cultivos como el tomate platense desde hace unos años, se está trabajando sobre su conservación y difusión de la mano de proyectos de promoción de variedades hortícolas locales coordinados por la UNLP y el INTA.

Es casi inevitable preguntarse ¿Por qué se están conservando estos cultivos en un territorio mercantilizado que tiende a la homogeneización de la agrobiodiversidad? La Tabla 6 detalla los cultivos registrados y los criterios por los cuales se conserva cada uno de ellos. Los criterios afectivo (14\%), culinario (33\%) e innovador (29\%) son los más presentes (Figura 20). Los criterios relacionados a los afectos y tradiciones de la mano 
con el quehacer culinario, se establecen como las principales motivaciones para la conservación de esta agrobiodiversidad. Inclusive en estos criterios se manifiesta la tradición productiva de los horticultores que llegaron a la zona con las primeras inmigraciones europeas. Las hortalizas que refieren a sus lugares de origen, son símbolo de su historia y en función de esta es que se continúan conservando: "Esa (refiriéndose al cultivo de cucuza (Lagenaria siceraria)) hace años (que la conserva), siempre acá algún paisano tuvo, porque ésta allá (en Italia) es la que más se vende, especialmente en Sicilia. Lo que pasa es que acá no la quieren" (Bonicatto 2011c. Entrevista a JP).

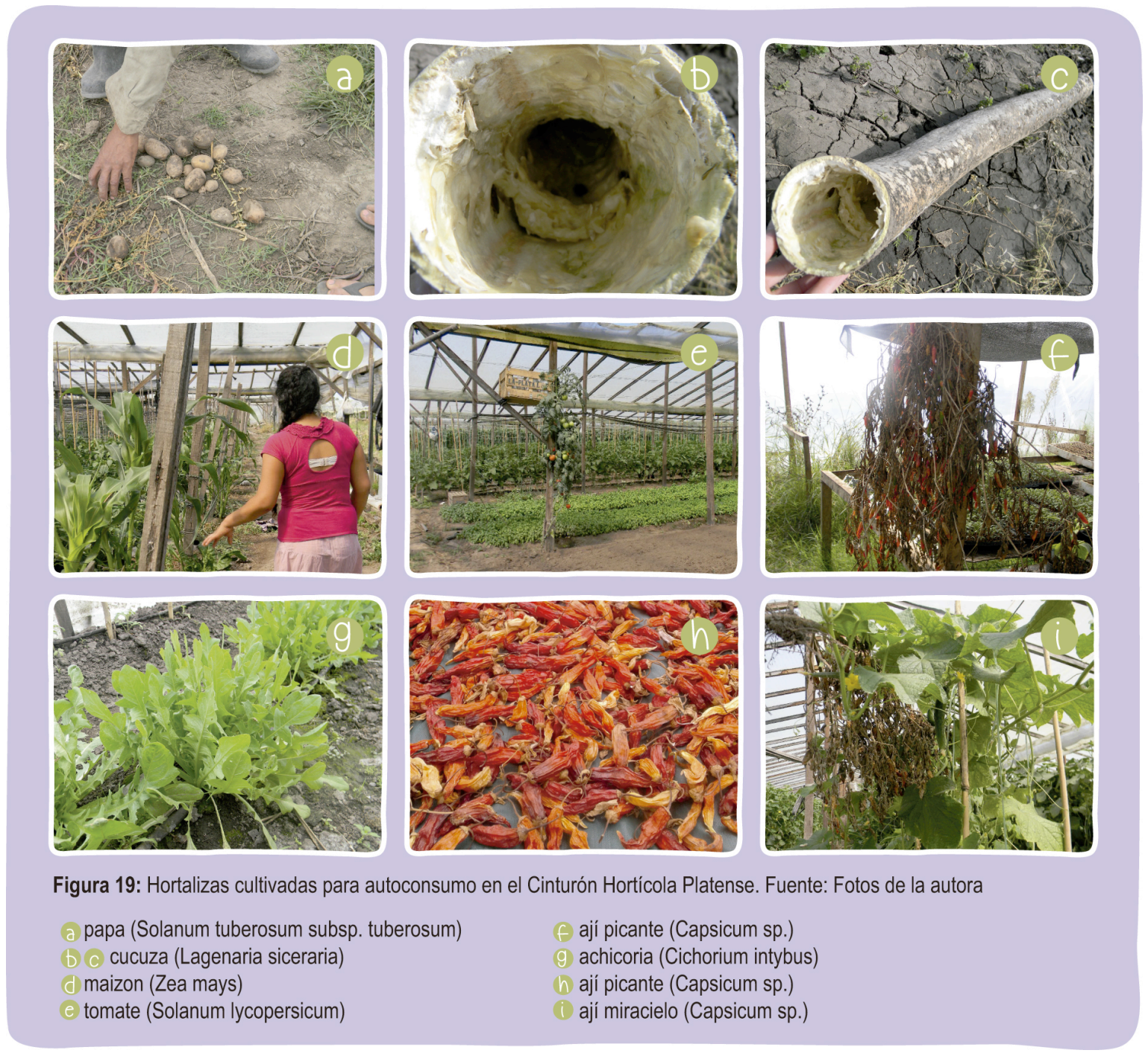

Cultivos característicos de países limítrofes como Bolivia comienzan a formar parte de la agrobiodiversidad presente en el Cinturón Hortícola Platense. En este caso una variedad de maíz llamada maizón (Zea mays) cultivado para hacer humita, un plato típico de la cocina andina, para el cual usan tanto los granos del maíz como la chala, y que según los 
agricultores y agricultoras, no lo pueden cocinar con las variedades comerciales que cultivan para la venta:

"maizón ponemos pero solo para consumo de nosotros. El maizón es el maíz grande, choclo grande, que es más carnoso, los granos son más grandes y no son tan aguados y con eso hacemos humita" (Bonicatto 2014i. Entrevista a S).

En tanto el criterio innovador expresa la voluntad de experimentar con nuevos cultivos, de incorporar aquello que se buscaba, se había perdido o sólo por inquietud despertada a través de lo nuevo o desconocido:

“invento, invento. Veo una verdura, una fruta extraña viste....averiguo de dónde viene, cómo viene y la compro y listo, para hacer los experimentos. Ahora estaba viendo allá...una boliviana, que tiene una cosa, es una rosca así, como papa viste, y esa la iba a comprar el año pasado y no la compré, no, no, no tenía la plata" (Bonicatto 2010b. Entrevista a JL).

Esta búsqueda puede estar ligada a variedades locales conservadas en manos de los agricultores como el yacón o el maní colorado y en otros casos a cultivos de origen comercial como la papa o la cebolla, los cuales se incorporan a las producciones en muchos casos a fin de disponer de ingredientes de amplio uso en las comidas locales. Según Pochettino et al. (2011), las semillas de autoproducción son parte de la identidad del agricultor y, por lo tanto, la expresión de su pueblo y de su vida. Estas autoras sostienen que los cultivos ligados a las familias, expresan en sí mismos, el vínculo estrecho entre las personas y el ambiente, y al perdurar en la esfera familiar, se constituyen en un reservorio tanto de material genético como de los saberes. La actitud innovadora de los agricultores y agricultoras familiares del Cinturón Hortícola Platense se pone en práctica, a fin de experimentar en la búsqueda de estrategias que les permitan cultivar aquellas hortalizas que responden a sus gustos y deseos. Estos cultivos destinados al autoconsumo, son utilizados para elaborar platos tradicionales, o ser parte de la cocina diaria de las familias, en donde se movilizan y relocalizan saberes y prácticas productivas y culinarias. Si bien la globalización homogeniza las diferencias acercando alimentos entre distintos países, al mismo tiempo genera una valoración de características locales y de procesos endógenos en donde se "intensifican" las culturas, reafirmándose las identidades de determinados grupos sociales (Novo da Silva et al., 2013). 


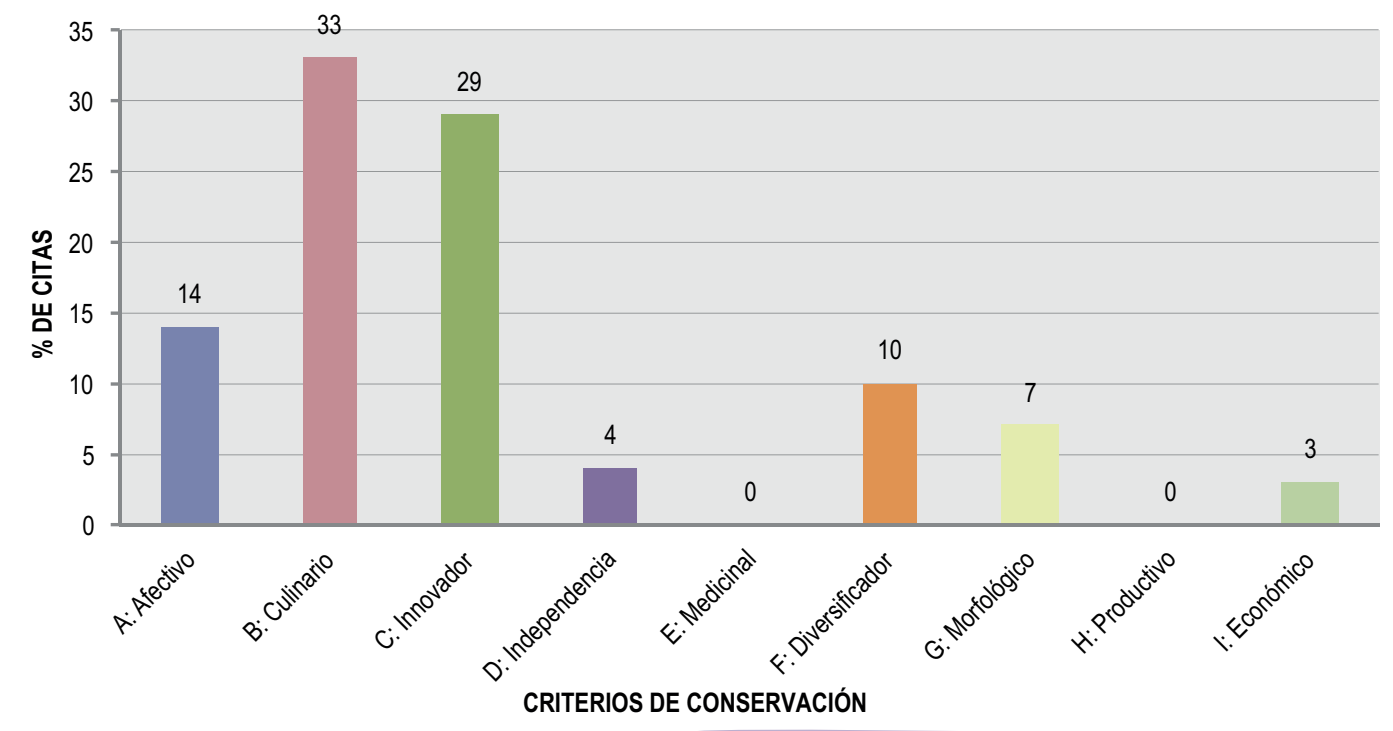

Figura 20: Criterios de conservación de hortalizas cultivadas para autoconsumo en el Cinturón Hortícola Platense.

En definitiva, el mantenimiento de esta agrobiodiversidad se vincula con las tradiciones culinarias, los afectos y la actitud innovadora de los agricultores y agricultoras. Estos dos componentes (hortalizas y saberes) interactúan en pos de conservar esta diversidad biocultural que permanece oculta a la mirada mercantil del territorio en el cual se encuentra. 
Tabla 6: Criterios que sustentan la conservación de hortalizas cultivadas para autoconsumo. (A) afectivo, (B) culinario, $(C)$ innovador, (D) independencia, $(E)$ medicinal, $(F)$ diversificador, $(G)$ morfológico, $(H)$ productivo, (I) económico.

\begin{tabular}{|c|c|c|c|c|c|c|c|c|c|c|c|c|}
\hline & Nombre científico & Nombre local & Familia botánica & A & B & C & D & $\mathbf{E}$ & $\mathbf{F}$ & G & $\mathrm{H}$ & I \\
\hline AT & Armoracia rusticana & Crin & Brassicaceae & * & * & & & & & & & \\
\hline BIS & Zea mays & Maíz enanito & Poaceae & * & * & & & & & & & \\
\hline CV & Smallanthus sonchifolius & Yacón & Asteraceae & & & * & & & * & & & \\
\hline CV & Zea mays & Choclo & Poaceae & & & & & & & & & \\
\hline DY & Zea mays & Maíz rojo & Poaceae & * & * & & & & & & & \\
\hline ES & Zea mays & Maices & Poaceae & & & * & & & * & & & \\
\hline ES & Cucurbita sp. & Zapallo de angola & Cucurbitaceae & & & * & & & * & & & \\
\hline ES & Helianthus annus & Girasol & Asteraceae & & & * & & & * & & & \\
\hline ES & Arachis hipogaea & Maní colorado & Fabaceae & & & * & & & * & & & \\
\hline ES & Allium tuberosum & Tare o puerro japonés & Alliaceae & & & * & & & * & & & \\
\hline ES & Physalis ixocarpa & Tomate verde vestido & Solanaceae & & & & & & & & & \\
\hline $\mathrm{HC}$ & Allium cepa var. cepa & Cebolla & Alliaceae & & & & & & & & & \\
\hline $\mathrm{HC}$ & Beta vulgaris var. cicla & Acelga & Chenopodiaceae & & & & & & & * & & \\
\hline $\mathrm{HC}$ & Cucumis melo & Melón & Cucurbitaceae & & & * & & & & * & & \\
\hline $\mathrm{HC}$ & Solanum lycopersicum & Tomate platense & Solanaceae & & & & & & & * & & \\
\hline IG & Zea mays & Choclito & Poaceae & & * & & & & & & & * \\
\hline IG & Cucurbita ficifolia & Acayote & Cucurbitaceae & & * & & & & & & & \\
\hline IG & Cucurbita maxima subsp. maxima & Zapallo plomo & Cucurbitaceae & & * & & & & & & & \\
\hline IG & Cucurbita pepo & Zapallo anco & Cucurbitaceae & & * & & & & & & & \\
\hline IG & Phaseolus vulgaris var. vulgaris & Chaucha & Fabaceae & & * & & & & & & & \\
\hline$J P$ & Cichorium intybus & Achicoria & Asteraceae & & & * & & & * & & & \\
\hline JP & Lagenaria siceraria & Cucuza & Cucurbitaceae & * & * & & & & & & & \\
\hline JP & Foeniculum vulgare & Hinojo & Apiaceae & & * & & & & & & & \\
\hline MS & Zea mays & Maizón & Poaceae & * & * & * & & & & & & \\
\hline NA & Sechium edule & Papa del aire & Cucurbitaceae & & & * & & & & & & \\
\hline NG & Cichorium intybus & Achicoria & Asteraceae & * & * & * & & & & * & & \\
\hline NG & Solanum lycopersicum & Tomate perita & Solanaceae & & * & * & & & & & & \\
\hline NG & Capsicum annuum & Ají de la mala palabra & Solanaceae & & * & & & & & * & & \\
\hline PA & Zea mays & Maizón amarillo & Poaceae & * & * & * & & & & & & \\
\hline PA & Capsicumsp. & Ají picante & Solanaceae & & * & & & & & & & \\
\hline PA & Capsicumsp. & Ají verde & Solanaceae & & * & & & & & & & \\
\hline PA & Solanum lycopersicum & Tomate perita & Solanaceae & & & & & & & & & * \\
\hline S & Zea mays & Maíz blanco & Poaceae & * & * & & & & & & & \\
\hline S & $\begin{array}{l}\text { Solanum tuberosum subsp. } \\
\text { tuberosum }\end{array}$ & Papa & Solanaceae & & * & * & & & & & & \\
\hline SV & Zea mays & Choclo & Poaceae & * & * & & & & & & & \\
\hline SV & Capsicum sp. & Ají miracielo & Solanaceae & * & * & & & & & & & \\
\hline SV & Cucurbita pepo & Calabaza batata & Cucurbitaceae & & * & * & & & & & & \\
\hline SV & Allium cepa var. cepa & Cebolla roja & Alliaceae & & * & * & & & & & & \\
\hline SV & $\begin{array}{l}\text { Solanum tuberosum subsp. } \\
\text { tuberosum }\end{array}$ & Papa & Solanaceae & & * & * & & & & & & \\
\hline $\mathrm{CA}$ & Brassica napus & Nabiza & Brassicaceae & & & * & & & & & & \\
\hline NA & Capsicum sp. & Ají campanita & Solanaceae & & & * & * & & & & & \\
\hline NA & Capsicum sp. & Ají redondito picante & Solanaceae & & & * & * & & & & & \\
\hline \multirow[t]{2}{*}{ NA } & Foeniculum vulgare & Hinojo & Apiaceae & & & * & * & & & & & \\
\hline & \multicolumn{3}{|l|}{ Total de menciones } & 10 & 24 & 21 & 3 & 0 & 7 & 5 & 0 & 2 \\
\hline
\end{tabular}




\subsection{Conclusiones}

La complejidad que otorgan los agricultores familiares a los motivos por los cuales conservan determinadas semillas, se relaciona con distintas dimensiones (económica, ecológico productiva y sociocultural) de la vida de las familias agricultoras. Es a través de estos criterios, que es posible interpretar los momentos vinculados al hogar, su economía, la salud y tradiciones. A su vez, expresan las coyunturas actuales y nos permiten ser testigos de cómo, aun en presencia de un contexto desfavorable, que presiona para la desaparición de aquellos cultivos sin "lugar" en el mercado concentrador, los agricultores y agricultoras del Cinturón Hortícola Platense mantienen dinámico el cultivo y la autoproducción de hortalizas que responden a sus gustos y tradiciones y permanecen "ocultas" ante una mirada productivista del territorio. En este contexto, se retoma la idea de entender a los cultivos producidos y conservados para autoconsumo como "resistencias" frente a las presiones del modelo productivo imperante, al romper con los criterios de homogeneización, desestacionalización y deslocalización, de la alimentación industrial. Por tanto, estos datos indican la existencia recursos genéticos "ocultos" cultivados por los agricultores familiares del Cinturón Hortícola Platense".

La confluencia de estos criterios y la agrobiodiversidad que los expresa, representa la soberanía alimentaria de las familias. Un punto importante a ser considerado es la movilidad en cuando al criterio comercial, este criterio que opera sobre toda la agrobiodiversidad cultivada, establece que ante la posibilidad de venta, estas hortalizas cambien de destino, pasando a destinarse tanto al autoconsumo como a la comercialización.

A su vez, en este territorio dinámico, la actitud innovadora de los agricultores y agricultoras familiares se expande y pone en práctica, a fin de experimentar en la búsqueda de estrategias que les permitan sostenerse en el ámbito de la producción de hortalizas. Es así que el criterio innovador se fusiona con un criterio económico y morfológico a fin de conservar semillas comerciales. A pesar de que en este caso, el fin último de la innovación, sea la funcionalidad hacia el mercado, la presencia del criterio innovador marca la apropiación de estas semillas a través de la experimentación y la práctica.

Así como la agrobiodiversidad no es estática, tampoco lo son los criterios ligados a su conservación. Por lo tanto, los motivos por los cuales los agricultores y agricultoras elijen conservar la agrobiodiversidad irán cambiando a lo largo del tiempo, junto con las tradiciones, hábitos alimenticios y agrobiodiversidad disponible para ser cultivada. En esta incorporación de la variable tiempo, los criterios ligados a la historia, afectos, recetas 
de cocina y salud, encuentran su existencia. La conservación de agrobiodiversidad de origen comercial, en tanto se mantenga ligada a factores externos como el precio y demanda del mercado, será interrumpida cuando estos motivos no estén presentes.

En este sentido, el "accionar individual" es una perspectiva importante de estudiar, al ser los individuos -y no las sociedades- los que manipulan las plantas y, por lo tanto, accionan hacia la permanencia $o$ no de los conocimientos en torno a la agrobiodiversidad.

Los resultados obtenidos sugieren la utilización de diferentes criterios que operan sobre la conservación de semillas hortícolas en el territorio en estudio, y sugieren la variación de los criterios de conservación según el origen de la semilla conservada. A su vez, dan cuenta de la utilización de criterios afectivos y culinarios como motivo de la conservación de agrobiodiversidad hortícola.

Nuevos interrogantes surgen para profundizar en la conservación de agrobiodiversidad hortícola ¿Qué saberes están sustentando la conservación de estas hortalizas? ¿Qué rol cumple el accionar individual en un territorio complejo?

Como se dijo al inicio de este capítulo, uno de los desafíos actuales que tiene la agroecología es definir aquellos principios que expliquen la resiliencia socioecológica de los agroecosistemas diversificados. Las conclusiones aquí presentadas abren un escenario para continuar profundizando sobre aquellas prácticas y principios en torno a la práctica de conservación de semillas, y cómo éstos pueden resultar elementos para fortalecer la resiliencia de los agroecosistemas familiares y, por ende, su sustentabilidad. 


\subsection{Bibliografía}

Aguirre P. 2010. Ricos Flacos y gordos pobres. La alimentación en crisis. Buenos Aires: Capital Intelectual.

Almekinders, C.J.M.; N.P. Louwaars \& G.H. de Bruijn. 1994. Local seed systems and their importance for an improved seed supply in developing countries. Euphytica 78: 207-216

Altieri, M.A. \& P. Koohafkan. 2008. Enduring farms: climate change, smallholders and traditional farming communities. Environment and Development Series 6. Penang. Thisrd World Network.

Amorozo, M.C.M.; M. Cultrera \& T. Mota Miranda. 2008. Ethnobotanical studies in small-scale agriculture: Local knowledge and maintenance of agricultural diversity, en: U.P. Albuquerque \& M. Alves Ramos (editores). Current Topics in Ethnobotany 81-99. Kerala, Research Sinpost. India.

Bellon, M.R. \& J. Risopoulos. 2001. Small-Scale Farmers Expand the Benefits of Improved Maize Germplasm: A Case Study from Chiapas, Mexico. Wold Development 29 (5): 799-811.

Berkes, F.; J. Colding, \& C. Folke. 2000. Rediscovery of Traditional ecological knowledge as adaptive management. Ecological Applications 10: 1251-1262.

Berkes, F. \& N.J. Turner. 2006. Knowledge, learning and the Evolution of Conservation Practice for Social-Ecological System Resilience. Human Ecology 34 (4): 479-494.

Bisht, I.S.; S.R. Pandravada, J.C. Rana, S.K. Malik, Archna Singh, P.B. Singh, Firoz Ahmed \& K.C. Bansal. 2014. Subsistence farming, Agrobiodiversity, and Sustainable Agriculture: A case Study. Agroecology and Sustainable Food Systems 38: 890-912.

Blandi, M.L.; M.S. Cavalcante; N.A. Gargoloff \& S.J. Sarandón. 2016. Prácticas, conocimientos y percepciones que dificultan la conservación de la agrobiodiversidad. El caso del Cinturón Hortícola Platense, Argentina. Cuadernos de Desarrollo Rural, 13 (78): $97-122$

Bonicatto, M.M.; V. Fernández, N.G. Gargoloff, M. Marasas, L. Muscio, M. Pérez \& M.L. Pochettino. 2010. Sembrando Esperanza. III Feria Provincial de Semillas Nativas y Criollas. En defensa de la vida de la soberanía alimentaria. Por una 
economía solidaria, construyendo la casa de todos. Ediciones INTA. Publicaciones IPAF- Región Pampeana. La Plata, Argentina.

Brush, S.B. 1992. Reconsidering the green revolution: Diversity and stability in cradle areas of crop domestication. Human Ecology 20 (2): 145-167.

Cababié, J.; M.M. Bonicatto \& E.A. Abbona. 2015. Semillas y saberes de los agricultores familiares. ¿Cuál es el rol de las ferias de intercambio en su reproducción y conservación? Revista Facultad de Agronomía La Plata 114 (Núm. Esp.1) Agricultura Familiar, Agroecología y Territorio: 122-128.

Carpenter, D. 2005. The In Situ Conservation of Rice Plant Genetic Diversity: A Case Study from a Philippine Barangay. Agriculture and Human Values 22 (4): 421-434.

Castro, A. S. 2016. Saberes migrantes. Trayectorias de productores bolivianos del periurbano platense (Tesis de grado). Presentada en Universidad Nacional de La Plata. Facultad de Humanidades y Ciencias de la Educación para optar al grado de Licenciada en Sociología. Disponible en:

http://www.memoria.fahce.unlp.edu.ar/tesis/te.1295/te.1295.pdf

Cieza, R.I.; G. Ferraris, C. Seibane, G. Larrañaga \& L. Mendicino. 2015. Aportes a la caracterización de la Agricultura Familiar en el partido de La Plata. Revista Facultad de Agronomía 114 (3): 129-142.

Díaz-Bautista, M.; B.E. Herrera-Cabrera, J. Ramírez-Juárez, M. Aliphat-Fernandez \& A. Delgado-Alvarado. 2008. Conocimiento campesino en la selección de variedades de haba (Vicia fava L.) en la sierra norte de Puebla México. Interciencia 33 (8): 610-615.

Domínguez, P. 2008. El contexto cultural en la implementación de proyectos de desarrollo rural. El caso de Parque Pereyra Iraola. Mundo Agrario 9, 17. Disponible en: http://www.mundoagrario.unlp.edu.ar/article/view/v09n17a10/918.

Elias, M.; L. Rival, \& D. McKey. 2000. Perception and management of cassava (Manihot esculenta CRANTZ) diversity among Makushi Amerindians of Guyana (South America). Journal of Ethnobiology 20 (2): 239-265.

Elverdín, J.; J. Catalano, F. Cardozo, D. Ramilo, G. Tito, R. Cittadini, G. Giordano, M. Gómez, C. Paulizzi, D. Alcoba, M.E. Aradas, J. Braña, L. Bilbao, G. Cap, S. Dumrauf, C. Golsberg, A. López, A. Maggio, M. Marasas, V. Mazacotte, G. Prividera, M. Quiroga Mendiola, D. 
Setta, N. Sosa Rolón \& F. Videla. 2005. La Pequeña Agricultura Familiar en Argentina: Problemas, oportunidades y líneas de acción. Programa Nacional de Investigación y Desarrollo Tecnológico para la Pequeña Agricultura Familiar (PNPAF) del INTA. Disponible en: http://agro.unc.edu.ar/ extrural/Elverdin.pdf [consulta noviembre de 2015].

Eyssartier, C. A.H. Ladio \& M. Lozada. 2011. Traditional horticultural knowledge change in a rural population of the Patagonian steppe. Journal of Arid Environments. 75: 7886.

Garat, J.J. 2002. Tomate platense en La Plata, Argentina. Biodiversidad № 34: 19-21.

Garat, J.J.; A. Ahumada, J. Otero, L. Terminiello, G. Bello \& M.L. Champagna. 2009. Las hortalizas típicas locales en el cinturón verde de La Plata: Su localización, preservación y valorización. Horticultura 28 (66): 32-39.

Garat, J.J.; A. Castro, S. Gramuglia, A. Nico \& A. Ahumada. 2007. El rescate de la biodiversidad local y la acción colectiva: una estrategia de desarrollo a través de la revalorización de hortalizas locales en el cinturón verde de La Plata, Buenos Aires, Argentina. Revista Brasileira de Agroecologia 2 (1): 430-434.

Henao, A. 2013. Propuesta metodológica de medición de la resiliencia agroecológica en sistemas sócio-ecológicos: un estúdio de caso en los Andes Colombianos. Agroecología 8 (1): 85-91.

Hilgert, N.I; F. Zamudio, V. Furlan \& L. Cariola. 2013. The Key Role of Cultural preservation in Maize Diversity Conservation in the Argentine Yungas. Evidence-Based Complementary and Alternative Medicine. Article ID 732760, Doi: $10.1155 / 2013 / 732760$.

Jiménez-Escobar, N.D., U.P. Albuquerque \& J.O, Rangel-Ch. 2011. Huertos familiares en la Bahía de Cispatá, Córdoba, Colombia. Bomplandia 20(2): 309-328.

Kiple, K. \& K.C. Ornelas. 2000. The Cambridge World History of Food. Volume 2. Inglaterra: Cambridge University Press.

Kraft, K.H.; J.J. Luna-Ruíz \& P. Gepts. 2010. Different Seed Selection and Conservation Practices for Fresh Market and Dried Chile Farmers in Aguascalientes, México. Economic Botany 64 (4): 318-328. 
Ladio, A.H. 2011. Traditional knowledge of edible wild native and exotic plants in the context of cultural change in human populations of arid Patagonia. Bioremediation, Biodiversity and Bioavailability. 5: 81-84.

May, M.P.; S.G. Fauret, I. Ciocchini, A. Ahumada \& M.M. Bonicatto. 2017. Cultivos tradicionales y saberes culinarios en el cinturón hortícola de La Plata, Argentina. Su rol en la conservación de agrobiodiversidad. Actas del VI Congreso Latinoamericano de Agroecología X Congreso Brasileiro de Agroecología y V Seminario de Agroecología del Distrito Federal y Región. 10 al 15 de septiembre de 2015. Brasilia. Brasil.

McGuire, S.; M, Gigi \& L. Sperling. 2003. Technical and Institutional Issues in Participatory Plant Breeding-Done from a Perspective of Farmer Plant Breeding. A Global Analysis of Issues and Current Experience. PPB Monograph N². PRGA. 124 Pp.

Montañez-Escalante, P.I.; M.d.R. Ruenes-Morales; M. Monserrat Ferrer-Ortega \& H. Estrada-Medina. 2014. Los huertos familiares Maya-Yucatecos: Situación actual y perspectivas en México. Revista ambienta 107: 100-109.

Muchnik, J. 2006. Identidad territorial y calidad de los alimentos: procesos de calificación y competencias de los consumidores. Agroalimentaria 22: 89-98.

Nicholls Estrada, C.I. 2013a. Enfoques agroecológicos para incrementar la resiliencia de los sistemas agrícolas al cambio climático, en: C.I. Nicholls Estrada.; L.A. Ríos Osorio \& M.A. Altieri (editores). Agroecología y resiliencia socioecológica: adaptándose al cambio climático. REDAGRES-SOCLA. Colombia. 1:18-29.

Nicholls Estrada, C.I. 2013b. Prólogo en: C.I. Nicholls Estrada.; L.A. Ríos Osorio \& M.A. Altieri (editores). Agroecología y resiliencia socioecológica: adaptándose al cambio climático. REDAGRES-SOCLA. Colombia. IX-X.

Novo Da Silva, F.; L. Schwartz \& R. Menasche. 2013. O tradicional e o moderno na alimentação de famílias rurais pomeranas: práticas em ressignificação. Revista Facultad de Agronomía 112: 93-102.

Nuñez, M.G. \& C. Traglia. 2015. Saberes y prácticas locales relacionadas a cultivos de autoconsumo entre pequeños productores tabacaleros de Colonia San Miguel, El Soberbio. Jornadas de Investigadores. Secretaría de Investigación y Postgrado. FHyCS-UNaM. ISSN 2469-0678 
Paleologos, M.F.; M.J. lermanó; M.L. Blandi \& S.J. Sarandón. 2017. Las relaciones ecológicas: un aspecto central en el rediseño de agroecosistemas sustentables, a partir de la Agroecología. Revista do Desenvolvimento Regional 22: 92- 92.

Peroni, N. \& N. Hanazaki. 2002. Current and lost diversity of cultivated varieties, especially cassava, under swidden cultivation systems in the Brazilian Atlantic Forest. Agriculture, Ecosystems and Environment 92: 171-183.

Pirachicán Avila, E. 2015. Autonomía alimentaria en sistemas agrícolas ecológicos y convencionales en Anolaima (Cundinamarca). Tesis presentada como requisito parcial para optar al título de Magister en Medio Ambiente y Desarrollo. Universidad nacional de Colombia. Instituto de Estudios Ambientales

Pochettino, M.L.; P. Arenas, D. Sánchez \& R. Correa. 2008. Conocimiento botánico tradicional, circulación comercial y consumo de plantas medicinales en un área urbana de Argentina. Boletín Latinoamericano y del Caribe de Plantas Medicinales 7 (3): 141-148.

Pochettino, M.L., V. Fernández, N.A. Gargoloff, L. Muscio, L. Pérez, L. González Espinosa, M.M. Bonicatto, M. Pérez, A. Cremaschi, E. Barreto, M.P. May, J. Cababié, \& M.E. Marasas. 2011. I Feria Nacional, IV Feria Provincial de Semillas Nativas y Criollas. "Sembrando Esperanza". Buenos Aires, Ed. INTA.

Pochettino, M.L. \& V. Lema. 2008. La variable tiempo en la caracterización del conocimiento botánico tradicional. Darwiniana. 2008, 46 (2). P.277-239

Reyes García, V. 2009. Conocimiento ecológico tradicional para la conservación: dinámicas y conflictos. Papeles 107: 39-105

Richeri, M.; Cardoso, M.B. \& A.H. Ladio. 2013. Soluciones locales y flexibilidad en el conocimiento ecológico tradicional frente a procesos de cambio ambiental: estudios de caso en Patagonia. Ecología Austral 23:184-193.

Salazar-Barrientos, L. d L.; Magaña-Magaña, M.A.; Aguilar-Jiménez, A.N. \& M.F. Ricalde-Pérez. 2016. Factores socio económicos asociados al aprovechamiento de la agrobiodiversidad de la milpa en Yucatán. Ecosistemas y Recursos Agropecuarios 3 (9): 391-400.

Silveira, R.P. 2015. Diversidade de variedades crioulas de tomates conservadas por camponeses no Municipio de Anchieta, oeste de Santa Catarina. Universidade Federal 
de Santa Catarina. Programa de Pósgraduação en agroecosistemas. 197 pp. Disponible en: https://repositorio.ufsc.br/handle/123456789/156749.

Swift M.J.; M.N. Izac \& M. van Noordwijk. 2004. Biodiversity and ecosystem services in agricultural landscapes_are we asking the right questions? Agriculture, Ecosystems and Environment 104 (2004) 113-134.

Thomas, E., I. Vanderbroek, P. Van Damme, P. Goeghebeur, D. Douterlungne, S. Sanca \& S. Arrazola. 2009. The relation between accessibility, diversity and indigenous valuation of vegetation in the Bolivian Andes. Journal of Arid Environments 73: 854-861.

Toledo, V. 1992. What is ethnoecology? Origins, scope, and implications of a rising discipline. Etnoecológica 1: 5- 21

Tomkins, E.L. \& W.N. Adger. 2004. Does Adaptive Management of Natural Resources Enhance Resilience to Climate Change? Ecology and Society 9(2): 10.

Tripp, R. 1996. Biodiversity and modern crop varieties: Sharpening the debate. Agriculture and Human Values 13(4): 48-63.

Tsegaye, B. 1997. The significance of biodiversity for sustaining agricultural production and role of women in the traditional sector: the Ethiopian experience. Agriculture, Ecosystems and Environment 62: 215-227.

Vernooy, R. 2003. Semillas generosas. Mejoramiento participativo de plantas. Centro Internacional Para el Desarrollo. Canadá.

Veteto, J.R. 2008. The history and survival of traditional heirloom vegetable varieties in the southern Appalachian Mountains of western North Carolina. Agriculture and Human Values 25:121-134

Veteto, J.R. 2014. Seeds of Persistence: Agrobiodiversity in the American Mountain South. Culture, Agriculture, Food and Environment 36 (1): 17-27.

Wood, D. \& J.M. Lenné. 1997. The conservation of agrobiodiversity on-farm: questioning the emerging paradigm. Biodiversity and Conservation 6: 109-129. 
(c) CAPÍTULO 4:

Saberes y prácticas sobre conservación de semillas.

Su importancia para la resiliencia de los agroecosistemas familiares

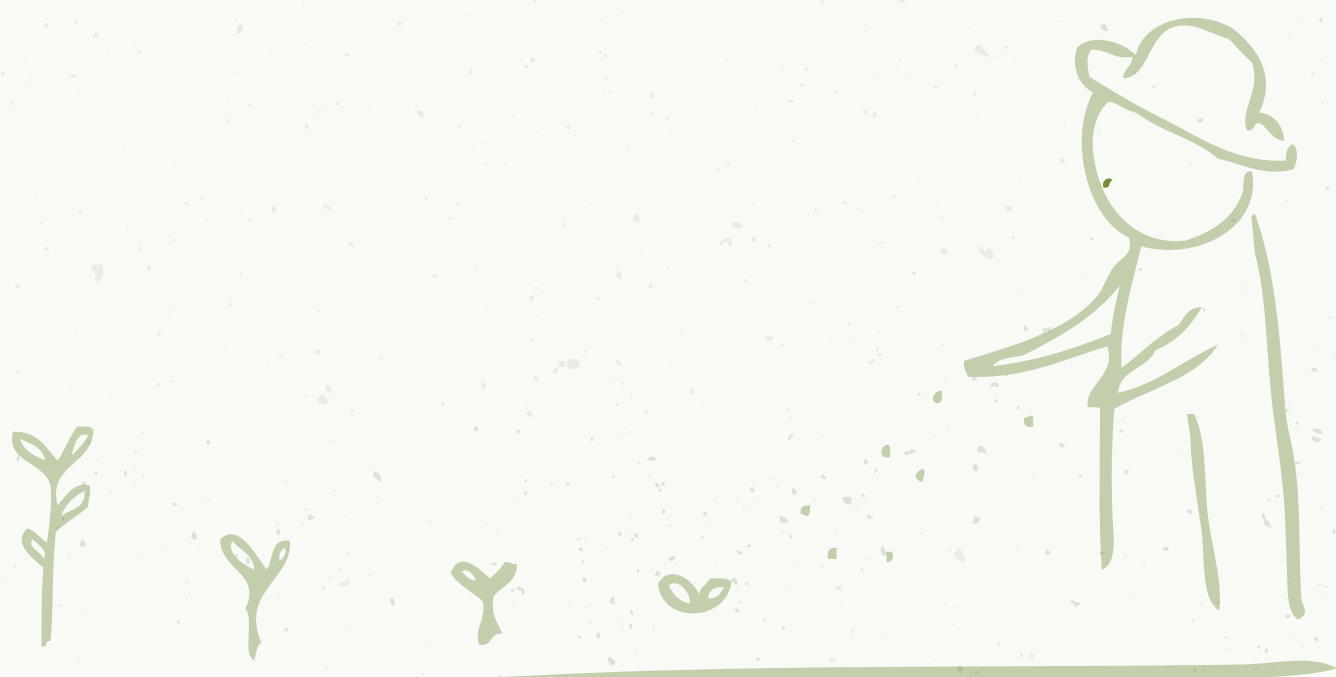




\section{CAPÍTULO 4 Saberes y prácticas sobre conservación de semillas. Su importancia para la resiliencia de los agroecosistemas familiares}

"Yo nunca voy a dejar de aprender [...] me junto con otros productores y vamos transmitiendo así unos a los otros. Porque cada productor tiene su manera de trabajar, todos no tenemos la misma idea"

(Bonicatto 2010b. Entrevista a JL)

\section{IIntroducción}

El paradigma de la Revolución Verde se basa en el uso de paquetes tecnológicos de altos insumos externos y una baja diversificación de los agroecosistemas. Este modelo implica una pérdida de diversidad biocultural y baja resiliencia, además de consecuencias en la salud del ambiente y las personas. Lograr aumentar la resiliencia de los sistemas productivos, implica el rediseño hacia modelos más sustentables que utilicen tecnologías basadas en los procesos ecológicos de ciclado de la materia, energía, optimización del agua y regulación biótica, a fin de reducir la dependencia de insumos externos. Para lograr este objetivo, es necesario contar con conocimientos que permitan a los agricultores y agricultoras, manejar y conservar la agrobiodiversidad. La vinculación de los agricultores con la naturaleza se realiza a través de una específica relación con la unidad agrícola familiar, es así que cada agroecosistema al estar intervenido por agricultores y agricultoras de acuerdo a sus objetivos, valores y prácticas, es único y es en esta particularidad que se concentra información de relevancia para el estudio y diseño de agroecosistemas sustentables (Sevilla Guzmán, 2006). Los saberes locales implicados en su manejo, son sistemas de conocimiento holísticos, acumulativos, dinámicos y abiertos, que se construyen con base en las experiencias locales transgeneracionales y por lo tanto, en constante adaptación a las dinámicas tecnológicas y socioeconómicas. Como la realidad cambia siempre según las circunstancias, la percepción y organización mental sobre el mundo natural no es fija ni estática, sino polisémica, multidimensional y polivalente (Toledo \& Barrera-Bassols, 2008). Según Mooney (1992) en Toledo \& Barrera-Bassols (2008), la diversidad agrícola será conservada solo si es utilizada, ya que propiamente su valor radica en sus usos. A su vez, este autor, sostiene que la diversidad agrícola no puede conservarse sin preservar las comunidades que la producen y viceversa. El presente capítulo busca profundizar 
acerca de los conocimientos presentes en el territorio sobre cómo conservar semillas y su relación con los cultivos conservados in situ. Para esto, el accionar individual de los agricultores y agricultoras sobre la conservación de semillas es incorporado, ya que permite visualizar, quiénes son los que efectivamente perpetúan y otorgan valor a dicha práctica. Numerosas investigaciones realizadas desde la perspectiva agroecológica, dan cuenta de la importancia de analizar la conservación de semillas focalizando los estudios en los agricultores y agricultoras (Altieri \& Merrick, 1987; Bonicatto et al., 2010; Cababié et al., 2015; Carpenter, 2005; de Boef, 2007; de Boef \& Thijssen, 2007; Del Cura et al., 2015; González et al., 2014; Lyon et al., 2011; Subedi et al., 2007). Desde la perspectiva etnobiológica, se resalta la importancia de estudiar el accionar de los individuos en el uso y conservación de la biodiversidad (Berkes et al., 2000; Hilgert \& Gil, 2005; Pochettino \& Lema, 2008; Reyes-García et al., 2007). La conservación de semillas in situ se incorpora a la planificación productiva, como un conjunto de prácticas y saberes que trascienden el momento de cosecha y limpieza de las semillas. Este objetivo se establece en el agroecosistema como un proceso continuo, cíclico, que habilitará la conservación a lo largo de los años. Diversos estudios establecen el tiempo de selección y conservación como una variable importante para el mantenimiento de variedad y variabilidad (Campbell \& Veteto. 2015; Garat et al., 2009; Red Andaluza de Semillas, 2009; Veteto, 2008). Por tanto, el cultivo de las plantas, la selección de aquellas que se destinarán a la obtención de semillas, la limpieza y el acondicionamiento de las semillas para ser conservadas, son parte fundamental del proceso de mantenimiento in situ de la agrobiodiversidad. Todas estas instancias son necesarias para el éxito de la conservación in situ. Cada una de las instancia de trabajo mencionada está guiada por conocimientos y creencias propias de cada agricultor (Berkes et al., 2000) con el fin de mantener, de cosecha en cosecha, sus semillas (Subedi et al., 2007). Por lo tanto, las valoraciones y deseos individuales, la multiplicidad de usos y las formas de comprender los propios agroecosistemas, son manifestaciones de las adaptaciones creativas (Ahumada et al., 2009; Lyon et al., 2011; Riat, 2012). El trabajo de Días-Bautista et al. (2008) realizado sobre el conocimiento campesino ligado a la selección y conservación de Vicia fava L., destaca la importancia de este conocimiento como fuente fundamental de información, al estar sustentado en la experiencia sobre el manejo de los sistemas de producción y el amplio conocimiento integral sobre los recursos genéticos. Según Soriano et al. (2012), los agricultores continuamente experimentan con los recursos genéticos disponibles localmente, para conseguir una adaptación cada vez más fina a las condiciones ambientales y culturales. A su vez, estos autores plantean que el mejoramiento se vuelve esencial para las comunidades, cuando se producen cambios acelerados en el entorno que afectan los 
recursos del agroecosistema. La agrobiodiversidad conservada in situ es la que permite establecer el correcto funcionamiento de los sistemas agrícolas, desempeñando un papel amortiguante ante las adversidades (Altieri et al., 2015). Los trabajos de Altieri \& Nicholls (2004), Montalba, (2013), Soriano et al. (2012) y Toledo, (2005) reflexionan sobre la pérdida de biodiversidad y conocimientos locales, en relación al avance de formas intensivas de producción ligadas al modelo de la Revolución Verde. A su vez, Eyssartier, et al. (2011) advierte que la pérdida de diversidad genética tradicional conlleva a la pérdida de conocimientos asociados. Retomando el capítulo I.I.I de esta tesis, la historia productiva del sector hortícola platense señala, que desde 1990 se profundiza la adopción del invernáculo, modificándose radicalmente los sistemas productivos a partir de esta incorporación y de un paquete tecnológico asociado al mismo, que incluyó semillas de alto potencial de rendimiento y mayor uso de insumos de síntesis química (Archenti et al., 1993; Selis, 2000). Este avance generó un proceso de sustitución masiva de los materiales genéticos típicos del área, poniendo en peligro la conservación de ciertas variedades de polinización abierta que históricamente se producían en las quintas o se adquirían por trueque o donación (Nico et al., 2006). Según Castro (2016) nuevos saberes y prácticas fueron necesarios para que los agricultores pudiesen adaptarse a esta forma intensiva de producción. En este contexto, la situación en torno a los conocimientos implicados en la conservación de semillas es desconocida. En referencia a otros territorios, hay estudios que documentan una actitud resiliente de agricultores y agricultoras para adaptarse a los cambios y transformaciones, que les permite disminuir la vulnerabilidad y aumentar la capacidad de reacción como se ha visto en otras partes del mundo (Ladio, 2011; Nicholls, 2013; Ríos-Osorio et al., 2013; Tengö \& Belfrage 2004). Cabe preguntarse ¿Persisten en el Cinturón Hortícola Platense conocimientos sobre conservación de semillas? ¿Quiénes los conservan? ¿Cuál es el accionar de los individuos en la conservación de la agrobiodiversidad registrada? ¿Qué características del conocimiento sobre la conservación in situ aporta a la sustentabilidad de las producciones familiares? ¿Qué prácticas y actitudes son aquellas que permiten adaptarse y reponerse a las perturbaciones?

El poder vislumbrar las resistencias, creaciones y adaptaciones de los agricultores y agricultoras, sus falencias y limitaciones, es un elemento imporatante para avanzar en el desarrollo de estrategias que habiliten la conservación in situ de agrobiodiversidad hortícola.

Ante lo expuesto, el presente capítulo aborda la hipótesis 5 planteada: Los agricultores y agricultoras familiares del Cinturón Hortícola Platense mantienen conocimientos sobre la 
práctica de conservación de semillas. Los conocimientos son condición necesaria para el mantenimiento in situ de agrobiodiversidad.

Los objetivos de este capítulo fueron:

- Registrar y analizar los conocimientos de los agricultores y agricultoras familiares del Cinturón Hortícola Platense sobre la conservación de semillas.

- Analizar el "accionar individual" de los agricultores en la conservación de la diversidad biocultural (recurso y saberes asociados).

- Registrar y categorizar impedimentos para la conservación de semillas manifestados por los agricultores y agricultoras familiares del Cinturón Hortícola Platense.

\subsection{Metodología}

Se realizaron entrevistas abiertas y semiestructuradas (Martin, 1995) en los 26 agroecosistemas visitados $y$, en aquellos casos donde surgieron temas de interés, se realizaron a posteriori entrevistas en profundidad (Taylor \& Bogdan, 1987). Durante las entrevistas se compartió con los interlocutores momentos vinculados a la conservación de semillas. Los detalles metodológicos correspondientes a las entrevistas fueron presentados en el capítulo 1.2. Trabajos realizados desde la agroecología dan cuenta de la importancia de los estudios que caracterizan las unidades de producción y profundizan en aquellas acciones locales que promueven la conservación de agrobiodiversidad (Abbona et al, 2007; Bisht et al., 2014; Carpenter, 2005; de Boef \& Thijssen, 2007; Girard et al., 2014; Stupino et al., 2008; Veteto, 2008, Veteto, 2014). Los 26 agroecosistemas familiares analizados representan situaciones heterogéneas en cuanto al origen de los agricultores, edad, género, cultivo a campo o bajo invernáculo y diferencias en cuanto al modelo agrícola utilizado (agroecológico, orgánico o intensivo en insumos externos). Para la identificación de los interlocutores se utilizaron siglas en letra mayúscula: JL, ES, JP, NG, PA, FLO, HC, DAG, MS, IG, DY, LP, MG, AT, BIS, BV, CA, JV, P, NA, CL, LO, ML, S, SV, CV.

\subsection{Saberes y prácticas sobre la conservación de semillas}

El análisis e interpretación de los datos vinculados a los saberes sobre la conservación de semillas se realizó utilizando el análisis en progreso (Taylor \& Bogdan, 1987). A lo 
largo del análisis se buscó lograr una comprensión más profunda del escenario estudiado, que permitiese comprender los datos en el contexto en el que fueron recogidos (Taylor \& Bogdan, 1987). Los detalles metodológicos se describen en el punto 1.2.2.3. A partir de los relatos de los agricultores y agricultoras se establecieron 5 categorías (Figura 21), cuyos rótulos fueron puestos por la autora. Estas categorías tuvieron por finalidad organizar los relatos en función de las prácticas productivas implicadas en el proceso de conservación in situ.

Las categorías A, B y C describen las instancias de trabajo realizadas por los agricultores y agricultoras durante el proceso completo de conservación de un cultivo hortícola. La categoría A, se inicia en la parcela con la siembra, continúa con el cuidado del cultivo y posterior selección de las plantas de las cuales se va a obtener semillas. Luego la categoría B, implica la recolección, limpieza y secado de las semillas que van a conservarse, esta actividad suele realizarse en espacios destinados para tal fin, como galpones o en el ámbito de la unidad domestica. La categoría C, implica las estrategias desarrolladas en relación al acondicionamiento de las semillas y su guardado hasta ser nuevamente sembradas. Las categorías $D$ y $E$ son transversales al proceso de conservación, ya que pueden estar vinculadas o presentarse en diferentes momentos del proceso. Estas dos categorías dan cuenta del hacer de los agricultores y agricultoras, en torno a los obstáculos o dificultades que se les van presentando durante el proceso de autoproducción de semillas. La categoría D incluye los relatos en torno a las dificultades encontradas y la $E$, los relatos sobre las prácticas creativas e innovadoras que desarrollan los agricultores y agricultoras para sobreponerse a estas dificultades.

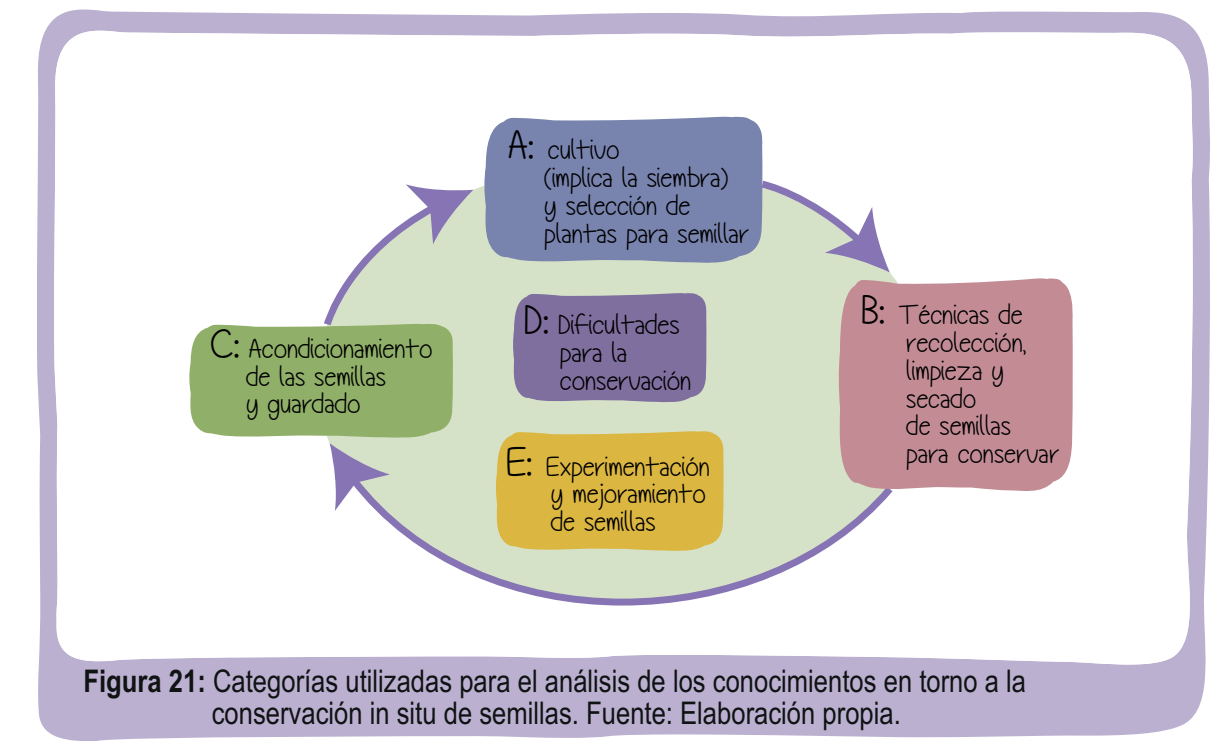


Luego de realizar un análisis profundo de los datos, se avanzó en el desarrollo de conceptos que permitiesen analizar el tema en estudio. Con la información recopilada se realizó un "banco de memoria" (Nazarea 1998), destinado a documentar el conocimiento local vinculado a la conservación in situ de agrobiodiversidad hortícola.

\subsubsection{El accionar individual}

A fin de analizar el rol de cada interlocutor en la conservación de semillas, se organizaron los datos según la agrobiodiversidad hortícola cultivada y conservada por cada familia entrevistada: Para dicho análisis se tomó el total de registros de plantas cultivadas mencionado por cada interlocutor. La intención de este análisis en observar la magnitud de la práctica de conservación en relación a los diferentes cultivos que cada familia realiza. Se detalló el tiempo que hace que se conserva cada cultivo hortícola.

Los datos registrados en los relatos de los interlocutores, exponen el tiempo de conservación como una variable a la cual se le da importancia. En relación a este tema, los interlocutores dan cuenta de un conjunto de semillas, principalmente de origen comercial, que son conservados por pocos años (no más de 4-5), y de semillas que son conservadas por más tiempo, entre ellas las variedades locales, que dan cuenta de la presencia en la actualidad de cultivos hortícolas con muchos años en la región (Garat et al., 2009) y cultivos que, aunque con origen comercial, son seleccionados y perpetuados por los agricultores y agricultoras, según deseos propios. Por tanto, se estableció como "añejas", aquellas semillas conservadas por más de 5 años.

A su vez se agrupó la agrobiodiversidad conservada por cada interlocutor, en relación a dos grupos etarios. Un conjunto conformado por aquellos interlocutores de 50 años o más, y otro de aquellos menores de 50 años. La división etaria se estableció en base a la historia del área de estudio (capítulo 1.2.1). El primer conjunto incluye aquellas personas, tanto varones como mujeres, cuya edad les permite haber vivido el final de la etapa descripta en el capítulo I.I.I.2, como "nacimiento de la horticultura comercial" y los primeros años del período descripto en el capítulo l.I.l.3 "expansión e intensificación de la producción", tiempos en los que se utilizaban comúnmente semillas de variedades tradicionales (Garat et al., 2007; Garat et al., 2009). El segundo conjunto implica aquellas personas nacidas a partir de las décadas de 1970 y 1980, momento en el cual estaba el modelo de la Revolución Verde se establece en la producción hortícola, y junto al éste, las semillas mejoradas (Benencia, 2006; Garat et al., 2009). Los cultivos conservados se vincularon a los criterios de conservación otorgados a cada uno y al origen de las 
semillas conservadas según las categorías de ingreso utilizadas en el capítulo 2.2.4, A: comprada en comercio. B: vínculos interpersonales (incluye las semillas obtenidas por herencia, regalo de otros agricultores, de consumidores, intercambio entre vecinos, agricultores, familiares, en ferias de intercambio o intercambio casuales). C: instituciones (incluye semillas obtenidas a través de Instituciones estatales Universidad/INTA). D: oportunista (incluye semillas obtenidas aprovechando la oportunidad de hortalizas descartadas del mercado, verdulerías, recolectadas de espacios públicos y privados. E: resiembra espontánea (incluye semillas que se siembran espontáneamente en el agroecosistema mediadas por la decisión de los agricultores y agricultoras). F: origen no especificado.

\subsection{Resultados y discusión}

En el Anexo 6 se presentan los datos vinculados a los conocimientos sobre la conservación de semillas según las categorías descriptas. Por su parte, la Tabla 7 relaciona dichas categorías con los interlocutores que refirieron a ellas. Los resultados obtenidos dejan ver que algunos interlocutores compartieron conocimientos vinculados a todas las categorías analizadas mientras que otros no. 25 de los 26 interlocutores expresaron conocimientos sobre alguno de los momentos que hacen a la conservación in situ, posicionando la conservación de semillas como un tema actual para los agricultores y agricultoras familiares. En la Tabla 7, resalta la presencia de relatos sobre las dificultades para la conservación, las cuales serán tratadas en detalle en el punto 4.3.1.4

Las situaciones analizadas resultaron altamente diversas en cuanto a la agrobiodiversidad conservada y los saberes vinculados a las diferentes instancias de este proceso. Ejemplo de esto es el interlocutor DY, quien comparte saberes sobre las categorías A-B-D-E y conserva solo el $6 \%$ de las hortalizas que cultiva. Este interlocutor, descendiente de japoneses que inmigraron a la Argentina, relata que su familia está en esa quinta de Colonia Urquiza desde el año 1960, y que previamente tenían quinta en Florencio Varela. Él cuenta que antes, sí se guardaban semillas, y que ahora no, "como son híbridas no se guarda". Por su parte, MG, hijo de horticultores, refiere haber aprendido de su padre a conservar semillas "las sacaba mi viejo, en esa época mi viejo sacaba de todo, porque no había otra clase de semillas, pero cuando fueron apareciendo los híbridos fueron desapareciendo" En los casos de BIS y LO refieren a todas las categorías de saberes y conservan el $23 \%$ y $26 \%$ de lo que cultivan respectivamente. 
Ellas son hija y nuera, de horticultores de nacionalidad boliviana, de quienes cuentan haber aprendido la práctica de cómo conservar. En tanto $\mathrm{CL}$ es el único caso que no conserva semillas de ninguno de los cultivos hortícolas que tiene. Sus relatos refieren a los intentos por conservar, al poco éxito obtenido según las expectativas de rendimiento, o al riesgo que implica para él la autoproducción de semillas. El caso de ML, quien conserva un $10 \%$ de lo cultivado, resultó estar ligada a la producción hortícola hace poco tiempo, inclusive en la zona, ya que su país de origen es Bolivia, la situación en las tierras que cultivan es muy precaria, ya alquilan solo una porción de la quinta para cultivar y vender en un puesto de venta directa al público.

La situación de NG, JL y NA es diferente. Ellos conservan altos porcentajes de las hortalizas que cultivan y muestran un mayor correlato entre las instancias de trabajo que esta práctica implica y la agrobiodiversidad conservada. En tanto IG conserva el $100 \%$ de las hortalizas cultivadas. Este interlocutor compartió saberes sobre el cultivo y selección (A) y sobre las estrategias de experimentación (E), sin dar detalles sobre las estrategias de de limpieza, secado, guardado e impedimentos para la conservación. Estas diferencias invitan a reflexionar sobre lo propuesto por Taylor \& Bogdan (1987), el detenerse y reflexionar en el modo en que estos datos fueron recogidos, considerar las preguntas realizadas, el contexto en el que fueron hechas, las acciones de los interlocutores además de sus palabras. En este sentido, el relato verbal sobre las prácticas, se completa con la práctica situada, registrada a partir de la observación participante. El producto de esta observación, permite reinterpretar la información antes presentada. Tal es el caso de LP, CV, AT, HC, PA. En estos casos los interlocutores no manifiestan a través del relato verbal saberes en relación a todas las categorías analizadas (Tabla 7). En este sentido algunos ejemplos son LP y AT que no resaltan dificultades en torno a la conservación. A su vez, AT no expresó particularidades en las estrategias de guardado de las semillas, sin embargo los registros producto de la observación participante corroboraron el acondicionamiento y conservación de semillas. Este agricultor es hoy en día un referente de la autoproducción de semillas de tomate platense, las cuales año a año conserva y distribuye a otros agricultores. Estos resultados retoman la importancia de la observación participante o de las entrevistas situadas (Gargoloff et al., 2011) para el relevamiento de saberes y practicas productivas. 
Tabla 7: Conocimientos de los agricultores y agricultoras familiares del Cinturón Hortícola Platense, sobre la conservación de semillas in situ y porcentaje de hortalizas conservadas sobre el total cultivado

(A) Cultivo y selección de plantas para semillar

(B) Técnicas de recolección, limpieza y secado de semillas

(C) Acondicionamiento de semillas y guardado

(D) Dificultades para la conservación

(E) Experimentación y mejoramiento de semillas

La primera columna refiere a la sigla de los interlocutores.

\begin{tabular}{|c|c|c|c|c|c|c|}
\hline & A & B & C & D & E & $\begin{array}{l}\% \text { de conservación } \\
\text { sobre lo cultivado }\end{array}$ \\
\hline $\mathrm{HC}$ & & & & & & 100 \\
\hline IG & & & & & & 100 \\
\hline CV & & & & & & 100 \\
\hline $\mathrm{JL}$ & & & & & & 86 \\
\hline DAG & & & & & & 82 \\
\hline NG & & & & & & 80 \\
\hline $\mathrm{JP}$ & & & & & & 78 \\
\hline NA & & & & & & 78 \\
\hline LP & & & & & & 72 \\
\hline ES & & & & & & 69 \\
\hline JV & & & & & & 66 \\
\hline$S$ & & & & & & 66 \\
\hline PA & & & & & & 57 \\
\hline MS & & & & & & 42 \\
\hline BV & & & & & & 42 \\
\hline AT & & & & & & 41,6 \\
\hline CA & & & & & & 40 \\
\hline SV & & & & & & 33 \\
\hline LO & & & & & & 26 \\
\hline$P$ & & & & & & 25 \\
\hline BIS & & & & & & 23 \\
\hline MG & & & & & & 21 \\
\hline FLO & & & & & & 11,7 \\
\hline ML & & & & & & 10 \\
\hline DY & & & & & & 6 \\
\hline$C L$ & & & & & & 0 \\
\hline
\end{tabular}

4.3.I Saberes sobre conservación de semillas en el Cinturón Hortícola Platense

En este apartado se resalta la síntesis realizada en base a las categorías que describen los conocimientos sobre las instancias de trabajo implicadas en la conservación de semillas (Anexo 6). 


\subsection{I.I Cultivo y selección de plantas para semillar}

La selección de plantas destinadas a la obtención de semillas se visualiza como una estrategia utilizada por la mayoría de los agricultores y agricultoras entrevistados (Figura 22). A partir de sus relatos los agricultores y agricultoras despliegan el conjunto de saberes y creencias que circundan esta práctica ancestral. Estos relatos coinciden con lo propuesto por Reijntjes et al. (1999), quienes plantean que el conocimiento local va más allá de técnicas e incluye nociones, percepciones e intuiciones relacionadas con el medio ambiente y se encuentra integrado a creencias, valores, tradiciones, mitos y a las formas de organización y cooperación social. Ejemplo de esto, es la valoración e incorporación de las fases de la Luna en el cultivo de hortalizas y producción de semillas, o algunas técnicas, que tienen que ver con la forma de separar las semillas que van a conservar:

"los viejos de antes y yo de algunas cosas me acuerdo y lo hago, se basaban mucho en la luna. Los tipos te decían -vos tenés que hacer tal luna este almácigo, esta variedad tal luna- y así" (Bonicatto 2011e. Entrevista a NG).

"una semilla de acelga hasta nueve años aguanta, ipor Dios! ¡9 años! El tomate 4, 5 años tranquilo, pero el ají, 13 lunas, 14 lunas. A no ser que ahora...viste que lo envasan al vacío y le hacen un proceso, ahí aguanta, pero como nosotros que lo pones en un frasco, lo tapas bien y lo guardas todo el invierno en un lugar oscuro, 13 lunas. Después ya no nace nada, no nace nada" (Bonicatto 2011e. Entrevista a NG).

En tanto otras estrategias se vinculan a la confianza que adjudican a las semillas que conservan, asegurando que al ser propias pueden saber "qué va a salir" de esa semilla sembrada. A su vez, se utilizan estrategias que les permiten evitar o propiciar la polinización cruzada como instancia en la producción de semillas:

"nosotros por ejemplo, hacemos así a campo la semilla cuando más o menos vemos que esa planta la queremos dejar para semilla la cerramos, le ponemos un mosquitero a la planta, porque no queremos que las abejas nos crucen las semillas, nos polenicen con otras, entonces ese es el tema, muchas veces las abejitas hacen ese trabajo" (Bonicatto 2014c. Entrevista a DAG)

En estas menciones se ve el carácter holístico con el que los agricultores y agricultoras observan sus producciones. Plantas, insectos, personas y astros interactuando en las 
estrategias desarrolladas para logar con éxito la autoproducción de semillas. Esta percepción compleja del agroecosistema habilita la aplicación de conocimientos que vinculen, simultáneamente, diferentes componentes internos y externos al agroecosistema.

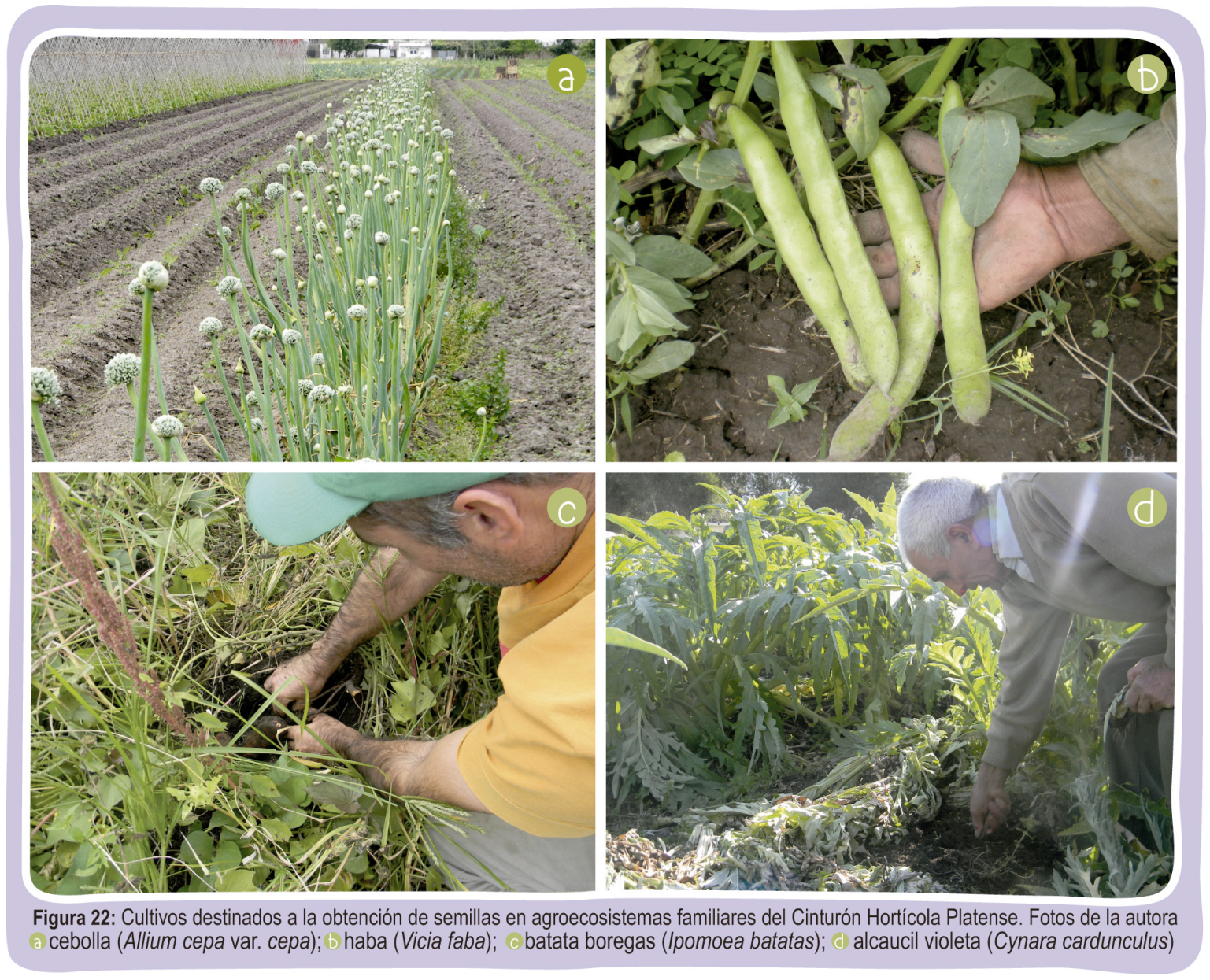

4.3.1.2 De la quinta a la alacena. Técnicas de recolección, limpieza, secado y guardado de semillas.

Gran parte del tiempo y trabajo que implica la conservación de semillas, está destinado a las tareas que van desde, la recolección de las semillas en el campo, hasta que son acondicionadas y ubicadas en bolsas o frascos de vidrio para ser guardadas para la siguiente siembra (Figura 23). Y es de esta serie de pasos que depende mucho del éxito o fracaso de su conservación. 
Los resultados aquí expuestos refieren a las categorías B (técnicas de recolección, limpieza y secado) y C (acondicionamiento de las semillas y guardado). Estos datos, dan cuenta de la presencia de saberes sobre técnicas para la conservación de diferentes semillas (capítulo 2.1.1). En este sentido, son utilizadas diferentes alternativas de recolección, limpieza y secado, en función de los frutos. Por ejemplo, frutos secos como la lechuga, o frutos carnosos como el tomate. Las variables consideradas si lo que se busca conservar son bulbos o semillas per se, así como la ubicación de las semillas en lugares sin humedad y lejos del sol, adaptándose a las condiciones de infraestructura y materiales que se tienen, transforman las alacenas y heladeras en desuso, en semilleros familiares. En estos semilleros, los elementos de guardado, son frascos de vidrio, bolsas de arpillera o polipropileno, con la ayuda de ceniza, naftalina o alguna planta aromática que permite reducir la humedad y el ataque de insectos o roedores. La utilización de estas estrategias no es única y constante para cada familia. Las mismas suelen hacer uso de los recursos locales disponibles, de manera conjunta (frascos, bolsas de polipropileno, arpillera). Por lo tanto es común encontrar en una misma alacena, semillas conservadas en diferentes recipientes.

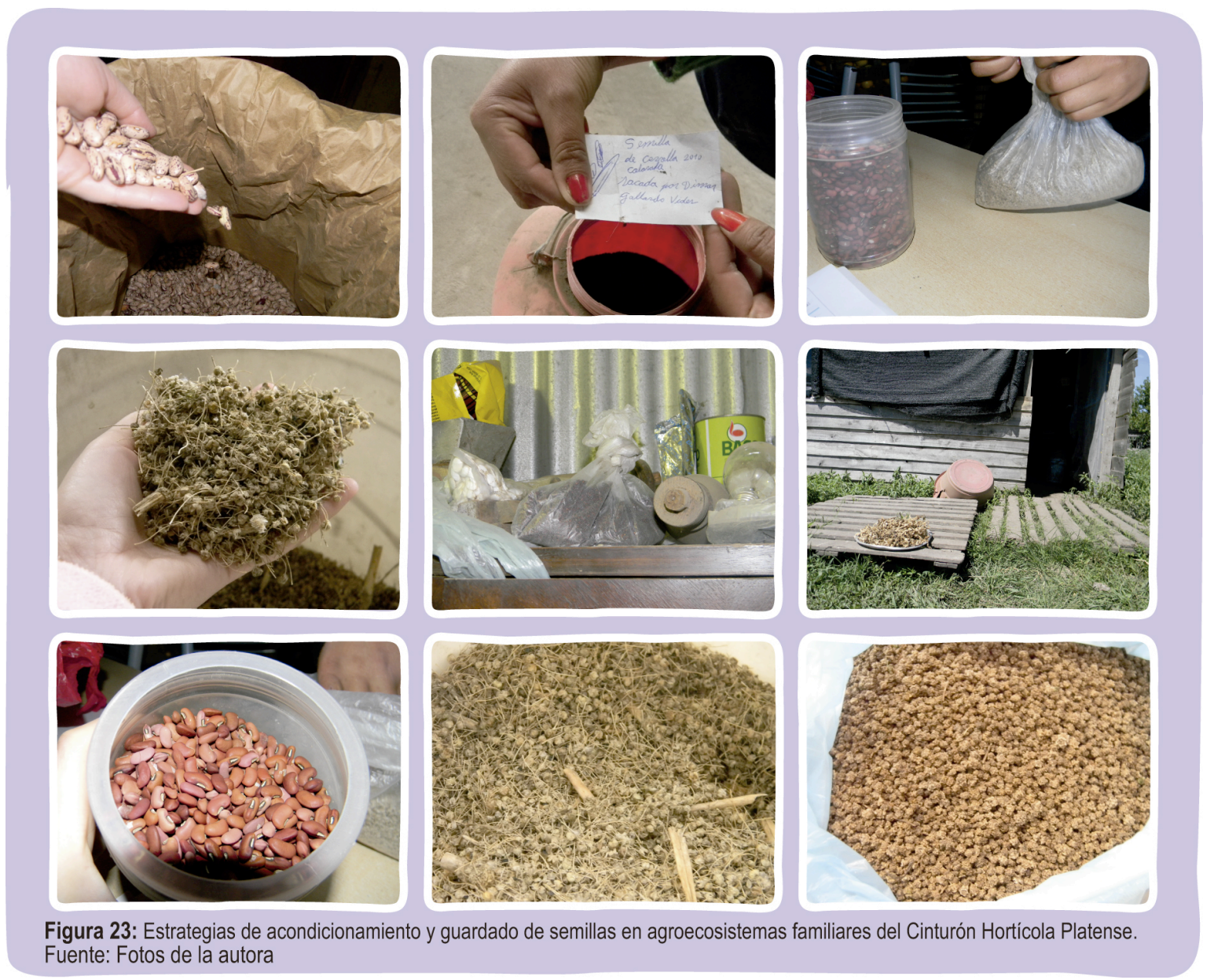

Fuente: Fotos de la autora 


\subsubsection{Dificultades para la conservación}

El tiempo que las semillas pasan esperando ser sembradas es crucial, y cuando esa estadía no cuenta con las condiciones apropiadas, la posibilidad de perderlas aumenta. 24 de los 26 interlocutores describen alguna dificultad en torno a la conservación de semillas (Tabla 7). Las dificultades mencionadas en el Anexo 6, se agruparon en 5 categorías.

1. Bióticas y abióticas: la cual incluye semilla comidas por ratas, polillas, gusanos, o semillas perdidas por condiciones inapropiadas de humedad.

2. Ecológicas: incluye aquellas semillas que no se adaptan a las condiciones ambientales, principalmente vinculado a semillas obtenidas por intercambio o traídas de otras zonas del país y del mundo.

3. Recursos productivos: incluye aquellas dificultades que se vinculan a la falta de tierra (superficie) para poder dejar los surcos ocupados con las hortalizas semillando. La mano de obra necesaria para la cosecha, limpieza y acondicionamiento. La relación en cuanto a la tenencia de la tierra (propietarios, arrendatario, mediero) la cual limita las posibilidades de decisión sobre las tareas y cultivos a realizar.

4. Tecnológicas: la imposibilidad de conservar híbridos o en el caso de hacerlo, la obtención de un producto no homogéneo, que no cumple con los estándares del mercado.

5. Políticas: vinculado a la imposibilidad de pasar las aduanas con semillas.

La principal limitante que surge es la tecnológica (38\% de las menciones) (Figura 24). El desánimo generado por un producto que "no se puede guardar" o que "se degenera, no te rinde, y le pones el mismo trabajo que si fuese comprado" al decir de DY y MG respectivamente, estaría accionando como la mayor dificultad que atraviesa esta práctica ancestral. Sin embargo, esta limitante, a la vez que condiciona la conservación en el tiempo de algunas semillas, también estimula la actitud innovadora de los agricultores y agricultoras para la generación de nuevos conocimientos, que permitan sortear el obstáculo ligado a su conservación. 


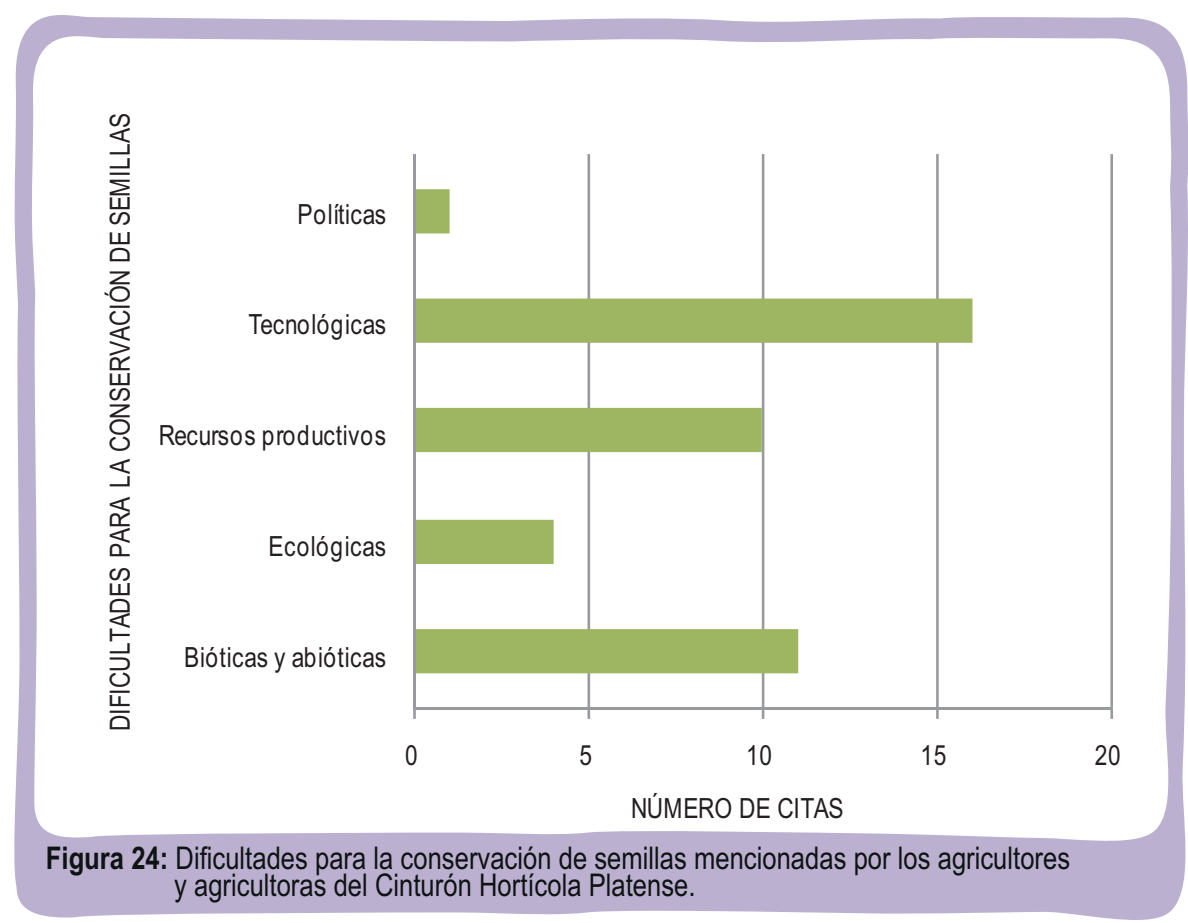

Las categorías bióticas y abióticas ( $26 \%$ de las menciones) y recursos productivos ( $24 \%$ de las menciones) similares en representatividad de las dificultades mencionadas, se vinculan entre sí dado que refieren a las condiciones internas del agroecosistema. Estas dos categorías dan cuenta de las condiciones insuficientes de la infraestructura con la que cuentan los agricultores familiares para asegurar la correcta conservación de las semillas que conservan. A su vez la insuficiente mano de obra y limitada disponibilidad de tierra, actúan restringiendo el cumplimiento del ciclo completo que hace a la conservación in situ. La categorías dificultades ecológicas ( $9,6 \%$ de las menciones) implica semillas que fueron obtenidas en intercambios en zonas con diferentes condiciones ecológicas 0 ingresadas a raíz de viajes. Por último, la dificultad políticas $(2,4 \%$ de las menciones) implican una situación particular, ya que refiere a semillas que no llegaron a ser sembradas por ser retenidas en la aduana.

A partir de estos datos y los capítulos previos, es interesante ver, cómo estos impedimentos, se instalan a la vez, como estímulos para la creatividad de los agricultores y agricultoras, los cuales lejos de abandonar la práctica de conservación de semillas, idean, recrean y resignifican conocimientos a fin de lograr el objetivo deseado. 


\subsubsection{Saberes y resiliencia}

Según Reyes García \& Martí Sanz (2007), el conocimiento local es producto de un proceso acumulativo y dinámico de experiencias prácticas y adaptación al cambio. $\mathrm{A}$ diferencia del conocimiento científico, el conocimiento de los agricultores es local, holístico y portador de una cosmovisión que integra aspectos físicos y espirituales (Toledo, 1992). Los relatos previamente analizados dan cuenta de un amplio manejo de información en torno al cultivo de hortalizas y de las estrategias que permitan realizar una conservación in situ. Sin embargo, surge una característica fundamental para la continuidad de esta práctica ligada de la actitud de los agricultores y agricultoras, y tiene que ver con la cualidad de exploración. En esta actitud en pos del aprendizaje, de adaptación al cambio, de experimentación, está la clave de la resiliencia. En este contexto, las múltiples variables y alternativas que un agricultor tiene para lograr con éxito la conservación, se establecen como un conjunto de herramientas puestas en juego cuando el contexto lo amerita. En estas estrategias se funden conocimientos provenientes de diferentes vías. La vinculación de los agricultores y agricultoras con otros actores del territorio, la interpretación y adaptación de los conocimientos producido por otros, sean científicos o locales abre las puertas a nuevos escenarios. Según Toledo \& Barrera-Bassols (2008) los saberes locales no son sistemas estáticos sino diseños innovadores alimentados por redes sociales y sus relaciones internas y externas. En este sentido, la incorporación de vocabulario y prácticas provenientes de otros ámbitos, la inquietud y generación de preguntas, la experimentación y puesta a prueba de las ideas, se posicionan como elementos que indican una actitud comprometida con la conservación de agrobiodiversidad. En definitiva este proceso ocurrido en el plano individual y grupal, genera capacidades aplicadas y mejoradas durante la conservación de semillas. ¿Qué semillas? Algunas serán rarezas obtenidas en intercambios entre agricultores, o variedades ligadas a la historia familiar o territorial, mientras que otras serán semillas de variedades compradas en comercios. En este punto, todas ellas, accionan para el mantenimiento en el tiempo de la práctica de conservación in situ. Los trabajos de Lyon et al. (2011), Olsson et al. (2004) y Tomkins \& Adger (2004), resaltan la importancia de las redes comunitarias y procesos de auto organización para avanzar en estrategias que permitan lidiar con el advenimiento de disturbios. A partir de los resultados obtenidos, queda claro, que los saberes sobre las técnicas de conservación de semillas están presentes en el territorio en estudio, son diversos y maleables. Sin embargo, surgen interrogantes para seguir analizando ¿Quiénes son los que 
efectivamente conservan estas semillas? Y ¿cuál es el aporte de las individualidades al mantenimiento de esta práctica?

\subsubsection{El accionar individual en la conservación de semillas}

El número de cultivos hortícolas realizados en los agroecosistemas varió entre 5 y 41 . Y el número de cultivos hortícolas conservados entre 0 y 32 (Figura 25 a y b). La edad de los interlocutores varió entre 20 y 75 años. Al separar los interlocutores según su grupo etario, se observó que en el grupo de los mayores a 50 años, 9 interlocutores conservan el $50 \%$ o más de lo que cultivan: PA (57\%), ES (69\%), LP (72\%), JP (78\%), NG (80\%), DAG (82\%), JL (86\%), HC (100\%) e IG (100). Mientras que en el caso de los menores a 50 años, solo 4 superan dicho porcentaje. JV (66\%), S (66\%), NA (78\%) y CV (100\%). Los datos obtenidos, en vinculación con los datos empíricos, revela un conjunto de agricultores y agricultoras con amplia experiencia en conservación de semillas. Desde la perspectiva agroecológica, y en función de la planificación de estrategias que fortalezcan la circulación de saberes sobre esta práctica, el registro de agricultores y agricultoras que se dedican a conservar in situ lo que cultivan es fundamental. A su vez, los datos presentados en la Figura 26, describen una situación peculiar, en la cual no se observan grandes diferencias entre los dos grupos etarios en función del origen de las semillas que están conservando. Estos resultados sugieren que ambos grupos etarios incorporan, semillas de origen comercial (compradas en comercios), así como a su vez mantienen activos los intercambios entre agricultores, como una vía de ingreso válida para la obtención de material genético (vínculos interpersonales). Lo mismo ocurre con aquellas semillas obtenidas de instituciones de Investigación y Desarrollo (UNLP o el INTA). 


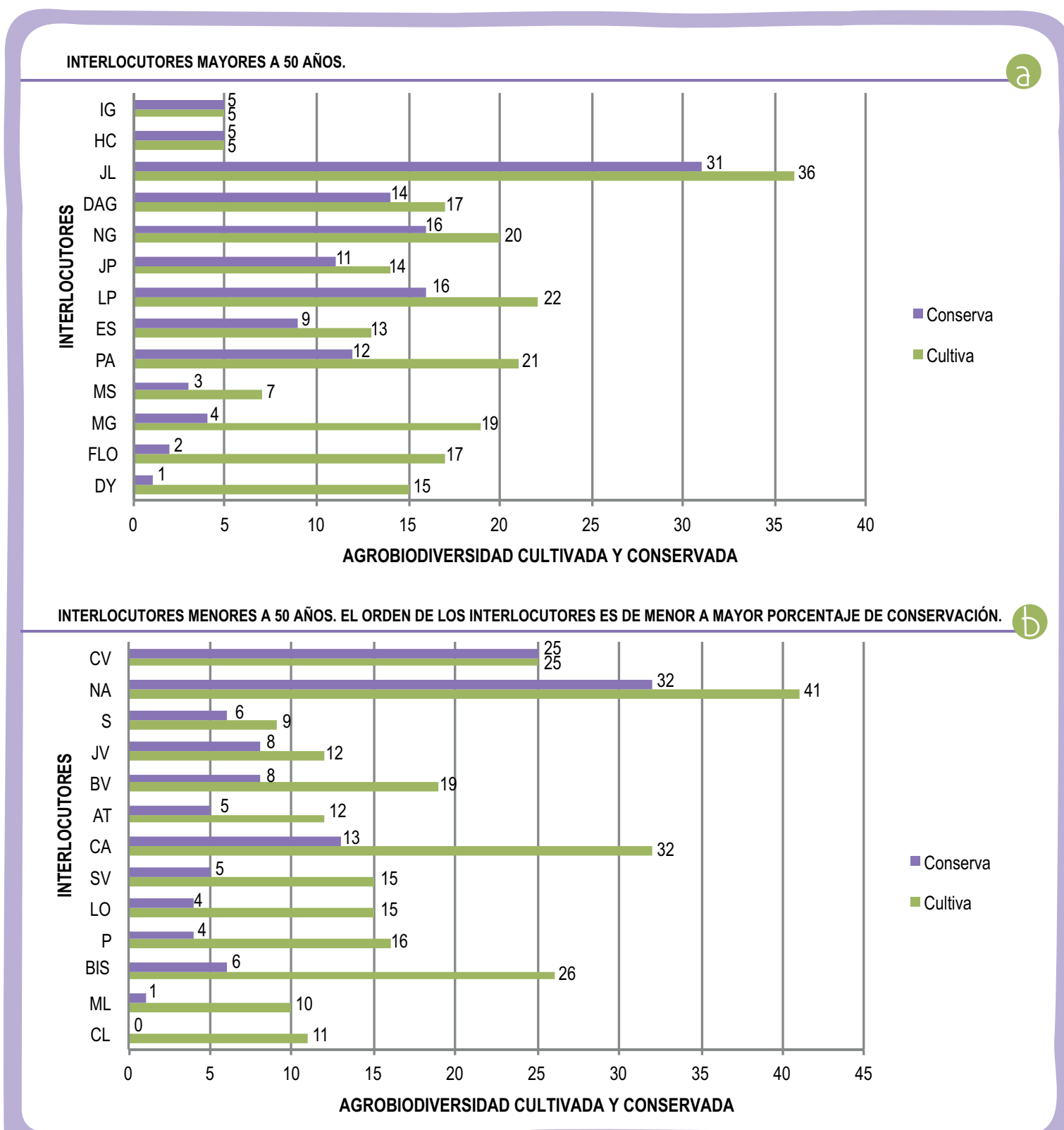

Figura 25 a y b: Agrobiodiversidad cultivada y conservada por agricultores y agricultoras familiares del Cinturón Hortícola Platense. mayores de 50 años. $b$ menores de 50 años.

Un punto importante a considerar es que el conjunto de interlocutores menores a 50 años, describió haber participado de ferias de intercambio de semillas y haber obtenido allí gran parte de las semillas conservadas por la vía vínculos interpersonales. En tanto los agricultores mayores a 50 años, aunque algunos participaron de encuentros de intercambio, manifestaron obtener las semillas por herencia familiar. En concordancia con lo expuesto por (Cababié et al., 2015), se destaca la importancia de las vías informales para la incorporación de semillas. El hecho de que los agricultores y agricultoras que suelen participar de estos eventos sean los menores a 50 años, invita a reflexionar sobre las características de estos eventos, en cuanto a la lejanía de la zona productiva, 
duración y convocatoria. Considerando el carácter exploratorio de esta investigación, se destaca la necesidad de profundizar en estudios sobre la circulación de semillas a través de vínculos interpersonales.

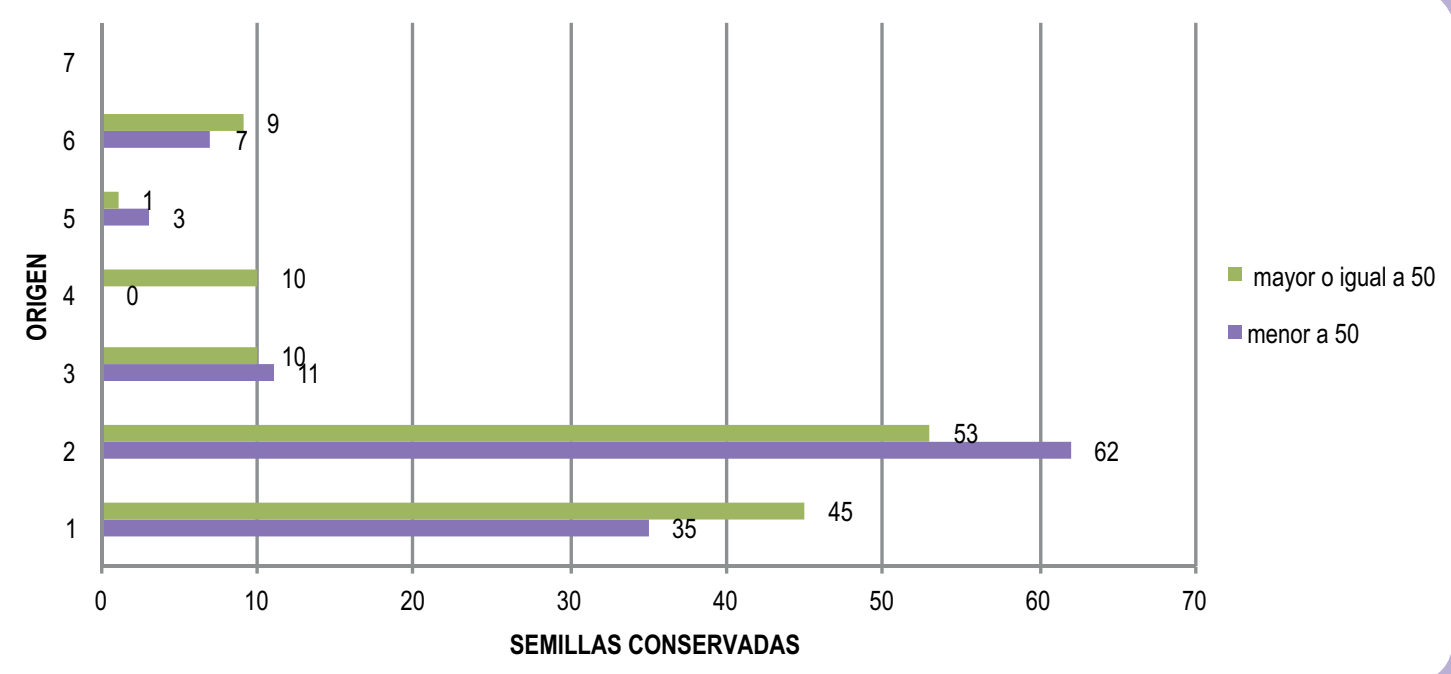

Figura 26: Origen de las semillas conservadas según el grupo etario de los agricultores y las agricultoras familiares del Cinturón Hortícola Platense.

\subsubsection{De especialistas y generalistas.}

Los resultados de la Tabla 8 exponen la agrobiodiversidad conservada por cada interlocutor. A partir de esta información se aclaran diversos aspectos en torno al rol individual de los agricultores en la conservación de agrobiodiversidad. En primer lugar, se evidencia cómo algunas personas se abocan a conservar diversidad intraespecífica, en definitiva a obtener diferentes etnotaxa. Ejemplos de esto son CA quien conserva 3 etnovariedades de Brassica napus a las cuales diferencia bajo los nombres grilo, grilo nabo y nabiza; NA que conserva 6 etnovariedades de Solanum lycopersicum, diferenciadas como tomate, tomate cherry, tomate perita amarillo, tomate perita largo, tomate platense y tomate tardío); CV quien conserva 6 etnovariedades de Zea mays, las cuales llama choclo, maíz puro blanco, maíz puro negro, maíz rojo, maíz morado chiquito, maíz de colores y maíz perla blanca. Estos datos dan cuenta de la especialización que desarrollan los agricultores y agricultoras en torno al cultivo, selección y conservación de algunas especies hortícolas. Implicando esto, la especialización de los conocimientos necesarios para evitar cruzamiento o favorecerlos, tiempos de siembra escalonados, estrategias de guardado de las semillas, entre otros: 
"estas plantitas son las que producen este maicito, este el negro ¿ves? y estas (señalando otras) son las que producen esto o esto. Entonces lo primero que tuvimos que hacer es averiguar el tiempo de floración de estas de estas y de estas (señalando tres) y hacerlo coincidir, hay 15 días de diferencia, entonces sembramos esto 15 días después de esto y florecieron juntas y recién ahí se cruzaron. Antes la habíamos sembrado el primer año juntos y no se cruzaron ¿entendes lo que nos paso? ¡No coincidía la floración! Entonces tuvimos que buscarle la vuelta a ver el tiempo de floración, a ver en cuanto floreció, cuanto tardó esta, cuanto tardó aquella, y recién lo pudimos hacer" (Bonicatto 2011j. Entrevista a CV)

A su vez, resaltan algunos interlocutores tales como JL, NA, DAG, LP, y NG quienes conservan un gran porcentaje de aquello que cultivan, implicando diferentes especies y familias botánicas. Retomando la sistematización de saberes presentada en el Anexo 6, se ve el vínculo entre lo cultivado y los saberes implicados en dicha práctica. Los relatos de CV en relación a la conservación y cultivo de maíces de diferentes colores, la planificación implicada en el mantenimiento de líneas puras, y la participación en espacios de intercambio de semillas, en busca de diversidad genética, es un ejemplo claro.

A su vez, en la Tabla 8, se ven cultivos hortícolas que son conservados solo por un interlocutor. Al cruzar dichos datos con los criterios por los cuales se conservan esos cultivos se ve que el repollo (Brasica oleracea var. capitata) es conservado por PA por el criterio económico; el nabo daikon (Raphanus sativus var. sativus) es conservado por NA por los criterios independencia y económico; la cebolla de verdeo (Allium fistulosum) es conservada por JP por el criterio culinario; el yacón (Smallanthus sonchifolius) es conservado por CV por los criterios innovador y diversificador, o el tare también llamado puerro japonés (Allium tuberosum) es conservado por ES por los criterios innovador y diversificador. Diferentes criterios sustentan la conservación de estas hortalizas, lo cual y en sintonía con lo planteado en el capítulo 3, da cuenta de los múltiples escenarios que intervienen en la conservación de agrobiodiversidad; sin embargo, si de conservación estamos hablando, no hay dudas de que aquellos cultivos hortícolas conservados solo por un interlocutor, tienen un gran riesgo de desaparecer. En este sentido, la redundancia, entendida como la conservación de una etnoespecie/etnovariedad llevada a cabo por más de una familia agricultora, se posiciona como una medida de resiliencia. Estos datos, sobre cultivos hortícolas conservados por una o pocas familias, son interesantes para los proyectos actuales de rescate y revalorización de la agrobiodiversidad (Garat et al., 2009; Garat et al., 2012). Para la distribución de las 
semillas conservadas, los espacios de intercambio como las ferias son fundamentales. Según Peroni \& Hanazaki (2002), los intercambios de semillas entre agricultores genera un tejido de contención contra la pérdida de agrobiodiversidad. En este sentido, tanto la especialidad de los agricultores y agricultoras sobre la diversidad conservada, como la existencia de circuitos para su circulación informal, son esenciales para la planificación de estrategias comunitarias de conservación de agrobiodiversidad.
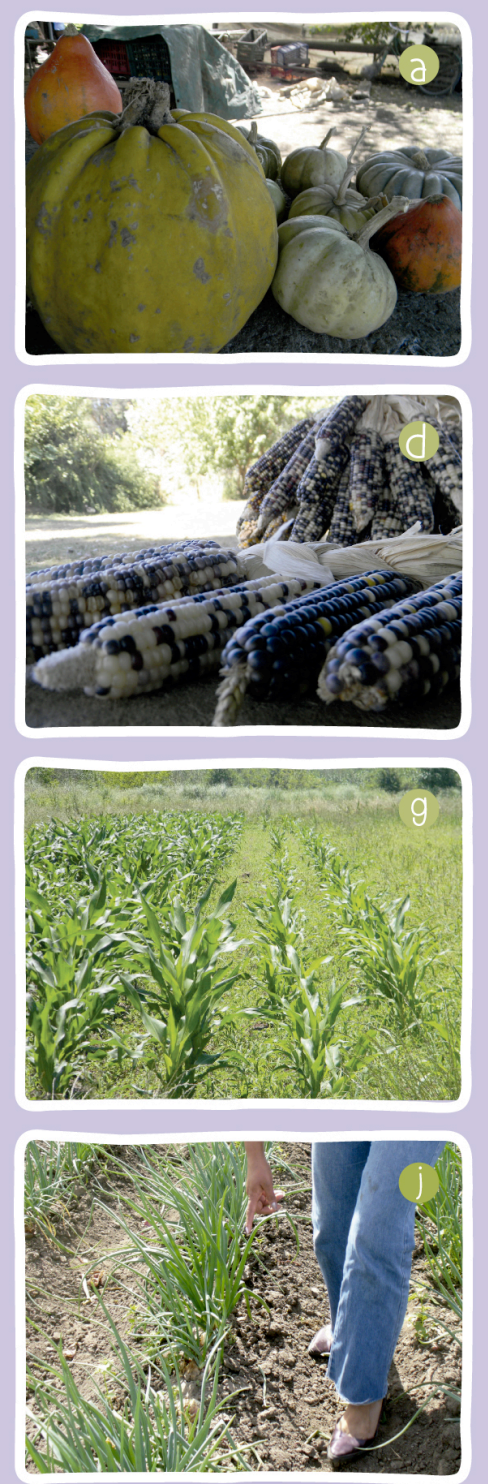
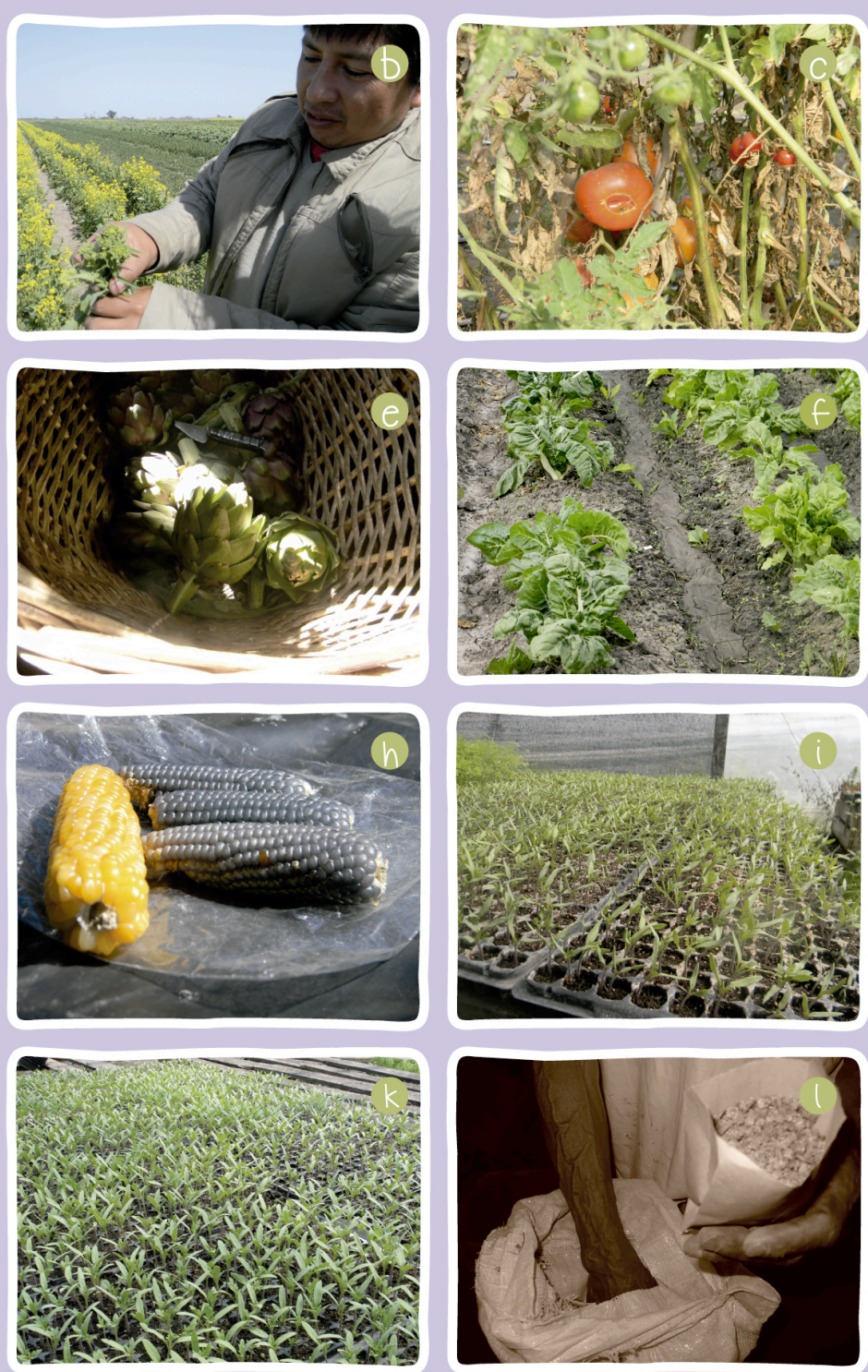

Figura 27: Etnoespecies cultivadas y conservadas en agroecosistemas del Cinturón Hortícola Platense. Fotos de la autora zapallos (Cucurbita spp.) grilo (Brassica napus) acelga de palo blanco (Beta vulgaris var. cicla) tomate platense (Solanum lycopersicum) maíz de colores (Zea mays) maíz turco y maíz (Zea mays) (j) tomate platense (Solanum lycopersicum) alcaucil ñato y alcaucil francés (Cynara cardunculus) 
Tabla 8: Agrobiodiversidad hortícola conservada por agricultores y agricultoras familiares del Cinturón Hortícola Platense.Cada asterisco (*) refiere a una etnoespecie registrada.

\begin{tabular}{|c|c|c|c|c|c|c|c|c|c|c|c|c|c|c|c|c|c|c|c|c|c|c|c|c|c|c|}
\hline Nombre cientifico & Nombre local & Familia & AT $\mid$ B & IIS B & $3 \mathrm{~V} / \mathrm{C}$ & CA & LCV & DAG & DY & ES F & $=\mathrm{LOH}$ & & IG & $\mathrm{JL} \mid \mathrm{J}$ & & & & LP $\mid \mathbf{M}$ & MG M & ILLMS & SNAl & & $\mathbf{P}$ & PA $\mid \mathrm{s}$ & $\mathbf{S} \mathbf{S}$ & sv \\
\hline Allium ampeloprasum & puerro, puerro francés de Caterá & Alliaceae & & & * & & & & & & & & & & & & & * & & & * & * & & & & \\
\hline Allium cep var.cepa & $\begin{array}{l}\text { cebolla morada, verdeo, cebolla, cebolla } \\
\text { balanceana, cebolla de verdeo morada, } \\
\text { cebolla morada, cebolla blanca, Cebolla } \\
\text { colorada, Cebolla roja }\end{array}$ & Alliaceae & & & * & * & & & & & & * & & **** & & & & & * & & ** & ** & & & & * \\
\hline Allium fistulosum & cebolla de verdeo & Alliaceae & & & & & & & & & & & & & * & & & & & & & & & & & \\
\hline Allium sativum & ajo orgánico, ajo & Alliaceae & & & & & & & & & & & & * & & & & & & & * & & & & & \\
\hline Allium tuberosum & tare o puerro japonés & Alliaceae & & & & & & & & * & & & & & & & & & & & & & & & & \\
\hline Arachis hypogaea & maní colorado & Fabaceae & & & & & & & & * & & & & & & & & & & & & & & & & \\
\hline Beta vulgaris var. Cicla & $\begin{array}{l}\text { acelga, acelga de penca verde, acelga de palo } \\
\text { blanco, acelga de palo verde, acelga de penca } \\
\text { blanca nacional, acelga de penca verde nacional }\end{array}$ & Chenopodiaceae & & & & * & & * & & & & * & & ** & & ** & & * & & & * & * & & * & * & \\
\hline Beta vulgari var. vulgaris & remolacha & Chenopodiaceae & & & * & & & * & & & & & & & & * & & * & & & * & & & & & \\
\hline Brassica napus & nabiza, grilo, grilo nabo, & Brassicaceae & * & & & *** & & & & & & & & * & & & & ** & & & & ** & & & & \\
\hline Brassica oleracea var. capitata & repollo & Brassicaceae & & & & & & & & & & & & & & & & & & & & & & * & & \\
\hline Brassica oleracea var. italica & brocoli & Brassicaceae & & & & & & & & & & & & & & * & & & & & * & & & & & \\
\hline Capsicum annuum & $\begin{array}{l}\text { morrón calahorra, morrón, pimiento calahorra, } \\
\text { morrón chiquito picante, aji de la mala palabra }\end{array}$ & Solanaceae & & & & * & & * & & & & & & ** & & & & & * & & ** & ** & * & & & \\
\hline Capsicum sp. & $\begin{array}{l}\text { ají vinagre, aji variedad } 1 \text {, aji variedad } 2 \text {, aji varie- } \\
\text { dad } 3 \text {, aji variedad } 4 \text {, aji variedad } 5 \text {, aji variedad } 6 \text {, } \\
\text { aji variedad } 7 \text {, aji variedad } 8 \text {, aji variedad } 9 \text {, ají } \\
\text { campanita, aji redondito picante, aji vinagre el } \\
\text { tradicional, aji picante, aji verde, ají miracielo. }\end{array}$ & Solanaceae & * & & & & $\begin{array}{l}* * * \\
* * * \\
* * *\end{array}$ & & & ** & & & & & & & & & & & ** & * & & ** & & * \\
\hline Cichorium intybus & radicheta, achicoria & Asteraceae & & & & & & * & & & & & & & * & & & & & & . & * & & & & \\
\hline Citrullus lanatus & sandía amarilla, sandía enana, sandía cuarentina & Cucurbitaceae & & & & & & & & & & & & * & & & * & * & & & * & & & & & \\
\hline Cucumis melo & melón, melón amarillo & Cucurbitaceae & & & & & & & & & & * & & * & * & & & & & & & & & & & \\
\hline Cucurbita ficifolia & cayote, acayote & Cucurbitaceae & & & & & * & & & & & & * & & & & & & & & & & & & & \\
\hline $\begin{array}{l}\text { Cucurbita maxima subsp. } \\
\text { maxima }\end{array}$ & $\begin{array}{l}\text { zapallo plomo, zapallo variedad 1, zapallo varie- } \\
\text { dad } 2 \text {, zapallo variedad } 3 \text {, zapallito de tronco, } \\
\text { zapallito }\end{array}$ & Cucurbitaceae & & & & * & *** & & & & & & * & * & & * & * & & & & * & * & & * & & \\
\hline Cucurbita pepo & $\begin{array}{l}\text { zapallo anco, zapallo anquito batata, zuchini, } \\
\text { calabaza batata }\end{array}$ & Cucurbitaceae & & & * & & & & & & & * & * & * & & & & * & & & * & & & * & & * \\
\hline Cucurbita sp. & $\begin{array}{l}\text { zapallo, Calabaza, zapallo de angola, calabaza } \\
\text { verde, zapallo angolita, zapallito zuquini verde } \\
\text { redondo, zapallo turco, zapallo anco batata, } \\
\text { zapallo okaido }\end{array}$ & Cucurbitaceae & & & & ** & & & & & * & & & ** & * & & & * & & & *** & & & & & \\
\hline Cynara cardunculus & $\begin{array}{l}\text { alcaucil gringo INTA, alcaucil francés, } \\
\text { alcaucil violeta, alcaucil, alcaucil ñato }\end{array}$ & Asteraceae & * & & & * & & & & * & & & & & ** & & & ** & & & * & & & & & \\
\hline Daucus carota subsp. sativus & s zanahoria & Apiaceae & & & & & & * & & & & & & & & & & * & & & 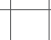 & & & & & \\
\hline Eruca vesicaria & rúcula & Brassicaceae & & & & & & * & & & & & & * & & & & . & & & & & & & & \\
\hline Foeniculum vulgare & hinojo platense, hinojo & Apiaceae & & & & * & & & & & & & & ( & * & & & & & & * & & & * & & \\
\hline Helianthus annus & girasol rojo, girasol & Asteraceae & & & & & * & & & * & & & & . & & & & & & & & & & & & \\
\hline Ipomoea batatas & batata, batata pata de rana & Convolvulaceae & & & * & & & * & & & & & & * & & & & * & & & & & & & & \\
\hline Lactuca sativa & $\begin{array}{l}\text { lechuga escarola fina, lechuga moradita, } \\
\text { lechuga, lechuga otra, lechuga }\end{array}$ & Asteraceae & & ** & & & & ** & & & & & & * & & & & & & & & & & & & \\
\hline Lagenaria siceraria & cucuza longa, calabaza de mate, cucuza & Cucurbitaceae & & & & & * & & & & & & & * & * & & & & & & & & & & & \\
\hline Luffa sp. & esponja vegetal & Cucurbitaceae & & & & & & & & & & & & * & & & & & & & & & & & & \\
\hline Petroselinum crispum & perejil & Apiaceae & & & & & & * & & & & & & * & & & & * & & & * & * & * & & & \\
\hline $\begin{array}{l}\text { Phaseolus vulgaris var. } \\
\text { vulgaris }\end{array}$ & $\begin{array}{l}\text { chaucha fina, chaucha balina, chaucha, } \\
\text { chaucha lengua de dragón, chaucha cronos, } \\
\text { poroto lengua de dragón, poroto }\end{array}$ & Fabaceae & * & & * & & & & & & * & & * & & & & * & * & * & & * & ** & & & & \\
\hline Physalis ixocarpa & tomate verde vestido & Solanaceae & & & & & & & & * & & & & & & & & & & & & & & & & \\
\hline Pisum sativum & arveja & Fabaceae & & & & & & & & & & & & * & & & & & & & & & & * & & \\
\hline Raphanus sativus var.sativus & nabo daikon & Brassicaceae & & & & & & & & & & & & & & & & & & & * & & & & & \\
\hline Sechium edule & papa del aire & Cucurbitaceae & & & & & & & & & & & & & & & & & & & * & & & & & \\
\hline Smallanthus sonchifolius & yacón & Asteraceae & & & & & * & & & & & & & & & & & & & & & & & & & \\
\hline Solanum lycopersicum & $\begin{array}{l}\text { tomate cherry variedad } 1 \text {, tomate cherry variedad } \\
2 \text {, tomate platense, tomate, tomate } 110, \text { tomate } \\
\text { cherry perita, tomate perita, tomate perita amarillo, } \\
\text { tomate perita largo, tomate tardío, tomate col } 45 \text {, } \\
\text { tomate perita zorzal, tomate perita zorzal }\end{array}$ & Solanaceae & * & ** & & * & * & * & & * & & * & & ** & * & ** & & ** & * & * & **** & ** & ** ** & ***** $*$ & ** & \\
\hline Solanum melongena & berenjena & Solanaceae & & & & & & * & & & & & & * & & * & & & & & * & & & & * & \\
\hline $\begin{array}{l}\text { Solanum tuberosum } \\
\text { subsp. tuberosum }\end{array}$ & рара & Solanaceae & & & & & & * & & & & & & * & & & & & & & & & & & * & * \\
\hline Vicia faba & haba & Fabaceae & & & & * & & & & & & & & * & * & & & & & & & & & & & \\
\hline $\begin{array}{l}\text { Vigna uinguiculata subsp. } \\
\text { sesquipedalis }\end{array}$ & chaucha metro & Fabaceae & & * & & & & & & & & & & & & & * & & & * & & & & & & \\
\hline Zea mays & $\begin{array}{l}\text { maíz enanito, choclo, maiz puro blanco, maíz puro } \\
\text { negro, maíz rojo, choclito, maíz colorado, máiz } \\
\text { turco, maizón, maíz choclo, maizón amarillo, maíz } \\
\text { blanco, maíz morado chiquito, maíz de colores, } \\
\text { maíz perla blanca }\end{array}$ & Poaceae & & * & * & & $\begin{array}{c}* * * \\
* * * \\
*\end{array}$ & * & * & * & & & * & *** & & & & & & * & * & & & * & * & * \\
\hline
\end{tabular}




\subsubsection{Semillas añosas}

Otro punto importante de analizar es aquel vinculado a la conservación de semillas que han pasado más de 5 años en manos de las familias agricultoras. Al ver el listado de semillas y quienes las conservan (Tabla 9) se ve que 19 de los cultivos hortícolas conservados, se mantienen en manos de las familias agricultoras por más de 5 años y que la conservación de dicha agrobiodiversidad está concentrada en 9 interlocutores. A su vez, resaltan algunas personas como LP que conserva las semillas más antiguas registradas y diversas variedades tradicionales del cinturón hortícola de La Plata (Garat et al., 2009), tales como el alcaucil ñato (Cynara cardunculus) conservada desde hace 60 años, el zapallo turco (Cucurbita sp.) y variedades heredadas como la batata pata de rana (Ipomoea batatas). En el caso de JP, conserva desde el año 1968 la cebolla de verdeo (Allium fistulosum) actualmente en desuso, ya que lo que se comercializa como cebolla de verdeo es el primer ciclo de (Allium cepa var. cepa). Puede verse que los interlocutores que conservan una mayor agrobiodiversidad añosa pertenecen al grupo etario de 50 años o más, lo cual no se contrapone con los resultados de la figura 4.6. Estos agricultores y agricultoras concentran la historia del territorio en sus relatos y sus semillas. Sus referencias acerca de que si la semilla es hibrida no se puede hacer muchos años, dos años nomás, ya que se va degenerando, y la distinción sobre las variedades locales, destacando la permanencia de sus características refleja años de conservar y seleccionar un cultivo, en sintonía con los cambios y deseos de los agricultores y agricultoras que lo conservan. Las situaciones analizadas, exponen la estrategia dual de conservación que está atravesando el territorio en estudio. Por un lado la conservación de lo tradicional, lo arraigado a la historia y por otro, la conservación como estrategia de permanencia en un sector altamente competitivo.

Trabajos realizados desde la perspectiva agroecológica (Carrascosa et al., 2011; Del Cura et al., 2015; Días-Bautista et al., 2008; Silveira 2015) vinculados a la conservación de saberes y semillas tienen un anclaje en las acciones de los individuos intervinientes. Desde una mirada de trabajo participativo la identificación de agricultores con experiencia sobre conservación de semillas es de suma importancia (González et al., 2014). Estos agricultores a los cuales podemos referirnos como sabedores o agricultores expertos, son esenciales para el mantenimiento de la práctica de conservación de semillas (González et al., 2014). La permanencia en el territorio de estos conocimientos, se vincula a su posible circulación. La transmisión a generaciones más jóvenes que se da durante la acción compartida, la circulación e intercambio en encuentros como las ferias de semillas o fiestas de variedades locales como el tomate platense, favorecen este proceso. Queda pendiente 
para futuros estudios profundizar en las formas de transmisión del conocimiento. El pasaje generacional, el diálogo entre agricultores y la incorporación de conocimientos provenientes del ámbito institucional, es de suma importancia para una comprensión más profunda acerca de la dinámica de este componente de la diversidad biocultural.

Tabla 9: Agrobiodiversidad conservada por más de 7 años en agroecosistemas del Cinturón Hortícola Platense.

\begin{tabular}{|c|c|c|c|c|c|}
\hline Sigla & Grupo etario & Nombre científico & Nombre local & Familia botánica & $\begin{array}{c}\text { Años que conserva } \\
\text { esa semilla }\end{array}$ \\
\hline $\mathrm{CA}$ & $<50$ & Cynara cardunculus & Alcaucil francés & Asteraceae & 16 años \\
\hline $\mathrm{HC}$ & $\geq 50$ & Cucurbita pepo & Zapallo anquito batata & Cucurbitaceae & 8 años \\
\hline$J \mathrm{~L}$ & $\geq 50$ & Beta vulgaris var. cicla & Acelga de palo blanco & Chenopodiaceae & 8 años \\
\hline \multirow[t]{3}{*}{$\mathrm{JP}$} & \multirow[t]{3}{*}{$\geq 50$} & Allium fistulosum & Cebolla de verdeo & Alliaceae & comprada en el 68 \\
\hline & & Cucurbita sp. & Zapallito zuquini verde redondo & Cucurbitaceae & de Italia \\
\hline & & Lagenaria siceraria & Cucuza & Cucurbitaceae & hace mucho \\
\hline \multirow[t]{2}{*}{ JV } & \multirow[t]{2}{*}{$<50$} & Beta vulgaris var. cicla & Acelga de penca verde & Chenopodiaceae & 35 años \\
\hline & & Solanum melongena & Berenjena & Solanaceae & 7-8 años \\
\hline \multirow[t]{6}{*}{ LP } & \multirow[t]{6}{*}{$\geq 50$} & Beta vulgaris var. cicla & Acelga & Chenopodiaceae & 10 años \\
\hline & & Cucurbita sp. & Zapallo turco & Cucurbitaceae & 30 años \\
\hline & & Ipomoea batatas & Batata pata de rana & Convolvulaceae & 20 años \\
\hline & & Cynara cardunculus & Alcaucil francés & Asteraceae & 40 años \\
\hline & & Solanum lycopersicum & Tomate platense & Solanaceae & años \\
\hline & & Cynara cardunculus & Alcaucil ñato & Asteraceae & 60 años \\
\hline NA & $<50$ & Citrullus lanatus & Sandía amarilla & Cucurbitaceae & muchos años \\
\hline \multirow[t]{3}{*}{ NG } & \multirow[t]{3}{*}{$\geq 50$} & Allium ampeloprasum & Puerro francés de Caterá & Alliaceae & 15 años \\
\hline & & Beta vulgaris var. cicla & Acelga penca verde nacional & Chenopodiaceae & hace años \\
\hline & & Cichorium intybus & Achicoria & Asteraceae & 6-7 años Italia \\
\hline SV & $<50$ & Zea mays & Choclo & Poaceae & años \\
\hline
\end{tabular}

\subsection{Conclusiones}

Si bien en el Cinturón Hortícola de La Plata las prácticas hortícolas y los conocimientos que las orientan, son el resultado de un tiempo relativamente corto de experiencia de los agricultores y agricultoras con el entorno local, pueden considerarse conocimientos y prácticas ligadas a tradiciones e incorporaciones tecnológicas, que han resultado en nueva agrobiodiversidad, y en acciones sobre el entorno. Dichas prácticas y conocimientos reflejan la adaptación a la situación socioambiental, por ejemplo, la presencia de tradiciones familiares, las preferencias culinarias, las estrategias desarrolladas para subsistir en un mercado exigente y la diversidad de criterios que 
operan en la conservación in situ. Así, la puesta en práctica de la conservación de semillas, mediada por los conocimientos implicados, se retroalimenta, para dar continuidad a la conservación de diversidad biocultural. Los resultados presentados en el presente capítulo, indican que los agricultores y agricultoras familiares del Cinturón Hortícola Platense, poseen conocimientos sobre el conjunto de prácticas que hacen a la conservación in situ de semillas. La diversidad de aplicaciones de esta práctica en el marco de las producciones, la restringen en algunos casos a la conservación de semillas locales, y en otros a una estrategia de conservación de variedades comerciales, o inclusive, a la experimentación con nuevas hortalizas. Las diferentes situaciones encontradas, en cuanto a la cantidad de hortalizas conservadas, manifiestan diferencias en el posicionamiento de los agricultores y agricultoras sobre cuánta agrobiodiversidad y qué conservar, inclusive en aquellas situaciones donde la presencia de conocimientos no implica conservación. Los resultados obtenidos sugieren un aspecto de suma importancia para comprender el vínculo entre agrobiodiversidad y saberes, y es que puede haber saberes sin conservación, pero no es posible el sentido inverso de estos componentes. Por lo tanto, el conocimiento trasciende la puesta en práctica de la conservación, y se establece como condición necesaria para hacer efectiva la conservación in situ. Este conocimiento orienta las prácticas hortícolas según los diversos criterios de selección y ajustan el conocimiento que las originó a las nuevas circunstancias, según Pochettino et al. (2014), en dicha característica, reside su valor adaptativo. Siendo que, incluso en los casos en donde la conservación se restringe a una única especie botánica, la actitud inquieta e innovadora de quienes conservan, acciona para la permanencia de los saberes.

La información registrada y discutida en el presente capítulo indica que "Los agricultores y agricultoras familiares del Cinturón Hortícola Platense mantienen conocimientos sobre la práctica de conservación de semillas. Los conocimientos son condición necesaria para el mantenimiento in situ de agrobiodiversidad".

Estos resultados, cobran especial relevancia al considerarlos en el marco del modelo productivista que prevalece en el territorio en estudio, el cual instala la lógica, de las semillas como insumo externo y rechaza las prácticas y saberes locales.

En relación con la dinámica de los saberes, se evidencia la existencia de conocimientos ligados a la conservación de semillas locales y a su vez, exponen la adquisición y adaptación de nuevos saberes vinculados a la conservación de semillas comerciales. Estas semillas, abundantes hoy en el territorio en estudio, son presentadas por los interlocutores como un insumo necesario para su permanencia en el sector productivo mercantil. Es dicha necesidad o deseo, la que acciona y promueve la creatividad, movilización e incorporación de conocimientos. En simultáneo con el desarrollo de 
estrategias para su conservación, el límite que establecen los híbridos en cuanto a la permanencia en el tiempo de sus características organolépticas, los posiciona como el impedimento más nombrado. Sin embargo, este impedimento a la vez que limita la conservación per se, estimula la dinamización de los conocimientos.

Nuevos interrogantes surgen para futuros estudios al contemplar un territorio que cuenta con agricultores y agricultoras con conocimiento sobre conservación de semillas dedicado a materiales genéticos de diferentes orígenes. ¿Se están transmitiendo a las generaciones jóvenes los saberes existentes? ¿Qué pasará con los saberes que no se están poniendo en práctica? En caso de que el costo de las semillas comerciales bajase y se abandonara su conservación ¿será suficiente la conservación aplicada a cultivos locales y de autoconsumo para mantener activa la práctica de conservación?

La contribución de este estudio, apunta a tener una mirada más clara sobre la situación en la que se encuentran los saberes sobre la conservación de semillas, en un contexto pluricultural, en constante transformación, a fin de aportar elementos conceptuales para el desarrollo y fortalecimiento de estrategias que promuevan la valoración y circulación de la diversidad biocultural. 


\subsection{Bibliografía}

Abbona, E.A.; S.J. Sarandón, M.E. Marasas \& M. Astier. 2007. Ecological sustainability evaluation of traditional management in different vineyard systems in Berisso, Argentina. Agriculture, Ecosystems and Environment 119 (3- 4): 335-345.

Ahumada, A.; F. Mainella, M.M. Bonicatto, M.L. Pérez, M.L. Pochettino, M. Marasas, M. Moricz, M. Pérez, N. Anglese, P. Domínguez \& V. Parmigiani. 2009. Segunda Feria Provincial de Semillas Nativas y Criollas "Sembrando Esperanza". Editor responsable CYTED- Programa Iberoamericano Ciencia y tecnología para el Desarrollo. Jujuy, Argentina.

Altieri, M.A \& C.I. Nicholls. 2004. Semillas nativas: patrimonio de la humanidad esencial para la integridad cultural y ecológica de la agricultura campesina en: Cavalho H.M (compilador) Semillas. Patrimonio del pueblo al servicio de la humanidad, 1: 161175.CLOC, Quito.

Altieri, M.A; C.I. Nicholls, A. Henao \& M.A. Lana. 2015. Agroecology and the design of climate change-resilient farming systems. Agronomy for Sustainable Development 35:869-890

Altieri, M.A. \& L.C. Merrick. 1987. In situ conservation of crop genetic resources through maintenance of traditional farming systems. Economic Botany 41: 86-96.

Archenti, A.; R. Ringuelet \& M. Salva. 1993. Los procesos de diferenciación de los productores hortícolas de La Plata. Continuidad y Cambio. Revista ETNIA. Olavarría 38-39: $57-83$

Benencia, R. 2006. Transformaciones de la horticultura periurbana bonaerense en los últimos cincuenta años. El papel de la tecnología y la mano de obra. Disponible en: https://periferiaactiva.files.wordpress.com/2012/08/roberto-benecencia.pdf [consulta octubre de 2015].

Berkes, F.; J. Colding, \& C. Folke. 2000. Rediscovery of Traditional ecological knowledge as adaptive management. Ecological Applications 10: 1251-1262.

Bisht, I.S., Pandravada, S.R.; Rana, J.C.; Malik, S.K.; Singh, A.; Singh, P.B.; Ahmed, F.; \& K.C. Bansal. 2014. Subsistence Farming, Agrobiodiversity, and Sustainable Agriculture: A case study. Agroecology and Sustainable Food Systems 38: 890-912. 
Bonicatto, M.M.; V. Fernández, N.G. Gargoloff, M. Marasas, L. Muscio, M. Pérez \& M.L.Pochettino. 2010. Sembrando Esperanza. III Feria Provincial de Semillas Nativas y Criollas. En defensa de la vida de la soberanía alimentaria. Por una economía solidaria, construyendo la casa de todos. Ediciones INTA. Publicaciones IPAF- Región Pampeana. La Plata, Argentina.

Cababié, J.; M.M. Bonicatto \& E.A. Abbona. 2015. Semillas y saberes de los agricultores familiares. ¿Cuál es el rol de las ferias de intercambio en su reproducción y conservación? Revista Facultad de Agronomía La Plata 114 (Núm. Esp.1) Agricultura Familiar, Agroecología y Territorio: 122-128.

Campbell, B.C \& J.R. Veteto. 2015. Free seeds and food sovereignty: anthropology and grassroots agrobiodiversity conservation strategies in the US South. Journal of Political Ecology 22: 357-465.

Carpenter, D. 2005. The In Situ Conservation of Rice Plant Genetic Diversity: A Case Study from a Philippine Barangay. Agriculture and Human Values 22 (4): 421-434.

Carrascosa, M.; T. García-Muñoz, I. Sanz \& J.J. Soriano. 2011. Guía de conocimiento sobre utilización y manejo tradicional ligadas a las variedades autóctonas. Volumen I. Ed. Red Andaluza de Semillas. Sevilla.

Castro, A. S. 2016. Saberes migrantes. Trayectorias de productores bolivianos del periurbano platense (Tesis de grado). Presentada en Universidad Nacional de La Plata. Facultad de Humanidades y Ciencias de la Educación para optar al grado de Licenciada en Sociología. Disponible en:http://www.memoria.fahce.unlp.edu.ar/tesis/te.1295/te.1295.pdf

de Boef, W.S. \& M.H. Thijssen. 2007. Ferramentas participativas no trabalho com cultivos, variedades e sementes. Wageningen UR. Brasil.

de Boef, W.S. 2007. Uma perspectiva de sistemas aproximando agricultores e pesquisadores no manejo comunitário da agrobiodiversidade, em W.S. de Boef.; M.H. Thijssen, J. Bernardi Ogliari \& B.R. Sthapit (organizadores). Biodiversidade e Agricultores. Fortalecendo o manejo comunitário. L\&PM Editores. Brasil. 2.5: 59-66.

Del Cura, F.; J.J. Quintero, E. Rosas, H. Porras, J. Bracho \& G. Bustos. 2015. Experiencia en la conservación del germoplasma local y conocimiento ancestral en 
comunidades rurales del Estado Mérida, Venezuela. Memorias del V Congreso Latinoamericano de Agroecología. 5 Pp. Disponible en:

http://sedici.unlp.edu.ar/handle/10915/52154.

Días-Bautista, M.; B.E. Herrera-Cabrera, J. Ramírez Juárez, M. Alipath-Fernández \& A. Delgado-Alvarado. 2008. Conocimiento campesino en la selección de variedades de Haba (Vicia faba L.) en la sierra norte de Puebla, México. Interciencia 33 (8): 610615.

Eyssartier, C.; A.H. Ladio \& M. Lozada. 2011. Traditional horticultural knowledge change in rural population of the Patagonian steppe. Journal of Arid Environments 75: 78-86.

Garat, J.J.; A. Castro, S. Gramuglia, A. Nico \& A. Ahumada. 2007. El rescate de la biodiversidad local y la acción colectiva: una estrategia de desarrollo a través de la revalorización de hortalizas locales en el cinturón verde de La Plata, Buenos Aires, Argentina. Revista Brasilera de Agroecología 2 (1): 430:434.

Garat, J.J.; Ahumada, A.; Otero, J.; Terminiello, L.; Bello, G. \& M.L. Ciampagna. 2009. Las hortalizas típicas locales en el cinturón verde de La Plata: su localización, preservación y valorización. Horticultura Argentina 28(66):32-39.

Garat, J.J. \& J. Otero. 2012. ¿Desde dónde intervenimos cuando intervenimos? El caso del proyecto "Tomate Platense". Mundo Agrario. Revista de estudios rurales, primer semestre, Vol. 12, n² 24. Con referato. ISSN: 1515-5994

Gargoloff, N.A.; C. Albaladejo \& S.J. Sarandón. 2011. La entrevista paisajística: un método para situar las prácticas y saberes de los agricultores. Cadernos de Agroecologia 6 (2): 1-5.

Girard, N.; D. Magda, C. Noseda \& S. Sarandón. 2014. Practicing agroecology: Management principles drawn from small farming in Misiones (Argentina): Communication au congrès IFSA. Berlín.

González, J.M.; M. Carrascosa, J.J. Soriano, T. García-Muñoz, L. Toledo, P. López, J. Hidalgo \& A. Navarro. 2014. Investigación-Acción Participativa como herramienta de empoderamiento: El caso de la descripción participativa de variedades tradicionales en las redes de intercambio de semillas. Actas del IV Congreso Internacional de Etnobotánica ICEB, España. 
Hilgert, N.I. \& G.E. Gil. 2005. Traditional Andean agriculture and changing processes in the Zenta river basin, Salta, Northwestern Argentina. Darwiniana 43 (1-4): 30-43.

Ladio, A.H. 2011. Traditional knowledge of edible wild native and exotic plants in the context of cultural change in human populations of arid Patagonia. Bioremediation, Biodiversity and Bioavailability. 5: 81-84

Lyon, A.; M.M. Bell, C. Gratton \& R. Jackson. 2011. Farming without a recipe: Wisconsin graziers and new directions for agricultural science. Journal of Rural Studies 27:384-393.

Martin, G.J. 1995. Etnobotánica. Manual de métodos. Editorial Nordan Comunidad. Montevideo, Uruguay.

Montalba, R. 2013. "Modernización" de sistemas agrícolas tradicionales, agrobiodiversidad y riesgo. Un análisis agroecológico a partir de la realidad e historia de los mapuches de Chile en: C.I. Nicholls Estrada.; L.A. Ríos Osorio \& M.A. Altieri (editores.) Agroecología y resiliencia socioecológica: adaptándose al cambio climático, 105-123. Medellín, Colombia: REDAGRES-CYTED.

Mooney, P.R. 1992. Towards a folk revolution. Intermediate Technology Publications, Londres, 125-145.

Nazarea, V. 1998. Cultural Memory and Biodiversity. The University of Arizona Press. Estados Unidos de América.

Nicholls, C.I. 2013. Enfoques agroecológicos para incrementar la resiliencia de los sistemas agrícolas al cambio climático en: C.I. Nicholls Estrada.; L.A. Ríos Osorio \& M.A. Altieri (editores.) Agroecología y resiliencia socioecológica: adaptándose al cambio climático, 18-29. Medellín, Colombia: REDAGRES-CYTED.

Nico, A.; J. Garat, A. Castro, S. Gramuglia, A. Ahumada, S. Gamboa \& S. Sarandón. 2006. Recursos genéticos de plantas hortícolas alóctonas en el cinturón verde metropolitano (La Plata, Buenos Aires, Argentina). Plant Genetic Resources Newsletter, №148.

Olsson, P.; C. Folke \& F. Berkes. 2004. Adaptive Comanagement for Building Resilience in Social-Ecological Systems. Environmental Management 34 (1): 75-90. 
Peroni, N. \& N. Hanazaki. 2002. Current and lost diversity of cultivated varieties, especialli cassava, under swidden cultivation systems in the Brazilian Atlantic Forest. Agriculture, Ecosystems and Environment 92: 171-183.

Pochettino, M.L.; Hurrell, J.A \& M.M. Bonicatto. 2014. Horticultura periurbana: estudios etnobotánicos en huertos familiares y comerciales de la Argentina. Ambienta. 107:8699.

Pochettino, M.L. \& V. Lema. 2008. La variable tiempo en la caracterización del conocimiento botánico tradicional. Darwiniana 46(2): 227-239.

Red Andaluza de Semillas. 2009. Manual para la utilización y conservación de variedades locales de cultivo Red Andaluza de Semillas valorización, comercialización y producción. Sevilla, España. 57 p.

Reijntjes, C.; B. Haverkort \& A. Waters Bayer. 1999. Agricultura para o futuro. Uma introdução a agricultura sustentável e de baixo uso de insumos externos. AS-PTA/ ILEIA, Rio de Janeiro.

Reyes-García, V. \& N. Marti Sanz. 2007. Etnoecología: punto de encuentro entre naturaleza y cultura. Ecosistemas. Revista científica de ecología y medioambiente 16 (3): 46-55.

Reyes-García, V.; N. Martí, T. McDade, S. Tanner \& V. Vadez. 2007. Concepts and methods in studies measuring individual Ethnobotanical knowledge. Journal of Ethnobiology 27(2): 182-203.

Riat, P. 2012. Conocimiento campesino, el "monte santiagueño" como recurso forrajero. Trabajo y Sociedad. 19: 477-491.

Ríos-Osorio, L.A.; W. Salas-Zapata \& J.A Espinosa-Alzate. 2013. Resiliencia socioecológica de los agroecosistemas. Más que una externalidad en: C.I. Nicholls Estrada.; L.A. Ríos Osorio \& M.A. Altieri (editores.) Agroecología y resiliencia socioecológica: adaptándose al cambio climático, 60-77. Medellín, Colombia: REDAGRES-CYTED.

Selis, D. 2000. Efectos del cambio tecnológico sobre las condiciones de producción y reproducción del sector hortícola de La Plata. Serie Estudios/Investigación. Facultad de Humanidades y Ciencias de la Educación. UNLP. 
Sevilla Guzmán, E. 2006. De la sociología rural a la Agroecología. Icaria, Barcelona.

Silveira, R.P. 2015. Diversidade de variedades crioulas de tomates conservadas por camponeses no Municipio de Anchieta, oeste de Santa Catarina. Universidade Federal de Santa Catarina. Programa de posgraduaçao en agroecosistemas. 197 pp. Disponible en: https://repositorio.ufsc.br/handle/123456789/156749.

Soriano J.J, M. Carrascosa, J.M. González, T. García \& I. Sanz. 2012. Mejora agroecológica participativa (map) y biodiversidad agrícola. Aplicación de la investigación acción participativa al manejo de las variedades tradicionales en Andalucía. Agroecología 7 (2): 21-30.

Stupino, S.A.; J.L. Frangi, S.J. Sarandón, M.F. Arturi \& A.C. Ferreira. 2008. Plant diversity in two horticultural farms under organic and conventional management in La Plata, Argentina: A case study. Revista Brasileira de Agroecologia 3(3): 24-35.

Subedi, A.; B. Sthapit, R.B. Rana, B. Baniya, D. Paudel, D. Singh \& P. Shrestha. 2007. Análise participative de redes sociais de sementes, en W.S. de Boef.; M.H. Thijssen, J. Bernardi Ogliari \& B.R. Sthapit (organizadores) Biodiversidade e Agricultores. Fortalecendo o manejo comunitário. L\&PM Editores. Brasil. 4.6: 168-177.

Taylor, S.J. \& R. Bogdan. 1987. Introducción a los métodos cualitativos de investigación. Ediciones Paidós Ibérica. Barcelona, 344 pp.

Tengö, M. \& K. Belfrage. 2004. Local Management Practices for dealing with Change and Uncertainty: A Cross-scale comparison of cases in Sweden and Tanzania. Ecology and Society 9 (3):4.

Toledo, V. 1992. What is ethnoecology? Origins, scope, and implications of a rising discipline, Etnoecológica 1: 5- 2.1

Toledo, V. 2005. La memoria tradicional. La importancia de agroecológica de los saberes locales. LEISA Revista de Agroecología 20 (4): 16-19.

Toledo, V. M. \& N. Barrera-Bassols. 2008. La memoria biocultural. La importancia ecológica de las sabidurías tradicionales. Serie Perspectivas Agroecológicas. Ícara. Barcelona.

Tomkins, E.L. \& W.N. Adger. 2004. Does Adaptive Management of Natural Resources Enhance Resilience to Climate Change? Ecology and Society 9(2): 10. 
Veteto J.R. 2008. The history and survival of traditional heirloom vegetable varieties in the southern Appalachian Mountains of western North Carolina. Agriculture and Human Values 25:121-134

Veteto, J.R. 2014. Seeds of Persistence: Agrobiodiversity in the American Mountain South. Culture, Agriculture, Food and Environment 36 (1): 17-27. 


\section{CAPÍTULO 5:}

La valoración de la conservación de semillas hortícolas en actores externos al agroecosistema

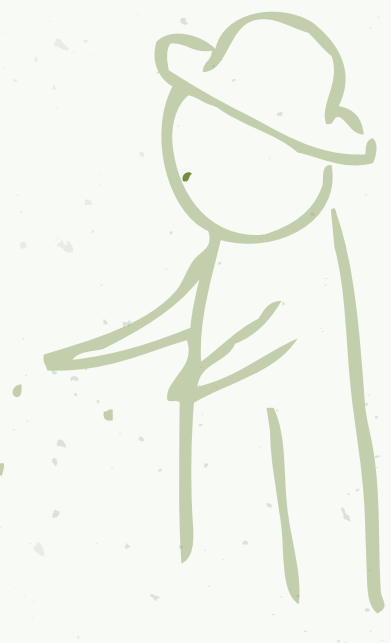




\section{CAPÍTULO 5 La valoración de la conservación de semillas hortícolas en actores externos al agroecosistema}

"La semilla tiene que ser buena sino ¿para qué sembrar?"

(Bonicatto 2014I. Entrevista a comercio 1)

\section{I Introducción}

En la actualidad nos enfrentamos a enormes presiones que pretenden imponer la uniformidad en vez de la diversidad, uniformidad tanto biológica como cultural, produciéndose un proceso de pérdida de biodiversidad (González, 2007). El trabajo realizado por de Boef (2007) plantea dos sistemas implicados en el uso y conservación de la agrobiodiversidad, el sistema informal, en el cual los agricultores y agricultoras son los actores principales de la agrobiodiversidad conservada y cultivada y el sistema formal, liderado por las instituciones y empresas implicadas en la conservación, mejoramiento y comercialización de agrobiodiversidad. Considerando lo descripto, la conservación de semillas interpretada desde la óptica de los agricultores y agricultoras, es sólo un eslabón, siendo necesario ampliar la mirada, para contemplar la valoración y acción de otros actores, que influyen en el dinamismo de la conservación de semillas. En este sentido, se entiende que las valoraciones de los actores externos, establecen un diálogo con las decisiones y acciones de los agricultores locales. Diversos estudios (Almekinders et al., 1994; de Boef, 2007; Wood \& Lenné, 1996) sostienen que el sistema formal de producción de semillas, suele ignorar el rol de los agricultores y agricultoras en el mejoramiento, producción y conservación de la agrobiodiversidad. A su vez el trabajo de Almekinders et al., 1994, plantea que la investigación en torno a la conservación in situ data de hace unos pocos años.

En el capítulo 1.1.1 se describe la historia del Cinturón Hortícola Platense, concluyendo en un tiempo actual, en el que el modelo productivo que predomina es el de la Revolución Verde. Este modelo, ligado al sistema formal, mercantiliza las semillas, transformando el concepto tradicional de símbolo de vida y cultura, en bienes comerciables con fines de lucro. Las semillas producidas tienen objetivos económicos, concretados a partir de semillas de alto potencial de rendimiento, en su mayoría de condición híbrida. Según Blandi (2016) y Seibane et al. (2014) las empresas que 
producen semillas y agroquímicos cuentan con una gran presencia en el Cinturón Hortícola Platense a través de un contacto permanente con las casas de ventas de agroquímicos y organizando a nivel local ensayos y demostraciones para difundir sus productos. Esto genera, desde las casas de venta de agroquímicos, una gran influencia sobre los agricultores, ya que se encuentran en permanente contacto con ellos. A su vez, el trabajo de Gallardo (2012) analiza los diferentes momentos por los que ha transitado la producción nacional de semillas, y reconoce la ausencia de políticas públicas consistentes de largo plazo en cuanto a tecnología agrícola. El trabajo de Castro (2016) realizado con agricultores bolivianos, establece que el discurso en torno al modelo convencional estuvo mediatizado por actores referentes para los agricultores, como sus connacionales y patrones e ingenieros agrónomos (asesores privados, de organismos públicos o de las agronomías). La legitimidad de estas voces radicaba en el reconocimiento del saber científico como sinónimo de progreso, versus el saber campesino considerado como atrasado.

Como se planteó en el capítulo 1.2.1, el Cinturón Hortícola Platense a lo largo de su historia, ha estado vinculado con diferentes instituciones y organismos estatales. Según Marasas et al. (2014), en los últimos años, el estado empezó a tener presencia en este territorio. Entre sus estrategias de desarrollo se destacan el programa de extensión rural llamado Cambio Rural, perteneciente al Instituto Nacional de Tecnología Agropecuaria (INTA); las articulaciones entre el Ministerio de Agricultura de la Nación y el Municipio de La Plata a través del programa del periurbano y el Ministerio de Asuntos agrarios de la Provincia de Buenos Aires y el Servicio Nacional de Sanidad y Calidad Agroalimentaria (SENASA) con charlas sobre buenas prácticas agrícolas (Seibane et al., 2014) e inclusive espacios de formación para agricultores y agricultoras como la Escuela periurbana de agroecología llevada adelante durante 2014 a 2016, y la proliferación de cadenas cortas de comercialización en la horticultura familiar a partir de iniciativas tanto de organizaciones de productores como del Estado (Castro \& Pérez, 2017). Es este sentido, Cromwell \& Tripp (1994), destacan la importancia de la vinculación de los agricultores y agricultoras con los programas de extensión brindados por las instituciones en procesos que apoyen la conservación in situ.

De la mano con el modelo hegemónico, se destaca la amplia incorporación tecnológica de invernáculos, agroquímicos y semillas de alto rendimiento (Hang et al., 2010; García, 2011), la cual motivó la instalación de comercios dedicados a la venta de los insumos mencionados y asesoramiento privado. A su vez, García (2014) sostiene que las innovaciones generadas bajo el modelo de la Revolución Verde, surgen como adiciones 
discretas, universalmente aplicables, a la vez que ignoran el conocimiento local. El trabajo de Blandi (2016) realizado en el Cinturón Hortícola Platense describe como el mercado y el asesoramiento técnico, juegan en contra de la sustentabilidad de los sistemas. Siendo que el mercado exige una alta calidad cosmética en la comercialización, que solo es lograda con una gran utilización de agroquímicos (Marasas et al., 2014), sumado a un avance en la presión ejercida desde la comercialización hacia las decisiones que habitualmente toma el agricultor (Hang et al., 2013). Sin embargo, en procesos puntuales como el descripto por Castro \& Pérez (2017), los autores sostienen que la intervención en el territorio de técnicos de instituciones del Estado, fue un elemento dinamizador de los cambios hacia la agroecología.

Según Blandi (2016) en el Cinturón Hortícola Platense, la dimensión económica subordinó la dimensión técnico-científica, induciendo a la propia ciencia a generar técnicas rentables pero ecológica y socialmente incorrectas. Esto se debe a que tradicionalmente los profesionales de las ciencias agrarias (los agrónomos) han sido formados de acuerdo con un modelo agrícola productivista, basado en una intensa mecanización agrícola, un uso creciente de agroquímicos y variedades mejoradas de cultivos (Sarandón, 2008; Sarandón \& Blandi, 2015). Por lo tanto, no es de extrañar que reproduzcan, en la investigación y extensión, el mismo estilo de agricultura con el que fueron formados.

La complejidad descripta conduce a nuevos preguntas en relación a otros actores que transitan el territorio en estudio y tienen injerencia sobre la agrobiodiversidad conservada. ¿Qué piensan los investigadores, técnicos, comerciantes sobre la práctica de conservar semillas realizada por agricultores y agricultoras? Estos actores, ¿incorporan valoraciones devenidas del modelo dominante? A través de su valoración, ¿promueven o debilitan la conservación de la biodiversidad, sustentabilidad y soberanía alimentaria? La propuesta de este capítulo es recorrer las apreciaciones sobre el tema en desarrollo a fin de contar con más elementos para evaluar las presiones externas y su acción positiva o negativa sobre la conservación de semillas y conocimientos.

Durante este capítulo se aborda la hipótesis 4, la cual enuncia que: "En los actores externos a la producción (técnicos, investigadores y comerciantes) prevalecen criterios productivistas en la valoración del material reproductivo hortícola"

Los objetivos de este capítulo fueron:

- Registrar criterios de valoración del material reproductivo en los actores externos a la producción (técnicos, investigadores y comerciantes). 
- Ordenar los criterios de valoración de los actores externos.

- Analizar la presencia de criterios productivistas en los actores externos.

\subsection{Metodología}

Para abordar estos interrogantes se analizaron las percepciones y opiniones referidas a las semillas de diferentes sujetos externos a la producción, pero que son parte de las relaciones y tensiones que se dan en el territorio en estudio en relación a la agrobiodiversidad cultivada. Para esto se entrevistó a aquellas personas a cargo de la comercialización en los negocios de venta de agroinsumos (incluidas las semillas) y a profesionales de diferentes instituciones de educación, investigación y desarrollo (INTA, Consejo Nacional de Investigaciones Científicas y Técnicas CONICET, Facultad de Ciencias Agrarias y Forestales-UNLP, Ministerio de Agroindustrias) cuyo trabajo se encuentre en vinculación con el territorio en estudio. Los criterios de estos actores son entendidos como criterios emic, que a diferencia de los analizados en el capítulo III, no vienen de la tradición en el cultivo, sino de otros sistemas, incorporados a partir de la experiencia formativa. La intervención de estos actores en el territorio es a través de asesoramiento, programas o áreas de investigación y extensión, y al hacerlo promueven, según sus objetivos y valoraciones, el uso y desuso de determinados cultivos y variedades, así como en la promoción o no del modelo productivista hegemónico. Para describir los criterios que operan sobre la agrobiodiversidad, se utilizaron entrevistas estructuradas (Anexo 3) con preguntas previamente establecidas en la misma secuencia (Albuquerque et al., 2010). Se establecieron dos conjuntos de interlocutores. Uno conformado por los comerciantes de agroinsumos en locales de venta y otro por profesionales Ingenieros Agrónomos, Licenciados en Biología cuyo trabajo se vincula a la investigación, docencia, extensión y/o asesoramiento técnico. Se realizaron entrevistas semiestructuradas a 10 comercios situados en diferentes localidades del Cinturón Hortícola de La Plata: Lisandro Olmos (5), Abasto (3), Etcheverry (1), El Peligro (1), y 13 personas vinculadas a los roles de investigador, técnico extensionista y técnico asesor. En el caso de los comercios las entrevistas se realizaron de manera presencial y para el caso de investigadores y técnicos extensionistas, se envió el cuestionario de forma digital. El primer momento de las entrevistas se dedicó a explicar a los interlocutores en lenguaje apropiado y divulgativo, o por escrito en los casos de archivo digital, los fundamentos, objetivos, implicancias y alcances de la investigación (Alexiades \& Laird, 2002), acordando con los interlocutores, el consentimiento en cuanto al uso y difusión de 
la información y fotografías. El número de entrevistas no se determinó previamente sino que se trabajó en el área de influencia y en función de la disposición a ser entrevistado. Durante el cuestionario se presentaron preguntas dicotómicas (si/no), preguntas de opción múltiple, ranking de preferencias y preguntas abiertas. En cuanto al ranking de preferencia se establecieron 6 características a ser ordenadas de manera creciente siendo el 1 la más importante. A partir de eso se construyó una tabla para poder asignar un valor a cada característica analizada (Albuquerque et al., 2010) y obtener una jerarquización de menor valor a mayor, siendo el valor más pequeño, el de mayor relevancia.

Las características utilizadas se seleccionaron a fin de profundizar en la valoración de diferentes aspectos ligados a cuestiones técnico productivas como la resistencia a plagas y enfermedades, económicas como la demanda del producto por parte del mercado, el rendimiento y el precio de la semilla, y por último, tres características: la estética del producto, el sabor y las cualidades nutricionales ligado a la percepción del producto hortícola como alimento, así como a las preferencias, hábitos y costumbres.

Para analizar los criterios acerca de los cultivos hortícolas, se tomó como base un listado de cultivos registrados durante las entrevistas a agricultores y agricultoras, y se solicitó a los interlocutores que mencionaran la o las característica/s que consideran más importantes de cada uno de ellos. Cada característica mencionada se consideró un registro. Posteriormente la información fue sistematizada en categorías (criterios). La organización y rótulo de las categorías fue puesto por la autora a posteriori del relevamiento. El número de registros para los investigadores y técnicos fue de 145 , mientras que para los comerciantes 188.

\subsection{Resultados y discusión}

\subsection{La percepción externa sobre la conservación in situ de semillas.}

La figura 28 da cuenta de una percepción diferente entre el conjunto de investigadores y técnicos y el conjunto de comerciantes de agroinsumos. Según los investigadores y técnicos (Figura 28 a) la calificación de importante e indispensable está ligada a diversas opiniones: Mientras que algunos interlocutores sostienen que el hecho de que los agricultores puedan guardar sus semillas les posibilitaría no depender de la disponibilidad y del costo que implica las semillas que se venden en la actualidad, que la autoproducción les permite tener mayor control y autonomía, otros agregan que la 
conservación in situ es un aspecto clave de la soberanía alimentaria, que fortalece la autonomía del sistema de producción, y es un derecho de los agricultores, que garantiza la conservación de la agrobiodiversidad. Además agregan que puede permitirles bajar los costos y utilizar materiales mejor adaptados a las condiciones locales de producción, mejorando así la sustentabilidad de sistema. En tanto algunas respuestas introducen la idea temporal de esta práctica resaltando que los quinteros han sabido conservar, seleccionar y multiplicar su semilla durante centurias. En tanto, la calificación de poco importante se vincula a la percepción de que la autoproducción de semillas es una propuesta válida, pero previamente el sistema debe romper ciertos paradigmas o mejorar en determinados aspectos tales como: rotación y asociación de cultivos y manejo integrado de plagas. En este sentido se valoriza la práctica de conservación, a la vez que se reconoce la dependencia que tienen los agricultores y agricultoras de la compra de semillas principalmente híbridas, situación que es reconocida inclusive en los relatos donde se visualiza la conservación como una práctica de mayor importancia.

En tanto los comerciantes de agroinsumos (Figura 28 b) perciben como poco importante o principalmente les es indiferente el hecho de que los agricultores y agricultoras conserven semillas. En este sentido, hay una percepción sobre el desuso o ausencia de esta práctica en la actual producción de hortalizas. Los comerciantes aseguran que hoy en día los quinteros no guardan semillas, que compran todo. A su vez, cuando es incorporada como una posible practica actual, la autoproducción de semillas es valorada como algo poco relevante para los comerciantes,

"si hacen de ellos no hay problema, pero no hay mucho. Si hacen la que compran que no reclamen cuando se pierden las características, muchas veces ni traen para hacer germinación de prueba", (Bonicatto 2014l. Entrevista a comercio 1).

"generalmente no guardan porque no sirven, la mayoría son híbridos y por más que no sean, no guardan", (Bonicatto 2014o. Entrevista a comercio 4).

"no guardan. Cada uno que maneje su economía como le convenga, me es indiferente" (Bonicatto 2014p. Entrevista a comercio 5).

Los comerciantes manifiestan la sensación de tranquilidad ante el hecho de que los agricultores están obligados a comprar semillas si desean obtener productos acordes a las exigencias del mercado. Solo un interlocutor manifestó que considera que: 
"sería importante que los productores y productoras pudiesen conservar sus semillas por un tema económico, para poder ser más rentable en su negocio, para aprovecha la semilla. Hay híbridos que no lo pueden volver a usar. Hay variedades que pueden como la cebolla de verdeo y otras que hay que comprar si o si". (Bonicatto 2017d. Entrevista a comercio 10).

Este caso aislado, estaba estrechamente ligado al posicionamiento político del comerciante.
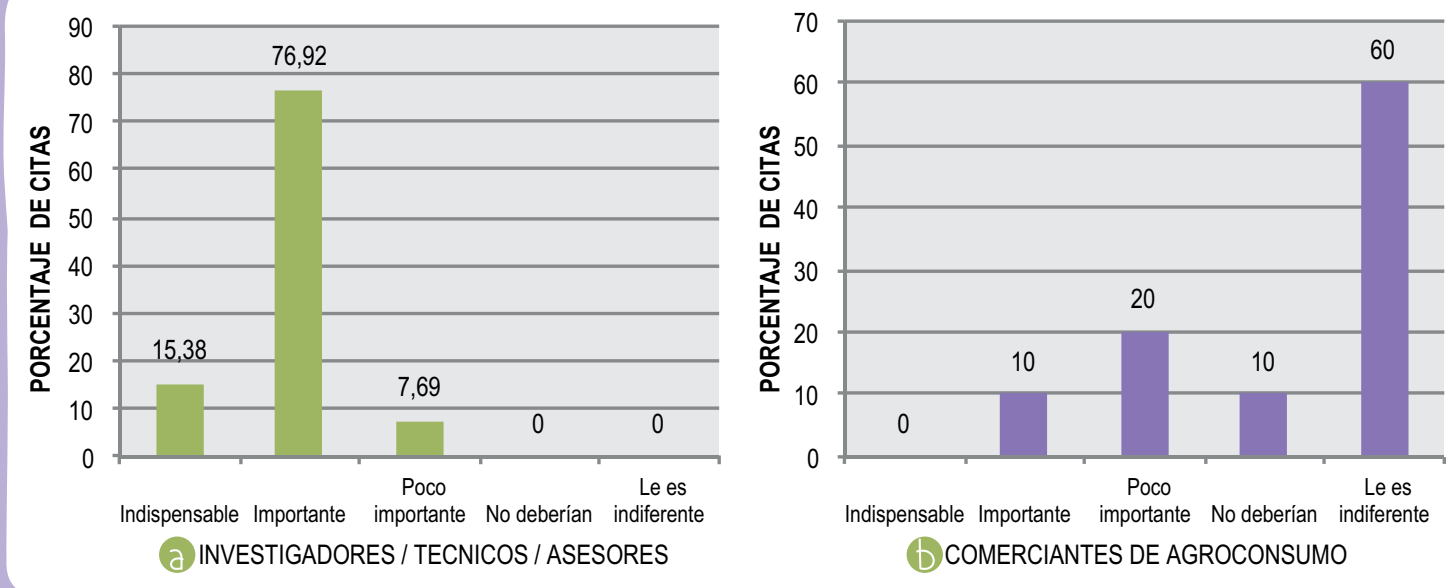

Figura 28: La autoproducción de semillas según a investigadores y técnicos extensionistas/asesores b comerciantes de agroinsumos.

\subsubsection{Valoración de las semillas producidas por los agricultores y agricultoras}

Para analizar la valoración de los actores externos se considero la percepción sobre las semillas de producción in situ. Se consideró la sugerencia del uso de dichas semillas como un indicador de esta valoración. Es así que 12 de los 13 investigadores y técnicos consultados, manifestaron interés y predisposición para sugerir el uso de variedades locales, sosteniendo que los productores las han probado y son variedades locales de buena recepción en el mercado y además resistente a las plagas habituales. En este sentido los interlocutores resaltaron algunas cualidades, principalmente ligadas a la dimensión ecológica productiva (capítulo 1.1.2) como la resistencia a adversidades y rusticidad de estas variedades y a la dimensión económica, como el ahorro dinero al no comprar semillas. Por otro lado, manifestaron preocupaciones, como las dificultades en la comercialización de hortalizas sin amplia aceptación en el mercado. Sobre este último punto, recalcaron la necesidad de trabajar en simultáneo sobre los canales de comercialización alternativos al mercado concentrador, tales como ferias de venta directa, 
ferias de productos sin agrotóxicos, bolsones de verdura de reparto a domicilio o la venta directa en las producciones, alternativas que cada vez son más aceptadas y demandadas por los consumidores. El trabajo de Garat et al. (2009) resalta la importancia del vínculo con los consumidores para la comercialización de estas hortalizas, las cuales ya no son concebidas solo como alimento, sino que su sabor e historia las presenta como un producto diferenciado. Mientras que Alcoba et al. (2011), reconocen la importancia para los agricultores familiares y consumidores de estos canales alternativos de comercialización, e invitan a empoderarse del mercado para fortalecer desde la esfera económica, procesos que se dan en las esferas sociocultural y ecológica productiva. Estas percepciones dan cuenta de que la subordinación de las dimensiones sociales y ecológicas a la dimensión económica, es una disputa vigente en el ámbito de las Instituciones Estatales ligadas al sector productivo.

En tanto el $80 \%$ de los comerciantes manifestó que no venderían semillas conservadas por los agricultores y agricultoras, argumentando que los productores no son creíbles, o poco confiables, u objetando características como la calidad y el origen. En este sentido, los comerciantes expresan el no poder garantizar que las semillas sean buenas si son producidas por los mismos agricultores, que desconocen su procedencia, los cuidados, y condiciones de guardado. Esta mirada peyorativa sobre los procesos locales de producción de semillas incorpora la idea de que las certificaciones son sinónimo de calidad, objetando los comerciantes que las semillas locales de autoproducción "no tienen calificación más que la de los quinteros y no está como para arriesgarse a vender semilla hecha por un quintero" (Bonicatto 2017b. Entrevista a comercio 8) o sosteniendo que si los quinteros tuviesen registro del INASE se podría vender sus semillas. Solo en dos casos mencionaron que si venderían semillas de autoproducción, siempre sobre la premisa de la confianza con el productor. En definitiva, la percepción de los comerciantes sobre las semillas producidas por los agricultores y agricultoras, concuerda con lo planteado por Blandi (2016) al manifestar una extrema confianza en las semillas producidas por empresas y al otro extremo, la desconfianza sobre aquellas cuyo proceso de selección y conservación ha sido realizado por los quinteros agricultores. Por lo expuesto se entiende que las acciones y valoraciones de estos actores, acompañan la lógica del modelo dominante para la dependencia de semillas comerciales.

Al ser consultados los comerciantes, sobre si recomiendan variedades tradicionales como el tomate platense, morrón calahorra, hinojo platense, 5 comerciantes respondieron que no venderían, 3 respondieron que sí, y 2 no dieron respuesta a esta pregunta. Aquellos casos que dieron una respuesta positiva lo hicieron con la salvedad de que no las recomiendan 
pero salvo que el cliente lo pida, o que sea para huertas urbanas de autoconsumo, pero no para una actividad productiva, o en otro caso, manifestaron recomendar esas variedades pero de producción comercial como el tomate platense italiano marca Giusty Chuchuy S.A. Uno de los interlocutores señala al respecto: "Está muy impuesto lo nuevo, el tomate platense está perdiendo presencia, deformidad. Lo nuevo es semillas con innovación del mercado" (Bonicatto 2017a. Entrevista a comercio 7), (Figura 29).

Estos datos y relatos refuerzan la expresión de confianza en aquellas semillas producidas por empresas, aun en aquellos casos en los que las semillas se vinculan a variedades locales que han sido conservadas y mejoradas durante años por los agricultores y agricultoras de este territorio y luego tomadas por empresas.

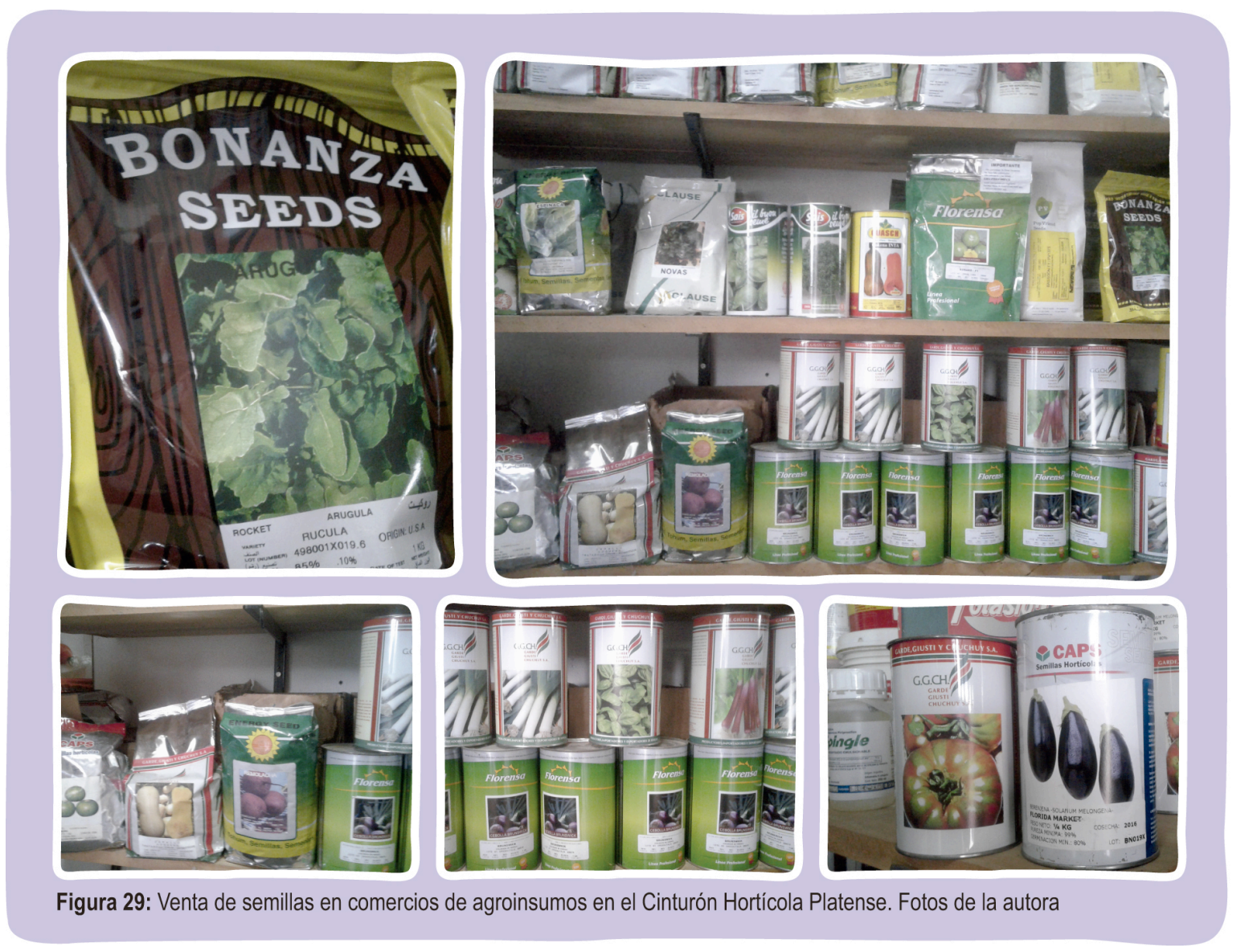

\subsubsection{Criterios de valoración}

Se describieron 9 criterios de valoración para el conjunto de investigadores y técnicos extensionistas, y 7 criterios para el conjunto de interlocutores comerciantes de agroinsumos. Siendo 7 de ellos, compartidos por ambos grupos de interlocutores (Figura 30). Los criterios 
descriptos y su descripción se exponen a continuación. Resistencia a adversidades: resistencia a plagas, enfermedades y adversidades climáticas. Morfológico: formas externas de las hortalizas y a las características organolépticas que se perciben a través de los sentidos, tales como el color, la textura. Rendimiento: promesa teórica de productividad por unidad de área. Económico: refiere al precio de la semilla en el mercado. Referencia de la semilla: procedencia, lote, empresa que la produjo, tamaño de la semilla. Aceptación del producto: calidad, sanidad, "presencia" en relación al aspecto externo, calidad en cuanto al prestigio otorgado a ciertas hortalizas que portan las condiciones estipuladas por el mercado. Resistencia post cosecha: mantenimiento de una hortaliza en condiciones de ser comercializada desde que es cosechada hasta que llega al consumidor. Comercialización: demanda del mercado, canales de venta. Productivista: Implica características ligadas al ciclo productivo. El criterio más utilizado en ambos casos fue el Morfológico $(52,4 \%$ de las menciones de investigadores y técnicos y $50 \%$ de las menciones de comerciantes). La preponderancia de este criterio sugiere una exigencia estética asociada a la producción de hortalizas destinadas al mercado concentrador.

En tanto, en las figuras (Figuras 31 a y b), puede verse la aplicación de estos criterios a algunas hortalizas de habitual cultivo en el Cinturón Hortícola Platense. Este criterio fue empleado para hacer referencia a características morfológicas relacionadas a la variedad cultivada y el órgano vegetal que se comercializa. Por ejemplo en un tomate comercial fue destacada su forma y en un tomate platense su forma y sabor. A su vez, se ve la variación de criterios según el cultivo. En este sentido el tomate, morrón y berenjena, se vinculan a todos los criterios descriptos, y se destaca la presencia del criterio resistencia post cosecha, utilizado para resaltar la cualidad de las hortalizas cuyo producto de comercialización es el fruto. Para el caso del choclo, el único criterio que se le asocia es el morfológico, ya que los interlocutores manifestaron como característica importante su vista y sabor dulce. En tanto los dos criterios no utilizados por los comerciantes, fueron los relacionados a la demanda del mercado y canales de venta. Estos datos sugieren que la comercialización de la producción no es incorporada por los comercios como una variable importante al momento de valorar una hortaliza. Otro dato interesante, que se manifiesta en la figura 31 a y b, es que ambos grupos de interlocutores, otorgaron la mayor cantidad de menciones y de criterios a los cultivos que implican una mayor incorporación de capital (tomate, berenjena, morrón) y que dejan una mayor ganancia (Castro 2016). Los trabajos de Blandi (2016) y Seibane et al. (2014) sostienen que el sector privado promueve la incorporación del invernáculo junto con su paquete tecnológico. Estos productos, basados en semillas comerciales, están asociados a la producción bajo invernáculo, y a insumos de síntesis químicas, para "asegurar" un potencial de rendimiento estándar. 


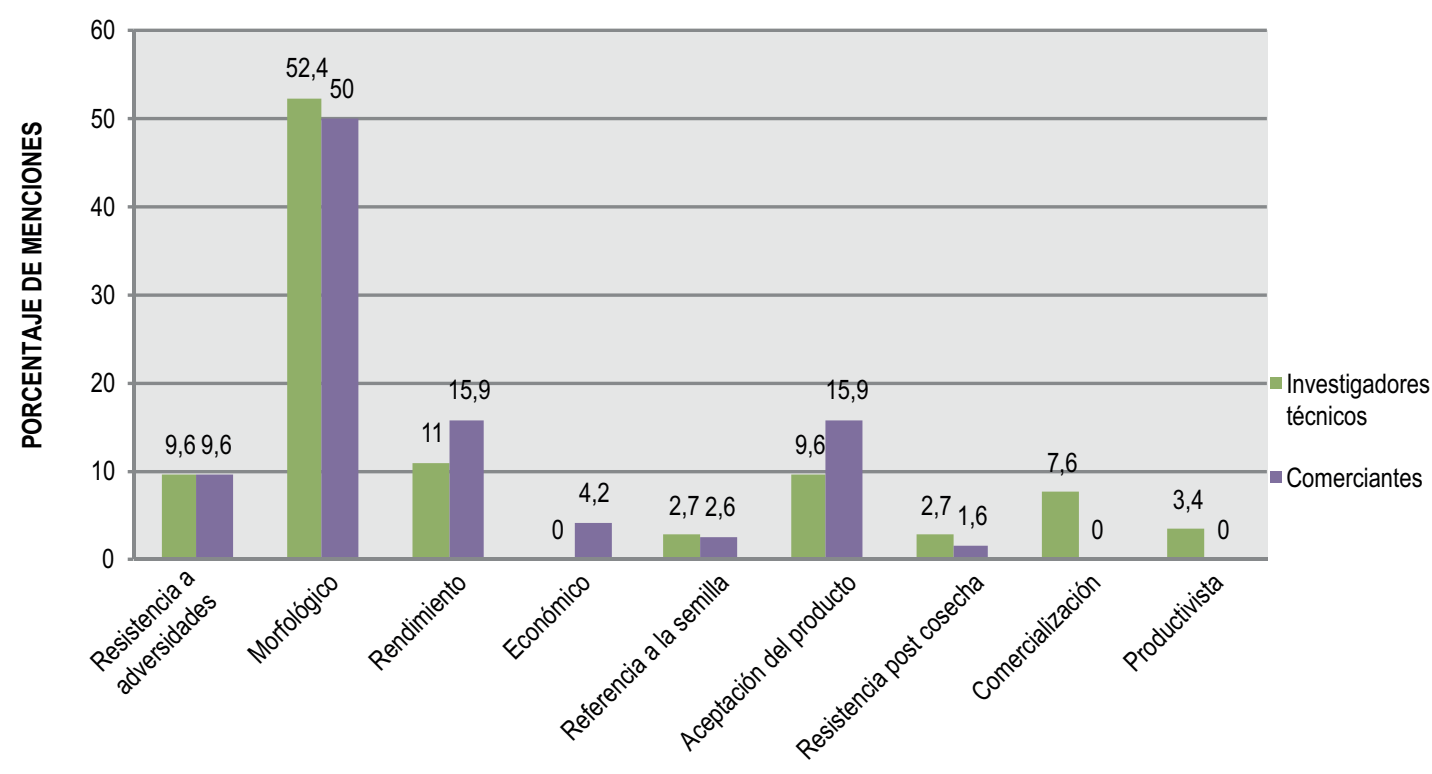

CRITERIOS

Figura 30: Criterios de valoración de semillas de hortalizas en actores externos a las producciones

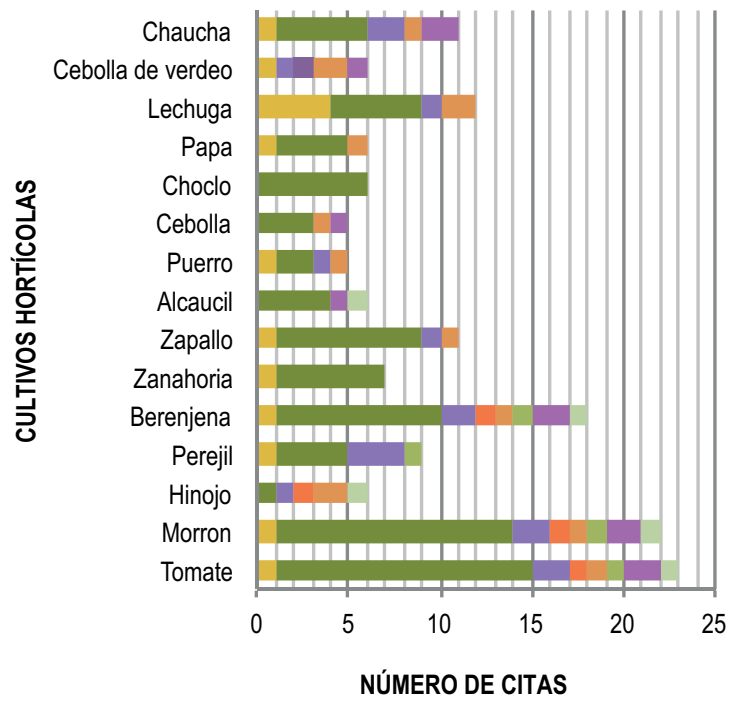

Resistencia a adversidades (plagas, enfermedades, clima)

- Morfológico

- Rendimiento

Económico

- Referencia a la semilla (cantidad, tamaño)

- Aceptación del producto (calidad/ sanidad)

- Resistencia post cosecha

- Comercialización (demanda del mercado )

- Productivista

Figura 31a: Criterios de selección de cultivos hortícolas mencionados por investigadores y técnicos vinculados al Cinturón Hortícola Platense. 


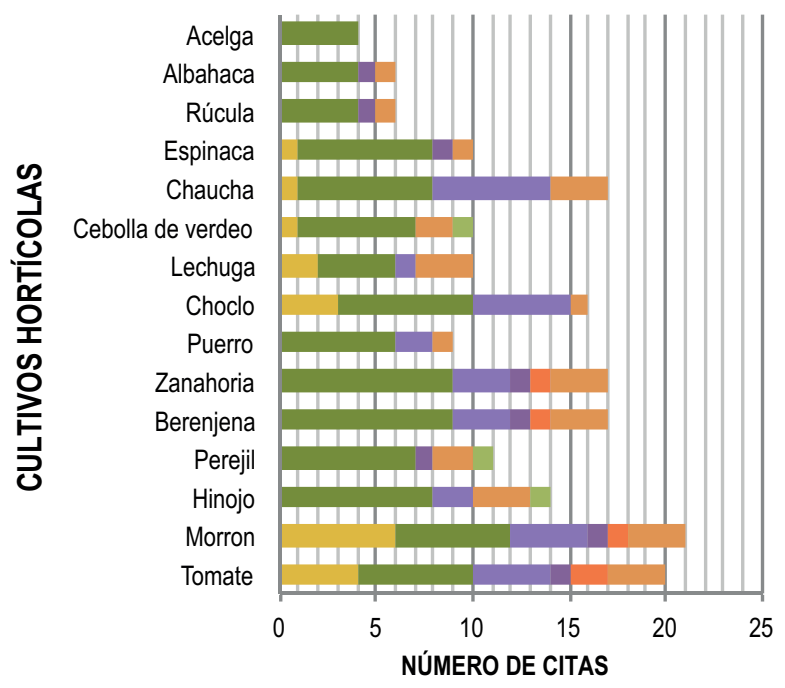

Resistencia a adversidades (plagas

y enfermedades)

Morfológico

Rendimiento

Económico

- Referencia a la semilla (lote, empresa)

- Aceptación del producto (calidad/ presencia)

Resistencia post cosecha

Figura 31b: Criterios de selección de cultivos hortícolas mencionados por comerciantes de agroinsumos en el Cinturón Hortícola Platense.

En cuanto al ranking de valoración los resultados obtenidos (Tabla 10) se mantienen en sintonía con lo expuesto. En ambos casos se mantienen en los tres primeros lugares la resistencia a plagas y enfermedades, la demanda del producto en el mercado y el rendimiento. En el caso de los investigadores y técnicos, el primer lugar es adjudicado a la demanda del producto en el mercado, ya que reconocen la fuerte presión que ejerce el mismo a través de la inclusión o exclusión de ciertos productos: "Una cosa es lo que pensamos que es o debería ser, y otra es la realidad social que a través de diferentes medios limita e impone" (Bonicatto 2014r. Entrevista a investigadores, técnicos). 
Tabla 10: Ranking de características vinculadas a las semillas hortícolas según actores externos a los agroecosistemas familiares del Cinturón Hortícola Platense.

INVESTIGADORES Y TÉCNICOS
\begin{tabular}{|l|c|c|c|c|c|c|c|c|c|c|c|c|c|c|c|}
\hline CARACTERíSTICAS & A1 & A2 & A3 & A4 & A5 & A6 & A7 & A8 & A9 & A10 & A11 & A12 & A13 & total orden \\
\hline Resistencia a plagas/enfermedades & 2 & 1 & 0 & 2 & 2 & 3 & 3 & 4 & 1 & 4 & 4 & 1 & 4 & 31 & 2 \\
\hline Demanda del producto en el mercado & 1 & 2 & 0 & 1 & 4 & 1 & 1 & 1 & 4 & 1 & 2 & 3 & 3 & 24 & 1 \\
\hline Rendimiento & 5 & 4 & 0 & 3 & 3 & 2 & 2 & 3 & 2 & 5 & 5 & 4 & 5 & 48 & 4 \\
\hline Sabor/ cualidades nutricionales & 6 & 3 & 0 & 5 & 1 & 4 & 6 & 6 & 6 & 2 & 1 & 2 & 2 & 46 & 3 \\
\hline Precio de la semilla & 4 & 5 & 0 & 4 & 5 & 6 & 4 & 5 & 3 & 3 & 3 & 5 & 1 & 49 & 5 \\
\hline Estética del producto & 3 & 6 & 0 & 6 & 6 & 5 & 5 & 2 & 5 & 6 & 6 & 6 & 6 & 68 & 6 \\
\hline
\end{tabular}

COMERCIANTES

$\begin{array}{llllllllllll}\text { CARACTERÍSTICAS } & \text { A1 } & \text { A2 } & \text { A3 } & \text { A4 } & \text { A5 } & \text { A6 } & \text { A7 } & \text { A8 } & \text { A9 } & \text { A10 total orden }\end{array}$

\begin{tabular}{|l|l|l|l|l|l|l|l|l|l|l|l|l|} 
Resistencia a plagas/enfermedades & 2 & 3 & 4 & 2 & 4 & 1 & 1 & 1 & 6 & 2 & 26 & 1 \\
\hline
\end{tabular}

\begin{tabular}{|l|l|l|l|l|l|l|l|l|l|l|l|l|}
\hline Demanda del producto en el mercado & 1 & 1 & 1 & 6 & 2 & 4 & 4 & 4 & 5 & 5 & 33 & 3 \\
\hline
\end{tabular}

\begin{tabular}{l|l|l|l|l|l|l|l|l|l|l|l|}
3 & 4 & 3 & 1 & 3 & 2 & 3 & 3 & 4 & 4 & 30 & 2 \\
\hline
\end{tabular}

\begin{tabular}{|l|l|l|l|l|l|l|l|l|l|l|l|}
6 & 6 & 5 & 5 & 6 & 5 & 5 & 5 & 1 & 1 & 45 & 6 \\
\hline
\end{tabular}

\begin{tabular}{|l|l|l|l|l|l|l|l|l|l|l|l|}
4 & 5 & 6 & 3 & 1 & 6 & 2 & 2 & 3 & 3 & 35 & 4 \\
\hline 5 & 2 & 2 & 4 & 5 & 3 & 6 & 6 & 2 & 6 & 41 & 5
\end{tabular}

Estos resultados dan cuenta de la presencia de criterios vinculados al paradigma productivo de la Revolución Verde en la valoración ejercida por los actores externos a las producciones. Ejemplo de esto son el criterio rendimiento y resistencia a adversidades. Estos expresan la mirada reduccionista sobre los agroecosistemas. El primero, posicionando la promesa teórica de alta productividad por unidad de área (rendimiento) y el segundo, al percibir a las semillas como entidades aisladas, con la capacidad de "resistir" el ataque de plagas y enfermedades. Esta percepción de la semilla como un componente biológico, cuya capacidad de resistir adversidades proviene del mejoramiento genético ex situ, es parte de la mirada reduccionista, que imposibilita comprender la agrobiodiversidad cultivada como un componente más del agroecosistema. En este mismo sentido, dicha percepción implica el desconocimiento de la capacidad del sistema en su conjunto de ser resiliente.

Esta forma de comprender la producción de bienes, implica la creciente utilización de fertilizantes, agroquímicos para el control de plagas, enfermedades y malezas, maquinarias, combustibles y riego (Sarandón \& Flores 2014). Como se planteo anteriormente, los trabajos realizados por Blandi (2016) y Seibane et al. (2014) en el Cinturón Hortícola Platense, coinciden en que el sector privado promueve la incorporación del paquete tecnológico del cual las semillas de alto rendimiento son una parte fundamental. Estos autores citan un gran vínculo entre agricultores y las casas de ventas de insumos, al brindarles información técnica continua y los insumos necesarios. 
Los datos aquí presentados definen un accionar vehemente de los comerciantes hacia la incorporación de semillas de origen comercial, de la mano de la desvalorización de la conservación de agrobiodiversidad realizada por agricultores y agricultoras.

Por otro lado, los investigadores y técnicos reconocen las cualidades nutricionales entre los 3 principales características (Tabla 10), así como rescatan la importancia de la importancia de la conservación in situ y las capacidades de los agricultores, las valoran, pero a su vez, reconocen que las presiones del mercado por imponer la uniformidad de los productos, son "las reglas del juego". En tanto, miradas diferentes surgen en cuanto a la comercialización de estas hortalizas. Algunos interlocutores visualizan posibles dificultades para comercializar verduras que no cumplan con lo demandado por el mercado, mientras que otros destacan la demanda creciente de los consumidores por comprar hortalizas locales y sin agroquímicos.

"se paga más por producción uniforme, y la única forma de lograr esto, es iniciando un cultivo con plantines uniformes. Para tener plantines uniformes hay que iniciar con semillas uniformes. Algo no fácil de lograr cuando la cosecha de semillas es propia". (Bonicatto 2017i. Entrevista a investigadores, técnicos 9)

"las variedades locales tienen un nicho de comercialización, donde el consumidor las reconoce y las demandan en mercados de venta directa" (Bonicatto 2017m. Entrevista a investigadores, técnicos 13)

\subsubsection{Investigación sobre semillas ¿hacia dónde ir?}

Según Sarandón \& Flores (2014) la agricultura industrializada se ha expandido en gran parte del mundo "ignorando" y "despreciando" los conocimientos locales, los que fueron visualizados como atrasados, arcaicos, primitivos o inútiles. A su vez, estos autores sostienen que el menosprecio y desconocimiento de las técnicas tradicionales de cultivo, y de sus bases ecológicas y culturales, provocó que, durante mucho tiempo, éstas fueran desplazadas y reemplazadas por una "tecnología moderna más eficiente". Esto generó una gran erosión cultural que tiene enormes repercusiones en los intentos de conservación de germoplasma in situ. En la actualidad, algunos científicos han reconocido la necesidad de un cambio de mirada y están revalorizando la cultura de los agricultores/as tradicionales y sus métodos de cultivo (Garat et al., 2007; Garat et al., 
2008; Garat et al., 2009; Lyon et al., 2011; Nicholls et al., 2016). Por su parte la FAO admitió que "se cometió el gravísimo error de no priorizar la generación de tecnologías de bajo costo que fuesen adecuadas para las circunstancias de escasez de capital y adversidad físico-productiva que caracteriza a la gran mayoría de los productores agropecuarios" (IICA, 1999).

Los temas presentados, corresponden a diferentes tópicos de investigación sugeridos por los interlocutores investigadores y técnicos como importantes para la conservación de semillas.

- Mejoramiento participativo, estrategias de reproducción, mejoramiento genético de variedades locales para adaptarlas a los requerimientos del mercado-desarrollo de nuevas variedades- generar conocimientos sobre la resistencia a plagas y enfermedades de hortalizas-

- Adaptación de materiales genéticos locales a condiciones socioeconómicas y culturales de las producciones locales - evaluación fitosanitaria de semillas hortícolas- viabilidad post cosecha.

- Generar información sobre los niveles de autofecundación y cruzamiento de las variedades locales

- Difusión de la importancia del uso de variedades locales

- Generar conocimientos sobre posible agregado de valor a hortalizas localespropiedades nutricionales-

Estas propuestas desde el momento en que son visualizadas como áreas de vacancia o de investigación en curso, dan cuenta de la existencia de una predisposición y preocupación por parte de la academia para avanzar en temas que generen información para fortalecer la conservación de semillas y los conocimientos locales. Según Sarandón (2008) desde la dimensión científico-académica, se está comenzando a reconocer que la incorporación de la problemática del manejo sustentable de agroecosistemas, implica un nuevo paradigma, una nueva concepción de la relación del hombre con la naturaleza, donde se permita cambiar el objetivo productivista y cortoplacista por uno sustentable a largo plazo: ecológicamente adecuado, económicamente viable y socialmente más justo. 


\subsection{Conclusiones}

Los datos presentados sugieren algunas diferencias entre los actores externos a la producción, en la valoración de la práctica de conservación de semillas de hortalizas del Cinturón Hortícola Platense. Mientras que para los comerciantes la conservación de semillas in situ, es una práctica en desuso y poco valorada, para el sector de los investigadores y técnicos es considerada importante, ya que fortalece la independencia, autogestión y soberanía alimentaria de los agricultores y agricultoras.

Sobre los criterios de valoración de las semillas de hortalizas, los datos aquí presentados dan cuenta de que, en el caso de los comerciantes de agroinsumos, las recomendaciones y valoraciones son coherentes con el modelo productivista. Estos actores están profundamente inmersos en la lógica del modelo que difunden, por tanto sostienen que la conservación de semillas es una práctica obsoleta y no visualizan motivos que justifiquen el cultivo de hortalizas, que no tienen aceptación en el mercado concentrador. Una situación más heterogénea se presenta al analizar el sector de investigadores y técnicos. Este segundo conjunto de actores considera importante el mantenimiento de semillas locales y los aspectos sociales que se asocian a estos, pero detectan complicaciones para el avance de esta práctica, dada la gran presión del modelo dominante. A su vez, los criterios y la jerarquización que establecen sugieren que en los investigadores y técnicos perdura en parte, una mirada productivista y reduccionista, sesgada al componente cultivado y no a la totalidad del agroecosistema. En este sentido, la resistencia a plagas y enfermedades es una de las características más destacadas. Sin embargo dejan clara la interpretación territorial de esta problemática compleja y proponen avances hacia el interior de las instituciones en las que trabajan, al dejar planteada la necesidad de que las mismas incorporen o fortalezcan programas de mejoramiento y multiplicación de variedades de interés, principalmente de polinización abierta y proyectos de mejoramiento participativo. Por lo tanto, los resultados obtenidos sugieren que "En los actores externos a la producción (técnicos, investigadores y comerciantes) prevalecen criterios productivistas en la valoración del material reproductivo hortícola".

Los criterios de valoración descriptos, son los que se ponen de manifiesto al intervenir sobre la agribiodiversidad desde los diferentes roles analizados. Los datos obtenidos presentan un escenario complejo para que la conservación in situ tome mayor relevancia y deje de transcurrir como una estrategia invisibilizada o de subsistencia. En el caso de los comerciantes, estos son un eslabón de la cadena implicada en la materialización del 
modelo hegemónico. Sin embargo, es sabido que a lo largo de la historia se han desarrollado diversas formas de hacer agricultura vinculadas a las distintas regiones y culturas. La percepción de los profesionales ligados a las ciencias agrarias, manifiesta avances en el reconocimiento de la necesidad de un manejo sustentable de los agroecosistemas, donde se permita cambiar el objetivo productivista y cortoplacista que prevalece en los actores externos a las producciones por uno sustentable a largo plazo: ecológicamente adecuado, económicamente viable y culturalmente aceptado (Sarandón, 2008). Por lo tanto profundizar en la incorporación de una mirada holística y sistémica en los actores externos a las producciones, es esencial para avanzar en formas sustentables y resilientes de producción que impliquen la valoración de la conservación de la diversidad biocultural. 


\subsection{Bibliografía}

Albuquerque, U.P.; R.F.P. Lucena \& N.L. Alencar. 2010. Métodos e técnicas para coleta de dados etnobiológicos, en: U.P. De Albuquerque, R.F.P. Lucena \& L.V.F. Cruz da Cunha (editores). Métodos e técnicas na pesquisa Etnobiológica e Etnoecológica 1: 41-64. Editorial NUPEEA. Brasil.

Alcoba, D. \& S. Dumrauf (compiladores). 2011. Del productor al consumidor. Apuntes para el análisis de las ferias y mercados de la Agricultura Familiar en Argentina. Ediciones INTA.

Alexiades, M.N. \& S.A. Laird. 2002. Estableciendo los fundamentos: relaciones equitativas de la investigación sobre biodiversidad, en: S.A. Laird (editor). Biodiversidad y conocimiento tradicional. Participación equitativa en práctica. Montevideo: Nordan Comunidad.

Almekinders, C.J.M.; N.P. Louwaars \& G.H. Bruijn. 1994. Local seed systems and their importance for an improved seed supply in developing countries. Euphytica 78: 207-216.

Blandi, M.L. 2016. Evaluación de la sustentabilidad de la incorporación del cultivo bajo cubierta en la horticultura platense. Tesis de doctorado Facultad de Ciencias Agrarias y Forestales UNLP. Argentina.

Castro, A. S. 2016. Saberes migrantes. Trayectorias de productores bolivianos del periurbano platense (Tesis de grado). Presentada en Universidad Nacional de La Plata. Facultad de Humanidades y Ciencias de la Educación para optar al grado de Licenciada en Sociología. Disponible en: http://www.memoria.fahce.unlp.edu.ar/tesis/te.1295/te.1295.pdf

Castro, A. S. \& M. Pérez. 2017. Cambios en las prácticas productivas y de comercialización de horticultores del Sur del Área Metropolitana de Buenos Aires. Reflexiones en el marco de un espacio de formación en Agroecología. Actas de las $X$ Jornadas Interdisciplinarias de Estudios Agrarios y Agroindustriales Argentinos y Latinoamericanos. 7 al 10 de noviembre. Buenos Aires.

Cromwell, E. \& R. Tripp. 1994. Proximity is a plus: the economics or farmer seed production and distribution in developing countries, en: J. Hanson (editor). Seed production by smallholder farmers. Proceedings of the JLCA/ICARDA Research Planning Workshop held at ILCA, Addis Ababa, Ethiopia, 13-15 de junio. PP 15-24. 
de Boef, W.S. 2007. Uma perspectiva de sistemas aproximando agricultores e pesquisadores no manejo comunitário da agrobiodiversidade, en W.S. de Boef.; M.H. Thijssen, J. Bernardi Ogliari \& B.R. Sthapit (organizadores) Biodiversidade e Agricultores. Fortalecendo o manejo comunitário. L\&PM Editores. Brasil. 2.5: 59-66.

Gallardo, G.S. 2012. Desarrollo institucional y política científica: el caso de la producción nacional de semilla hortícola. Tesis de Maestría en Gestión de la Ciencia, Tecnología e Innovación. Universidad Nacional de general Sarmiento.

Garat, J.J.; A. Ahumada, J. Otero, L. Terminiello, G. Bello \& M.L. Ciampagna. 2009. Las hortalizas típicas locales en el cinturón verde de La Plata: su localización, preservación y valorización. Horticultura Argentina 28(66):32-39.

Garat, J.J.; A. Castro, S. Gramuglia, A. Nico \& A. Ahumada. 2007. El rescate de la biodiversidad local y la acción colectiva: una estrategia de desarrollo a través de la revalorización de hortalizas locales en el cinturón verde de La Plata, Buenos Aires, Argentina. Revista Brasilera de Agroecologia 2 (1): 430:434.

Garat, J.J.; J. Otero, A. Ahumada, G. Bello, \& L. Terminiello. 2008. El enfoque SIAL como instrumento de intervención: El caso el tomate platense y las hortalizas típicas locales en el Cinturón Verde de La Plata, Argentina. Actas del IV Congreso Internacional de la Red SIAL. Argentina.

García, M. 2011. El cinturón hortícola platense: ahogándonos en un mar de plásticos. Un ensayo acerca de la tecnología, el ambiente y la política. Theomai 23: 35-53.

García, M. 2014. Crítica al enfoque clásico de innovación tecnológica. Estudio de caso del invernáculo en el Cinturón Hortícola Platense. Geograficando, 10(1).

González, J. 2007. ¿Por qué las variedades locales? en: Manual para la utilización y conservación de variedades locales de cultivo. Ed. Red Andaluza de Semillas 1: 12-21.

Hang, G.M.; M.L. Bravo, G. Ferraris, G. Larragaña, C.I. Seibane, C.A. Kebat, M. Otaño \& V.L. Blanco. 2013. Modalidades de trabajo y tenencia de la tierra en sistemas hortícolas localizados en el territorio platense. República Argentina. Facultad de Agronomía 112 (2):114-122. 
Hang G.; C. Kebat, M.L. Bravo, G. Larrañaga, C. Seibane, G. Ferraris, M. Otaño \& V. Blanco. 2010. Identificación de sistemas de producción hortícola en el partido de La Plata, provincia de Buenos Aires, Argentina. Revista Bioagro 22(1): 81-86.

IICA, 1999. Discurso de Severino De Melo Araujo, Subdirector General de FAO para América Latina y el Caribe. XI Conferencia Latinoamericana de ALEAS. Abril 1997. Santiago, Chile, en: R. Chateneuf.; A. Violic \& E. Paillacar (editores): Educación Agrícola Superior, Desarrollo Sostenible, Integración Regional y Globalización 9-13.

Lyon, A.; M.M. Bell, C. Gratton \& R. Jackson. 2011. Farming without a recipe: Wisconsin graziers and new directions for agricultural science. Journal of Rural Studies 27: 384-393.

Marasas, M.; M.L. Blandi, N. Dubrovsky Berensztein \& V. Fernández. 2014. Transición agroecológica: de sistemas convencionales de producción a sistemas de producción de base ecológica: características, criterios y estrategias, en: S.J. Sarandón \& C.C. Flores (editores). Bases teóricas para el diseño y manejo de agroecosistemas sustentables. Editorial de la Universidad Nacional de La Plata 15:411-436.

Nicholls, C.I.; M.A. Altieri \& L. Vázquez. 2016. Agroecology: Principles for the Conversion and redesign of Farming Systems. Journal of Ecosystems \& Ecography S5: 010. doi:10.4172/2157-7625.S5-010.

Sarandón, S.J. \& M.L. Blandi. 2015. Impactos del manejo hortícola obre la biodiversidad y sus causas según agricultores de La Plata, Argentina. Memorias del V Congreso Latinoamericano de Agroecología, La Plata 7 al 9 de octubre.

Sarandón, S.J. \& C.C Flores. 2014. La insustentabilidad del modelo agrícola actual en: S.J. Sarandón \& C.C. Flores (editores). Bases teóricas para el diseño y manejo de agroecosistemas sustentables. Editorial de la Universidad Nacional de La Plata 1:13-41.

Sarandón, S.J. 2008. La agroecología en la formación de profesionales de la agronomía: una necesidad para una agricultura sustentable. Actas del VIII Congreso SEAE, Bullas, Murcia.

Seibane, C.; G. Larrañaga, C. Kebat, G. Hang, G. Ferraris \& M.L. Bravo. 2014. Redes para la promoción del desarrollo territorial en el cinturón hortícola platense Reflexiones y aportes. Mundo Agrario 15 (29):19.

Wood, D. \& Lenné, J.M. 1997. The conservation of agrobiodiversity on-farm: questioning the emerging paradigm. Biodiversity and Conservation 6: 109-129. 
DISCUSIÓN GENERAL

Y CONCLUSIONES
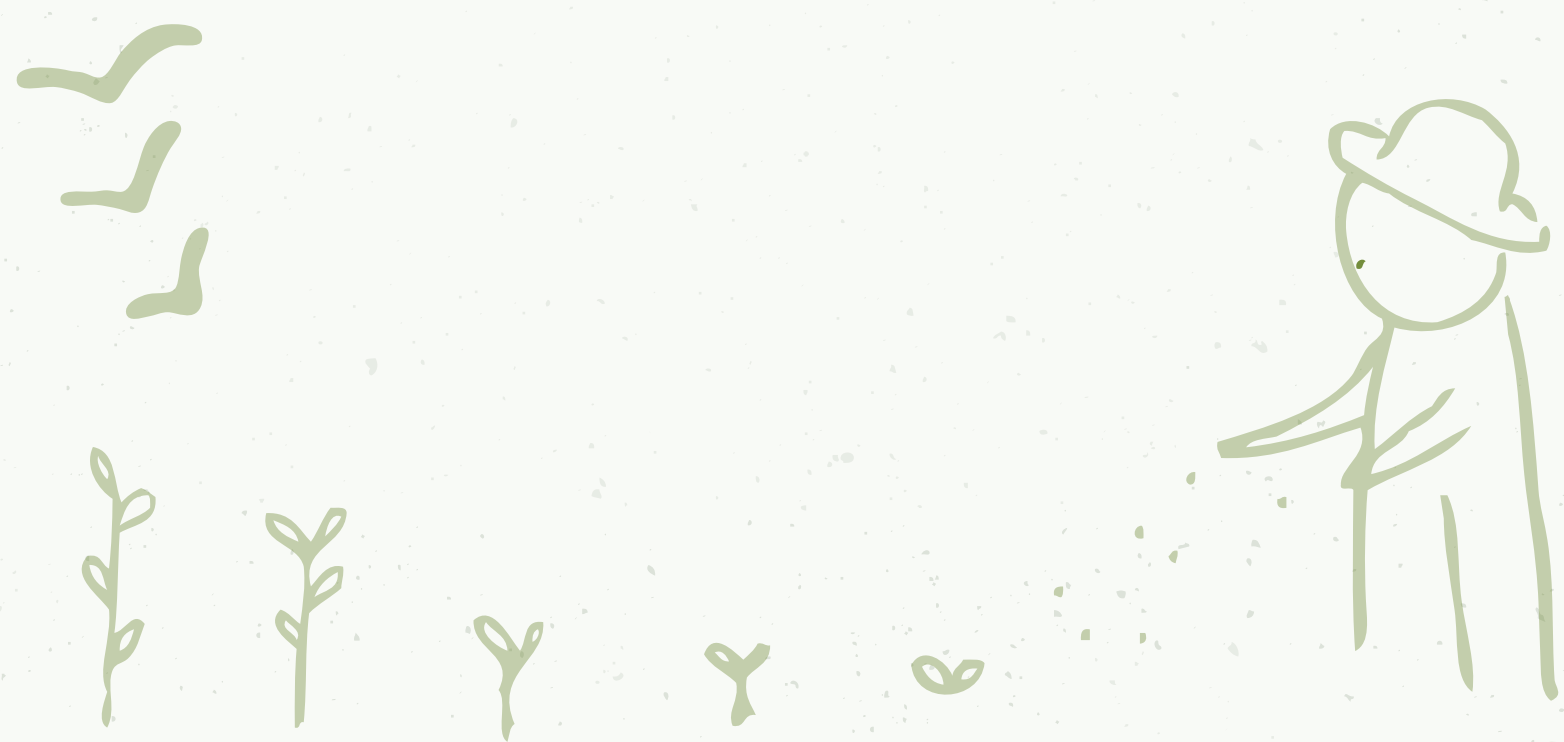


\section{DISCUSIÓN GENERAL y CONCLUSIONES}

El rol de la conservación de semillas en la sustentabilidad de las producciones familiares del Cinturón Horticola Platense.

El propósito de esta discusión general es analizar los capítulos previos a la luz de la sustentabilidad de los agroecosistemas familiares del Cinturón Hortícola Platense. Retomando los conceptos planteados en la introducción general, la sustentabilidad implica un concepto multidimensional y complejo que incluye el cumplimiento simultáneo de varias dimensiones: ecológico-productiva, económica y sociocultural. Estas dimensiones son igualmente importantes, de cumplimiento simultáneo, y no son reemplazables entre sí (Sarandón \& Flores, 2014). Para cumplir con la sustentabilidad y satisfacer las necesidades de las generaciones actuales y futuras, el estilo de agricultura debe poder mantenerse en el tiempo. Según diversos autores referentes para la agroecología (Altieri, 1995; Altieri \& Toledo, 2011; de Boef, 2007; Nicholls, 2013; Nicholls et al., 2016; Sarandón, 2009; Toledo, 1992; Toledo \& Barrera-Bassols, 2008), la agrobiodiversidad y el conocimiento local sobre el manejo de recursos, son fundamentales para que los agroecosistemas sean resilientes y sustentables, ya que a través del vinculo entre agricultores y agrobiodiversidad, se sostienen las formas locales de producción y de vida, la provisión de bienes necesarios y las funciones ecológicas básicas para fortalecer los servicios ecosistémicos. En palabras de Altieri et al. (2015) el nivel de agrobiodiversidad establece la diferencia entre un sistema productivo estresado y uno resiliente, que pueda confrontar una perturbación biótica o abiótica. Por lo tanto, para que existan agroecosistemas diversificados, además de la presencia de diversidad espontánea, debe coexistir la disponibilidad de recursos vegetales (semillas) y los conocimientos implicados en su manejo, uso y conservación.

Durante los años transcurridos en la toma de datos (2009-2017) el Cinturón Hortícola Platense mantuvo un proceso de profundización del modelo de la Revolución Verde, altamente dependiente de insumos externos (invernáculo, semillas híbridas y agroquímicos) (Blandi, 2016; García 2011; Sarandón \& Blandi, 2015). Este avance se reflejó en la apertura de nuevos comercios de venta de insumos, que fueron incorporados al estudio. En este sentido, la valoración de los comerciantes sobre la conservación in situ, no sugirió desacuerdos entre ambas etapas de entrevista, sosteniéndose la lógica productivista. A su vez, la intensificación del modelo se percibió a lo largo de los años, a través de la sostenida incorporación de semillas comerciales en los agroecosistemas. A este proceso, se suma un problema que se agudiza, relacionado a la forma de tenencia 
de la tierra, con valores exorbitantes, la cual, en su mayoría está caracterizada por el arrendamiento por parte de productores de origen boliviano (Merchán, 2016). La coyuntura socioeconómica que atraviesa la Argentina durante los últimos años, principalmente en relación al proceso inflacionario, se hizo presente en el universo de las producciones (Prividera et al., 2018), generando que algunas familias entrevistadas, arrendaran parte de sus tierras, incorporaran superficie bajo cubierta, o incluso, retomaran la producción a campo, a fin de disminuir los costos y el riesgo. Otro factor en expansión en el territorio que dada su complejidad y magnitud no fue abordado durante este trabajo, es la expansión de las plantineras como grandes abastecedoras de agrobiodiversidad. Según García (2016), en el año 2016, hay más de 20 plantineras que abastecen a la región y se especializan en diferentes cultivos (de hoja, crucíferas y solanáceas) mayoritariamente. Los materiales genéticos que siembran, responden a la lógica productivista del territorio y la mirada mercantil de la semilla, excluida de toda valoración simbólica. El impacto de la consolidación y expansión de las plantineras sobre la erosión biocultural, es un tema pendiente para futuros estudios.

Estos cambios, posicionan al sector de la agricultura familiar, de una manera muy vulnerable en cuanto a su sustentabilidad (Blandi, 2016; DPBA, 2015; García, 2015; Sarandón \& Blandi, 2015). El avance de formas intensivas de producción, con baja diversificación y un mercado exigente en rendimiento y estética de los productos, presionan para la utilización de semillas comerciales de alto potencial de rendimiento, en lugar de conservar una alta variabilidad genética que se adecue a la diversidad de ambientes y costumbres (Sarandón \& Flores, 2014). En el marco de esta coyuntura compleja, y a lo largo de esta investigación, se percibió un proceso en el cual las estrategias de manejo basadas en recursos y saberes locales, que generan independencia y permiten ahorrar dinero, fueron consideradas y revalorizadas. En este sentido, la conservación in situ de agrobiodiversidad encontró y encuentra una coyuntura oportuna para su difusión.

Los agroecosistemas familiares, al ser manejados por los propios agricultores y agricultoras, mantienen vigente la estrecha relación entre ellos, ellas y el ambiente, cuya importancia se destacó anteriormente. Los conocimientos y prácticas producto de este vínculo, los posiciona en un rol central para la conservación de diversidad biocultural.

En resistencia al avance reduccionista del modelo de la Revolución Verde, los datos obtenidos dan cuenta de que los agricultores familiares del Cinturón Hortícola Platense cultivan una importante agrobiodiversidad (31 familias botánicas, 120 especies botánicas y 305 etnoespecies) ligadas a diferentes rubros productivos que exceden la horticultura 
(fruticultura, floricultura, cultivos forrajeros, aromáticas y medicinales, cultivos forestales entre otros). A su vez, la agrobiodiversidad hortícola conservada in situ (53.7\%) corresponden a una riqueza de 10 familias botánicas, 41 especies y 152 etnoespecies, sugiriendo la prevalencia de la práctica de conservación in situ. A su vez, se visualiza una importante complejidad ligada a la decisión de qué conservar, cómo y por qué hacerlo. En este sentido, la práctica de conservación in situ se hace extensiva a todo cultivo hortícola cuyas características botánicas lo permitan, entendiendo por esto, el sentido ampliado del término semilla, e incluyendo aquí las semillas obtenidas por diferentes vías de ingreso. Por otro lado, ellos y ellas, deciden qué agrobiodiversidad dejar por fuera de esta práctica, existiendo un conjunto de cultivos hortícolas, de origen comercial principalmente, que elijen no conservar (35\% de lo cultivado). Las diversas vías de ingreso (compradas en comercios, vínculos interpersonales, oportunista, instituciones y resiembra espontánea), que incluyen el sistema formal de semillas y su posterior conservación, manifiestan una ampliación en el uso tradicional de la práctica, incorporando recursos genéticos de origen comercial al universo de la autoproducción (33\% de lo conservado). Estos datos, permiten ver que el abastecimiento de semillas de las producciones familiares está vinculado tanto al sistema formal como al informal.

A partir de los resultados obtenidos y las discusiones planteadas, se propone visualizar la conservación in situ, como dos estrategias diferentes entre sí, que conviven en un mismo territorio. Una, es la conservación aplicada para el mantenimiento de variedades locales, con un gran número de etnovariedades, que circulan libremente, a través de vías informales de semillas (ferias, intercambio con otros agricultores, herencia familiar), cuya conservación y perdurabilidad se encuentra sustentada principalmente por criterios ligados a la experimentación, la independencia, los afectos, los hábitos culinarios y los simbolismos. El cultivo y conservación de esta agrobiodiversidad, habilita la continuidad de tradiciones y celebraciones, y por tanto, es símbolo de la soberanía alimentaria de las familias ligadas a la horticultura y de la población en general.

Por otro lado, está la conservación de semillas obtenidas por vías formales en comercios de agroinsumos, muchas de ellas de condición híbrida incorporadas en pos de cumplir con las expectativas y demandas del mercado. Esta conservación presenta una baja diversidad de etnoespecies, está ligada a un carácter transitorio ya que suelen ser semillas conservadas solo por pocos años, y los criterios que sustentan su conservación se vinculan principalmente a su precio, oscilando entre dos opciones: cuando caras son conservadas, cuando baratas son compradas. A su vez, el criterio morfológico delimita el tiempo de conservación, siendo que el fin de su conservación se establece cuando se pierden las características deseadas. Es así que estas semillas cuando son de condición 
híbrida, son conservadas durante dos, o a lo sumo tres años. En este sentido, la dependencia externa de semillas comerciales, se mantiene. Esta conservación se entiende como una estrategia coyuntural, que permite a las familias reducir los costos de la incorporación del paquete tecnológico de la Revolución Verde, al sustituir las semillas compradas, por semillas de autoproducción.

Según Nicholls (2013) uno de los desafíos actuales que tiene la agroecología, es identificar aquellas prácticas que permiten disminuir la vulnerabilidad de las sociedades agrícolas y aumentar la capacidad de reacción de los agricultores. Las diferentes alternativas para concretar con éxito la conservación de semillas, el mantenimiento en el tiempo de agrobiodiversidad añosa, la habilidad para moldear las estrategias de conservación y responder ante coyunturas como el avance de semillas de condición híbrida, la capacidad de trasmitir en palabras o acciones las estrategias desarrolladas, son algunas de las manifestaciones de la actitud resiliente de los agricultores y agricultoras de este territorio. Según Berkes et al., (2000), si la práctica es tradicional o contemporánea no es la clave o punto más importante. El aspecto importante es si existe o no conocimiento local que ayude a monitorear, interpretar y responder a los cambios dinámicos de los agroecosistemas y los recursos y servicios que ellos generan. En el contexto analizado, la actitud innovadora de los agricultores y agricultoras, es clave para la adaptación de la práctica y resiliencia de los agroecosistemas. Este posicionamiento ante la agrobiodiversidad, implica observación, experimentación, y selección de los resultados obtenidos, tamizados a través de los criterios de conservación. En consecuencia, aun cuando el fin último de la conservación de semillas comerciales sea la adecuación para el mercado, se da un proceso de apropiación de estas semillas, donde los saberes involucrados en su selección, reproducción y conservación, son locales y propios de los agricultores. Resulta interesante esta situación en la cual los conocimientos se ponen en juego a fin de adaptarse a los requerimientos externos, pero concluyen por resignificar la realidad presente y generan una nueva, a través de una síntesis de lo local y lo comercial, de lo deseado y lo exigido, de lo valorado y lo demandado. Tanto las semillas locales como las de origen comercial, actúan como el eslabón necesario para sostener esta práctica activa y dinámica. En la Tabla 11 se sintetizan las similitudes y diferencias de las estrategias de conservación descriptas. 
Tabla 11: Conservación de semillas locales y comerciales en agroecosistemas familiares del Cinturón Hortícola Platense. Similitudes y diferencias.

\begin{tabular}{|l|l|l|}
\cline { 2 - 3 } \multicolumn{1}{l|}{} & $\begin{array}{l}\text { CONSERVACIÓN DE } \\
\text { SEMILLAS LOCALES }\end{array}$ & $\begin{array}{l}\text { CONSERVACIÓN DE } \\
\text { SEMILLAS COMERCIALES }\end{array}$ \\
\hline Origen del material genético & Sistema informal & Sistema formal \\
\hline Diversidad de etnovariedades & Alta & Baja \\
\hline $\begin{array}{l}\text { Principales criterios implicados en la } \\
\text { conservación }\end{array}$ & Innovador, independencia & Económico, morfológico \\
\hline Acción sobre la práctica de conservación & Habilita la permanencia de la práctica & Habilita la permanencia de la práctica \\
\hline Dependencia económica & No implica dependencia & Implica dependencia \\
\hline Posibilidades de comercialización & $\begin{array}{l}\text { Canales cortos: ferias de productores, } \\
\text { venta directa, bolsones de verdura }\end{array}$ & $\begin{array}{l}\text { Canales largos: mercado concentrador en } \\
\text { su mayoría. Canales alternativos }\end{array}$ \\
\hline Acción sobre la autonomía & Fortalece & Debilita \\
\hline
\end{tabular}

Desde el punto de vista de la sustentabilidad, no quedan dudas de la importancia de que el proceso de mejoramiento y conservación de agrobiodiversidad sea realizado por los agricultores y agricultoras, estableciéndose razones por las cuales la conservación de semillas locales y comerciales tiene diferentes consecuencias. Las semillas locales generan independencia, autonomía, habilitan el autoabastecimiento de material genético, promueven la producción local basada en recursos locales, y accionan para el mantenimiento de la identidad y tradición de los agricultores y agricultoras. Por lo expuesto, su conservación se posiciona de manera adecuada para fortalecer la sustentabilidad de los agroecosistemas familiares.

A pesar de lo expuesto, y considerando la incorporación de agrobiodiversidad de origen comercial a las producciones, y las presiones y valoraciones de los actores externos, se concluye que la diversificación de los agroecosistemas familiares, basada exclusivamente en semillas locales de conservación in situ, no es una alternativa que se ajuste a la situación territorial actual que transita este sector. Esta circunstancia es un emergente de la lógica productivista hegemónica en el Cinturón Hortícola Platense, en el cual la dimensión económica se impone por sobre las dimensiones ecológico productiva y sociocultural (Blandi, 2016). La incorporación de invernáculos, la baja diversificación, las semillas híbridas, los agroquímicos, son parte de un modelo que promete la obtención de productos hortícolas congruentes con un mercado exigente en rendimiento y estética de los productos. En el Cinturón Hortícola Platense, el límite que encuentran las semillas que circulan por fuera de la lógica del mercado, está estrechamente ligado a la dificultad de su comercialización. En este sentido, los comerciantes de semillas, al desvalorizar la conservación in situ y las semillas que circulan por fuera del circuito formal, presionan para la elección de una agrobiodiversidad acorde a valoraciones mercantiles. La presión por obtener altos rendimientos y hortalizas comerciables, se posiciona como una coyuntura visualizada tanto por los agricultores, como por los actores externos a la 
producción. El sector de investigadores y técnicos, acompaña la dualidad de la coyuntura descripta, ya que, reconoce la importancia del mantenimiento de semillas locales y los aspectos sociales que se asocian a ella, pero, a su vez, detectan complicaciones para el avance de esta agrobiodiversidad dada la gran presión del modelo. Ante el escenario descripto, es necesario cuestionar la idealización de una agricultura familiar de base agroecológica, que base su producción exclusivamente en semillas derivadas del sistema informal y de producción propia. Dicho cuestionamiento, no tiene que perder de vista la importancia de la autonomía, entendida como la facultad de las personas para obrar según criterios propios, en el uso y conservación in situ de la agrobiodiversidad, para poder avanzar hacia estrategias sustentables. Se entiende que la construcción de autonomía en relación a la agrobiodiversidad, no implica el aislamiento de los agricultores y agricultoras, sino que se concreta a través del trabajo colectivo. El mismo puede tener diferentes escalas: una escala intrapredial (familiar) a través del trabajo de manejo y conservación realizada en el agroecosistema. Una escala local o regional que implique el manejo y conservación comunitaria realizada por agricultores y agricultoras. $Y$ una escala territorial ampliada, que incorpore actores externos a las producciones, vinculados a la conservación de agrobiodiversidad.

Por lo tanto, y a fin de avanzar en estrategias que favorezcan la autonomía y sustentabilidad de los agroecosistemas familiares, se sostiene que el camino a seguir es aquel que complemente las acciones de mejoramiento, conservación y distribución de semillas, entre las instituciones del Estado y los agricultores y agricultoras. Según Atalan Helicke (2015), de Boef (2007), Louwaars (1994); Olsson et al. (2004) y Wood \& Lenné (1997), una mejor aproximación entre los sistemas de conservación in situ de agricultores, y el sistema formal ligado a las instituciones, ofrece muchas oportunidades para combinar fuerzas entre ambos, generando un aumento de la disponibilidad y el acceso a semillas para los agricultores familiares. Un ejemplo de ello, sería un Estado que incorpore los criterios locales y las necesidades y preferencias de quienes cultivan, al desarrollo y mejoramiento de semillas. Esta propuesta implica la valoración de este sector productivo y el reconocimiento del importante rol que cumple en el mantenimiento de la diversidad biocultural y la soberanía alimentaria. El fortalecimiento de formas participativas de mejoramiento, la promoción del uso de la agrobiodiversidad local, la construcción conjunta de espacios de intercambio de semillas y conocimientos, el desarrollo y ejecución de proyectos de rescate, multiplicación y difusión de variedades hortícolas, son algunos ejemplos de acciones que aportan al mantenimiento de la diversidad biocultural. 
A su vez, es necesario interpelar al Estado, a través de sus instituciones, acerca del rol de este sector en la construcción de un modelo nacional de desarrollo rural (Feito, 2013). Según Canci (2006) las iniciativas de apoyo a los procesos locales de manejo y conservación de la agrobiodiversidad tienen que estar ligados a otros procesos de desarrollo rural local. Según Castro \& Pérez (2017), si se pretende avanzar hacia formas sustentables de producción en el Cinturón Hortícola Platense, es necesaria la atención del Estado e instituciones del sector agropecuario, no sólo en materia de innovaciones tecnológicas y de comercialización, sino también a partir de marcos normativos y figuras de ordenamiento territorial o políticas públicas para regular las actividades sobre los territorios.

Mientras tanto, atravesando y atravesados por el modelo productivo de la Revolución Verde, los agricultores y agricultoras familiares son quienes custodian la diversidad biocultural del Cinturón Hortícola Platense. La clave del mantenimiento de esta agrobiodiversidad está en las semillas que ellos y ellas conocen, cultivan, conservan y usan. Queda claro que estas semillas son conservadas a través de una práctica dinámica, que es a la vez ancestral y actualizada, que se materializa y resignifica a través de la conservación de semillas de diferentes orígenes, expresando la actitud investigativa de los agricultores y agricultoras.

Por último, estos resultados y las reflexiones compartidas, aportan conocimientos científicos, para avanzar en propuestas que promuevan la conservación de diversidad biocultural y la valoración del sector. También permiten, profundizar en estrategias de investigación acción participativa ligadas a la selección, conservación y mejoramiento de semillas. La planificación y desarrollo de acciones de producción y conservación colectiva. La comprensión acerca de la transmisión del conocimiento sobre la conservación de la agrobiodiversidad y el vínculo con el enfoque de género, son inquietudes para futuras acciones, para avanzar en el fortalecimiento de la sustentabilidad de las producciones familiares de este territorio. 


\section{CONCLUSIONES}

- Los agricultores y agricultoras familiares del Cinturón Hortícola Platense, mantienen cultivos hortícolas mediante estrategias de conservación in situ.

- Las semillas conservadas provienen de diferentes orígenes incluyendo el sistema informal y formal.

- La práctica de conservación de semillas no se aplica a la totalidad de cultivos hortícolas, quedando por fuera de esta estrategia cultivos obtenidos principalmente del sistema formal.

- Existen diversos criterios que condicionan la conservación del material reproductivo, los cuales difieren según el origen de las semillas. Las semillas locales están asociadas a un mayor número de criterios, entre los cuales se encuentran motivos ligados al quehacer cotidiano e historia familiar.

- Existe un conjunto de hortalizas cultivadas y conservadas para autoconsumo que permanecen "ocultas" y son un reservorio de diversidad biocultural.

- Los agricultores y agricultoras familiares del Cinturón Hortícola Platense tienen amplios conocimientos sobre las diferentes instancias que hacen a la práctica de conservación de semillas.

- La actitud innovadora de los agricultores y agricultoras es clave para la resiliencia de los agroecosistemas.

- Los actores externos a las producciones incorporan criterios productivistas ligados al modelo de la Revolución Verde sobre la valoración de la agrobiodiversidad.

- Se visualiza una predisposición en las instituciones del Estado para avanzar en estrategias que valoricen y promuevan la conservación de la diversidad biocultural.

- La conservación de semillas locales presenta adecuadas condiciones para fortalecer la sustentabilidad de las producciones familiares.

- En el contexto actual, pensar en la diversificación de los agroecosistemas basada exclusivamente en semillas locales de conservación in situ, no es suficiente para asegurar la autonomía y permanencia de las familias en el territorio.

- Las acciones participativas entre instituciones estatales ligadas al sector y los agricultores y agricultoras, se posicionan como una estrategia para favorecer el mejoramiento, la conservación y distribución de semillas, que promuevan la sustentabilidad de las producciones familiares en el Cinturón Hortícola Platense. 


\section{BIBLIOGRAF'́A}

Altieri, M.A. \& V.M. Toledo. 2011. The agroecological revolution in Latin America: rescuing nature, ensuring food sovereignty and empowering peasants. The Journal of Peasant Studies 38(3):587-612.

Altieri, M.A. 1995. Agroecology: the science of sustainable agriculture. Westview Press, Boulder, CO.

Altieri, M.A.; C.I. Nicholls, A. Henao \& M.A. Lana. 2015. Agroecology and the design of climate change-resilient farming systems. Agronomy for Sustainable Development 35:869-890.

Atalan Helicke, N. 2015. Seed exchange networks and food system resilience in the United States. Journal of Environmental Studies and Sciences 5 (4): 636-649.

Berkes, F.; I.J. Colding \& C. Folke. 2000. Rediscovery of traditional ecological knowledge as adaptive management. Ecological Applications 10 (5): 1251-1262.

Blandi, M.L. 2016. Evaluación de la sustentabilidad de la incorporación del cultivo bajo cubierta en la horticultura platense. Tesis de doctorado Facultad de Ciencias Agrarias y Forestales UNLP. Argentina.

Canci, I.J. 2006. Relações dos sistemas informais de conhecimento no manejo da agrobiodiversidade no oeste de Santa Catarina. Universidade Federal de Santa Catarina Centro de Ciências Agrárias. Programa de Pós-Graduação em Recursos Genéticos Vegetais.

Castro, A. S. \& M. Pérez. 2017. Cambios en las prácticas productivas y de comercialización de horticultores del Sur del Área Metropolitana de Buenos Aires. Reflexiones en el marco de un espacio de formación en Agroecología. Actas de las $X$ Jornadas Interdisciplinarias de Estudios Agrarios y Agroindustriales Argentinos y Latinoamericanos. 7 al 10 de noviembre. Buenos Aires.

de Boef, W.S. 2007. Uma perspectiva de sistemas aproximando agricultores e pesquisadores no manejo comunitário da agrobiodiversidade, en W.S. de Boef.; M.H. Thijssen, J. Bernardi Ogliari \& B.R. Sthapit (organizadores). Biodiversidade e Agricultores. Fortalecendo o manejo comunitário. L\&PM Editores. Brasil. 2.5: 59-66.

Feito, C. 2013. Agricultura familiar para el desarrollo rural argentino. Avá no.23. Disponible en: http://www.scielo.org.ar/scielo.php?script=sci_arttext\&pid=S185116942013000200006

García, M. 2016. Surgimiento, dinámica y rol de las plantineras en el aglomerado hortícola de La Plata. Revista Geografía 20:84-102. 
García, M. 2011. El cinturón hortícola platense: ahogándonos en un mar de plásticos. Un ensayo acerca de la tecnología, el ambiente y la política. Theomai 23: 35-53.

Louwaars, N.P. 1994. Integrated seed supply: a flexible approach, en: J. Hanson (editor). Seed production by smallholder farmers. Proceedings of the JLCA/ICARDA Research Planning Workshop held at ILCA, Addis Ababa, Ethiopia, 13-15 de junio. PP. 15-24.

Merchán, A.G. 2016. Valorización de la Tierra en el Cinturón Hortícola Platense. Disparidad en el Valor de los Arrendamientos. Tesis para optar al título: Magister en Economía Agroalimentaria. Orientación en Desarrollo Rural. Universidad Nacional de La Plata. Facultad de Ciencias Agrarias y Forestales. Departamento de Desarrollo Rural.

Nicholls, C.I. 2013. Enfoques agroecológicos para incrementar la resiliencia de los sistemas agrícolas al cambio climático en: C.I. Nicholls Estrada.; L.A. Ríos Osorio \& M.A. Altieri (editores.) Agroecología y resiliencia socioecológica: adaptándose al cambio climático 2: 18-29. Medellín, Colombia: REDAGRES-CYTED.

Nicholls, C.I.; M.A. Altieri \& L. Vázquez. 2016. Agroecology: Principles for the Conversion and redesign of Farming Systems. Journal of Ecosystems \& Ecography S5: 010. doi:10.4172/2157-7625.S5-010.

Olsson, P.; C. Folke \& F. Berkes. 2004. Adaptive Comanagement for Building Resilience in Social-Ecological Systems. Environmental Management 34 (1): 75-90.

Prividera, G.; A. Castro \& S. Dumrauf. 2018. El presente de los productores hortícolas del cinturón verde platense. Realidad económica. Boletín digital del instituto argentino para el desarrollo económico. Disponible en http://www.iade.org.ar/noticias/elpresente-de-los-productores-horticolas-del-cinturon-verde-platense [consulta marzo 2018].

Sarandón, S.J. \& M.L. Blandi. 2015. Impactos del manejo hortícola obre la biodiversidad y sus causas según agricultores de La Plata, Argentina. Memorias del V Congreso Latinoamericano de Agroecología, La Plata 7 al 9 de octubre.

Sarandón, S.J. \& C.C Flores. 2014. La insustentabilidad del modelo agrícola actual en: S.J. Sarandón \& C.C. Flores (editores). Bases teóricas para el diseño y manejo de agroecosistemas sustentables. Editorial de la Universidad Nacional de La Plata 1:13-41. 
Sarandón, S.J. 2009. Biodiversidad, agrobiodiversidad y agricultura sustentable: Análisis del Convenio sobre Diversidad Biológica, en: T.L. Siccard \& M.A. Altieri (editores). Vertientes del pensamiento agroecológico: fundamentos y aplicaciones. IDEAS 21, Sociedad Científica Latinoamericana de Agroecología (SOCLA), Bogotá, Colombia. PP. 105-130.

Toledo, V. M. \& N. Barrera-Bassols. 2008. La memoria biocultural. La importancia ecológica de las sabidurías tradicionales. Serie Perspectivas Agroecológicas. Ícara. Barcelona.

Toledo, V.M. 1992. La racionalidad ecológica de la producción campesina, en: E. Sevilla Guzmán \& M. González de Molina (editores). Ecología, campesinado e historia. Ed. La Piqueta. Madrid. España. 5: 197-218.

Wood, D. \& Lenné, J.M. 1997. The conservation of agrobiodiversity on-farm: questioning the emerging paradigm. Biodiversity and Conservation 6: 109-129. 
PUBLICACIONES

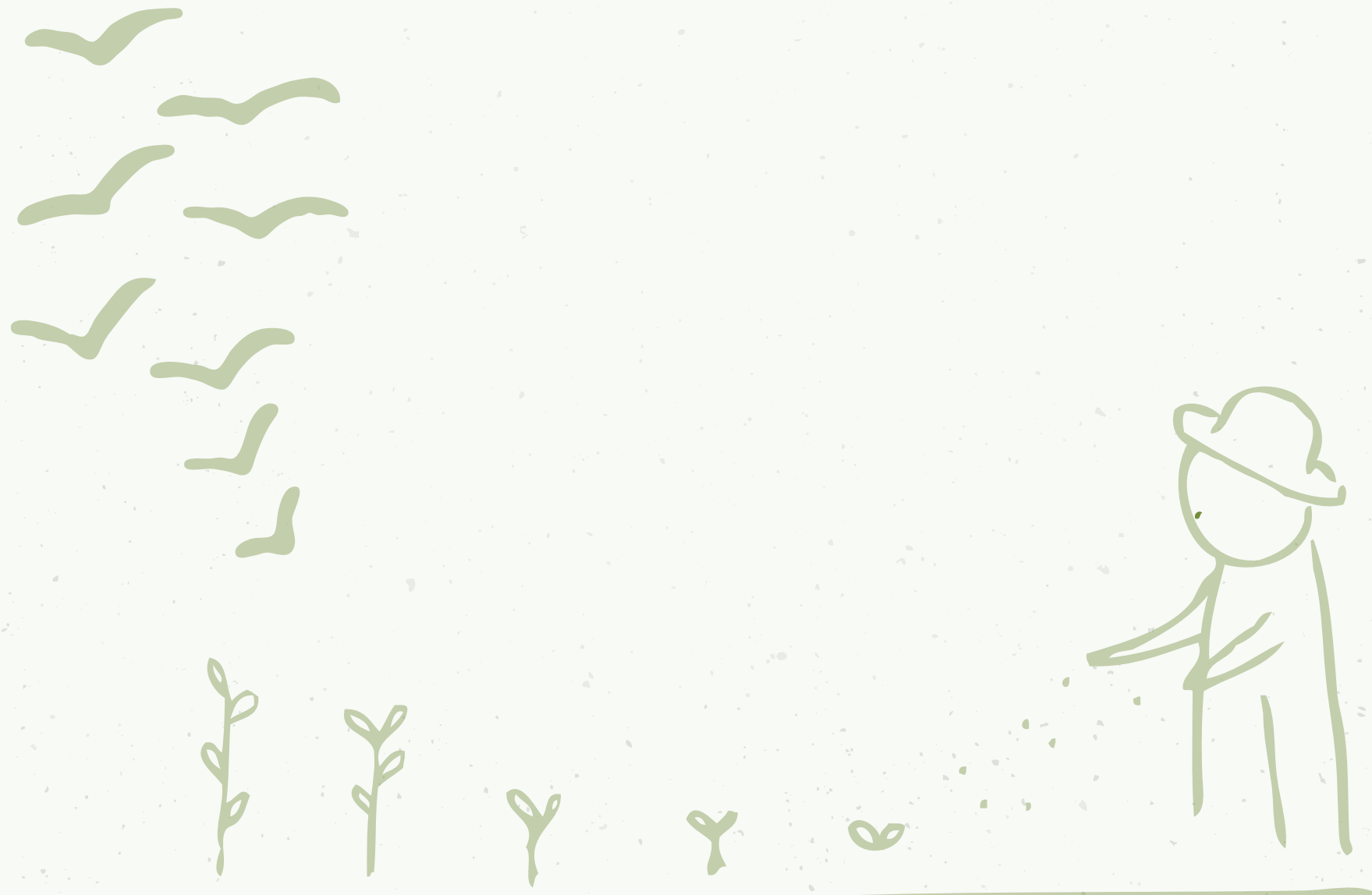




\section{PUBLICACIONES}

\section{Capítulos de Libros}

Pochettino, M.L.; M.M. Bonicatto \& J.A. Hurrell. 2017. Huertos comerciales del periurbano de La Plata (Buenos Aires, Argentina): Reservorio de diversidad biocultural, en: A. Casas.; J. Torres-Guevara \& F. Parra. Domesticación en el continente Americano. Investigación para el manejo sustentable de recursos genéticos en el Nuevo Mundo 2 (17): 413-430.

\section{Trabajos publicados en revistas científicas}

Bonicatto, M.M.; M.E. Marasas, S.J. Sarandón \& M.L. Pochettino. 2015. Seed Conservation by Family Farmers in the Rural-Urban Fringe Area of La Plata Region, Argentina: The Dynamics of an Ancient Practice. Agroecology and Sustainable Food Systems 39 (6): 625-646.

Bonicatto, M.M.; S.J. Sarandón, M.L. Pochettino \& M.E. Marasas. 2011. Criterios locales para la conservación de semillas en agricultores familiares de Argentina. Su importancia para el manejo agroecológico. Cadernos de Agroecología 6 (2): 1-4. Disponible en: http://abaagroecologia.org.br/revistas/index.php/cad/article/view/10725/0

\section{Trabajos presentados en congresos.}

Bonicatto, M.M.; M.P. May, S.J. Sarandón, M.E. Marasas \& M.L. Pochettino. 2017. Cultivo de hortalizas para autoconsumo en el Cinturón Verde de La Plata, Argentina. Su rol en la conservación de saberes y diversidad. Jornadas Interdisciplinarias de Estudios Agrarios y Agroindustriales 7 al 10 de noviembre.

Bonicatto, M.M.; M.L. Pochettino, S.J. Sarandón \& M.E. Marasas. 2017. Conservación de semillas comerciales ¿un impedimento o una estrategia adecuada para mejorar la resiliencia de los agroecosistemas? VI Congreso Latinoamericano de Agroecología, $X$ Congreso Brasileiro de Agroecología y $V$ Seminario de Agroecología del Distrito Federal y Región 12 al 15 de octubre.

Bonicatto, M.M.; M.L. Pochettino, S.J. Sarandón \& M.E. Marasas. 2015. Conservación de Semillas por Agricultores Familiares en un Contexto Periurbano en La Plata, Argentina. Memorias del V Congreso Latinoamericano de Agroecología. UNLP. Disponible en: http://sedici.unlp.edu.ar/handle/10915/52154

Hilgert, N.; J.A. Hurrell, A.H. Ladio, V.S. Lema, M.L. Pochettino, M. Bonicatto, C. Eyssartier, V. Furlan \& D.A. Lambaré. 2014. The Horticulture in Argentina: Characterization and comparison of homegardens indifferent contexts and regions. VI Congreso Internacional de Etnobotánica (ICEB), Córdoba España 17 al 21 de noviembre. 
Gargoloff, N.A.; M.M. Bonicatto \& S.J. Sarandón. 2017. Saberes sobre la agrobiodiversidad cultivada como aporte a la resiliencia socioecológica de agroecosistemas familiares. Jornadas Argentinas sobre Etnobiología y Sociedad en Humahuaca. Humahuaca 8 al 10 de junio.

Gargoloff, N.A.; M.M. Bonicatto \& S.J. Sarandón. 2016. Agrobiodiversidad Cultivada y Resiliencia ante la variabilidad climática en Agroecosistemas Familiares. V Congreso Internacional Cambio Climático y Desarrollo Sostenible. 14-16 de septiembre de 2016. La Plata, Argentina.

Pochettino, M.L.; M.M. Bonicatto \& J.A. Hurrell. 2015. Huertos comerciales del periurbano de La Plata (Buenos Aires, Argentina): Reservorio de Diversidad Biocultural. Simposio Latinoamericano "Domesticación y manejo de Recursos Genéticos. Lima, Perú. 9 al 11 de Julio.

Pochettino, M.L.; M.M. Bonicatto, F. Buet Costantino \& J.A. Hurrell. 2012. La horticultura en contextos periurbanos: estudio comparativo entre huertos familiares y productivos en la Provincia de Buenos Aires (Argentina). II Congreso Boliviano de Botánica, III Congreso Boliviano de Etnobiología, I Simposio Boliviano de Etnobotánica. Bolivia 11, 12 y 13 de octubre.

Bonicatto, M.M.; M.L. Pochettino, S.J. Sarandón \& M. Marasas. 2010. Conservación de semillas y saberes en un agroecosistema de producción familiar. II Simposio de Agroecología en el XXXIII Congreso Argentino de Horticultura. Rosario. Santa Fé. ASAHO- Facultad de Cs. Agrarias UNR-INTA

Bonicatto, M.M.; S.J. Sarandón \& M.L. Pochettino. 2009. El concepto de "semilla" y su relación con la agrobiodiversidad en una zona hortícola (Buenos Aires, Argentina). Vth Internacional Congress of Ethnobotany. Bariloche, 21 al 24 de septiembre de 2009.

\section{Artículos de divulgación}

Bonicatto, M.M.; M.E. Marasas, M.L. Pochettino \& S.J. Sarandón. 2014. La semilla en la conservación de los gustos y la historia. LEISA Revista de Agroecología 30 (4): 24-27.

Pochettino, M.L.; J.A. Hurrell \& M.M. Bonicatto. 2014. Horticultura periurbana: estudios etnobotánicos en huertos familiares y comerciales de la Argentina. Revista Ambienta 107: 1-15.

Bonicatto, M.M. 2012. Semillas y agricultores, un vínculo ancestral que sigue activo. Boletín Electrónico El Graduado, FCAyF- UNLP. N 15. 
ANEXOS

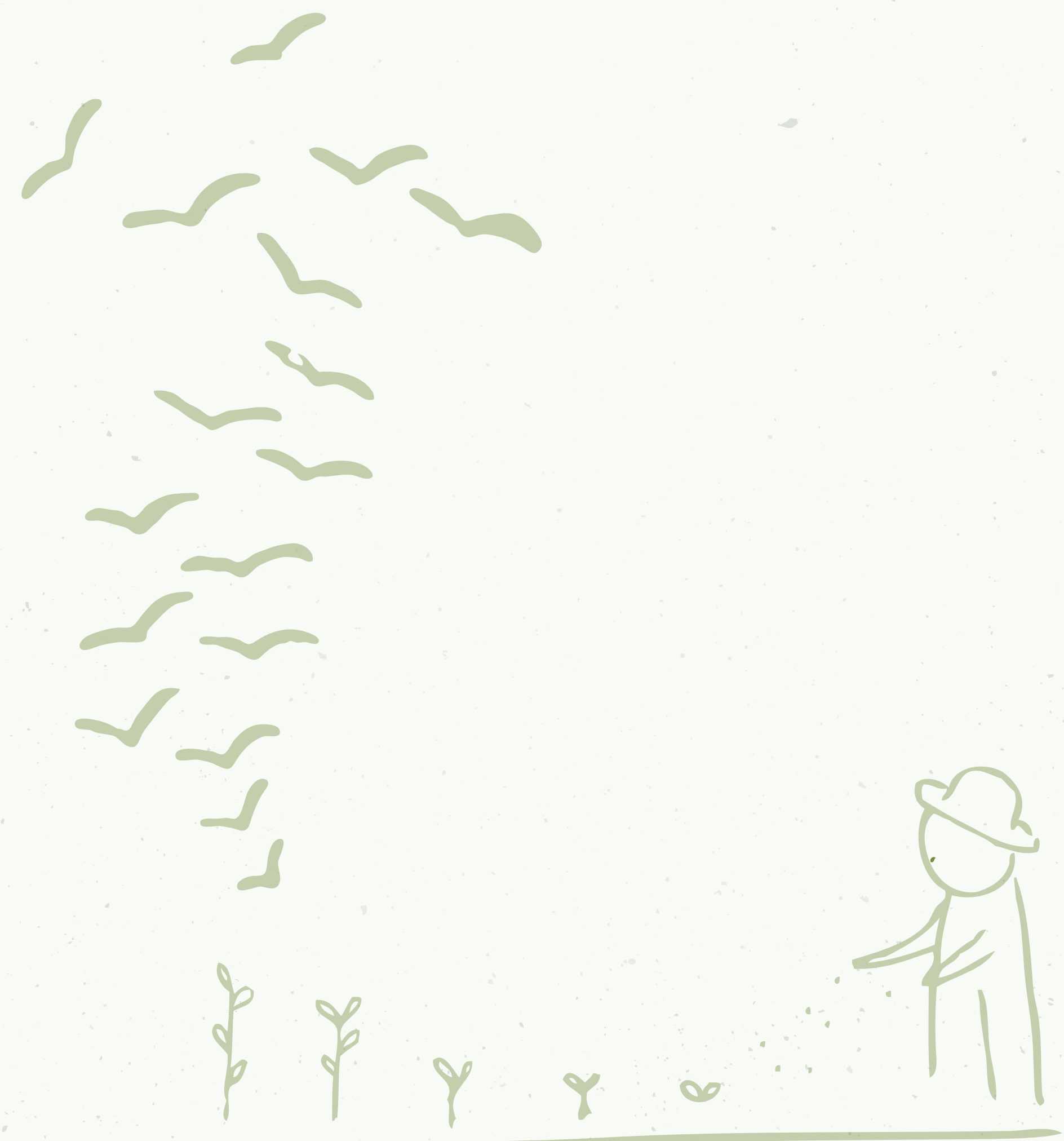




\section{LISTADO DE ENTREVISTAS REALIZADAS}

\section{AGRICULTORES Y AGRICULTORAS}

\section{Bonicatto 2009}

a. Entrevista a JL, Parque Pereyra Iraola

b. Entrevista a JL, Parque Pereyra Iraola

c. Entrevista a JL, Parque Pereyra Iraola

d. Entrevista a NA, Etcheverry

\section{Bonicatto 2010}

a. Entrevista a JL, Parque Pereyra Iraola

b. Entrevista a JL, Parque Pereyra Iraola

c. Entrevista a BV, Parque Pereyra Iraola

\section{Bonicatto 2011}

a. Entrevista a BV, Parque Pereyra Iraola

b. Entrevista a ES, Parque Pereyra Iraola

c. Entrevista a JP, Colonia Urquiza

d. Entrevista a CA, Arana

e. Entrevista a NG, Hernández

f. Entrevista a JV, Parque Pereyra Iraola

g. Entrevista a P, El Peligro

h. Entrevista a PA, Arana

i. Entrevista a LO, El Pato

j. Entrevista a CV, Florencio Varela

\section{Bonicatto 2013}
a. Entrevista a BIS, Arana
b. Entrevista a MS, Arana
c. Entrevista a MG, parque Pereyra Iraola
d. Entrevista a IG, Abasto
e. Entrevista a $\mathrm{CL}$, Abasto

\section{Bonicatto 2014}
a. Entrevista a FLO, El Pato
b. Entrevista a HC, Gorina
c. Entrevista a DAG, Los Hornos
d. Entrevista a NA, Etcheverry
e. Entrevista a LO, El Pato
f. Entrevista a AT, Etcheverry
g. Entrevista a ML, Colonia Urquiza
h. Entrevista a DY, Colonia Urquiza
i. Entrevista a S, Lisandro Olmos
j. Entrevista a SV, Lisandro Olmos
k. Entrevista a LP, Arana

\section{COMERCIANTES}

\section{Bonicatto 2014}

I. Entrevista a comercio 1, Lisandro Olmos

m. Entrevista a comercio 2, Abasto

n. Entrevista a comercio 3, Lisandro Olmos

o. Entrevista a comercio 4, Lisandro Olmos

p. Entrevista a comercio 5, Abasto

q. Entrevista a comercio 6, Lisandro Olmos

\section{Bonicatto 2017}
a. Entrevista a comercio 7, Abasto
b. Entrevista a comercio 8, El Peligro
c. Entrevista a comercio 9, Lisandro Olmos
d. Entrevista a comercio 10, Etcheverry

\section{INVESTIGADORES / TÉCNICOS}

\section{Bonicatto 2014}

r. Entrevista a investigadores, técnicos 1, CONICET-UNLP

s. Entrevista a investigadores, técnicos 2, CONICET-UNLP

t. Entrevista a investigadores, técnicos 3, INTA - Universidad Nacional Arturo Jauretche

u. Entrevista a investigadores, técnicos 4, INTA Programa Cambio Rural

\section{Bonicatto 2017}

e. Entrevista a investigadores, técnicos 5, INTA Estación Experimental Agropecuaria Área Metropolitana de Buenos Aires

f. Entrevista a investigadores, técnicos 6, Estación Experimental Gorina. Ministerio de Agroindustria. Buenos Aires

g. Entrevista a investigadores, técnicos, 7 UNLP

h. Entrevista a investigadores, técnicos 8, INTA

i. Entrevista a investigadores, técnicos 9, CONICET

j. Entrevista a investigadores, técnicos 10, INTA Programa Cambio Rural- UNLP

k. Entrevista a investigadores, técnicos 11, UNLP

I. Entrevista a investigadores, técnicos 12, UNLP

m. Entrevista a investigadores, técnicos 13, CONICET-UNLP 


\section{Consentimiento informado | ANEXO 2}

Lugar y fecha

Estimado/a:

Gracias por destinar su tiempo para ser entrevistado en el marco del trabajo de tesis doctoral "Sustentabilidad y agrobiodiversidad: análisis de las "semillas" locales y su relación con los conocimientos sobre su conservación y uso en agroecosistemas familiares del Cinturón Hortícola Platense". El propósito de este trabajo, es dar cuenta de las semillas locales en agroecosistemas familiares del Cinturón Hortícola Platense y analizar su relación con los conocimientos asociados a su conservación, usos y prácticas de manejo. Esto se realiza en el marco de un trabajo de investigación de la Cátedra de Agroecología, de Facultad de Ciencias Agrarias y Forestales de la Universidad Nacional La Plata.

Los resultados podrán ser útiles para visualizar el rol que cumplen los agricultores familiares del Cinturón Hortícola Platense en torno a la conservación de material genético local y los conocimientos vinculados al mismo. Esta información aporta a la valoración del sector como guardianes de agrobiodiversidad y aporta al desarrollo de alternativas productivas sustentables a través de la diversificación de las quintas. Asimismo permitirá visualizar impedimentos para la conservación y limitantes de carácter técnico.

Asimismo, cabe aclarar que el beneficio por participar de la presente investigación, será el aporte de conocimientos para las futuras generaciones.

Si está de acuerdo con la propuesta, por medio de esta carta exprese su voluntad de permitir la incorporación en este trabajo de:

$\begin{array}{lll}\text { Nombre y apellido } & \text { SI } \square & \text { NO } \\ \text { Imágenes fotográficas } & \text { SI } \square & \text { NO } \\ \text { Grabaciones } & \text { SI } \square & \text { NO } \\ \text { Saberes } & \text { SI } \square & \text { NO }\end{array}$

Semillas, tubérculos y otros materiales

Acepto participar de la entrevistas realizadas por la Lic. María Margarita Bonicatto en el marco de su trabajo de investigación, siempre y cuando se me reconozca como fuente de información y se mantenga este conocimiento disponible para el uso.

Una vez más, agradecemos mucho su cooperación 


\section{ENTREVISTA BONICATTO MM "SUSTENTABILIDAD Y AGROBIODIVERSIDAD"}

A). INFORMACIÓN DE LA FAMILIA

Dirección:

Localidad:

Teléfono:

C.P

Mapa/ anotaciones para llegar a la casa:

Has:

DATOS PERSONALES DEL INTERLOCUTOR:

\begin{tabular}{|l|l|l|l|l|}
\hline Nombre y apellido & Edad & Sexo: F/M & Lugar de nacimiento & Actividades en la quinta \\
\hline 1 & & & & \\
\hline
\end{tabular}

Tiempo en esta quinta:

Número de generaciones en la quinta:

¿Quiénes trabajan en la quinta?

¿Comercializa su producción?

¿Dónde?

¿Participa de alguna organización de productores?

¿Trabaja el tema de semillas en la organización?

\section{B). DESCRIPCIÓN DE LA AGROBIODIVERSIDAD: "CONOCIMIENTO" Y "USOS"}

¿Qué cultivos tiene en la quinta?

¿Guarda semillas?

¿Para qué los usa?

¿Son para consumo de la familia?

¿Comercialización?

¿Ambos?

C). VALORACIÓN DE LAAGROBIODIVERSIDAD: "CONSERVACIÓN"

1.¿Cómo obtiene las semillas que siembra?

2.¿Por qué las conserva?

3.¿Qué opinión tiene sobre incorporar nuevas semillas en su quinta?

4.¿Qué busca de una semilla nueva?

5.¿Quién se encarga de la selección y guardado de las semillas?

6.¿Qué beneficios encuentra en tener sus propias semillas?

7. ¿Cómo describiría lo que significan para Ud/s. las semillas que guarda/n?

8.¿Qué información tiene en cuenta para guardar una semilla?

9. ¿Realiza nuevos cruzamientos, mejoramiento de sus variedades?

10.¿Qué información incluye en la etiqueta?

11. ¿Cómo obtiene la información para el cultivo y reproducción de las semillas que incorpora?

\section{CONSERVACIÓN PER SE DE LAAGROBIODIVERSIDAD}

¿En qué recipiente guarda las semillas?

¿En qué lugar de la quinta (interior / exterior)?

¿Utiliza etiquetas al guardar las semillas?

¿Qué condiciones recomienda para el lugar y forma donde se guarden las semillas?

¿Encuentra alguna complicación para mantener las semillas?

\section{D). ESPACIOS DE INTERCAMBIO DE SEMILLAS}

¿Participa de espacios de intercambio de semillas?

\section{E). RECOMENDACIÓN DE OTROS INFORMANTES}

1) Nombre y apellido:

Apodo:

Dirección:

Teléfono:

Localidad:

¿Por qué lo sugiere? 
Esta entrevista forma parte del trabajo de tesis doctoral "Sustentabilidad y agrobiodiversidad: "Análisis de las semillas conservadas y conocimientos asociados en agroecosistemas familiares del Cinturón Hortícola Platense". El mismo se realiza en el marco de un trabajo de investigación de la Cátedra de Agroecología, de Facultad de Ciencias Agrarias y Forestales de la Universidad Nacional La Plata.

Los resultados serán útiles para visualizar el rol que cumplen los agricultores familiares del Cinturón Hortícola Platense en la conservación de material genético y los conocimientos vinculados al mismo. Si está de acuerdo con la propuesta, por favor exprese su voluntad de permitir la incorporación de la información compartida.

Deseo que la información por mi brindada sea incluida en el presente trabajo

$$
\mathrm{SI} \quad \text { NO }
$$

1-Indique que actividad desarrolla:

Técnico $\square$ Investigador $\square$ Otro $\square$ ¿cuál/es?

¿En qué localidad/es desarrolla su actividad?

¿En qué Institución trabaja?

2-Mencione temas que considera de importancia en la investigación sobre semillas, siendo el primero el más importante y sucesivamente:

3-¿Cómo calificaría el que los quinteros guarden sus propias semillas?

Indispensable $\square \quad$ Importante $\square \quad$ Poco importante $\square \quad$ No deberían $\square \quad$ Otra $\square$ ¿cuál?

¿Indique el por qué de su respuesta?

4- ¿Sugeriría el uso de semillas conservadas por los propios quinteros? $\quad$ SI $\square \quad$ NO $\square$ ¿Por qué?

5- Ordene numerando del 1 al 6 (siendo el número 1 el de mayor importancia) las siguientes características al momento de elegir/sugerir una semilla:

$\square$ Resistencia a plagas/enfermedades

Demanda del producto en el mercado

Rendimiento

Sabor/ cualidades nutricionales

Precio de la semilla

Estética del producto

6- ¿Sugiere en su ámbito de trabajo el uso de variedades locales/tradicionales? Describa brevemente el por qué de su respuesta: SI $\square$ NO $\square$ En caso de responder $\mathrm{SI}_{¿}$ Cuáles?

7-¿Cuáles considera que son las semillas más utilizadas hoy en día por los quinteros?

¿Qué característica se busca de ellas?

8- ¿y las menos utilizadas?

9- Mencione la/s característica/s que considera más importante de estos cultivos

Tomate:

Morrón:

Hinojo:

Perejil:

Berenjena:

Zanahoria:

Zapallo:

Alcaucil:

Puerro:

Cebolla:

Choclo:

Papa:

Lechuga:

Cebolla de verdeo:

Chaucha:

Otro/s:

Alguna otra información que desee incluir: 
Esta entrevista forma parte del trabajo de tesis doctoral "Sustentabilidad y agrobiodiversidad: "Análisis de las semillas conservadas y conocimientos asociados en agroecosistemas familiares del Cinturón Hortícola Platense". Este trabajo se realiza en el marco de un trabajo de investigación de la Cátedra de Agroecología, de Facultad de Ciencias Agrarias y Forestales de la Universidad Nacional La Plata.

Los resultados serán útiles para visualizar el rol que cumplen los agricultores familiares del Cinturón Hortícola Platense en torno a la conservación de material genético y los conocimientos vinculados al mismo. Esta información aporta a la valoración del sector como guardianes de agrobiodiversidad y aporta al desarrollo de alternativas productivas sustentables a través de la diversificación de las quintas. Asimismo permitirá visualizar impedimentos para la conservación y limitantes de carácter técnico.

Asimismo, cabe aclarar que el beneficio por participar de la presente investigación, será el aporte de conocimientos para las futuras generaciones. Si está de acuerdo con la propuesta, por medio de esta carta exprese su voluntad de permitir la incorporación de la información compartida

Deseo que la información por mi brindada sea incluida en el presente trabajo

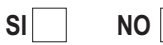

1-Indique que actividad desarrolla:

Profesional / Técnico $\square \quad$ Productor agropecuario $\square$

Estudiante

Otro $\square$ ¿cuál/es?

Especificar en qué localidad/es desarrolla su actividad:

3-¿Cómo calificaría el que los quinteros guarden sus propias semillas?

Indispensable $\square \quad$ Importante $\square \quad$ Poco importante $\square \quad$ No deberían $\square \quad$ Otra $\square$ ¿cuál?

3- ¿Vendería semillas guardadas por los propios quinteros? $\quad$ SI $\square \quad$ NO $\square$ ¿Por qué?

5- Ordene numerando del 1 al 6 (siendo el número 1 el de mayor importancia) las siguientes características al momento de elegir/sugerir una semilla:

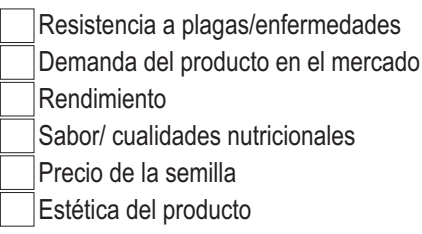

5- ¿Vende en su comercio variedades locales/tradicionales? SI $\square$ NO $\square$ ¿Por qué? En caso de responder $\mathbf{S I}_{\llcorner}$Cuáles?

6- Al momento de vender ¿recomienda semillas de variedades locales/tradicionales? Como por ejemplo tomate platense, hinojo platense, sandía amarilla SI $\square \quad$ No $\square$ ¿Por qué?

En caso de responder $\mathbf{S I}_{¿}$ Cuáles? y ¿Por qué?

7- En su comercio ¿Cuáles son las semillas más vendidas?

¿Qué característica de ellas se busca?

8- ¿y las menos vendidas?

9- ¿de dónde obtiene las semillas que vende?

10- ¿le interesaría tener alguna semilla que no consigue? SI $\square$ NO $\square$

En caso de responder $\mathrm{Sl}_{¿}$ Cuáles? y ¿Por qué?

9- Mencione la/s característica/s que considera más importante de estos cultivos

Tomate:

Morrón:

Hinojo:

Perejil:

Berenjena:

Zanahoria:

Zapallo:

Alcaucil:

Puerro:

Cebolla:

Choclo:

Papa:

Lechuga:

Cebolla de verdeo:

Chaucha:

Otro/s:

Alguna otra información que desee incluir: 


\begin{tabular}{|c|c|c|c|c|c|}
\hline Familia botánica & Sigla (interlocutor) & Nombre científico & Nombre local & ¿Cultiva? & ¿Guarda semillas? \\
\hline Alliaceae & $\mathrm{CA}$ & Allium ampeloprasum $\mathrm{L}$. & Ajo puerro & si & no \\
\hline Alliaceae & $\mathrm{CL}$ & Allium ampeloprasum L. & Puerro & si & no \\
\hline Alliaceae & DY & Allium ampeloprasum $\mathrm{L}$. & Puerro & si & no \\
\hline Alliaceae & PA & Allium ampeloprasum $\mathrm{L}$. & Puerro & si & no \\
\hline Alliaceae & SV & Allium ampeloprasum $\mathrm{L}$. & Puerro & si & no \\
\hline Alliaceae & BIS & Allium ampeloprasum $\mathrm{L}$. & Puerro & si & no \\
\hline Alliaceae & BV & Allium ampeloprasum L. & Puerro & si & si \\
\hline Alliaceae & LP & Allium ampeloprasum L. & Puerro & si & si \\
\hline Alliaceae & NA & Allium ampeloprasum L. & Puerro & si & si \\
\hline Alliaceae & NG & Allium ampeloprasum $\mathrm{L}$. & Puerro francés de Caterá & si & si \\
\hline Alliaceae & FLO & Allium ampeloprasum L. & Puerro & si & perdió la semilla \\
\hline Alliaceae & BIS & Allium cepa L. var. cepa & Verdeo & si & no \\
\hline Alliaceae & CA & Allium cepa L. var. cepa & Verdeo & si & no \\
\hline Alliaceae & DAG & Allium cepa L. var. cepa & Verdeo & si & no \\
\hline Alliaceae & DY & Allium cepa L. var. cepa & Verdeo & si & no \\
\hline Alliaceae & $\mathrm{ML}$ & Allium cepa L. var. cepa & Verdeo & si & no \\
\hline Alliaceae & NG & Allium cepa L. var. cepa & $\begin{array}{l}\text { Cebolla colorada var. } \\
\text { cometa }\end{array}$ & si & no \\
\hline Alliaceae & $S$ & Allium cepa L. var. cepa & Cebolla & si & no \\
\hline Alliaceae & SV & Allium cepa L. var. cepa & Verdeo & si & no \\
\hline Alliaceae & BV & Allium cepa L. var. cepa & Cebolla morada & si & si \\
\hline Alliaceae & BV & Allium cepa L. var. cepa & Verdeo & si & si \\
\hline Alliaceae & $\mathrm{CA}$ & Allium cepa L. var. cepa & Cebolla & si & si \\
\hline Alliaceae & $\mathrm{HC}$ & Allium cepa L. var. cepa & Cebolla & si & si \\
\hline Alliaceae & $J L$ & Allium cepa L. var. cepa & Cebolla balanceana & si & si \\
\hline Alliaceae & $J \mathrm{~L}$ & Allium cepa L. var. cepa & Cebolla de verdeo morada & si & si \\
\hline Alliaceae & $\mathrm{JL}$ & Allium cepa L. var. cepa & Cebolla morada & si & si \\
\hline
\end{tabular}




\begin{tabular}{|c|c|c|c|c|c|}
\hline Familia botánica & Sigla (interlocutor) & Nombre científico & Nombre local & ¿Cultiva? & ¿Guarda semillas? \\
\hline Alliaceae & $\mathrm{JL}$ & Allium cepa L. var. cepa & Verdeo & si & si \\
\hline Alliaceae & MG & Allium cepa L. var. cepa & Verdeo & si & si \\
\hline Alliaceae & NA & Allium cepa L. var. cepa & Cebolla blanca & si & si \\
\hline Alliaceae & NA & Allium cepa L. var. cepa & Verdeo & si & si \\
\hline Alliaceae & NG & Allium cepa L. var. cepa & Cebolla colorada & si & si \\
\hline Alliaceae & NG & Allium cepa L. var. cepa & Cebolla variedad Purea & no & si \\
\hline Alliaceae & NG & Allium cepa L. var. cepa & Verdeo & si & si \\
\hline Alliaceae & SV & Allium cepa L. var. cepa & Cebolla roja & si & si \\
\hline Alliaceae & FLO & Allium cepa L. var. cepa & Verdeo & si & perdió la semilla \\
\hline Alliaceae & $J P$ & Allium fistulosum $\mathrm{L}$. & Cebolla de verdeo & si & si \\
\hline Alliaceae & NA & Allium sativum $\mathrm{L}$. & Ajo orgánico & si & si \\
\hline Alliaceae & $\mathrm{JL}$ & Allium sativum $\mathrm{L}$. & Ajo & si & si \\
\hline Alliaceae & NG & Allium schoenoprasum L. & Ciboullete & si & si \\
\hline Alliaceae & JV & Allium schoenoprasum L. & Cibulet & si & si \\
\hline Alliaceae & ES & Allium tuberosum Rottler ex Spreng. & Tare o puerro japonés & si & si \\
\hline Apiaceae & MG & Apium graveolens L. var. graveolens & Apio & si & no \\
\hline Apiaceae & ML & Apium graveolens L. var. graveolens & Apio & si & no \\
\hline Apiaceae & JV & Conium maculatum $\mathrm{L}$. & Cicuta & si & no especificó \\
\hline Apiaceae & ES & Coriandrum sativum L. & Cilandro & si & si \\
\hline Apiaceae & NA & Coriandrum sativum $\mathrm{L}$. & Cilantro & si & si \\
\hline Apiaceae & BIS & $\begin{array}{l}\text { Daucus carota L. subsp. sativus (Hoffm.) Schübl. } \\
\text { et G. Martens }\end{array}$ & Zanahoria & si & no \\
\hline Apiaceae & MG & $\begin{array}{l}\text { Daucus carota L. subsp. sativus (Hoffm.) Schübl. } \\
\text { et G. Martens }\end{array}$ & Zanahoria & si & no \\
\hline Apiaceae & NA & $\begin{array}{l}\text { Daucus carota L. subsp. sativus (Hoffm.) Schübl. } \\
\text { et G. Martens }\end{array}$ & Zanahoria & si & no \\
\hline Apiaceae & DAG & $\begin{array}{l}\text { Daucus carota L. subsp. sativus (Hoffm.) Schübl. } \\
\text { et G. Martens }\end{array}$ & Zanahoria & si & si \\
\hline Apiaceae & LP & $\begin{array}{l}\text { Daucus carota L. subsp. sativus (Hoffm.) Schübl. } \\
\text { et G. Martens }\end{array}$ & Zanahoria & si & si \\
\hline
\end{tabular}




\begin{tabular}{|c|c|c|c|c|c|}
\hline Familia botánica & Sigla (interlocutor) & Nombre científico & Nombre local & ¿Cultiva? & ¿Guarda semillas? \\
\hline Apiaceae & CA & Foeniculum vulgare Mill. & Hinojo híbrido & si & no \\
\hline Apiaceae & MG & Foeniculum vulgare Mill. & Hinojo & si & no \\
\hline Apiaceae & PA & Foeniculum vulgare Mill. & Hinojo importado & si & no \\
\hline Apiaceae & PA & Foeniculum vulgare Mill. & Hinojo nacional & si & no \\
\hline Apiaceae & CA & Foeniculum vulgare Mill. & Hinojo platense & si & si \\
\hline Apiaceae & $\mathrm{JP}$ & Foeniculum vulgare Mill. & Hinojo & si & si \\
\hline Apiaceae & NA & Foeniculum vulgare Mill. & Hinojo & si & si \\
\hline Apiaceae & PA & Foeniculum vulgare Mill. & Hinojo & si & si \\
\hline Apiaceae & $\mathrm{CA}$ & Petroselinum crispum (Mill.) Fuss & Perejil & si & no \\
\hline Apiaceae & DY & Petroselinum crispum (Mill.) Fuss & Perejil & si & no \\
\hline Apiaceae & FLO & Petroselinum crispum (Mill.) Fuss & Perejil & si & no \\
\hline Apiaceae & LO & Petroselinum crispum (Mill.) Fuss & Perejil & si & no \\
\hline Apiaceae & MG & Petroselinum crispum (Mill.) Fuss & Perejil & si & no \\
\hline Apiaceae & ML & Petroselinum crispum (Mill.) Fuss & Perejil & si & no \\
\hline Apiaceae & SV & Petroselinum crispum (Mill.) Fuss & Perejil & si & no \\
\hline Apiaceae & DAG & Petroselinum crispum (Mill.) Fuss & Perejil & si & si \\
\hline Apiaceae & LP & Petroselinum crispum (Mill.) Fuss & Perejil & si & si \\
\hline Apiaceae & NA & Petroselinum crispum (Mill.) Fuss & Perejil & si & si \\
\hline Apiaceae & NG & Petroselinum crispum (Mill.) Fuss & Perejil & si & si \\
\hline Apiaceae & $\mathrm{P}$ & Petroselinum crispum (Mill.) Fuss. & Perejil & si & si \\
\hline Apiaceae & $\mathrm{JL}$ & Apium graveolens $\mathrm{L}$. var. graveolens & Apio & si & no \\
\hline Apiaceae & $\mathrm{JL}$ & $\begin{array}{l}\text { Daucus carota L. subsp. sativus (Hoffm.) Schübl. } \\
\text { et G. Martens }\end{array}$ & Zanahoria & si & no \\
\hline Apiaceae & $\mathrm{JL}$ & Petroselinum crispum (Mill.) Fuss & Perejil & si & si \\
\hline Apocinaceae & $J \mathrm{~L}$ & Araujia odorata (Hook et Arn) Fontella et Goyder & Tasi & no & no \\
\hline Asteraceae & $\mathrm{JL}$ & Artemisia absinthium L. & Ejenjo & si & si \\
\hline Asteraceae & MG & Calendula officinalis $\mathrm{L}$. & Caléndula & no & no \\
\hline Asteraceae & NA & Calendula officinalis $\mathrm{L}$. & Caléndula & si & si \\
\hline
\end{tabular}




\begin{tabular}{|c|c|c|c|c|c|}
\hline Familia botánica & Sigla (interlocutor) & Nombre científico & Nombre local & ¿Cultiva? & ¿Guarda semillas? \\
\hline Asteraceae & BV & Cichorium intybus $\mathrm{L}$. & Radicheta & si & no \\
\hline Asteraceae & MG & Cichorium intybus $\mathrm{L}$. & Achicoria & si & no \\
\hline Asteraceae & NA & Cichorium intybus $\mathrm{L}$. & Radicheta & si & no \\
\hline Asteraceae & $P$ & Cichorium intybus $\mathrm{L}$. & Radicheta & si & no \\
\hline Asteraceae & DAG & Cichorium intybus $\mathrm{L}$. & Radicheta & si & si \\
\hline Asteraceae & NG & Cichorium intybus $\mathrm{L}$. & Achicoria & si & si \\
\hline Asteraceae & $\mathrm{JP}$ & Cichorium intybus L. & Achicoria & si & si \\
\hline Asteraceae & $\mathrm{CA}$ & Cynara cardunculus L. & Alcaucil híbrido & si & no \\
\hline Asteraceae & AT & Cynara cardunculus L. & Alcaucil gringo INTA & si & si \\
\hline Asteraceae & $J P$ & Cynara cardunculus L. & Alcaucil francés & si & si \\
\hline Asteraceae & $J P$ & Cynara cardunculus $\mathrm{L}$. & Alcaucil violeta & si & si \\
\hline Asteraceae & NA & Cynara cardunculus L. & Alcaucil & si & si \\
\hline Asteraceae & $\mathrm{CA}$ & Cynara cardunculus $\mathrm{L}$. & Alcaucil francés & si & si \\
\hline Asteraceae & ES & Cynara cardunculus $\mathrm{L}$. & Alcaucil & si & si \\
\hline Asteraceae & LP & Cynara cardunculus $\mathrm{L}$. & Alcaucil francés & si & si \\
\hline Asteraceae & LP & Cynara cardunculus L. & Alcaucil ñato & si & si \\
\hline Asteraceae & LP & Gazania rigens (L.) R. Br. & Gazania & si & si \\
\hline Asteraceae & CV & Helianthus annus L. & Girasol rojo & si & si \\
\hline Asteraceae & ES & Helianthus annus L. & Girasol & si & si \\
\hline Asteraceae & BIS & Lactuca sativa L. & Lechuga capuchina & si & no \\
\hline Asteraceae & $\mathrm{CA}$ & Lactuca sativa L. & Lechuga criolla & si & no \\
\hline Asteraceae & $\mathrm{CL}$ & Lactuca sativa L. & Lechuga capuchina & si & no \\
\hline Asteraceae & $\mathrm{CL}$ & Lactuca sativa L. & Lechuga crespa & si & no \\
\hline Asteraceae & DY & Lactuca sativa L. & Crespa & si & no \\
\hline Asteraceae & DY & Lactuca sativa $\mathrm{L}$. & Lechuga manteca & si & no \\
\hline Asteraceae & $\mathrm{JV}$ & Lactuca sativa L. & Lechuga crespa & si & no \\
\hline Asteraceae & LO & Lactuca sativa L. & Lechuga & si & no \\
\hline Asteraceae & $M G$ & Lactuca sativa L. & Lechuga & si & no \\
\hline
\end{tabular}




\begin{tabular}{|c|c|c|c|c|c|}
\hline Familia botánica & Sigla (interlocutor) & Nombre científico & Nombre local & ¿Cultiva? & ¿Guarda semillas? \\
\hline Asteraceae & ML & Lactuca sativa L. & Escarola fina & si & no \\
\hline Asteraceae & ML & Lactuca sativa L. & Escarola morada & si & no \\
\hline Asteraceae & ML & Lactuca sativa L. & Lechuga crespita & si & no \\
\hline Asteraceae & ML & Lactuca sativa L. & Lechuga manteca & si & no \\
\hline Asteraceae & NA & Lactuca sativa L. & Lechuga & si & no \\
\hline Asteraceae & $\mathrm{P}$ & Lactuca sativa L. & Lechuga capuchina & si & no \\
\hline Asteraceae & $\mathrm{P}$ & Lactuca sativa L. & Lechuga manteca & si & no \\
\hline Asteraceae & $\mathrm{P}$ & Lactuca sativa L. & Lechuga morada & si & no \\
\hline Asteraceae & JV & Lactuca sativa L. & Leguga manteca & si & no \\
\hline Asteraceae & BIS & Lactuca sativa L. & Lechuga escarola fina & si & si \\
\hline Asteraceae & BIS & Lactuca sativa L. & Lechuga moradita & si & si \\
\hline Asteraceae & DAG & Lactuca sativa L. & Lechuga & si & si \\
\hline Asteraceae & DAG & Lactuca sativa L. & Lechuga (otra) & si & si \\
\hline Asteraceae & $\mathrm{JL}$ & Lactuca sativa L. & Lechuga & si & si \\
\hline Asteraceae & ML & Matricaria chamomilla L. & Manzanilla & esp & espontánea \\
\hline Asteraceae & JV & Matricaria chamomilla L. & Manzanilla & esp & no \\
\hline Asteraceae & CV & Smallanthus sonchifolius (Poepp. et Endl.) H. Rob. & Yacón & si & si \\
\hline Asteraceae & CV & Stevia rebaudiana (Bertoni) Bertoni & Stevia & si & si \\
\hline Asteraceae & LP & Tagetes minuta L. & Copete & si & si \\
\hline Asteraceae & NA & Tagetes minuta $\mathrm{L}$. & Copete & si & si \\
\hline Brassicaceae & $\mathrm{JP}$ & Brassica napus L. & Grilo & no & perdió la semilla \\
\hline Brassicaceae & $\mathrm{JP}$ & Brassica oleracea L. var. italica Plenck & Brócoli & si & no \\
\hline Brassicaceae & AT & Armoracia rusticana P. Gaertn.,B. Mey. et Scherb. & Crin & si & si \\
\hline Brassicaceae & $\mathrm{CA}$ & Brassica napus L. & Grilo comercial & si & no \\
\hline Brassicaceae & $P$ & Brassica napus L. & Grilo & si & no \\
\hline Brassicaceae & AT & Brassica napus L. & Nabiza & si & si \\
\hline Brassicaceae & $\mathrm{CA}$ & Brassica napus $\mathrm{L}$. & Grilo & si & si \\
\hline Brassicaceae & $\mathrm{CA}$ & Brassica napus L. & Grilo nabo & si & si \\
\hline
\end{tabular}




\begin{tabular}{|c|c|c|c|c|c|}
\hline Familia botánica & Sigla (interlocutor) & Nombre científico & Nombre local & ¿Cultiva? & ¿Guarda semillas? \\
\hline Brassicaceae & CA & Brassica napus L. & Nabiza & si & si \\
\hline Brassicaceae & $\mathrm{JL}$ & Brassica napus L. & Nabiza & si & si \\
\hline Brassicaceae & LP & Brassica napus L. & Grilo & si & si \\
\hline Brassicaceae & LP & Brassica napus L. & Grilo nabo & si & si \\
\hline Brassicaceae & NG & Brassica napus L. & Grilo & si & si \\
\hline Brassicaceae & NG & Brassica napus L. & Nabiza & si & si \\
\hline Brassicaceae & $\mathrm{CA}$ & Brassica oleracea L. var gemmifera (DC.) Zenker & Repollo de bruselas & si & no \\
\hline Brassicaceae & AT & Brassica oleracea L. var. botrytis L. & Coliflor & si & no \\
\hline Brassicaceae & FLO & Brassica oleracea L. var. botrytis L. & Coliflor & si & no \\
\hline Brassicaceae & AT & Brassica oleracea L. var. capitata L. & Repollo & si & no \\
\hline Brassicaceae & CA & Brassica oleracea L. var. capitata L. & Repollo blanco & si & no \\
\hline Brassicaceae & CA & Brassica oleracea L. var. capitata L. & Repollo rojo & si & no \\
\hline Brassicaceae & $\mathrm{CL}$ & Brassica oleracea L. var. capitata L. & Repollo & si & no \\
\hline Brassicaceae & DAG & Brassica oleracea L. var. capitata L. & Repollo & si & no \\
\hline Brassicaceae & DAG & Brassica oleracea L. var. capitata L. & Repollo colorado & si & no \\
\hline Brassicaceae & DY & Brassica oleracea L. var. capitata L. & Repollo & si & no \\
\hline Brassicaceae & FLO & Brassica oleracea L. var. capitata L. & Repollo & si & no \\
\hline Brassicaceae & MG & Brassica oleracea L. var. capitata L. & Repollo & si & no \\
\hline Brassicaceae & NA & Brassica oleracea L. var. capitata L. & Repollo corazón de buey & si & no \\
\hline Brassicaceae & LP & Brassica oleracea L. var. capitata L. & Repollo & no & perdió la semilla \\
\hline Brassicaceae & NG & Brassica oleracea L. var. capitata L. & Repollo blanco & no & perdió la semilla \\
\hline Brassicaceae & PA & Brassica oleracea L. var. capitata L. & Repollo blanco & si & si \\
\hline Brassicaceae & FLO & Brassica oleracea L. var. litalica Plenck & Brócoli & si & no \\
\hline Brassicaceae & BIS & Brassica oleracea L. var. italica Plenck & Brócoli & si & no \\
\hline Brassicaceae & BV & Brassica oleracea L. var. italica Plenck & Brócoli & si & no \\
\hline Brassicaceae & JV & Brassica oleracea L. var. italica Plenck & Brócoli comprado & si & no \\
\hline Brassicaceae & MG & Brassica oleracea L. var. italica Plenck & Brócoli & si & no \\
\hline Brassicaceae & $J$ & Brassica oleracea L. var. italica Plenck & Brócoli italiano & no & perdió la semilla \\
\hline
\end{tabular}




\begin{tabular}{|c|c|c|c|c|c|}
\hline Familia botánica & Sigla (interlocutor) & Nombre científico & Nombre local & ¿Cultiva? & ¿Guarda semillas? \\
\hline Brassicaceae & JV & Brassica oleracea L. var. italica Plenck & Brócoli & si & si \\
\hline Brassicaceae & NA & Brassica oleracea L. var. italica Plenck & Brócoli & si & si \\
\hline Brassicaceae & AT & Brassica oleracea L. var. italica Plenck. & Brócoli & si & no \\
\hline Brassicaceae & CA & Brassica oleracea L. var. italica Plenck. & Brócoli & si & no \\
\hline Brassicaceae & $\mathrm{CL}$ & Brassica rapa L. var. chinensis (L.) Kitam. & Hakusai & si & no \\
\hline Brassicaceae & P & Brassica rapa L. var. chinensis (L.) Kitam. & Pak-choi & si & no \\
\hline Brassicaceae & NA & Brassica rapa L. var. rapa & Nabo & si & no \\
\hline Brassicaceae & BV & Eruca vesicaria (L.) Cav. & Rúcula & si & no \\
\hline Brassicaceae & $\mathrm{CL}$ & Eruca vesicaria (L.) Cav. & Rúcula & si & no \\
\hline Brassicaceae & ES & Eruca vesicaria (L.) Cav. & Rúcula & si & no \\
\hline Brassicaceae & MG & Eruca vesicaria (L.) Cav. & Rúcula & si & no \\
\hline Brassicaceae & NA & Eruca vesicaria (L.) Cav. & Rúcula & si & no \\
\hline Brassicaceae & JV & Eruca vesicaria (L.) Cav. & Rúcula & si & no \\
\hline Brassicaceae & $\mathrm{CA}$ & Eruca vesicaria (L.) Cav. & Rúcula & si & no \\
\hline Brassicaceae & DAG & Eruca vesicaria (L.) Cav. & Rúcula & si & si \\
\hline Brassicaceae & $\mathrm{JL}$ & Eruca vesicaria (L.) Cav. & Rúcula & si & si \\
\hline Brassicaceae & $\mathrm{CL}$ & Raphanus sativus L. var. sativus & Rabanito & si & no \\
\hline Brassicaceae & $J L$ & Raphanus sativus $L$. var. sativus & Rabanito & si & no \\
\hline Brassicaceae & NA & Raphanus sativus L. var. sativus & Rabanito & si & no \\
\hline Brassicaceae & $P$ & Raphanus sativus L. var. sativus & Rabanito & si & no \\
\hline Brassicaceae & NA & Raphanus sativus $L$. var. sativus & Nabo daikon & si & si \\
\hline Brassicaceae & $J P$ & Sonchus oleraceus L. & Cardella & esp & espontánea \\
\hline Cannabaceae & NA & Humulus lupulus L. & Lúpulo & si & si \\
\hline Caricaceae & $\mathrm{JL}$ & Carica papaya L. & Mamon & si & si \\
\hline Caryophyllaceae & MG & Dianthus barbatus L. & Macetilla & si & si \\
\hline Chenopodiaceae & $\mathrm{CL}$ & Beta vulgaris $\mathrm{L}$. var. cicla $\mathrm{L}$. & Acelga & si & no \\
\hline Chenopodiaceae & DY & Beta vulgaris L. var. cicla L. & Acelga & si & no \\
\hline Chenopodiaceae & ES & Beta vulgaris L. var. cicla L. & Acelga & si & no \\
\hline
\end{tabular}




\begin{tabular}{|c|c|c|c|c|c|}
\hline Familia botánica & Sigla (interlocutor) & Nombre científico & Nombre local & ¿Cultiva? & ¿Guarda semillas? \\
\hline Chenopodiaceae & LO & Beta vulgaris L. var. cicla L. & Acelga & si & no \\
\hline Chenopodiaceae & MG & Beta vulgaris L. var. cicla L. & Acelga & si & no \\
\hline Chenopodiaceae & NG & Beta vulgaris $\mathrm{L}$. var. cicla $\mathrm{L}$. & $\begin{array}{l}\text { Acelga penca blanca } \\
\text { importada }\end{array}$ & si & no \\
\hline Chenopodiaceae & NG & Beta vulgaris $\mathrm{L}$. var. cicla $\mathrm{L}$. & $\begin{array}{l}\text { Acelga penca verde } \\
\text { importada }\end{array}$ & si & no \\
\hline Chenopodiaceae & $P$ & Beta vulgaris $\mathrm{L}$. var. cicla $\mathrm{L}$. & Acelga & si & no \\
\hline Chenopodiaceae & PA & Beta vulgaris L. var. cicla L. & Acelga & si & no \\
\hline Chenopodiaceae & SV & Beta vulgaris $\mathrm{L}$. var. cicla L. & Acelga & si & no \\
\hline Chenopodiaceae & CA & Beta vulgaris L. var. cicla L. & Acelga & si & no \\
\hline Chenopodiaceae & MG & Beta vulgaris $\mathrm{L}$. var. cicla $\mathrm{L}$. & Acelga de penca verde & no & perdió la semilla \\
\hline Chenopodiaceae & CA & Beta vulgaris $\mathrm{L}$. var. cicla $\mathrm{L}$. & Acelga de penca verde & si & si \\
\hline Chenopodiaceae & DAG & Beta vulgaris L. var. cicla L. & Acelga & si & si \\
\hline Chenopodiaceae & $\mathrm{HC}$ & Beta vulgaris $\mathrm{L}$. var. cicla $\mathrm{L}$. & Acelga & si & si \\
\hline Chenopodiaceae & $\mathrm{JL}$ & Beta vulgaris $\mathrm{L}$. var. cicla $\mathrm{L}$. & Acelga de palo blanco & si & si \\
\hline Chenopodiaceae & $\mathrm{JL}$ & Beta vulgaris $\mathrm{L}$. var. cicla $\mathrm{L}$. & Acelga de palo verde & si & si \\
\hline Chenopodiaceae & JV & Beta vulgaris $\mathrm{L}$. var. cicla $\mathrm{L}$. & $\begin{array}{l}\text { Acelga de penca blanca } \\
\text { nacional }\end{array}$ & si & si \\
\hline Chenopodiaceae & JV & Beta vulgaris $\mathrm{L}$. var. cicla $\mathrm{L}$. & Acelga de penca verde & si & si \\
\hline Chenopodiaceae & LP & Beta vulgaris $\mathrm{L}$. var. cicla $\mathrm{L}$. & Acelga & si & si \\
\hline Chenopodiaceae & NA & Beta vulgaris $\mathrm{L}$. var. cicla $\mathrm{L}$. & Acelga & si & si \\
\hline Chenopodiaceae & NG & Beta vulgaris $\mathrm{L}$. var. cicla $\mathrm{L}$. & $\begin{array}{l}\text { Acelga penca verde } \\
\text { nacional }\end{array}$ & si & si \\
\hline Chenopodiaceae & S & Beta vulgaris $\mathrm{L}$. var. cicla $\mathrm{L}$. & Acelga & si & si \\
\hline Chenopodiaceae & FLO & Beta vulgaris $\mathrm{L}$. var. cicla $\mathrm{L}$. & Acelga & si & perdió la semilla \\
\hline Chenopodiaceae & BIS & Beta vulgaris $\mathrm{L}$. var. cicla $\mathrm{L}$. & Acelga & si & no \\
\hline Chenopodiaceae & BV & Beta vulgaris $L$. var. cicla $L$. & Acelga & si & si \\
\hline Chenopodiaceae & BIS & Beta vulgaris $\mathrm{L}$. var. vulgaris & Remolacha & si & no \\
\hline Chenopodiaceae & BV & Beta vulgaris $\mathrm{L}$. var. vulgaris & Remolacha & si & no \\
\hline Chenopodiaceae & CA & Beta vulgaris $L$. var. vulgaris & Remolacha & si & no \\
\hline
\end{tabular}




\begin{tabular}{|c|c|c|c|c|c|}
\hline Familia botánica & Sigla (interlocutor) & Nombre científico & Nombre local & ¿Cultiva? & ¿Guarda semillas? \\
\hline Chenopodiaceae & ES & Beta vulgaris $L$. var. vulgaris & Remolacha & si & no \\
\hline Chenopodiaceae & $\mathrm{JL}$ & Beta vulgaris $\mathrm{L}$. var. vulgaris & Remolacha & si & no \\
\hline Chenopodiaceae & LO & Beta vulgaris $\mathrm{L}$. var. vulgaris & Remolacha & si & no \\
\hline Chenopodiaceae & MG & Beta vulgaris $L$. var. vulgaris & Remolacha & si & no \\
\hline Chenopodiaceae & $\mathrm{P}$ & Beta vulgaris L. var. vulgaris & Remolacha & si & no \\
\hline Chenopodiaceae & DAG & Beta vulgaris $\mathrm{L}$. var. vulgaris & Remolacha & si & si \\
\hline Chenopodiaceae & JV & Beta vulgaris $L$. var. vulgaris & Remolacha & si & si \\
\hline Chenopodiaceae & LP & Beta vulgaris $\mathrm{L}$. var. vulgaris & Remolacha & si & si \\
\hline Chenopodiaceae & NA & Beta vulgaris $L$. var. vulgaris & Remolacha & si & si \\
\hline Chenopodiaceae & NA & Dysphania ambrosioides (L.) Mosyakin \& Clemants & Paico/ pasote & si & si \\
\hline Chenopodiaceae & ML & Dysphania ambrosioides (L.) Mosyakin \& Clemants & Paico & si & si \\
\hline Chenopodiaceae & $\mathrm{P}$ & Spinacia oleracea L & Espinaca & si & no \\
\hline Chenopodiaceae & BIS & Spinacia oleracea L. & Espinaca & si & no \\
\hline Chenopodiaceae & BV & Spinacia oleracea L. & Espinaca & si & no \\
\hline Chenopodiaceae & CA & Spinacia oleracea L. & Espinaca & si & no \\
\hline Chenopodiaceae & NA & Spinacia oleracea L. & Espinaca & si & no \\
\hline Convolvulaceae & AT & Ipomoea batatas (L.) Lam. & Batata boregas & si & no \\
\hline Convolvulaceae & BV & Ipomoea batatas (L.) Lam. & Camote & no & no \\
\hline Convolvulaceae & LP & Ipomoea batatas (L.) Lam. & Batata blanca & no & perdió la semilla \\
\hline Convolvulaceae & BV & Ipomoea batatas (L.) Lam. & Batata & si & si \\
\hline Convolvulaceae & DAG & Ipomoea batatas (L.) Lam. & Batata & si & si \\
\hline Convolvulaceae & $\mathrm{JL}$ & Ipomoea batatas (L.) Lam. & Batata & si & si \\
\hline Convolvulaceae & LP & Ipomoea batatas (L.) Lam. & Batata pata de rana & si & si \\
\hline Cucurbitaceae & $\mathrm{JL}$ & Citrullus lanatus (Thunb.) Matsum. et Nakai & Sandía amarilla & si & si \\
\hline Cucurbitaceae & LO & Citrullus lanatus (Thunb.) Matsum. et Nakai & Sandía enana & si & si \\
\hline Cucurbitaceae & LP & Citrullus lanatus (Thunb.) Matsum. et Nakai & Sandía cuarentina & si & si \\
\hline Cucurbitaceae & NA & Citrullus lanatus (Thunb.) Matsum. et Nakai & Sandía amarilla & si & si \\
\hline Cucurbitaceae & FLO & Citrullus lanatus (Thunb.) Matsum. et Nakai & Sandía & si & perdió la semilla \\
\hline
\end{tabular}




\begin{tabular}{|c|c|c|c|c|c|}
\hline Familia botánica & Sigla (interlocutor) & Nombre científico & Nombre local & ¿Cultiva? & ¿Guarda semillas? \\
\hline Cucurbitaceae & BIS & Cucumis melo L. & Melón & si & no \\
\hline Cucurbitaceae & $\mathrm{HC}$ & Cucumis melo L. & Melón & si & si \\
\hline Cucurbitaceae & $\mathrm{JL}$ & Cucumis melo L. & Melón & si & si \\
\hline Cucurbitaceae & $J P$ & Cucumis melo L. & Melón amarillo & si & si \\
\hline Cucurbitaceae & FLO & Cucumis melo L. & Melón & si & perdió la semilla \\
\hline Cucurbitaceae & BIS & Cucumis sativus $\mathrm{L}$. & Pepinito & si & no \\
\hline Cucurbitaceae & BIS & Cucumis sativus $\mathrm{L}$. & Pepino & si & no \\
\hline Cucurbitaceae & DY & Cucumis sativus $\mathrm{L}$. & Pepino & si & no \\
\hline Cucurbitaceae & SV & Cucumis sativus $\mathrm{L}$. & Pepino & si & no \\
\hline Cucurbitaceae & ES & Cucurbita ficifolia Bouché & Cayote & no & perdió la semilla \\
\hline Cucurbitaceae & CV & Cucurbita ficifolia Bouché & Cayote & si & si \\
\hline Cucurbitaceae & IG & Cucurbita ficifolia Bouché & Acayote & si & si \\
\hline Cucurbitaceae & BIS & Cucurbita maxima Duchesne subsp. maxima & Zapallito & si & no \\
\hline Cucurbitaceae & CA & Cucurbita maxima Duchesne subsp. maxima & Zapallito & si & no \\
\hline Cucurbitaceae & DY & Cucurbita maxima Duchesne subsp. maxima & Zapallito & si & no \\
\hline Cucurbitaceae & FLO & Cucurbita maxima Duchesne subsp. maxima & Zapallito de tronco & si & no \\
\hline Cucurbitaceae & LP & Cucurbita maxima Duchesne subsp. maxima & Zapallito de tronco & si & no \\
\hline Cucurbitaceae & LP & Cucurbita maxima Duchesne subsp. maxima & Zapallito redondo & si & no \\
\hline Cucurbitaceae & $\mathrm{CA}$ & Cucurbita maxima Duchesne subsp. maxima & Zapallo plomo & si & si \\
\hline Cucurbitaceae & CV & Cucurbita maxima Duchesne subsp. maxima & Zapallo plomo & si & si \\
\hline Cucurbitaceae & CV & Cucurbita maxima Duchesne subsp. maxima & Zapallo variedad 1 & si & si \\
\hline Cucurbitaceae & CV & Cucurbita maxima Duchesne subsp. maxima & Zapallo variedad 2 & si & si \\
\hline Cucurbitaceae & $\mathrm{CV}$ & Cucurbita maxima Duchesne subsp. maxima & Zapallo variedad 3 & si & si \\
\hline Cucurbitaceae & IG & Cucurbita maxima Duchesne subsp. maxima & Zapallo plomo & si & si \\
\hline Cucurbitaceae & $\mathrm{JL}$ & Cucurbita maxima Duchesne subsp. maxima & Zapallito de tronco & si & si \\
\hline Cucurbitaceae & JV & Cucurbita maxima Duchesne subsp. maxima & Zapallito & si & si \\
\hline Cucurbitaceae & LO & Cucurbita maxima Duchesne subsp. maxima & Zapallito & si & si \\
\hline Cucurbitaceae & NA & Cucurbita maxima Duchesne subsp. maxima & Zapallito & si & si \\
\hline
\end{tabular}




\begin{tabular}{|c|c|c|c|c|c|}
\hline Familia botánica & Sigla (interlocutor) & Nombre científico & Nombre local & ¿Cultiva? & ¿Guarda semillas? \\
\hline Cucurbitaceae & NG & Cucurbita maxima Duchesne subsp. maxima & Zapallito & si & si \\
\hline Cucurbitaceae & PA & Cucurbita maxima Duchesne subsp. maxima & Zapallito & si & si \\
\hline Cucurbitaceae & AT & Cucurbita moschata (Lam.) Poir. & Anquito & si & no \\
\hline Cucurbitaceae & BIS & Cucurbita pepo L. & Zucchini & si & no \\
\hline Cucurbitaceae & BV & Cucurbita pepo L. & Zuchini & si & no \\
\hline Cucurbitaceae & CA & Cucurbita pepo L. & Zuchini & si & no \\
\hline Cucurbitaceae & $J P$ & Cucurbita moschata (Lam.) Poir. & Anquito & si & no \\
\hline Cucurbitaceae & LP & Cucurbita pepo L. & Zucchini & si & no \\
\hline Cucurbitaceae & PA & Cucurbita pepo L. & Zuchini & si & no \\
\hline Cucurbitaceae & BV & Cucurbita moschata (Lam.) Poir. & Zapallo anco & si & si \\
\hline Cucurbitaceae & $\mathrm{HC}$ & Cucurbita moschata (Lam.) Poir. & Zapallo anquito batata & si & si \\
\hline Cucurbitaceae & IG & Cucurbita moschata (Lam.) Poir. & Zapallo anco & si & si \\
\hline Cucurbitaceae & $\mathrm{JL}$ & Cucurbita moschata (Lam.) Poir. & Zapallo anco & si & si \\
\hline Cucurbitaceae & LP & Cucurbita moschata (Lam.) Poir. & Zapallo anco & si & si \\
\hline Cucurbitaceae & NA & Cucurbita moschata (Lam.) Poir. & Zapallo anco & si & si \\
\hline Cucurbitaceae & PA & Cucurbita pepo L. & Zuchini & si & si \\
\hline Cucurbitaceae & SV & Cucurbita moschata (Lam.) Poir. & Calabaza batata & si & si \\
\hline Cucurbitaceae & FLO & Cucurbita sp & Zapallo & si & si \\
\hline Cucurbitaceae & MG & Cucurbita sp. & Zapallo híbrido & si & no \\
\hline Cucurbitaceae & PA & Cucurbita sp. & Calabaza & si & no \\
\hline Cucurbitaceae & FLO & Cucurbita sp. & $\begin{array}{l}\text { Zapallo grande redondo } \\
\text { verde }\end{array}$ & no & perdió la semilla \\
\hline Cucurbitaceae & $\mathrm{CA}$ & Cucurbita sp. & Calabaza & si & si \\
\hline Cucurbitaceae & $\mathrm{CA}$ & Cucurbita sp. & Zapallo & si & si \\
\hline Cucurbitaceae & ES & Cucurbita pepo L. & Zapallo de angola & si & si \\
\hline Cucurbitaceae & $\mathrm{JL}$ & Cucurbita sp. & Calabaza verde & si & si \\
\hline Cucurbitaceae & $\mathrm{JL}$ & Cucurbita sp. & Zapallo angolita & si & si \\
\hline Cucurbitaceae & $J P$ & Cucurbita sp. & $\begin{array}{l}\text { Zapallito zuquini verde } \\
\text { redondo }\end{array}$ & si & si \\
\hline
\end{tabular}




\begin{tabular}{|c|c|c|c|c|c|}
\hline Familia botánica & Sigla (interlocutor) & Nombre científico & Nombre local & ¿Cultiva? & ¿Guarda semillas? \\
\hline Cucurbitaceae & LP & Cucurbita pepo L. & Zapallo turco & si & si \\
\hline Cucurbitaceae & NA & Cucurbita sp. & Zapallo & si & si \\
\hline Cucurbitaceae & NA & Cucurbita moschata (Lam.) Poir. & Zapallo anco batata & si & si \\
\hline Cucurbitaceae & NA & Cucurbita sp. & Zapallo okaido & si & si \\
\hline Cucurbitaceae & $\mathrm{CV}$ & Lagenaria siceraria (Mol.) Standl. & Cucusa longa & si & si \\
\hline Cucurbitaceae & $\mathrm{JL}$ & Lagenaria siceraria (Mol.) Standl. & Calabaza de mate & si & si \\
\hline Cucurbitaceae & $J P$ & Lagenaria siceraria (Mol.) Standl. & Cucuza & si & si \\
\hline Cucurbitaceae & CV & Lagenaria siceraria (Mol.) Standl. & Mate & si & si \\
\hline Cucurbitaceae & NA & Lagenaria siceraria (Mol.) Standl. & Calabaza de mate & si & si \\
\hline Cucurbitaceae & $\mathrm{JL}$ & Luffa sp. & Esponja vegetal & si & si \\
\hline Cucurbitaceae & NA & Sechium edule (Jacq.) Sw. & Papa del aire & si & si \\
\hline Ebenaceae & DY & Diospyros kaki Thunb. & Caqui chocolate & si & no especificó \\
\hline Ebenaceae & DY & Diospyros kaki Thunb. & Caqui común & si & no especificó \\
\hline Ebenaceae & NA & Diospyros kaki Thunb. & Caqui (variedad 1) & si & no especificó \\
\hline Ebenaceae & NA & Diospyros kaki Thunb. & Caqui (variedad 2) & si & no especificó \\
\hline Ebenaceae & AT & Diospyros kaki Thunb. & Caqui & si & si \\
\hline Fabaceae & $\mathrm{JL}$ & Acacia aroma Gill. ex Hook et Arn & Tusca & si & si \\
\hline Fabaceae & CV & Arachis hypogaea L. & Maní & no & perdió la semilla \\
\hline Fabaceae & ES & Arachis hypogaea L. & Maní colorado & si & si \\
\hline Fabaceae & BV & Arachis hypogaea L. & Maní & no & no \\
\hline Fabaceae & JV & Mimosa sp. & Mimosa & si & si \\
\hline Fabaceae & FLO & Phaseolus lunatus L. & Poroto mantecoso & si & perdió la semilla \\
\hline Fabaceae & BV & Phaseolus vulgaris $\mathrm{L}$. var. vulgaris & Chaucha larga & si & no \\
\hline Fabaceae & $\mathrm{CA}$ & Phaseolus vulgaris L. var. vulgaris & Chaucha & si & no \\
\hline Fabaceae & MS & Phaseolus vulgaris L. var. vulgaris & Chaucha rolliza & si & no \\
\hline Fabaceae & BV & Phaseolus vulgaris L. var. vulgaris & Chaucha fina & si & si \\
\hline Fabaceae & BIS & Phaseolus vulgaris L. var. vulgaris & Chaucha & si & no \\
\hline Fabaceae & BIS & Phaseolus vulgaris L. var. vulgaris & Chaucha & si & no \\
\hline
\end{tabular}




\begin{tabular}{|c|c|c|c|c|c|}
\hline Familia botánica & Sigla (interlocutor) & Nombre científico & Nombre local & ¿Cultiva? & ¿Guarda semillas? \\
\hline Fabaceae & DY & Phaseolus vulgaris $\mathrm{L}$. var. vulgaris & Chaucha & si & no \\
\hline Fabaceae & LO & Phaseolus vulgaris $\mathrm{L}$. var. vulgaris & Chaucha & si & no \\
\hline Fabaceae & NG & Phaseolus vulgaris $L$. var. vulgaris & Chaucha & si & no \\
\hline Fabaceae & SV & Phaseolus vulgaris $L$. var. vulgaris & Chaucha rolliza & si & no \\
\hline Fabaceae & AT & Phaseolus vulgaris $\mathrm{L}$. var. vulgaris & Chaucha balina & si & si \\
\hline Fabaceae & FLO & Phaseolus vulgaris $L$. var. vulgaris & Chaucha & si & si \\
\hline Fabaceae & IG & Phaseolus vulgaris $\mathrm{L}$. var. vulgaris & Chaucha & si & si \\
\hline Fabaceae & LP & Phaseolus vulgaris $\mathrm{L}$. var. vulgaris & Chaucha & si & si \\
\hline Fabaceae & MG & Phaseolus vulgaris $\mathrm{L}$. var. vulgaris & $\begin{array}{l}\text { Chaucha lengua de } \\
\text { dragón }\end{array}$ & si & si \\
\hline Fabaceae & NA & Phaseolus vulgaris $\mathrm{L}$. var. vulgaris & Chaucha & si & si \\
\hline Fabaceae & NG & Phaseolus vulgaris $\mathrm{L}$. var. vulgaris & Chaucha cronos & si & si \\
\hline Fabaceae & NG & Phaseolus vulgaris $L$. var. vulgaris & Poroto lengua de dragón & si & si \\
\hline Fabaceae & LO & Phaseolus vulgaris $\mathrm{L}$. var. vulgaris & Poroto & si & si \\
\hline Fabaceae & FLO & Phaseolus vulgaris $\mathrm{L}$. var. vulgaris & Chaucha ancha & si & perdió la semilla \\
\hline Fabaceae & FLO & Phaseolus vulgaris $\mathrm{L}$. var. vulgaris & Chaucha fina & si & perdió la semilla \\
\hline Fabaceae & CA & Pisum sativum $\mathrm{L}$. & Arveja & si & no \\
\hline Fabaceae & $\mathrm{JP}$ & Pisum sativum $\mathrm{L}$. & Arveja & si & no \\
\hline Fabaceae & ML & Pisum sativum $\mathrm{L}$. & Arveja & si & no \\
\hline Fabaceae & SV & Pisum sativum L. & Arveja & si & no \\
\hline Fabaceae & $\mathrm{JL}$ & Pisum sativum L. & Arveja & si & si \\
\hline Fabaceae & PA & Pisum sativum L. & Arveja & si & si \\
\hline Fabaceae & FLO & Pisum sativum L. & Arveja & si & perdió la semilla \\
\hline Fabaceae & PA & Vicia faba $\mathrm{L}$. & Haba & no & no \\
\hline Fabaceae & ML & Vicia faba L. & Habas & si & no \\
\hline Fabaceae & $\mathrm{CA}$ & Vicia faba L. & Habas & si & si \\
\hline Fabaceae & $J \mathrm{~L}$ & Vicia faba L. & Haba & si & si \\
\hline Fabaceae & $J P$ & Vicia faba $\mathrm{L}$. & Haba & si & si \\
\hline
\end{tabular}




\begin{tabular}{|c|c|c|c|c|c|}
\hline Familia botánica & Sigla (interlocutor) & Nombre científico & Nombre local & ¿Cultiva? & ¿Guarda semillas? \\
\hline Fabaceae & BIS & Vigna unguiculata subsp. sesquipedalis (L.) Verdc. & Chaucha metro & si & si \\
\hline Fabaceae & LO & Vigna unguiculata subsp. sesquipedalis (L.) Verdc. & Chaucha metro & si & si \\
\hline Fabaceae & MS & Vigna unguiculata subsp. sesquipedalis (L.) Verdc. & Chaucha metro & si & si \\
\hline Fabaceae & $\mathrm{JV}$ & Wisteria sinensis (Sims.) Sweet & Glicina & si & si \\
\hline Geraniaceae & NA & Pelargonium hortorum Bailey & Malvón & si & no \\
\hline Iridaceae & $\mathrm{JV}$ & Freesia refracta (Jacq.) Klatt & Fresia & si & si \\
\hline Lamiaceae & ML & Melisa officinalis L. & Toronjil & no & no \\
\hline Lamiaceae & MG & Melisa officinalis $\mathrm{L}$. & Melisa & si & no especificó \\
\hline Lamiaceae & NA & Melisa officinalis $\mathrm{L}$. & Melisa & si & si \\
\hline Lamiaceae & $\mathrm{JL}$ & Melisa officinalis $\mathrm{L}$. & Toronjil & si & si \\
\hline Lamiaceae & NA & Mentha sp. & Menta cítrica & si & si \\
\hline Lamiaceae & NA & Mentha sp. & Menta inglesa & si & si \\
\hline Lamiaceae & ES & Mentha spicata L. & Menta & si & no especificó \\
\hline Lamiaceae & MG & Mentha spicata L. & Menta & si & no especificó \\
\hline Lamiaceae & CV & Mentha spicata L. & Menta & si & si \\
\hline Lamiaceae & NA & Mentha x piperita L. & Yerba buena & si & si \\
\hline Lamiaceae & BV & Ocimum basilicum L. & Albahaca & si & no \\
\hline Lamiaceae & LO & Ocimum basilicum L. & Albahaca & si & no \\
\hline Lamiaceae & SV & Ocimum basilicum $\mathrm{L}$. & Albahaca & si & no \\
\hline Lamiaceae & $S$ & Ocimum basilicum L. & Albahaca & si & no \\
\hline Lamiaceae & NA & Ocimum basilicum L. & Albahaca & si & si \\
\hline Lamiaceae & NG & Ocimum basilicum L. & Albahaca & si & si \\
\hline Lamiaceae & MG & Origanum vulgare L. & Orégano & si & no especificó \\
\hline Lamiaceae & ES & Origanum vulgare L. & Orégano & si & si \\
\hline Lamiaceae & NA & Origanum vulgare $\mathrm{L}$. & Orégano más intenso & si & si \\
\hline Lamiaceae & NA & Origanum vulgare $\mathrm{L}$. & Orégano suave & si & si \\
\hline Lamiaceae & JV & Origanum vulgare L. & Orégano & si & si \\
\hline Lamiaceae & MG & Rosmarinus officinalis L. & Romero & si & no especificó \\
\hline
\end{tabular}




\begin{tabular}{|c|c|c|c|c|c|}
\hline Familia botánica & Sigla (interlocutor) & Nombre científico & Nombre local & ¿Cultiva? & ¿Guarda semillas? \\
\hline Lamiaceae & CV & Rosmarinus officinalis L. & Romero & si & si \\
\hline Lamiaceae & $\mathrm{JV}$ & Rosmarinus officinalis $\mathrm{L}$. & Romero & si & si \\
\hline Lamiaceae & NA & Rosmarinus officinalis $\mathrm{L}$. & Romero & si & si \\
\hline Lauraceae & $\mathrm{JL}$ & Persea americana Mill. & Palta & si & si \\
\hline Liliaceae & LP & Lilium sp. & Azucena & si & si \\
\hline Malvaceae & NA & Gossypium hirsutum L. & Algodón & si & si \\
\hline Monimiaceae & ML & Peumus boldus Molina & Boldo & no & no \\
\hline Moraceae & DY & Ficus carica L. & Higo & si & no especificó \\
\hline Moraceae & JV & Ficus carica L. & Higo & si & no especificó \\
\hline Moraceae & $\mathrm{JL}$ & Ficus carica L. & Higo blanco & si & si \\
\hline Moraceae & $\mathrm{JL}$ & Ficus carica L. & Higo negro & si & si \\
\hline Moraceae & DY & Morus alba L. & Mora & si & no especificó \\
\hline Plantaginaceae & NA & Plantago sp. & Llantén & esp & espontánea \\
\hline Plantaginaceae & LO & Plantago sp. & Llantén & esp & espontánea \\
\hline Poaceae & ES & Avena sativa $\mathrm{L}$. & Avena & si & si \\
\hline Poaceae & MG & Cymbopogon citratus (DC) Stapf & Cedrón paraguayo & si & no especificó \\
\hline Poaceae & $S$ & Cymbopogon citratus (DC) Stapf & Cedrón & si & no especificó \\
\hline Poaceae & NA & Cymbopogon citratus (DC) Stapf & Cedrón & si & si \\
\hline Poaceae & ES & Cymbopogon citratus (DC) Stapf & Citronella & si & si \\
\hline Poaceae & $\mathrm{JL}$ & Cymbopogon citratus (DC) Stapf. & Cedrón pasto & si & no especificó \\
\hline Poaceae & CV & Oryza sativa L. & Arróz & no & perdió la semilla \\
\hline Poaceae & SV & Saccharum officinarum L. & Caña de azúcar & si & si \\
\hline Poaceae & IG & Sorghum sp. & Sorgo & si & no \\
\hline Poaceae & FLO & Zea mays L. & Maizón & no & perdió la semilla \\
\hline Poaceae & AT & Zea mays L. & Choclo & si & no \\
\hline Poaceae & $\mathrm{CL}$ & Zea mays L. & Maíz & si & no \\
\hline Poaceae & DY & Zea mays $\mathrm{L}$. & Maíz & si & no \\
\hline Poaceae & LP & Zea mays L. & Choclo & si & no \\
\hline
\end{tabular}




\begin{tabular}{|c|c|c|c|c|c|}
\hline Familia botánica & Sigla (interlocutor) & Nombre científico & Nombre local & ¿Cultiva? & ¿Guarda semillas? \\
\hline Poaceae & $P$ & Zea mays L. & Choclo & si & no \\
\hline Poaceae & PA & Zea mays L. & Choclo & si & no \\
\hline Poaceae & PA & Zea mays L. & Choclo & si & no \\
\hline Poaceae & BV & Zea mays L. & Maíz para humita & no & no \\
\hline Poaceae & PA & Zea mays L. & Maizón & no & perdió la semilla \\
\hline Poaceae & BIS & Zea mays L. & Maíz enanito & si & si \\
\hline Poaceae & BV & Zea mays L. & Choclo & si & si \\
\hline Poaceae & $\mathrm{CV}$ & Zea mays $\mathrm{L}$. & Choclo & si & si \\
\hline Poaceae & $\mathrm{CV}$ & Zea mays $\mathrm{L}$. & Maíz puro blanco & si & si \\
\hline Poaceae & CV & Zea mays $\mathrm{L}$. & Maíz puro negro & si & si \\
\hline Poaceae & $\mathrm{CV}$ & Zea mays L. & Maíz rojo & si & si \\
\hline Poaceae & DAG & Zea mays L. & Choclo & si & si \\
\hline Poaceae & DY & Zea mays L. & Maíz rojo & si & si \\
\hline Poaceae & ES & Zea mays L. & Maices & si & si \\
\hline Poaceae & IG & Zea mays L. & Choclito & si & si \\
\hline Poaceae & $J \mathrm{~L}$ & Zea mays L. & Maíz & si & si \\
\hline Poaceae & $\mathrm{JL}$ & Zea mays L. & Maíz colorado & si & si \\
\hline Poaceae & $\mathrm{JL}$ & Zea mays L. & Maíz turco & si & si \\
\hline Poaceae & ML & Zea mays L. & Choclo & si & si \\
\hline Poaceae & MS & Zea mays L. & Maizón & si & si \\
\hline Poaceae & NA & Zea mays L. & Maíz choclo & si & si \\
\hline Poaceae & PA & Zea mays L. & Maizón amarillo & si & si \\
\hline Poaceae & $S$ & Zea mays L. & Maíz blanco & si & si \\
\hline Poaceae & SV & Zea mays L. & Choclo & si & si \\
\hline Poaceae & CV & Zea mays L. & Maíz morado chiquito & si & si \\
\hline Poaceae & $\mathrm{CV}$ & Zea mays L. & Maiz de colores & si & si \\
\hline Poaceae & $\mathrm{CV}$ & Zea mays L. & Maíz perla blanca & si & si \\
\hline Poaceae & BIS & Zea mays L. & Maizón & si & si \\
\hline
\end{tabular}




\begin{tabular}{|c|c|c|c|c|c|}
\hline Familia botánica & Sigla (interlocutor) & Nombre científico & Nombre local & ¿Cultiva? & ¿Guarda semillas? \\
\hline Portulacaceae & ML & Portulaca oleracea L. & Verdulaga & esp & espontánea \\
\hline Portulacaceae & s & Portulaca oleracea L. & Verdulaga & esp & espontánea \\
\hline Primulaceae & NA & Cyclamen persicum Mill. & Violeta de los alpes & si & no \\
\hline Rosaceae & $\mathrm{JL}$ & Cydonia oblonga Mill. & Membrillo & si & no \\
\hline Rosaceae & $\mathrm{JV}$ & Cydonia oblonga Mill. & Membrillo & si & si \\
\hline Rosaceae & DY & Eriobotrya japonica (Thunb.) Lindl. & Níspero & si & no especificó \\
\hline Rosaceae & LP & Eriobotrya japonica (Thunb.) Lindl. & Níspero & si & si \\
\hline Rosaceae & s & Fragaria $\mathrm{x}$ ananassa (Weston) Duchesne & Frutilla & si & no \\
\hline Rosaceae & NA & Fragaria $\mathrm{x}$ ananassa (Weston) Duchesne & Frutilla & si & no \\
\hline Rosaceae & $\mathrm{HC}$ & Prunus americana L. & Damasco & si & si \\
\hline Rosaceae & LP & Prunus armeniaca L. & Damasco & si & si \\
\hline Rosaceae & $\mathrm{HC}$ & Prunus domestica L. & Ciruela cristal & si & si \\
\hline Rosaceae & $\mathrm{HC}$ & Prunus domestica L. & Ciruela genovesa & si & si \\
\hline Rosaceae & $\mathrm{HC}$ & Prunus domestica L. & Ciruela reina claudia & si & si \\
\hline Rosaceae & $\mathrm{JV}$ & Prunus domestica L. & Ciruela & si & si \\
\hline Rosaceae & LP & Prunus domestica L. & Ciruela blanca & si & si \\
\hline Rosaceae & DY & Prunus persica (L.) Batsch. & Durazno & si & no especificó \\
\hline Rosaceae & DY & Prunus persica (L.) Batsch. & Pelón & si & no especificó \\
\hline Rosaceae & $\mathrm{HC}$ & Prunus persica (L.) Batsch. & Durazno & si & si \\
\hline Rosaceae & LP & Prunus persica (L.) Batsch. & Durazno & si & si \\
\hline Rosaceae & JV & Rosa sp. & Rosa rococó & si & no especificó \\
\hline Rosaceae & BV & Rosa sp. & Rosa & si & si \\
\hline Rosaceae & JV & Rosa sp. & Rosa chiquita & si & si \\
\hline Rosaceae & NA & Rosa sp. & Rosa roja perfumada & si & si \\
\hline Rosaceae & NA & Rosa sp. & Rosas blanca & si & si \\
\hline Rosaceae & NA & Rubus ulmifolius Schott & Zarzamora & esp & espontánea \\
\hline Rutaceae & ES & Citrus japonica Thunb. & Quinoto & si & si \\
\hline Rutaceae & DY & Citrus reticulata Blanco & Mandarina común & si & no especificó \\
\hline
\end{tabular}




\begin{tabular}{|c|c|c|c|c|c|}
\hline Familia botánica & Sigla (interlocutor) & Nombre científico & Nombre local & ¿Cultiva? & ¿Guarda semillas? \\
\hline Rutaceae & DY & Citrus reticulata Blanco & Mandarina japoesa & si & no especificó \\
\hline Rutaceae & JV & Citrus reticulata Blanco & Mandarina & si & no especificó \\
\hline Rutaceae & $\mathrm{HC}$ & Citrus reticulata Blanco & Mandarina & si & si \\
\hline Rutaceae & $\mathrm{HC}$ & Citrus $\mathrm{x}$ aurantium $\mathrm{L}$. [Grupo naranja amarga] & Naranja para pie de injerto & si & si \\
\hline Rutaceae & $\mathrm{HC}$ & Citrus $\mathrm{x}$ aurantium L. [Grupo naranja amarga] & Naranja salvaje & si & si \\
\hline Rutaceae & DY & Citrus $\mathrm{x}$ aurantium L. [Grupo Naranja Dulce] & Naranja ombligo & si & no especificó \\
\hline Rutaceae & DY & Citrus $x$ aurantium L. [Grupo Pomelo] & Pomelo & si & no especificó \\
\hline Rutaceae & DY & Citrus $\mathrm{x}$ limon (L.) Osbeck & Limón 4 estaciones & si & no especificó \\
\hline Rutaceae & JV & Citrus $x$ limon (L.) Osbeck & Limón & si & no especificó \\
\hline Rutaceae & $\mathrm{HC}$ & Citrus x limon (L.) Osbeck & Limón & si & si \\
\hline Rutaceae & LP & Citrus $\mathrm{x}$ limon (L.) Osbeck & Limón & si & si \\
\hline Rutaceae & JV & Ruta chalepensis L. & Ruda & si & si \\
\hline Solanaceae & BIS & Capsicum annuum L. & Morrón amarillo & si & no \\
\hline Solanaceae & BIS & Capsicum annuum L. & Morrón rojo & si & no \\
\hline Solanaceae & BV & Capsicum annuum L. & Morrón rojo & si & no \\
\hline Solanaceae & BV & Capsicum annuum L. & Morrón verde & si & no \\
\hline Solanaceae & DY & Capsicum annuum L. & Morrón & si & no \\
\hline Solanaceae & LO & Capsicum annuum L. & Morrón & si & no \\
\hline Solanaceae & MS & Capsicum annuum L. & Morrón & si & no \\
\hline Solanaceae & NA & Capsicum annuum L. & Morrón no orgánico & si & no \\
\hline Solanaceae & $S$ & Capsicum annuum L. & Morrón & si & no \\
\hline Solanaceae & MS & Capsicum annuum L. & Calahorra & no & perdió la semilla \\
\hline Solanaceae & $\mathrm{CA}$ & Capsicum annuum L. & Morrón calahorra & si & si \\
\hline Solanaceae & DAG & Capsicum annuum L. & Morrón & si & si \\
\hline Solanaceae & $\mathrm{JL}$ & Capsicum annuum L. & Morrón & si & si \\
\hline Solanaceae & $J L$ & Capsicum annuum L. & Pimiento calahorra & si & si \\
\hline Solanaceae & MG & Capsicum annuum L. & Morrón calahorra & si & si \\
\hline Solanaceae & NA & Capsicum annuum L. & Morrón & si & si \\
\hline
\end{tabular}




\begin{tabular}{|c|c|c|c|c|c|}
\hline Familia botánica & Sigla (interlocutor) & Nombre científico & Nombre local & ¿Cultiva? & ¿Guarda semillas? \\
\hline Solanaceae & NA & Capsicum annuum L. & Morrón chiquito picante & si & si \\
\hline Solanaceae & NG & Capsicum annuum L. & Ají de la mala palabra & si & si \\
\hline Solanaceae & NG & Capsicum annuum L. & Morrón & si & si \\
\hline Solanaceae & $P$ & Capsicum annuum L. & Morrón & si & si \\
\hline Solanaceae & MG & Capsicum sp. & Ajís & si & no \\
\hline Solanaceae & NG & Capsicum sp. & Ají vinagre el tradicional & no & perdió la semilla \\
\hline Solanaceae & NA & Capsicum sp. & Ají vinagre & si & perdió la semilla \\
\hline Solanaceae & AT & Capsicum sp. & Ají vinagre & si & si \\
\hline Solanaceae & $\mathrm{CV}$ & Capsicum sp. & Aji variedad 1 & si & si \\
\hline Solanaceae & CV & Capsicum sp. & Aji variedad 2 & si & si \\
\hline Solanaceae & CV & Capsicum sp. & Aji variedad 3 & si & si \\
\hline Solanaceae & $\mathrm{CV}$ & Capsicum sp. & Aji variedad 4 & si & si \\
\hline Solanaceae & $\mathrm{CV}$ & Capsicum sp. & Aji variedad 5 & si & si \\
\hline Solanaceae & CV & Capsicum sp. & Aji variedad 6 & si & si \\
\hline Solanaceae & CV & Capsicum sp. & Aji variedad 7 & si & si \\
\hline Solanaceae & CV & Capsicum sp. & Aji variedad 8 & si & si \\
\hline Solanaceae & CV & Capsicum sp. & Aji variedad 9 & si & si \\
\hline Solanaceae & ES & Capsicum sp. & Aji & si & si \\
\hline Solanaceae & NA & Capsicum sp. & Aji campanita & si & si \\
\hline Solanaceae & NA & Capsicum sp. & Ají redondito picante & si & si \\
\hline Solanaceae & NG & Capsicum sp. & Ají vinagre el tradicional & si & si \\
\hline Solanaceae & PA & Capsicum sp. & Ají picante & si & si \\
\hline Solanaceae & PA & Capsicum sp. & Aji verde & si & si \\
\hline Solanaceae & SV & Capsicum sp. & Ají miracielo & si & si \\
\hline Solanaceae & NA & Nicotiana glauca Graham & Palan-palan & si & si \\
\hline Solanaceae & ES & Nicotiana tabacum L. & Tabaco & si & si \\
\hline Solanaceae & ES & Physalis ixocarpa Brot. ex Hornem & Tomate verde vestido & si & si \\
\hline Solanaceae & $\mathrm{CV}$ & Solanum betaceum Cav. & Tomate de árbol & si & si \\
\hline
\end{tabular}




\begin{tabular}{|c|c|c|c|c|c|}
\hline Familia botánica & Sigla (interlocutor) & Nombre científico & Nombre local & ¿Cultiva? & ¿Guarda semillas? \\
\hline Solanaceae & BIS & Solanum lycopersicum L. & Tomate & si & no \\
\hline Solanaceae & DY & Solanum lycopersicum L. & Tomate & si & no \\
\hline Solanaceae & $\mathrm{JL}$ & Solanum lycopersicum L. & Tomate perita & si & no \\
\hline Solanaceae & LO & Solanum lycopersicum L. & Tomate & si & no \\
\hline Solanaceae & LO & Solanum Iycopersicum L. & Tomate cherry & si & no \\
\hline Solanaceae & LP & Solanum lycopersicum L. & Tomate redondo & si & no \\
\hline Solanaceae & MG & Solanum lycopersicum L. & Tomate híbrido & si & no \\
\hline Solanaceae & MS & Solanum Iycopersicum L. & Tomate & si & no \\
\hline Solanaceae & SV & Solanum lycopersicum L. & Tomate & si & no \\
\hline Solanaceae & JV & Solanum lycopersicum L. & Tomate cherry amarillo & no & no \\
\hline Solanaceae & JV & Solanum lycopersicum L. & $\begin{array}{l}\text { Tomate cherry amarillo } \\
\text { perita }\end{array}$ & no & no \\
\hline Solanaceae & $\mathrm{JV}$ & Solanum lycopersicum L. & Tomate cherry grande & no & perdió la semilla \\
\hline Solanaceae & $\mathrm{JV}$ & Solanum lycopersicum L. & Tomate platense & no & perdió la semilla \\
\hline Solanaceae & MS & Solanum lycopersicum L. & Tomate bonanza & no & perdió la semilla \\
\hline Solanaceae & AT & Solanum lycopersicum L. & Tomate platense & si & si \\
\hline Solanaceae & BIS & Solanum lycopersicum L. & $\begin{array}{l}\text { Tomate cherry (variedad } \\
\text { 1) }\end{array}$ & si & si \\
\hline Solanaceae & BIS & Solanum lycopersicum L. & $\begin{array}{l}\text { Tomate cherry (variedad } \\
\text { 2) }\end{array}$ & si & si \\
\hline Solanaceae & $\mathrm{CA}$ & Solanum lycopersicum L. & Tomate platense & si & si \\
\hline Solanaceae & CV & Solanum lycopersicum L. & Tomate & si & si \\
\hline Solanaceae & DAG & Solanum lycopersicum L. & Tomate platense & si & si \\
\hline Solanaceae & ES & Solanum lycopersicum L. & Tomate platense & si & si \\
\hline Solanaceae & $\mathrm{HC}$ & Solanum lycopersicum L. & Tomate platense & si & si \\
\hline Solanaceae & $J \mathrm{~L}$ & Solanum lycopersicum L. & Tomate 110 & si & si \\
\hline Solanaceae & $\mathrm{JL}$ & Solanum lycopersicum L. & Tomate platense & si & si \\
\hline Solanaceae & $J P$ & Solanum lycopersicum L. & Tomate & si & si \\
\hline Solanaceae & $\mathrm{JV}$ & Solanum lycopersicum L. & Tomate cherry perita & si & si \\
\hline
\end{tabular}




\begin{tabular}{|c|c|c|c|c|c|}
\hline Familia botánica & Sigla (interlocutor) & Nombre científico & Nombre local & ¿Cultiva? & ¿Guarda semillas? \\
\hline Solanaceae & JV & Solanum lycopersicum L. & Tomate platense & si & si \\
\hline Solanaceae & LP & Solanum Iycopersicum L. & Tomate perita & si & si \\
\hline Solanaceae & LP & Solanum lycopersicum L. & Tomate platense & si & si \\
\hline Solanaceae & MG & Solanum Iycopersicum L. & Tomate platense & si & si \\
\hline Solanaceae & MS & Solanum lycopersicum L. & Tomate cherry & si & si \\
\hline Solanaceae & NA & Solanum Iycopersicum L. & Tomate & si & si \\
\hline Solanaceae & NA & Solanum lycopersicum L. & Tomate Cherry & si & si \\
\hline Solanaceae & NA & Solanum Iycopersicum L. & Tomate perita amarillo & si & si \\
\hline Solanaceae & NA & Solanum lycopersicum L. & Tomate perita largo & si & si \\
\hline Solanaceae & NA & Solanum lycopersicum L. & Tomate platense & si & si \\
\hline Solanaceae & NA & Solanum lycopersicum L. & Tomate tardío & si & si \\
\hline Solanaceae & NG & Solanum Iycopersicum L. & Tomate col 45 & si & si \\
\hline Solanaceae & NG & Solanum lycopersicum L. & Tomate perita & si & si \\
\hline Solanaceae & $\mathrm{P}$ & Solanum Iycopersicum L. & Tomate cherry & si & si \\
\hline Solanaceae & $P$ & Solanum lycopersicum L. & Tomate perita zorzal & si & si \\
\hline Solanaceae & PA & Solanum lycopersicum L. & Tomate cherry & si & si \\
\hline Solanaceae & PA & Solanum lycopersicum L. & Tomate perita & si & si \\
\hline Solanaceae & PA & Solanum lycopersicum L. & Tomate perita zorzal & si & si \\
\hline Solanaceae & PA & Solanum lycopersicum L. & Tomate platense & si & si \\
\hline Solanaceae & $S$ & Solanum lycopersicum L. & Tomate & si & si \\
\hline Solanaceae & $S$ & Solanum lycopersicum L. & Tomate cherry & si & si \\
\hline Solanaceae & AT & Solanum melongena $\mathrm{L}$. & Berenjena & si & no \\
\hline Solanaceae & BIS & Solanum melongena L. & Berenjena negra & si & no \\
\hline Solanaceae & BIS & Solanum melongena L. & Berenjena rayada & si & no \\
\hline Solanaceae & BV & Solanum melongena L. & Berenjena & si & no \\
\hline Solanaceae & $\mathrm{CL}$ & Solanum melongena $\mathrm{L}$. & Berenjena & si & no \\
\hline Solanaceae & DY & Solanum melongena L. & Berenjena & si & no \\
\hline Solanaceae & ES & Solanum melongena L. & Berenjena & si & no \\
\hline
\end{tabular}




\begin{tabular}{|c|c|c|c|c|c|}
\hline Familia botánica & Sigla (interlocutor) & Nombre científico & Nombre local & ¿Cultiva? & ¿Guarda semillas? \\
\hline Solanaceae & LO & Solanum melongena $\mathrm{L}$. & Berenjena & si & no \\
\hline Solanaceae & LP & Solanum melongena $\mathrm{L}$. & Berenjena & si & no \\
\hline Solanaceae & MG & Solanum melongena $\mathrm{L}$. & Berenjena & si & no \\
\hline Solanaceae & MS & Solanum melongena L. & Berenjena & si & no \\
\hline Solanaceae & PA & Solanum melongena $\mathrm{L}$. & Berenjena & si & no \\
\hline Solanaceae & SV & Solanum melongena $\mathrm{L}$. & Berenjena & si & no \\
\hline Solanaceae & DAG & Solanum melongena $\mathrm{L}$. & Berenjena & si & si \\
\hline Solanaceae & $J \mathrm{~L}$ & Solanum melongena $\mathrm{L}$. & Berenjena & si & si \\
\hline Solanaceae & JV & Solanum melongena $\mathrm{L}$. & Berenjena & si & si \\
\hline Solanaceae & NA & Solanum melongena $\mathrm{L}$. & Berenjena & si & si \\
\hline Solanaceae & $S$ & Solanum melongena L. & Berenjena & si & si \\
\hline Solanaceae & BV & Solanum tuberosum L. subsp. tuberosum & Papa & no & no \\
\hline Solanaceae & $\mathrm{CL}$ & Solanum tuberosum L. subsp. tuberosum & Papa & si & no \\
\hline Solanaceae & LO & Solanum tuberosum L. subsp. tuberosum & Papa colorada & si & no \\
\hline Solanaceae & $P$ & Solanum tuberosum L. subsp. tuberosum & Papa & si & no \\
\hline Solanaceae & DAG & Solanum tuberosum L. subsp. tuberosum & Papa & si & si \\
\hline Solanaceae & $\mathrm{JL}$ & Solanum tuberosum L. subsp. tuberosum & Papa & si & si \\
\hline Solanaceae & SV & Solanum tuberosum L. subsp. tuberosum & Papa & si & si \\
\hline Solanaceae & FLO & Solanum tuberosum L. subsp. tuberosum & Papa & si & perdió la semilla \\
\hline Solanaceae & S & Solanum tuberosum L. subsp. tuberosum & Papa & si & si \\
\hline Solanaceae & ES & $\begin{array}{l}\text { Solanum tuberosum subsp. andigenum (Juz. et } \\
\text { Bukasov) Hawkes }\end{array}$ & Papa andina & no & perdió la semilla \\
\hline Urticaceae & BIS & Urtica urens $\mathrm{L}$. & Ortiga & esp & espontánea \\
\hline Urticaceae & LO & Urtica urens $\mathrm{L}$. & Ortiga & esp & espontánea \\
\hline Urticaceae & MS & Urtica urens $\mathrm{L}$. & Ortiga & esp & espontánea \\
\hline Urticaceae & $S$ & Urtica urens $\mathrm{L}$. & Ortiga & esp & espontánea \\
\hline Verbenaceae & BIS & Aloysia citriodora Palau & Cedrón & si & no especificó \\
\hline Verbenaceae & MG & Aloysia citriodora Palau & Cedrón arbolito & si & no especificó \\
\hline
\end{tabular}


Agrobiodiversidad total registrada | ANEXO 5

\begin{tabular}{|c|c|c|c|c|c|}
\hline Familia botánica & Sigla (interlocutor) & Nombre científico & Nombre local & ¿Cultiva? & ¿Guarda semillas? \\
\hline Verbenaceae & NA & Aloysia citriodora Palau & Cedrón & si & no especificó \\
\hline Verbenaceae & $\mathrm{JL}$ & Aloysia citriodora Palau & Cedrón árbol & si & si \\
\hline Verbenaceae & JV & Aloysia citriodora Palau & Cedrón & si & si \\
\hline Verbenaceae & ES & Aloysia citriodora Palau & Cedrón & si & si \\
\hline Verbenaceae & LO & Aloysia polystachya (Griseb.) Moldenke & Burrito & si & no \\
\hline Verbenaceae & BIS & Aloysia polystachya (Griseb.) Moldenke & Burrito & si & no especificó \\
\hline Verbenaceae & $\mathrm{JL}$ & Aloysia polystachya (Griseb.) Moldenke & Burro & si & si \\
\hline Verbenaceae & ES & Aloysia polystachya (Griseb.) Moldenke & Burrito & si & si \\
\hline Verbenaceae & $\mathrm{JL}$ & Lippia turbinata Griseb. & Poleo & si & no especificó \\
\hline Verbenaceae & NA & Lippia turbinata Griseb. & Poleo & si & si \\
\hline Vitaceae & DY & Vitis labrusca L. & Uva chinche blanca & si & no especificó \\
\hline Vitaceae & $\mathrm{HC}$ & Vitis labrusca L. & Uva & si & si \\
\hline Vitaceae & NG & Vitis vinifera L. & Uva rosada & si & si \\
\hline
\end{tabular}




\title{
ORGANIZACIÓN DE SABERES EN TORNO A LA CONSERVACIÓN DE SEMILLAS
}

\author{
CATEGORIA A: Cultivo y selección de plantas para obtener semillas \\ CATEGORIA B: Técnicas de recolección, limpieza y secado de semillas para conservar \\ CATEGORIA C: Acondicionamiento y guardado de semillas \\ CATEGORIA D: Dificultades para la conservación de semillas \\ CATEGORIA E: Experimentación y mejoramiento de semillas
}

\section{DY}

A Cultivo y selección de plantas para obtener

"puerro se puede guardar semilla, yo se que se puede guardar, porque el puerro es salvaje, es más dicen que si ese puerro, vos lo cortas a esta altura vuelve a crecer, saca hojas nuevas" (Bonicatto, 2014h. Entrevista a DY-renglón 135)

B Técnicas de recolección, limpieza y secado de semillas para conservar

"de tomate si, la vez que sacamos tenés que dejar el tomate bien rojo, la primer camada siempre, dejar la semilla creo que era 24 o 12 hs en agua, limpiarlo con la mano, dejarla secar (me enseñó) mi tío y los chicos bolivianos que saben porque allá hacen eso". (Bonicatto, 2014h. Entrevista a DY-renglón 153)

\section{Acondicionamiento y guardado}

D Dificultades para la conservación "todo lo que sea tomate morrón y berenjena son todas híbridas, probamos un año hacer tomate de semilla y no, no viene, se degenera" (Bonicatto, 2014h. Entrevista a DY-renglón 35) "si son semillas comunes se puede guardar, pero si son semillas importadas el $90 \%$ no se puede, no sale, sale muy, en vez de venir con acelga sí, se te espiga, viene revirada, se torce vos plantas una remolacha, sacas una semilla, de una semilla híbrida redondita así capas que te sale una remolacha larga que parece una zanahoria, tomate pasa lo mismo, vos plantas un tomate de semilla híbrida bien y viene así por ejemplo...vos le sacas la semilla a ese tomate al otro año lo plantas y por ahí te salen chiquititos, medianito, que no tienen fuerza" (Bonicatto, 2014h. Entrevista a DY-renglón 98) "lo que pasa es que cuando uno está en quinta mucho tiempo para dejarlo no hay, o sea, es ocupar tierra al divino botón, yo allá tengo 10-8 surcos de puerro en flor, pero yo a eso lo voy a disquear, el tema es que yo eso lo tengo que dejar para febrero, para cosechar la semilla porque cuando está bien seca tiene que ser, y yo plantines no hago más" (Bonicatto, 2014h. Entrevista a DY-renglón 137) "ahora no se guarda semilla porque el costo es casi lo mismo que esperar" (Bonicatto, 2014h. Entrevista a DY-renglón 149)

E Experimentación y mejoramiento de semillas

"todo lo que sea tomate morrón y berenjena son todas híbridas, probamos un año hacer tomate de semilla y no, no viene, se degenera" (Bonicatto, 2014h. Entrevista a DY-renglón 35)

\section{FLO}

A Cultivo y selección de plantas para obtener

"también hacemos el zapallo, el zapallito de tronco hay que comprarlo y después hacer, se hace en agosto y viene en primavera, más de una sembrada nos se guarda, ya no sirve. Toda, toda la semilla se hace un año, lo dejas para dos años y ya no sirve". (Bonicatto, 2014a. Entrevista a FLO-renglón 47)

\section{B Técnicas de recolección, limpieza y secado de semillas para conservar}

\section{Acondicionamiento y guardado}

"lo tenían guardado en tachos de plástico grandes o bolsas" (Bonicatto, 2014a. Entrevista a FLOrenglón 18)

\section{Dificultades para la conservación}

"papa, perejil, acelga, chaucha ancha, chaucha fina, poroto mantecoso, arveja, puerro, verdeo, zapallo grande redondo verde. Era todo de semilla guardada pero con la lluvia que hubo se les pudrió. También les atacaron las ratas". (Bonicatto, 2014a. Entrevista a FLO-renglón 19) "acá no se puede guardar porque le entra el gusano, se hace cada año porque se pudre por el calor, si tenés más de un año no nace, en Bolivia es más seco, se guarda mucho tiempo acá es más húmedo" (Bonicatto, 2014a. 
Entrevista a FLO-renglón 38) "mi tío cuando fui a Bolivia me regaló de todo, maní, zapallo, maíz, ese zapallo para tomar el mate, pero me lo sacaron cuando pasé la aduana, me dijeron esta bolsita se queda, en Bolivia hay de todo". (Bonicatto, 2014a. Entrevista a FLO-renglón 41) "el año pasado saqué tanta semilla que me fui a la semillería para venderla, pero no la quisieron". (Bonicatto, 2014a. Entrevista a FLO-renglón 44) "esta papa la compró Laura en el mercado una bolsita, es papa boliviana, es más rica que la de acá y más cara, la tenemos hace 4 años pero ahora se perdió toda por la lluvia" (Bonicatto, 2014a. Entrevista a FLO-renglón 58) "tuvimos el maizón, lo dejamos en el galpón y se lo agarró la rata" (Bonicatto, 2014a. Entrevista a FLO-renglón 70)

E Experimentación y mejoramiento de semillas

MG

A Cultivo y selección de plantas para obtener

"lo que más se sacaba era el zapallo, perejil, acelga que son semillas fáciles de sacar, el puerro" "sobre la acelga: esa es semilla que yo había comprado y yo la fui haciendo, ya como diez años que la voy haciendo yo esa semilla" (Bonicatto, 2013c. Entrevista a MG-renglón 62) "la chaucha lengua de dragón se llama, no sé si la conoces, bueno esa la sacamos porque no se consigue en ningún lado, es una semilla que no sé donde la trajieron, no sé si italiana de donde es un día arriba del camión venia con esa y la sacamos, entonces la tenemos para sacar...esa si se vende! La gente le encanta, porque como se hace el poroto, no se come la chaucha viste, se come el poroto...eso no lo conseguís en ningún lado, no se ve, se ve la otra la chaucha, la común" (Bonicatto, 2013c. Entrevista a MG-renglón 106) "nosotros todos los años sacamos verdeo, si porque que verdeo este es una barbaridad! Es una planta! Aparte no es como el verdeo común este que compras en la semillería es diferente, vos lo ves esta así de alto y unos troncos así tiene! Todo carne la hoja, en cambio el otro no, el otro el que vos compras es chiquito, bajito, se apesta en seguida, este la trajo un boliviano, la trajo de allá y bueno, nosotros como éramos conocidos nos dio un...me acuerdo que me abra dado 100 gramos me habrá dado! Y bueno ese año la sembramos...nació y bueno de ahí este.....la replicamos y sacamos semilla, bueno ahora tenemos para sembrar lo que uno quiera...y hace como 3 años, que me dio la semilla, me parece que un poquito más, así que ahí le sacamos la semilla y bueno después que la sacas ya pones un surco y te da cantidad, te da como 5, 6 kilos, y con eso ¿sabes lo que sembras? Haces plantines todo" (Bonicatto, 2013c. Entrevista a MGrenglón 139) "la consiguió mi hermano (al morrón calahorra) [...] consiguió un poquito y ese año me acuerdo que hice un surco, la almacigué y todos los años la estamos haciendo" (Bonicatto, 2013c. Entrevista a MG-renglón 223)

B Técnicas de recolección, limpieza y secado de semillas para conservar

"pero yo lo que puede así de las semillas si, la hago [...] la tenés que secar, guardarla adentro que no se humedezca viste es medio complicado" (Bonicatto, 2013c. Entrevista a MG-renglón 204) "acá para hacer un kilo vos este tenés que dejarla que se crie, que la semilla se haga, cosecharla, ponerla al sol, secarla y después hacerla, que lleva su trabajo, no es fácil, y después volver a hacerla, secarla bien porque si vos la guardas húmeda cuando vos la guardaste cuando la queres sembrar esta toda hongueada, tenés que secarla bien al sol, eso lo tenés que hacer en pleno verano, para que viste y lleva su trabajo, tenés que tener tu tiempo para hacerla porque no es fácil" (Bonicatto, 2013c. Entrevista a MG-renglón 269)

\section{Acondicionamiento y guardado}

"ya te digo lleva mucho trabajo sacar la semilla" (Bonicatto, 2013c. Entrevista a MG-renglón 206)

D Dificultades para la conservación

"nosotros en una época se sacaba la semilla pero te va superando el tiempo viste y a veces no te dan porque lleva su trabajo sacar semillas y como uno no planta así o sea cantidades, plantas poquito, por ahí plantas 5 surcos de remolacha, viste esas cosas así poquito, nosotros no vendemos casi al mercado" (Bonicatto, 2013c. Entrevista a MG-renglón 32) "la lechuga no porque da mucho trabajo sacarla, incluso como no sembrás mucha cantidad vos terminas comprando medio kilo de criolla y sembrás casi toda la temporada, entonces no te da para estar sacando semilla" (Bonicatto, 2013c. Entrevista a MGrenglón 63) "un año probamos sacar semillas de un híbrido de tomate, pero no, no, no degenera todo viste, o por ahí la primer corona de abajo no te la da, al medio por ahí te da dos o tres tomates y por ahí te da descarte viste, y eso no lo podes arriesgar plantando de semilla sacada porque vos a ese tomate le 
estas dando el mismo trabajo que si hubieras comprado el verdadero hibrido viste, vos compras semilla que ya viene preparada, porque le tenés que hacer el mismo trabajo, cuidarlo, regarlo, entonces es como que eso no lo sacas, así todos los híbridos...le podes sacar semilla, o sea vos la plantas va a venir o sea, pero la calidad no es la misma, en la semilla híbrida" (Bonicatto, 2013c. Entrevista a MG-renglón 69) "el tema de la semilla es que en ese entonces, los viejos se ponían a sacar y sacaban, guardaban y...uno es como que se acostumbró viste uno no dice voy a ordeñar la vaca, voy al almacén y me compro un litro de leche....es medio parecido, el tema es el tiempo que llevas a sacar la semilla porque te lleva muchísimo tiempo, que tenés que secarla, guardarla, viste y eso hay muchos que ya no lo hacen es más fácil ir y comprar un kilo de semilla y sembrarlas que sacarla para guardar y sembrar el año que viene...viste para mi ahí hay ...y después como fueron apareciendo los híbridos, entonces viste es como que la semilla común fue desapareciendo, por ahí algún quintero viejo todavía saca, pero ya no encontras, la mayoría...todo el mundo compra" (Bonicatto, 2013c. Entrevista a MG-renglón 82) "hasta que fueron apareciendo los híbridos, y ya te obligaba...vos tenías un tomate hibrido y un platense y la gente no lo llevaba...entonces es como que te van obligando a comprar eso para...poder seguir vendiendo" (Bonicatto, 2013c. Entrevista a MG-renglón 96) "nos iba a salir un subsidio para una plantinera pero nunca llegó nada [...] no apareció eso y la gente no lo hace porque lleva muchísimo tiempo hacer los plantines, te agarra un verano y todos los días tenés que regarlo, porque yo los tengo ahí afuera con una media sombra, tenés que tener el trabajo de regarlo porque no le puede faltar agua (Bonicatto, $2013 \mathrm{c}$. Entrevista a MG-renglón 210) "estas semillas comunes tenés que sacarla todos los años porque sino al año siguiente ya no sirve, entonces todos los años tenés que sacarla, viste y mi viejo hace rato que dejo la quinta entonces nosotros, viste yo sigo el camino de él porque si veo una semilla que me interesa voy y la saco pero si fuera por mi hermano no le da ni bola" (Bonicatto, 2013c. Entrevista a MG-renglón 233) "tenés que tener tu tiempo para hacerla porque no es fácil" (Bonicatto, 2013c. Entrevista a MG-renglón 269)

\section{E Experimentación y mejoramiento de semillas}

"un año probamos sacar semillas de un híbrido de tomate, pero no, no, no degenera todo viste...o por ahí la primer corona de abajo no te la da, al medio por ahí te da dos o tres tomates y por ahí te da descarte viste, y eso no lo podes arriesgar plantando de semilla sacada porque vos a ese tomate le estas dando el mismo trabajo que si hubieras comprado el verdadero hibrido viste, vos compras semilla que ya viene preparada, porque le tenés que hacer el mismo trabajo, cuidarlo, regarlo, entonces es como que eso no lo sacas, así todos los híbrido le podes sacar semilla, o sea vos la plantas va a venir o sea, pero la calidad no es la misma, en la semilla híbrida" (Bonicatto, 2013c. Entrevista a MG-renglón 69) "a mí me gusta, guardar...o sea veo una semilla que a mí me gusta, la calidad y digo bueno, de esta semilla vamos a sacarle, de esta verdura vamos a sacar semilla, y ahí la saco, me doy el trabajo viste... y ...la hago, por ejemplo como el Calahorra todas esas cosas, después lo demás lo compramos, el anco...porque como son semillas hibridas, le podes sacar la semilla pero ya al siguiente año no da la calidad que tiene que dar, aparte hemos visto otros quinteros que lo han hecho y la producción no le rindió en la calidad, o da poquito, o es chico, o la planta queda como enferma, no sé que le pondrán al hibrido, pero algo le deben poner porque si no todo el mundo sacaría semilla, porque con lo caro que son" (Bonicatto, 2013c. Entrevista a MG-renglón 239)

\section{MS}

A Cultivo y selección de plantas para obtener

B Técnicas de recolección, limpieza y secado de semillas para conservar

\section{Acondicionamiento y guardado}

\section{Dificultades para la conservación}

"antes mis padres allá (en Bolivia) siempre guardaron las semillas, o sea de todo, pero el tema es que acá no se puede por el tema comercial, o sea un tomate si no es híbrido y si no es adentro de un invernáculo no se puede" (Bonicatto, 2013b. Entrevista a MS-renglón 540) "lo que tenga pinta, todo, todo es semilla y otra que este otro el común, las variedades no dan mucho o sea, no dan mucho cantidad, eso también es otra y los costos son muchos, hay que curar la tierra, los alquileres, los fertilizantes que antes no se hay que tratar de sacar calidad y cantidad. Eso es lo que no nos permite guardar...eh...seguir con nuestras semillas" (Bonicatto, 2013b. Entrevista a MS-renglón 547) 


\section{E Experimentación y mejoramiento de semillas}

\section{PA}

A Cultivo y selección de plantas para obtener

"el zapallito dejabas un surco o los primeros surcos que no valía, no se vendía lo dejabas para semilla, sacaba tachos de semillas de zapallito" (Bonicatto, 2011h. Entrevista a PA-renglón 479) "vamos a ver si viene bien, hacemos semillas, ya tenemos para hacer semilla si queremos. Total mucho no se precisa, con 10 mazorcas de eso ya tiene semilla para hacer varios surcos" (Bonicatto, 2011h. Entrevista a PArenglón 81) "las semillas (de tomate platense) las guardábamos esos años, sacábamos semillas no había problema con la inversión de semillas, nada, uno agarraba un surco para semilla y va los primeros frutos, los que salen primero. Y de esos sacamos no precisa mucho también, en cajones para semilla capaz que con dos cajones de tomate sacás casi 200 gramos, un cuarto de semilla iy es mucho! Te rinde un montón si yo el año pasado hice de cuatro cajones y repartí semillas para la facultad y todavía me queda para el año" (Bonicatto, 2011h. Entrevista a PA-renglón 89)

B Técnicas de recolección, limpieza y secado de semillas para conservar

"yo la semilla sé cómo hacerla toda, de zapallito, de tomate, toda" (Bonicatto, 2011h. Entrevista a PArenglón 242) "tomate por ejemplo hay que dejarle dos tres días que se fermente y....la semilla que sirve se asienta, la semilla que no sirve se levanta toda pa'arriba, uno la lava entonces se cae toda la semilla que no sirve y la que sirve queda abajo asentada. $Y$ esa después las secamos. Hay que tener cuidado de que no se pase mucho en el agua porque se brota. Tres días lo podes tener sin que se fermente, después ya la tenés que lavar, que limpiar bien, la limpias bien, le echas agua para que se asiente la semilla buena y que la otra se levante, y vas tirando, lavando, lavando" (Bonicatto, 2011h. Entrevista a PA-renglón 247)

\section{Acondicionamiento y guardado}

D Dificultades para la conservación

"también no se puede sacar semillas del choclo, no da nada, tiene que si o si comprar una semilla, todos los años, y no es como el maizón que digamos que había antes que uno lo hacía la semilla, no digamos ahora que el choclo es híbrido" (Bonicatto, 2011h. Entrevista a PA-renglón 98) "el problema está en los tomates, el morrón también uno lo saca, viene un año el morrón el híbrido ese digamos que para el otro año le da bien, pero si usted vuelve a hacer semilla de ahí no le da bien. El hinojo, hay uno híbrido y hay un hinojo, va uno importado y otro que no es importado, ves allá está en flor, y el otro que ese no se va en flor, son distintas variedad este es un Trevi y aquel es un Orión, este es el Trevi (y este que ya está en flor ¿lo guardan?) no, no, no porque no tengo tiempo de meterle el disco nomás. Pero tenemos semilla igual, se puede dejar semilla si lo dejas" (Bonicatto, 2011h. Entrevista a PA-renglón 139) "no se puede hacer semilla (del zuchini), yo he intentado hacer pero se hace toda la semilla así, como hueca, no tiene nada" (Bonicatto, 2011h. Entrevista a PA-renglón 650)

\section{E Experimentación y mejoramiento de semillas}

"el zapallito lo que tiene que es un zapallito híbrido entonces da cantidad se ponen se siembra menor, menos surcos y le rinde el doble, capaz que del otro siembra una hectárea y del otro media hectárea y con la misma cantidad del híbrido, se puede pero digamos, no germinan todas las semillas. ¡Hay que tener un cuidado! Porque digamos, hay algunas que nacen por ejemplo capaz que de las que sacamos este año al año nacen un 50 porciento, no nace todo igual que el choclo" (Bonicatto, 2011h. Entrevista a PArenglón 98) "el problema está en los tomates, el morrón también uno lo saca, viene un año el morrón el híbrido ese digamos que para el otro año le da bien, pero si usted vuelve a hacer semilla de ahí no le da bien" (Bonicatto, 2011h. Entrevista a PA-renglón 139) "depende del precio, igual que este, este no se puede hacer semilla del zucchini, este es un híbrido, y si usted hace semilla y no le viene para el año, no da, es también igual que el zapallito, que nace un $50 \%$ o sea, o tiene que tirar de dos semillas o este es una clase nueva, ahora vamos a ver si hacemos semilla de este. Porque había un año que me venían a hacer pruebas unos ingenieros de las semillería, que han traído como quince clases de zucchinis, de distintos colores, color, todo y el tamañito, todo. Había uno que era bueno, habían uno que era malo, venían lo miraba y lo cosechaban ellos y después últimamente han dejado para semilla, han venido y cosechado la semilla, pero y trataba de explicarle y cómo podía hacer la semilla y me decían "no, lo que pasa es que este medio complicado es" (Bonicatto, 2011h. Entrevista a PA-renglón 159) "voy a probar, 
esa orilla voy a dejar para semilla. No toda pero...capaz que de 10 plantas sacas como medio $\mathrm{kg}$ de semillas, Larga una varita así para arriba" (Bonicatto, 2011h. Entrevista a PA-renglón 815) "y ahora de esto (et tomate), yo lo que quiero hacer es como te contaba del zuquini, de cómo puedo hacer para mantener la semilla...buscarle la vuelta, algunos me dicen que hay que dejarle pasar dos años y seguirle, seguirle. Por ahí se adapta al clima, por ahí a lo mejor que se yo, por ahí para el año, este año que viene no creo, si saco, como te digo, veo...si salen como 100 semillas, 1 o 2 te va a nacer, las otras no te nacen y de esas dos plantas guardar de nuevo" (Bonicatto, 2011h. Entrevista a PA-renglón 848)

A Cultivo y selección de plantas para obtener

"traje papa, la papa andina me traje, la sembré y puse dos kilos y me dio 5 kilos, no sé si estuvo mal atendida, si, pero si tengo la semillas. O sea, conservo la semillita, que es muy linda papa, una papita rojita o sea. Me la dieron la chiquitita y acá sale más o menos como una pelotita de golf, más o menos" (Bonicatto, 2011b. Entrevista a ES-renglón 114)

B Técnicas de recolección, limpieza y secado de semillas para conservar

\section{Acondicionamiento y guardado}

"me dieron así (hace la seña con un puño casi cerrado indicando la cantidad de semilla recibida) era un puñadito. Y de ahí empecé a hacerla y bueno este año pasado hice para los animales y guardé esto de semilla (mostrando la bolsa), y ya había sembrado la otra parte la sembré, y siempre la conservo así en bolsas de papel ves mirá" (Bonicatto, 2011b. Entrevista a ES-renglón 51)

D Dificultades para la conservación "yo trato de sembrar casi todo lo que cambio porque, así uno va viendo" (Bonicatto, 2011b. Entrevista a ES-renglón 111)

E Experimentación y mejoramiento de semillas

LP

A Cultivo y selección de plantas para obtener

"semillas de acelga por ahí, perejil se puede hacer también, no precisa comprar toda la semilla, remolacha a veces se puede hacer un año o a veces se cruza con la acelga, ya pasó otro año, este año había cruzada" (Bonicatto, 2014k. Entrevista a LP-renglón 29) "y ñato, debe hacer 60 años fácil, que viene siempre ese alcaucil, porque era ya de la época del abuelo se plantaba, que eso ya desapareció el ñato ya casi que no queda, pasa que al ñato lo desplazó el francés, el ñato francés que le decían, venía más temprano y mas rinde, más larga la cosecha, están las semillas híbridas pero no han dado resultado, del alcaucil. A mí me han ofrecido semilla pero no lo quise plantar porque no, no se vende en el mercado iba a hacer la prueba yo pero vi que no se vende en el mercado, o sea ya me lo dijo el fletero, me dijo si queres gastar plata gasta pero no, no se vende, por ahí para comer, así para envasado puede andar, pero en el mercado no sé si por la vista...no se cual es" (Bonicatto, 2014k. Entrevista a LP-renglón 37) "y esa semilla ellos la hacían, hacían un año repollo, otro año coliflor, porque si la deja se cruza, y si no ¿sabe que hacían? La tapaban toda cuando la hacían, pero la semilla la hacían ellos, ese repollo que digo yo que duraban 3,4 meses en el mismo cuadro" (Bonicatto, 2014k. Entrevista a LP-renglón 124) "bueno como te digo, duraban tres meses la Brusela se hacía semilla también se hacía, lo que no había que poner es juntas repollo coliflor, o sea, se tapaba toda la planta cuando se florecía o sino hacían un año una cosa otro año otra, era el único problema que había...o sea...tenían ese cuidado" (Bonicatto, 2014k. Entrevista a LP-renglón 268) "esta conservan es la sandía redonda la cuarentina que le decían...esa también la conservan ellos de antes" (Bonicatto, 2014k. Entrevista a LP-renglón 333) "sobre la batata: esa la....que le dicen pata de rana, que la hoja es como la pata de rana...pero también la semilla la hacemos nosotros esa, y esa hace como y hace como 20 años que se viene haciendo" (Bonicatto, 2014k. Entrevista a LP-renglón 356) "puerro, ese es para hacer semilla también, hará 6,7 años que venimos haciendo la semilla. Este lo tenía un vecino ahí y cuando abandonó la quinta fue mi papá y sacó una planta, los cositos esos de coso y hizo la semilla de ahí" (Bonicatto, 2014k. Entrevista a LP-renglón 372) "este es el turquito, es zapallo redondo, como amarillo así con franjitas negras, este también, este yo me olvidé este zapallo turco debe hacer como 30 años lo tenemos, también este lo hacemos de semilla" (Bonicatto, 2014k. Entrevista a LP-renglón 389) 
B Técnicas de recolección, limpieza y secado de semillas para conservar

"aca había zanahoria que ya se está semillando, la semilla si la guardamos, ves allá hay más eso está todo para hacer semilla, la compramos y hace como tres años que se viene haciendo semilla, no, no es problema" (Bonicatto, 2014k. Entrevista a LP-renglón 344)

\section{Acondicionamiento y guardado}

D Dificultades para la conservación "otra semilla había repollo, lo perdimos al final esa semilla, ese no hace muchos años que se perdió, perdimos eso perdimos había una clase de batata también, que era media blanca también, esa la perdimos, porque un año llovedor la pudrió y no pudimos sacar semilla, también que se venía conservando hace un montón de años que era la época del abuelo" (Bonicatto, 2014k. Entrevista a LP-renglón 23) "lo que pasa es que si es semilla hibrida no se puede hacer muchos años...dos años nomás, después se va como degenerando" (Bonicatto, 2014k. Entrevista a LP-renglón 282)

\section{E Experimentación y mejoramiento de semillas}

"si, lo que pasa es que si es semilla hibrida no se puede hacer muchos años, dos años nomás, después se va como degenerando. Ahora, el tomate platense no, el tomate platense es siempre igual" (Bonicatto, 2014k. Entrevista a LP-renglón 282) "sobre la acelga: esa es semilla que yo había comprado y yo la fui haciendo, ya como diez años que la voy haciendo yo esa semilla" (Bonicatto, 2014k. Entrevista a LPrenglón 350) "este es hecho de semilla, lo hicimos acá, se puede hacer pero después con el tiempo se va degenerando, y la batata también el almácigo lo hacemos nosotros" (Bonicatto, 2014k. Entrevista a LP. renglón 396)

\section{JP}

A Cultivo y selección de plantas para obtener

"esa sirve para...esa nunca saca esa espiga la deja ahí, ahora la saco de ahí y la planto, ahora ni semilla hago mas, antes hacia semilla, ahora no se vende más. Esta la compre en los años 70, 68 [...] yo agarro esta y la planto. Esto con una planta, ahora esta espigada, noo, el año pasado había quedado un poquito, pero esa después cuando termino de espigar, eso es todo una mata y yo puedo sembrar hasta 10 surcos". (Bonicatto, 2011c. Entrevista a JP-renglón 62) "miro el tamaño y el color. Le hago ver uno que ya, porque el alcaucil son 4 por planta dos clases. Hay 2 tipos. Este es más vistoso, (el alcaucil Francés) mas coso...ese el tipo ñato pero francés. Este es el violeta. Pero es más tierno el violeta aunque parezca más duro, es mucho más tierno. Con el tiempo podes plantar, podes plantar en marzo abril y ahora. Los que es tan plantados ahí, son de acá...Lo único que le agarra es el piojo. Generalmente en tiempo de cosecha no le agarra". (Bonicatto, 2011c. Entrevista a JP-renglón 187)

\section{B Técnicas de recolección, limpieza y secado de semillas para conservar}

\section{Acondicionamiento y guardado}

D Dificultades para la conservación

"yo traje unas semillas de melones este año de estos amarillos y acá salieron chiquititos. Pero ahora hicimos la semilla de acá y dicen que a lo mejor era hibrida y entonces al año siguiente puede ser que venga un poco mejor". (Bonicatto, 2011c. Entrevista a JP-renglón 263)

E Experimentación y mejoramiento de semillas

"los alcauciles no se degenera la planta en sí". (Bonicatto, 2011c. Entrevista a JP-renglón 266)

\section{NG}

A Cultivo y selección de plantas para obtener

"teóricamente las semillas tienden a degenerarse, más ahora con las cruzas que hay ahora de los híbridos viste, las abejas le transmiten al verdadero viste y tiene tendencia, pero este se ve que tiene resistencia a todo. Es una ají que ya te digo, lo trajo mi abuelo, qué se yo de donde lo trajeron y bueno es que yo desde 
que tengo uso de razón siempre estuvo en la familia, el, el ají vinagre y el ají es una de las semillas que dura 13 lunas ¿sabías? cualquier semilla una semilla de acelga hasta nueve años aguanta, ipor Dios 9 años! El tomate 4, 5 años tranquilo, pero el ají, 13 lunas, 14 lunas no nace. A no ser que ahora. Después ya no nace nada, no nace nada, y hay muchas semillas que duran dos años" (Bonicatto, $2011 e$. Entrevista a NG-renglón 22) "esta es una variedad de cebolla que viene en el verano que se llama cometa, esteee, porque la cebolla esta si fuera la cebolla tradicional, ahora hace cabeza (refiriéndose a la primavera- verano), vos lo plantas, lo pasas al campo y desarrolla un poquito más y hace cabeza viste, hace bulbo, viste, después vos, la dejas dormir, tiene que dormir por lo menos un mes, en el verano, y a partir del 15 de febrero en adelante, vos el bulbo lo plantas en el campo y cada bulbo te da 5, 6 brotes viste, y ahí ese es el verdeo, esto también es cebolla de verdeo, pero el verdadero verdeo es de bulbo, vos plantas el bulbo, el bulbo brota y de ahí sacás" (Bonicatto, 2011e. Entrevista a NG-renglón 127) "pasa que ahora viene la primavera y se está floreciendo, viste. Ya empieza a largar el canuto" (Bonicatto, 2011e. Entrevista a NG-renglón 154) "este si es el vinagre que te comentaba, y ya está para pasarlo al campo. Mira como se está poniendo la raíz marrón ves. Cuando se le pone la raíz marrón es porque ya esta envejeciéndose la planta. Y este es el morrón que es de la experimental de Gorina". (Bonicatto, 2011e. Entrevista a NG-renglón 178) "esta la dejamos para semilla, es una variedad de cebolla colorada que tiene la hoja bien parada, que no se quiebra la hoja porque en el mercado si quiebra la hoja no la quieren. Esta me la dio un boliviano a mí. Y él la trajo de Bolivia, del abuelo era, no se viste...productor de Gorina, que ahora casualmente dejó la quinta y él no me la daba la semilla hay otra variedad que se llama Purea que yo el año pasado la planté y la dejé un surco para semilla, se quiebra toda. Se cae la hoja. Esto no! Mirá el canuto que tiene. Y esta yo calculo que para fin de año ya está madura. Si, si, si, esto no hay que ir haciendo nada, esto ahora florece, se madura, y hay que dejar madurar, madurar, madurar" (Bonicatto, 2011e. Entrevista a NG-renglón 275) "acá va el vinagrito. Esto se planta, te explico, este surco y este surco, este se deja, no se planta nada, porque si vos lo plantas a este, después cuando estas juntando como viene un árbol. Viene grande cuando pasas con el canasto viste rompes todo, entonces se deja un surco sin plantar, se plantan dos se deja uno". (Bonicatto, 2011e. Entrevista a NG-renglón 244) "yo la nacional; porque esta es importada, la nacional no se puede plantar ahora porque se florece viste, ahora a partir de 15 días en adelante ya se puede plantar, yo la tengo desde hace años la semilla, todos los años dejo un surco y cantidad sale de semilla. Con un surco saco semilla para plantar yo todo el tiro, y ¡es toda plata que te ahorras! Sino ¡tenés que tener de socio al semillero!" (Bonicatto, 2011e. Entrevista a NG-renglón 323) "nosotros teníamos semilla de repollo blanco, que era semilla casera también, era un repollo que era dulce como la miel era. Bueno, después cuando salieron los híbridos que son éstos, no lo quisieron más en el mercado a ese repollo blanco, eran unos repollos así (hace seña con las maños refiriéndose al tamaño) y bueno, lo dejé de plantar y perdí la semilla, ¡no me olvido nunca! Había que hacer el almácigo la segunda luna de noviembre, porque los viejos de antes y yo de algunas cosas me acuerdo y lo hago, se basaban mucho en la luna, los tipos te decían "vos tenés que hacer tal luna este almácigo, esta variedad tal luna" y así" (Bonicatto, 2011e. Entrevista a NG-renglón 338) "y por ejemplo perejil, 24 de junio y tenía que caer la luna, si no caía la luna entre el 24 y el 30 había que esperar para plantar el perejil, no se va en flor, vos el perejil lo plantas el 24 de junio, teóricamente en la primavera tiene que dar, no se va en flor, no sé qué secreto hay ...el viernes santo también, cualquier semilla que plantes el viernes santo te dura de un año pa' otro, no se florece, yo lo he comprobado eh!" (Bonicatto, $2011 e$. Entrevista a NG-renglón 349) "¡Hace como 15 años! Es un puerro francés, no es el puerro azul, porque ahora hay un puerro azul, bueno este se llama puerro francés de caterá, yo te digo hace como 15 años que lo hago todos los años". (Bonicatto, 2011e. Entrevista a NG-renglón 452)

B Técnicas de recolección, limpieza y secado de semillas para conservar

"cuando vos venís para ver si está a punto agarras 4 de estos que tienen la semillita, si la semillita ya está negra quiere decir que ya está buena, la cosechas y se cosecha a la mañana y a la tarde está seca, vos la tocas y se cae la semilla, en cambio a la mañana está húmeda, y se queda quietita, entonces vos la cortas y la llevas al galpón, y después la desgranas un día que llueve que tenés un rato de tiempo la desgranas, y para separarla de la granza lo metes en el agua, y la granza se va toda arriba viste y abajo en el piso del tarro queda la semilla negra...la granza es toda la impureza. El capullito. Esto es pimpollo! ¡Hay que separar la granza del trigo!" (Bonicatto, 2011e. Entrevista a NG-renglón 275) "en el momento de secado tiene que estar bien soleadita, que se seque bien en el sol, vos una vez que la semilla la hiciste que está toda limpita, la dejas 5-6 días al sol, todos los días la sacas, a la noche la metes adentro para que no la agarre la humedad, que el sol la seque bien, bien sequita, y después la guardas" (Bonicatto, 2011 e. Entrevista a NG-renglón 393) 
"el secreto que tiene la semilla es que tiene que estar a oscuras en un lugar seco, en un tarro si es posible de vidrio" (Bonicatto, 2011e. Entrevista a NG-renglón 162) "la chaucha esta cronos tiene el gorgojo incorporado de nacimiento, si vos la dejas en la vaina, seca viste y la dejas en la vaina te aguanta todo el período, la sacas de la vaina, la pones en un paquete, si no le pones naftalina a los quince días tapada la tenés de gorgojo. O sea que tiene el gorgojo incorporado lo debe tener. La naftalina, el olor de la naftalina no deja entrar el bicho" (Bonicatto, 2011e. Entrevista a NG-renglón 362) "no tiene mayormente secreto, tiene que estar en un lugar seco y te digo, en un tarro de vidrio" (Bonicatto, 2011e. Entrevista a NGrenglón 390) "adentro tiene una, esta no pero porque es, pero yo le pongo la etiqueta adentro" (Bonicatto, 2011e. Entrevista a NG-renglón 391) "viste que lo envasan al vacío y le hacen un proceso. Ahí aguanta, pero como hacíamos nosotros que lo ponías en un frasco, lo tapabas bien y lo guardabas todo el invierno en un lugar oscuro. Igual ¡13 lunas!" (Bonicatto, 2011e. Entrevista a NG-renglón 22)

D Dificultades para la conservación

"hay muchas semillas que salieron ahora nuevas que nada que ver con las que estaban antes, unos rendimientos bárbaros, lo único que tienen que no están acostumbradas al clima, por ejemplo el tomate, que se yo la cantidad de híbridos que hay. Pero no están aclimatadas y por eso después le agarra la peste negra, el trip, ¿no viste que después te dicen resistente a peste negra? Pero el verdadero tomate platense podía venir cualquier peste que no se lo agarraba" (Bonicatto, 2011e. Entrevista a NG-renglón 266) "sobre el ají vinagre tradicional: Después hubo un tiempo que se dejó de plantar, se perdió la semilla, se perdió, porque había salido el aji banana, viste uno amarillo largo que hay así...bueno, son todos inventos de lo moderno viste, y ese no se le dio más bola. Bueno se dejó de plantar como diez años, se dejó de plantar" (Bonicatto, 2011e. Entrevista a NG-renglón 22)

E Experimentación y mejoramiento de semillas

"depende de la semilla, si es de, si es de decencia híbrida no conviene guardarla, viste, ahora si es de buena descendencia de descendencia así casera y es de buena calidad, la hago guardar porque digo ¿dónde voy a embocar otra vez una semilla buena? (Bonicatto, 2011e. Entrevista a NG-renglón 249) "el tomate es una variedad híbrida, este es hijo de primer cría, del original, se llama "col 45", este tomate, y yo hice la prueba en hacer la semilla porque es carísima, vale 400 pesos mil semillas y con mil semillas plantas dos surcos, más no plantas, entonces, cuatrocientos pesos mil semillas, el sobrecito viene de mil semillas. Entonces yo hice la prueba hacerlo, el primer año viene bien o sea este, si yo este lo dejo otra vez para semilla ya no viene tan bien, viene igual, pero no viene tan bien, viene chiquito, deformadito, o sea que yo ayer casualmente de la plantinera me trajeron dos bandejas del original, ese hago semilla este año porque es original porque te dice el sobrecito, F1 quiere decir que es original, F2 hijo, y F3 ya" (Bonicatto, 2011e. Entrevista a NG-renglón 374)

\section{DAG}

A Cultivo y selección de plantas para obtener

"así vamos recolectando y vamos haciendo la siembra, nosotros hacemos tomate un año y ese ya nos alcanza para ese año, porque todos los años renovamos la semilla asique no es que hacemos un kilo de tomate y tenés para tres años porque no te dura tanto la semilla" (Bonicatto, 2014c. Entrevista a DAGrenglón 188) "lo mismo pasa con las plantas cuando uno está cultivando, berenjena, zapallito verde, todas esas cosas, que dan repetitivos productos, o sea que si una planta la dejas con todos sus frutos, ya está ya cumplió su ciclo digamos...5, 6 zapallitos y ya se quedó ahí, vos le empezas a juntar día por medio el zapallito y empieza a dar flores y flores, dura como para cumplir su ciclo la planta, lo puedo ver yo como que la planta se estimula porque ella quiere cumplir su ciclo, en cambio vos lo sacas siempre y la tipa te da flores, te da producto, vos en cambio lo dejas y con 4, 5 zapallitos, chau ahí ya tiró a secarse a madurar su fruta y ya está quiere dar la semilla porque ese es su ..El ciclo de la planta, el ciclo natural de la planta, eso es muy importante por ahí detenerse y observar la naturaleza porque la naturaleza enseña al hombre" (Bonicatto, 2014c. Entrevista a DAG-renglón 128) "porque nosotros por ejemplo, hacemos así a campo la semilla cuando más o menos vemos que esa planta la queremos dejar para semilla la cerramos, le ponemos un mosquitero a la planta, porque no queremos que las abejas nos crucen las semillas, nos polenicen con otras, entonces ese es el tema, muchas veces las abejitas hacen ese trabajo" (Bonicatto, 2014c. Entrevista a DAG-renglón 167) 
C Acondicionamiento y guardado

"lo guardamos en tarros de madera a presión ahí y lo dejamos ahí, no tiene ningún problema " (Bonicatto, 2014c. Entrevista a DAG-renglón 181)

D Dificultades para la conservación

"lo que pasa así como te digo, es mucha la inversión que hay que hacer para hacer la semilla, porque hay que hacer galpones cerrados, con mosquiteros, entonces muchas veces vos por ejemplo te sale una berenjena cruzada con un zapallo, por decirte así y vos ves que el producto no es como tiene que ser, entonces algo pasó en el transcurso de la semilla, entonces cuando elegimos que esa planta va a ser para eso, lo cubrimos con una malla para que las abejas no interfieran en la flor, y los frutos que da esa planta no se toca, eso para que madure, cumpla su función y después sacamos la semilla. Es un trabajo de loco" (Bonicatto, 2014c. Entrevista a DAG-renglón 167) "si lo que pudimos constatar es que la semilla tiene que estar un año, año y media porque después ya sé como que se llena de gorgojos, porque es natural, ese es el tema, todos los productos que sea natural es un año, año y pico, y se hacen gorgojos, así pasa con el arroz, con la chía, con al quinoa, ese tipo de producto que estamos trabajando, allá en el norte...es su ciclo natural, o la semilla toca la tierra, o se hace gorgojo" (Bonicatto, 2014c. Entrevista a DAGrenglón 182)

E Experimentación y mejoramiento de semillas

JL

A Cultivo y selección de plantas para obtener

JL: "vos la plantas la cabeza que viene más rápido, y te rinde más. Vos lo pones semilla y te da una plantita nomás, viste. Y vos la plantas la cabeza y mira cuantas te da, tres, ya voy a dejar un surco para levantar semilla. Entonces ya para el año ya tengo la semilla y sé que la semilla es buena"(Bonicatto, 2009b. Entrevista a JL-renglón 343) "con el zapallito de tronco también hay que saberlo elegir, no es cualquier zapallito hay que dejarlo madurar. El zapallo bueno del, del tronco, hay que saberlo elegir, porque hay zapallos, como puedo decir, no hay una, cosa redonda viste en la punta del zapallito, tiene una cosa como anillo, el ombliguito, que no sirve para semilla por el anillito que tiene, después se deforma el zapallo, sale todo zapallo feo" (Bonicatto, 2009c. Entrevista a JL-renglón 112) "elegir las plantas es la ventaja de levantar la semilla buena, igual que el choclo, el maíz, vos sacas unas dos, tres mazorcas del maíz, para que te salga buena no tenés que desgranarla entera viste. Este es el choclo, está madura ya, ya está seco viste, vos tenés que, desgranarlo... más o menos dejas dos dedos de la punta, de la punta del choclo, ese no lo desgranes, no lo plantes, te venís para abajo. Lo mismo que la sandía, la sandía vos nunca guardes semilla de la sandía completa, siempre tenés que guardar de la mitad de la sandía, una sola mitad, esta la sandía buena" (Bonicatto, 2009c. Entrevista a JL-renglón 143) "a la batata le gusta la tierra arenosa y caliente, acá viene cada batata" (Bonicatto, 2009d. Entrevista a JL-renglón 201) "por dos años nomás la cosecho, dos años más no, después se degenera. Si es tomate, un año, para el otro, podes sacar semilla para el otro año y hacer esa cosecha nomás. Si seguís sembrando esa semilla se te viene el tomatito todo bolillita, viste. Ahora jel platense no! El platense ya es carne de perro, ese ya está." Es como el choclo, el choclo vos el primer año, la compras la semilla de choclo, vas cosechas un choclo, vos lo dejas madurar ese choclo, decís, ya al siguiente año te viene cortito ya no te sirve." (Bonicatto, 2009d. Entrevista a JL-renglón 79) sobre la cebolla morada: "esa morada también la hice yo aquí. Y esa es la que tengo semilla ahí para sembrar, pero no la siembro por el almacigo, porque tengo roto el invernáculo. Después tengo la otra semilla de Balanceana, también la cabeza, tampoco la puedo sembrar porque no tengo tiempo," (Bonicatto, 2009d. Entrevista a JL-renglón 179) "Ese zapallo me fallo (se refiere a zapallito de tronco): porque me dio toda flor vacía, en mala luna lo sembré (¿y cuándo es que se siembra entonces?) En cuarto menguante" (Bonicatto, 2009d. Entrevista a JL-renglón 274) "vos comprate un híbrido de platense hibrida...y yo pongo mi tomate, el tuyo híbrido y comé uno de los míos a ver cual es...más sabroso. Cambia mucho la híbrida con la nacional, no nada que ver." (Bonicatto, 2010a. Entrevista a JL-renglón 59) "el maíz le empezas en el mes de julio, agosto, septiembre podes sembrarlo hasta fines de enero y tenés febrero, marzo, abril y mayo para cosechar. No hay problema con el maíz lo podes sembrar ahora o a fin de diciembre". (Bonicatto, 2010a. Entrevista a JL-renglón 248) (Sobre la acelga que tiene la blanca y la verde) "se siembra separada, sino se te cruza y después es trabajo para levantar la semilla, viste" (Bonicatto, 2009c. Entrevista a JL-renglón 272)

B Técnicas de recolección, limpieza y secado de semillas para conservar 
"en el agua, tenelo mas o menos, tres cuatro días y ahí empezalo a mover y mover y ahí empieza a la semilla (de tomate) y levantarse la basura para arriba, y después le vas volcando despacito, le vas volcando agua, viste, le vas volcando agua y aumentando agua cosa de que viste sola queda la semilla que no sirve se levanta para arriba, la semilla vacía, y la buena te queda abajo en el asiento. Y después esa es la que saco y la pongo a secar. Pero no en el sol, en la sombra. Adentro, para que le dé el aire. Si le da el sol que quema porque como está mojada, el sol caliente la quema, es como echarle agua caliente". (Bonicatto, 2009b. Entrevista a JL-renglón 112) "yo siempre guardo, elijo la semilla para que sea grande si, buena variedad" (Bonicatto, 2009b. Entrevista a JL-renglón 250) "el anquito, ese lo corta y se lo mete con toda la pulpa, va el zapallito se lo come, pero se saca todo y se lo deja fermentar ahí, esa semilla se termina de rellenar, le da una lavada, dos lavadas, dejalo dos tres días adentro que fermente todo eso y después lo vas lavando. La semilla fea que no sirve para nada se levanta para arriba" (Bonicatto, 2009c. Entrevista a JL-renglón 211) "la cabeza (de ajo) se guarda, no da flor, no sirve. El ajo es como la higuera, guardalo al higo pero no te da la planta, el ajo viene del propio ajo" (Bonicatto, 2009 c. Entrevista a JL-renglón 218) "la semilla? (de berenjena) Tenés que sacarle la cáscara y dejarla con pulpa y todo y ponerla en un tacho como esos y echarle un poco de agua pa' que fermente Después se pudre la pulpa y que la semilla abajo, tenés que lavarla, viste ir volcando el agua, esa sucia, ir lavando , bien lavadita, que no le quede después ponés a secar bien y guardas la...se levanta sola, esa hay que tirarla sino se te pudre la semilla o le entra el bicho, la pulpa junta el" (Bonicatto, 2010a. Entrevista a JLrenglón 66)

\section{Acondicionamiento y guardado}

"yo la semilla de tomate la tengo aquí en estos frasquitos. Y la tapo bien. La tapo bien y las guardo ahí adentro, tengo una heladera especial para...una heladera vieja, viste y la meto ahí por los ratones, viste, vieja le digo porque, va funciona pero la dejé, como saqué esta nueva" (Bonicatto, 2009b. Entrevista a JL-renglón 143) "La semilla de lechuga vos la guardas hoy, cosechas este año y tenés que plantarla para el otro año, sino se te hace tiene las arañas viste adentro, no te sirve más. Le agarra como el hongo" (Bonicatto, 2009b. Entrevista a JL-renglón 155) (sobre la papa) "si que aguantan porque yo las embolso y las guardo adonde no les dé mucho el aire, sol, calor, te aguanta un año. Y esta la podes comer hasta...Recién el otro día terminamos la papa del año pasado". (Bonicatto, 2009b. Entrevista a JLrenglón 424) "zapallito, el anquito, la calabaza grande eh. Ves como se mantiene ahí fresquita no le entra ningún bicho. $Y$ después tengo acá que levante la semilla de la rúcula, acá tengo semillas de melón (¿y les anota algo?) No, tengo todo en mi cabeza. Y después los tengo en tarros, viste, así. Es por los ratones. Se mantiene mas, mas linda la semillas, más fresca, y no les da el viento." (Bonicatto, 2009c. Entrevista a JL-renglón 41) "Todas las semillas dos años. Depende como las guardés" (Bonicatto, 2009c. Entrevista a JL-renglón 189) "tenés que taparla viste, taparla, frasco de vidrio tener que poner. Porque el vidrio no puede entrar la semilla de la lechuga te dura un año, año y medio. Como el zapallo mismo, el anco todo eso, un año, para otro, dos años y ya. Si la mantenes bien te dura dos años la semilla, si no, no" (Bonicatto, 2010a. Entrevista a JL-renglón 223)

D Dificultades para la conservación

"me comieron los ratones, me descuidé la puse en el tarro y el tarro de cartón de dulce de leche. Y cuando las fui a buscar estaba el agujero en el tarro y ¡me comieron todo!" (Bonicatto, 2009b. Entrevista a JLrenglón 385)"no ves que tenía una bolsa de semillas que son del año pasado de la hibrida para sembrar, porque no tenía, y me la comieron los ratones también, y mira que estaba con veneno eh! Sacaban el veneno de la cascara y le comían lo de adentro.fui a buscas y una agujero en la bolsa de semilla, cuando vi el maíz comido fui a ver el anquito y también" (Bonicatto, 2009b. Entrevista a JL-renglón 390) "pero la gente, los quinteros no quieren semillas, quieren semilla hibrida, porque son boludos. Ellos quieren todos los grandotes que vienen de un día para otro. Ellos quieren plantar hoy para cosechar mañana" (Bonicatto, 2009d. Entrevista a JL-renglón 222)

\section{E Experimentación y mejoramiento de semillas}

"el híbrido con el criollo, ya para el año voy a ver si lo cruzo, al maíz criollo con el choclo, y ponés un surco de cada uno, y se cruzan, la misma flor que cae una arriba de la otra viste, y se cruzan, se cruza el maíz, vos sembrás cuatro surcos de maíz ponele maíz blanco y maíz amarillo y te va a salir overo viste...el choclo, querés cruzar el maíz diente de caballo con el otro y lo cruzas, sembras uno y uno, querés sembrar con uno de grano chiquito, se cruzan. Salen como injertos viste" (Bonicatto, 2009c. Entrevista a JL-renglón 255) 
A Cultivo y selección de plantas para obtener

"para guardar la semilla es muy sencillo, la semilla se saca ponele, ponele el tomate si fuera el tomate platense, se deja en un cuadro un caballete, vos dejas un caballete y ahí seleccionas las plantas, pasas le tiras los tomates deformados, dejas que se madure bien en la planta porque si no está bien maduro en la planta la semilla queda verde, cuando está el tomate bien maduro vos lo sacas les sacas bien la semilla lo dejas secar al sol...hacer un trabajito bien hecho, después se le saca todo la pelusa, se le pasa como una zaranda y queda una semilla de tomate espectacular, lo mismo el ají, vos el ají lo dejas en un planta a madurar en el campo ese ají es espectacular, elegís la mejor planta, el mejor fruto, ahora se terminó todo eso" (Bonicatto, 2014b. Entrevista a HC-renglón 287)

B Técnicas de recolección, limpieza y secado de semillas para conservar

"vamos renovando, plantamos un año (zapallo anco batata), después al otro año hacemos semilla nueva" (Bonicatto, 2014b. Entrevista a HC-renglón 105) "donde hay una planta que viste, vamos sacando, vamos marcando. Con 15-20 plantas sabes la semilla que sacas! (¿Qué es lo que miras de cada planta?) la calidad del fruto, vos el zapallo, el tamaño, porque para ir a agarrar un zapallo que es medio degenerado, porque para agarrar un zapallo que vino grande así después te sale cualquier cosa, vos fijate mira...este zapallo no se puede sacar semillas (señalando uno alargado con forma de banana) ya ese no, no hay mucho" (Bonicatto, 2014b. Entrevista a HC-renglón 134) "para guardar la semilla es muy sencillo, la semilla se saca ponele, ponele el tomate si fuera el tomate platense, se deja en un cuadro un caballete, vos dejas un caballete y ahí seleccionas las plantas, pasas le tiras los tomates deformados, dejas que se madure bien en la planta porque si no está bien maduro en la planta la semilla queda verde, cuando está el tomate bien maduro vos lo sacas les sacas bien la semilla lo dejas secar al sol, hacer un trabajito bien hecho, después se le saca todo la pelusa, se le pasa como una zaranda y queda una semilla de tomate espectacular, lo mismo el ají, vos el aji lo dejas en un planta a madurar en el campo ese ají es espectacular, elegís la mejor planta, el mejor fruto, ahora se terminó todo eso" (Bonicatto, 2014b. Entrevista a HC-renglón 287)

\section{Acondicionamiento y guardado}

D Dificultades para la conservación

"el híbrido no le podes sacar semilla" (Bonicatto, 2014b. Entrevista a HC-renglón 312)

\section{E Experimentación y mejoramiento de semillas}

"voy ponele un año al mercado hay un anquito que me gusta a mi...porque este es una variedad que no se si la sentiste nombrar que es el anco batata...es un zapallo que yo lo compré en el año 2006, 2007" (Bonicatto, 2014b. Entrevista a HC-renglón 108) "yo hice la prueba (con híbridos) de sacar semilla y después te sale todo degenerado, te sale, diez plantas buenas y cinco malas, entonces lo que pijoteas en un lado lo perdes en el otro, es muy sencillo, había una semilla de aji que se llamaba Yatasto, una variedad que se llamaba Yatasto, híbrida, podías hacer semilla de un año para otro, ponele sacar este año, para volver a plantarlo, le sacabas una cosecha pero después ya empezó a decaer, decaer, decaer no se pudo hacer más semilla, se degeneró, se ve que los semillleros algo le han hecho, alguna trampa que no se podía sacar semilla, porque como valía tanta plata" (Bonicatto, 2014b. Entrevista a HCrenglón 312)

IG

A Cultivo y selección de plantas para obtener

"pero he aprendido con trabajo sobrevivir o vivir tal vez" (Bonicatto, 2013d. Entrevista a IG-renglón 102) "este maíz no sé yo es que no soy muy a veces por la calle lo encuentro, así echado, botado ya me traigo alguna vez y lo siembro porque yo tengo fe" (Bonicatto, 2013d. Entrevista a IG-renglón 142)

\section{B Técnicas de recolección, limpieza y secado de semillas para conservar}

\section{Acondicionamiento y guardado}

D Dificultades para la conservación

E Experimentación y mejoramiento de semillas 
"siempre un poco digo....la semilla yo la siembro, hasta mi esposa duda, dice pero "eso no va producir", ¿cómo no va a producir? Entonces el año pasado hemos sembrado y ha producido, no sé si bien o no pero ahora mejoró la semilla" (Bonicatto, 2013d. Entrevista a IG-renglón 137)

$\mathrm{CL}$

A Cultivo y selección de plantas para obtener

B Técnicas de recolección, limpieza y secado de semillas para conservar

C Acondicionamiento y guardado

D Dificultades para la conservación

"una vez hice de berenjena, de cherry pero no tuvo mucho rendimiento, no tuvo la misma germinación que la de la semillería que nace el $98 \%$. Nace...pero no tiene desarrollo. De berenjena tira un poco pero no como la original que viene de fábrica" (Bonicatto, 2013e. Entrevista a CL-renglón 44) Si vos la guardas y te entra un gusano o polilla, te arriesgas mucho" (Bonicatto, 2013e. Entrevista a CL-renglón 52)

\section{E Experimentación y mejoramiento de semillas}

"una vez hice de berenjena, de cherry pero no tuvo mucho rendimiento, no tuvo la misma germinación que la de la semillería que nace el $98 \%$. Nace...pero no tiene desarrollo. De berenjena tira un poco pero no como la original que viene de fábrica" (Bonicatto, 2013e. Entrevista a CL-renglón 44)

ML

A Cultivo y selección de plantas para obtener

B Técnicas de recolección, limpieza y secado de semillas para conservar

C Acondicionamiento y guardado

D Dificultades para la conservación

E Experimentación y mejoramiento de semillas

BIS

A Cultivo y selección de plantas para obtener

"después si sacamos semilla de la moradita (lechuga), o la escarola fina también se saca, pero eso en primavera cuando empieza a florecer la tenés que dejar para que semille" (Bonicatto, 2013a. Entrevista a BIS-renglón 100) "de una o dos plantitas, semillas, hizo que den más semillas para poder plantar, bueno ella rescató así la semilla, y yo planté aquí con mi suegro porque a mi suegro le habían hecho plantines para una sola fila y de ahí. No, no, miento porque eran 4 o 5 palos que puso, y esa fila de hasta 5 palos dejó sólo para semilla, bueno de ahí sacó para semilla y de ahí nos repartimos para nosotros, así que me dio un poco para mi otro que lo tiene él, pero de ahí la verdad es que es muy salvaje la semilla porque cuando vos no lo cosechas bien se cae o lo tiras al suelo y con el tiempo otra vez están dando igual que la chaucha" (Bonicatto, 2013a. Entrevista a BIS-renglón 122) "ahí dejamos una parte todo para que semille" (Bonicatto, 2013a. Entrevista a BIS-renglón 147) "de la semilla sólo nosotros, porque aparte no es taan difícil, te lleva tiempo nada más, nosotros lo seleccionamos las más grandes, que se pinten bien y lo traemos acá" (Bonicatto, 2013a. Entrevista a BIS-renglón 160) "saqué un tiempo fue de la escarola fina que mi suegro había sacado hace muuucho, sacó y yo no sabía cómo se sacaba de la escarola fina, porque es más dura la flor, entonces sabíamos poner una cosa grande así y empezar a sacudirlo fuerte y luego no sé como lo sabíamos para que salga la semilla" (Bonicatto, 2013a. Entrevista a BIS-renglón 211)

B Técnicas de recolección, limpieza y secado de semillas para conservar

"la verdad nadie nos enseño, va...nosotros no teníamos idea" (Bonicatto, 2013a. Entrevista a BISrenglón 137) "este es el cherry, esto lo tenía que poner en frasco pero no" (Bonicatto, 2013a. Entrevista a BIS-renglón 140) "de la semilla sólo nosotros, porque aparte no es taan difícil, te lleva tiempo nada más, 
nosotros lo seleccionamos las más grandes, que se pinten bien y lo traemos acá, en un balde para poner lo que no sirve y la semilla aparte, lo vamos sacando la semilla y lo vamos dejando dos o tres días con agua, con poquito agua, que se....hay como se hace......se hace....claro se fermenta, y luego de ahí lo sacamos todo lo que está de arriba es lo que no sirve y lo que esta de abajo si sirve. Y nada...lo sacamos de ahí lo escurrimos bien con tipo...que lo conseguimos...unas telitas.....que no es tan abierta ni muy cerrada, y lo colamos ahí, y lo apretamos y lo volvemos a enjuagar con otra agua y luego dejarlo que se seque pero no en el sol sino en la sombra porque en el sol hemos hecho la prueba y no nacieron (se ríe) es como que se quema la semilla, entonces de ahí aprendimos a hacer...de los errores vamos aprendiendo. O si no preguntamos a otra persona como lo hacen, bueno es como que ya nos dan otra idea y bueno terminamos haciendo semillas así" (Bonicatto, 2013a. Entrevista a BIS-renglón 160) (E1 211) "saqué un tiempo fue de la escarola fina que mi suegro había sacado hace muuucho, sacó y yo no sabía cómo se sacaba de la escarola fina, porque es más dura la flor, entonces sabíamos poner una cosa grande así y empezar a sacudirlo fuerte y luego no sé como lo sabíamos para que salga la semilla, y luego la mamá era que lo hacía con un fuentón a moverlo así cosa de que todas las chalas se las llevaba el viento e iba quedando el más bueno, y así iba seleccionando la semilla, pero si dio lindas esa, de esas variedades, no sé qué variedad si la perdió o no la perdió la variedad, porque hay de muchas variedades, y hay que saber qué variedad" (Bonicatto, 2013a. Entrevista a BIS-renglón 211) "semilla de eso si sé, yo de verdura todo acá, aprendí todo aquí. Lo que es maíz y maní aprendí en Bolivia" (Bonicatto, 2013a. Entrevista a BIS-renglón 293)

\section{Acondicionamiento y guardado}

"estas son las más nuevas, después hay otras más viejas que tengo pero esas es como que ya no sirven así que ...pero siempre dura para un año para el otro año ya no se secan, se mueren las cositas que es la semillita de adentro y estas año a año, este es de una variedad y este es de otra variedad (de cherry) pero son las mismas semillas" (Bonicatto, 2013a. Entrevista a BIS-renglón 142) "ahorita esa semilla la tiene mi suegro, el lo conserva pero con el marlo y todo completo, no lo pela nada, lo guarda así, bien seco con unas bolsas así tipo de estas (plásticas) y lo guarda en un lugar sin humedad y ya para el año lo vuelve a poner" (Bonicatto, 2013a. Entrevista a BIS-renglón 314)

\section{Dificultades para la conservación}

"a mí me gustaría aprender más que todo del morrón ...como conservar la semilla, para que no se pierda esa fuerza que tiene porque vos compras la semilla, lo haces los plantines...viene linda los morrones, los frutos pero si vos sacas semilla y dejas para la otra siembra es como que no tiene esa fuerza, no crece grande, ni la planta, ni los morrones y otra es que...es muy débil para que, o sea, muy propenso a enfermedades es esa la diferencia" (Bonicatto, 2013a. Entrevista a BIS-renglón 183)

\section{E Experimentación y mejoramiento de semillas}

"como ser la escarola fina nos resulta bien sacar la semilla y volverla a plantar porque...sale linda en cambio hay otras que vos no tienen mucha fuerza para...son muy débiles y quedan chiquitas" (Bonicatto, 2013a. Entrevista a BIS-renglón 103) "hacemos la prueba.....hacemos la prueba...la acelga también vienen lindas las acelgas. un año guardamos, hacemos así para que dure porque al otro año, ya no" (Bonicatto, 2013a. Entrevista a BIS-renglón 107) "después que nosotros no sacamos semilla de morrón si no hubiésemos sacado hace mucho, hemos hecho la prueba pero no nos dio resultado" (Bonicatto, 2013a. Entrevista a BIS-renglón 187) "luego dejarlo que se seque pero no en el sol sino en la sombra porque en el sol hemos hecho la prueba y no nacieron (se ríe) es como que se quema la semilla , entonces de ahí aprendimos a hacer...de los errores vamos aprendiendo. O si no preguntamos a otra persona como lo hacen, bueno es como que ya nos dan otra e idea y bueno terminamos haciendo semillas así" (Bonicatto, 2013a. Entrevista a BIS-renglón 160)

$\mathbf{P}$

A Cultivo y selección de plantas para obtener

"tengo que sacar de la segunda camada" (Bonicatto, 2011g. Entrevista a P-renglón 56) "de perejil si se puede, a veces cuando lo dejas mucho tiempo y no tenés tiempo, se va haciendo semilla" (Bonicatto, 2011g. Entrevista a P-renglón 205)

B Técnicas de recolección, limpieza y secado de semillas para conservar 


\section{Acondicionamiento y guardado}

D Dificultades para la conservación

"cuando tenemos tiempo más o menos nosotros lo hacemos. Si lo hacemos digamos, compramos a veces la semilla y lo hacemos. Si porque más nos conviene hacer, que comprar el plantín" (Bonicatto, $2011 \mathrm{~g}$. Entrevista a P-renglón 83) "de la semilla sacada viene menos, no con tanta diferencia pero viene" (Bonicatto, 2011g. Entrevista a P-renglón 112) "tenés que darle un poquito más remedio, más abono...todo eso, más. Pero si le llegas a atender bien, con el agua, con el abono, eh...todo eso, casi llega a ser igual" (Bonicatto, 2011g. Entrevista a P-renglón 118) "no sacamos porque cuesta" (Bonicatto, 2011g. Entrevista a P-renglón 202) "no tienes casi de otra cosa para sacar semilla porque tarda un montón, se llena de yuyo. Por eso no podes sacar la semilla. Mientras del tomate y del morrón...mientras esto tiene que florecer para poder sacar semilla...aparte se te llena de yuyo y aparte en esos dos meses no podes sacar otra planta" (Bonicatto, 2011g. Entrevista a P-renglón 208) "no se puede guardar semillas de este (el pack-choi). Directamente te florece y se hace fea" (Bonicatto, 2011g. Entrevista a P-renglón 316)

\section{E Experimentación y mejoramiento de semillas}

"era de una semilla que nos había vendido, después lo saque yo la semilla. Y esto es todo cherry, que es de semilla sacada" (Bonicatto, 2011g. Entrevista a P-renglón 73)

\section{LO}

A Cultivo y selección de plantas para obtener

"vamos a ver cómo nos va porque dicen que se tiene que secar, o sea, primero larga la flor y después se seca la...después la tenés que desenterrar" (Bonicatto, 2011i. Entrevista a LO-renglón 32) "la planta tenés que dejar unas 4, 5 plantas, que carguen bien así, o sea esas no cosecharlas...nada, que se dediquen a cargar y a cargar, y....tiene que esperar que se seque, la chaucha o sea que se aporote, que se seque" (Bonicatto, 2011i. Entrevista a LO-renglón 153) "lo tengo que dejar madurar bien al zapallito, dejar en la planta un buen tiempo, y yo digo bueno como tengo un cuadro de zapallito ahí y no valía nada....dejalo, porque te lleva tiempo al zapallito cosecharlo, es pesado....y no valía 4 \$ la jaula! $Y$ nosotros por cosecharlo estamos toda la mañana ahí, teníamos muchas cosas para hacer" (Bonicatto, 2011i. Entrevista a LO-renglón 182) "vamos a probar y ahora lo estamos dejando madurar en la planta porque se tiene que poner la cáscara bien dura" (Bonicatto, 2011i. Entrevista a LO-renglón 189) "tiene que estar bastante tiempo para que te salga la semilla bien, entonces tiene que florecer y todo como ser la acelga o la remolacha, y este pedacito como no era tan grande lo dejamos" (Bonicatto, 2011i. Entrevista a LO-renglón 203)

B Técnicas de recolección, limpieza y secado de semillas para conservar

"ahí recién las cosechas y las juntábamos nosotros así en el canasto y después o las tirábamos en un nylon extendido y la dejábamos ahí que se seque bien y ahí pa' agarraba un palo y empezaba así a garrotearlas, a las cosas y solas empezaban a salir las semillas, y después empezaba a sacar todas como que quedaba las palitas de la chaucha, empezaba a sacar todas y la semilla quedaba abajo, y ahí empezaba a juntar toda la semillas" (Bonicatto, 2011i. Entrevista a LO-renglón 155) "ahí la tengo que sacar y dejar secar a la semilla, le saco lo de adentro y la tengo que dejar secar" (Bonicatto, 2011i. Entrevista a LO-renglón 190) "con el tomate solo hay que dejarlo madurar bien para sacar la semilla...como para hacer tomate relleno, lo tiras en un tacho con agua" (Bonicatto, 2011i. Entrevista a LO-renglón 233) "a mi papa se la dimos con estas y él las tiene en un nylon así, después me la puse a golpear" (Bonicatto, 2011i. Entrevista a LO-renglón 298) "yo lo ayudaba (a mi padre) porque yo tengo 21, nací en la quinta esa donde él está y me acuerdo que era chica, desde los ocho años más o menos que lo ayudaba a él, él me decía que le ayude, yo me acuerdo que agarraba el palo para que golpeara la chaucha y quedaba toda la semilla abajo" (Bonicatto, 2011i. Entrevista a LO-renglón 320)

\section{Acondicionamiento y guardado}

E1 162) "la guarda en un tacho, la tapa bien y no ahí ya para el año que viene las planta" (Bonicatto, 2011i. Entrevista a LO-renglón 162) "la tengo que guardar bien, que no le entre nada de aire" (Bonicatto, 2011i. Entrevista a LO-renglón 191) "juntarlo todo y ponerlo adentro de un canasto, después lo volcábamos en el tacho" (Bonicatto, 2011i. Entrevista a LO-renglón 326) 
D Dificultades para la conservación

"porque el año pasado mi papá quería sacar así la semilla de chaucha y le entró el bicho y ya no le sirve la semilla esa" (Bonicatto, 2011i. Entrevista a LO-renglón 192) "hay plantas que se puede sacar semilla y plantas que no, porque no...es decir...no tiran mucho fruto, esta sí, sacas una y otra y te sigue dando, en cambio así sacas remolacha o acelga y no germina todo, no se puede...y hay que tener bastante tierra para este para poder sacar semilla, porque como nosotros pagamos alquiler tenemos que juntar y preparar y preparar y para sacar semilla tenés que tener un buen tiempo" (Bonicatto, 2011i. Entrevista a LOrenglón 131)

E Experimentación y mejoramiento de semillas

"la variedad, más que todo se puede sacar de chaucha o morrón pero no, no viene es decir si plantas uno, no, no te rinde" (Bonicatto, 2011i. Entrevista a LO-renglón 99) "hay plantas que se puede sacar semilla y plantas que no, porque no...es decir...no tiran mucho fruto, esta sí, sacas una y otra y te sigue dando, en cambio así sacas remolacha o acelga y no germina todo, no se puede" (Bonicatto, 2011i. Entrevista a LO-renglón 131) "después te muestro allá, un pedazo de zapallito que estamos...que lo dejamos ahí para ver cómo nos va con la semilla de zapallito" (Bonicatto, 2011i. Entrevista a LO-renglón 174) "el año pasado quisimos sacar pero nos desanimamos porque la dejamos crecer las cosechamos, la dejamos en una jaula aparte y después no desanimamos no la sacamos, nos olvidamos y después ya la perdimos, pero si ahora que preparamos la tierra salen algunas plantitas y vamos a ver así como vienen, esas plantitas las dejamos, son como 4 plantitas y yo le digo por ahí carga bien....quien te dice le digo...y si para mi estaría re bien poder sacar la semilla" (Bonicatto, 2011i. Entrevista a LO-renglón 241)

\section{SV}

A Cultivo y selección de plantas para obtener "¿viste que había una que ya estaba floreciendo? La dejo que se madure bien y de ahí le saco" (Bonicatto, 2014j. Entrevista a SV-renglón 125)

B Técnicas de recolección, limpieza y secado de semillas para conservar

C Acondicionamiento y guardado

D Dificultades para la conservación

E Experimentación y mejoramiento de semillas

CA

A Cultivo y selección de plantas para obtener

"aquello sembré para dejar para semilla, las habas, (señala los primeros dos surcos que están seguido del invernadero) deje dos surcos para semilla" (Bonicatto, 2011d. Entrevista a CA-renglón 79) "tenemos semilla sembrada allá arriba que guardamos del año pasados, Queremos hacer eso también, por eso me gusta la idea de intercambiar semilla porque encontras verdura de variedad cosa que se sigue sacando semilla y viene la misma calidad, no se diferencia en nada" (Bonicatto, 2010c. Entrevista a BV-renglón 87) "esto lo seguimos ( el alcaucil) porque esto todo era una zona alcaucilera así que nos fuimos quedando con menos pero seguimos manteniendo la misma variedad. La tenemos desde hace 16 años" (Bonicatto, 2011d. Entrevista a CA-renglón 259) "por ejemplo acá me quedó un tramo, por ejemplo les cuento, este es el que sembramos el anteaño pasado y que de acá saqué semilla para trasplantar y yo trasplanté algunas, hice algunos plantines" (Bonicatto, 2011d. Entrevista a CA-renglón 426)

\section{B Técnicas de recolección, limpieza y secado de semillas para conservar}

\section{Acondicionamiento y guardado}

"para conservarla tratamos de conservarla en botellas de vidrio" (Bonicatto, 2011d. Entrevista a CArenglón 150) "pero tengo los nombres anotado ahí, de quien vienen las producciones y todo eso" (Bonicatto, 2011d. Entrevista a CA-renglón 218) "en la vitrina allá (guarda las semillas)" (Bonicatto, 2011d. Entrevista a CA-renglón 820) "en este tiempo y uno por ahí por quedado, poooor no anotar 
digamos no tenés un control de lo que vos a la hora de ....al tiempo que vos sembrás vos decís mira aparte de anotarle el tiempo que yo sembré, nada me costaría agarrar y decir, bueno hoy planté, y ya sé que si me sale bien bueno lo voy a volver a sembrar en ese tiempo y que si me sale mal bueno ya no sembraré, y este es tomate platense, sacó mi viejo" (Bonicatto, 2011d. Entrevista a CA-renglón 827)

\section{Dificultades para la conservación}

"a veces no te da el tiempo o son muchos los pedidos que hay entonces se trata de cumplir con el pedido" (Bonicatto, 2011d. Entrevista a CA-renglón 85) "hace bastante tiempo lo hacíamos...hacíamos bastante a campo...mi viejo también...después se perdió la semilla o capaz que hay no....no...lo dejamos de hacer porque había un tiempo que plantábamos y no se por la inclemencia del tiempo empezamos a ver que las plantas...había muchos hongos y se caían mucho las plantas, no nos daba resultado porque no llegábamos a buen término con todas las plantaciones... entonces dejamos de hacer" (Bonicatto, 2011d. Entrevista a CA-renglón 193) "el lugar, para dejar que se haga semilla lo puede aprovechar con otras plantaciones" (Bonicatto, 2011d. Entrevista a CA-renglón 524) "recién ahora vamos a empezar esa que te dije con lolo, pero después otras no, no teníamos, no veníamos teniendo, porque fueron empezando a ser desplazadas las semillas de variedad por los híbridos, que venía....que era mucho mejor" (Bonicatto, 2011d. Entrevista a CA-renglón 702) "la verdad tampoco conozco a los del parque Pereyra (de quienes recibió semillas), siempre el interlocutor fue lolo" (Bonicatto, 2011d. Entrevista a CA-renglón 911)

\section{E Experimentación y mejoramiento de semillas}

"las semillas de variedades son más rusticas, ya están adaptadas acá a la zona, así que no se complica tanto en el crecimiento de la planta...por ejemplo me paso con el hinojo que me trajo y un hermoso hinojo y eso que la tierra no estaba tan trabajada" (Bonicatto, 2011d. Entrevista a CA-renglón 97) "intercambie semillas las que lleve yo de allá... pero bueno después tenemos que ver como se adaptan al clima de acá, uno trae esa semilla" (Bonicatto, 2011d. Entrevista a CA-renglón 184) "ahora traje semillas vamos a intentar de nuevo hacer" (Bonicatto, 2011d. Entrevista a CA-renglón 198) "yo intercambie...tengo una caja llena de semillas para ver, ahora hay que sembrarlas" (Bonicatto, 2011d. Entrevista a CA-renglón 210) "todo lo que se pueda guardar semilla voy a tratar" (Bonicatto, 2011d. Entrevista a CA-renglón 341)

A Cultivo y selección de plantas para obtener

"antiguamente mi viejo si usaba semilla porque no había tanta oferta, te hablo de la década del 60 del 70 del 80 , se acostumbraba a hacer la semilla uno porque por ejemplo mi viejo quería semilla de apio entonces había un hermano que la hacía, entonces no había tanta oferta, a partir de más acá en la década del 90 había más oferta de semilla de importada que se yo, cuando uno dejo de lado ya hacer eso, y se priorizaba comprar porque decía que era mejor, después a raíz del proyecto de Lolo empecé a sacar a juntar semilla de tomate, de un ají vinagre que es también del proyecto, que más saco? Ajíes, tomates, por ahí chaucha balina (Bonicatto, 2014f. Entrevista a AT-renglón 26) "yo tengo un pariente, un amigo, un hombre vive en Berazategui antiguo quintero de Hudson, ahora se enfermó y hacía una chaucha y la sembré y vi que era la balina esta la antigua. La voy a usar plante dos caballetes y saqué semilla, voy a sacar semilla" (Bonicatto, 2014f. Entrevista a AT-renglón 98)

\section{B Técnicas de recolección, limpieza y secado de semillas para conservar}

\section{Acondicionamiento y guardado}

D Dificultades para la conservación

"por ejemplo el anquito no se puede sacar porque se degenera mucho, es problema de que no te da lo mismo al otro año, la berenjena porque son híbridas y las híbridas sacadas tengo entendido que no sirven" (Bonicatto, 2014f. Entrevista a AT-renglón 35)

E Experimentación y mejoramiento de semillas "prove conservar híbridos" (Bonicatto, 2014f. Entrevista a AT-renglón 218) 
A Cultivo y selección de plantas para obtener

"nosotros esa la ponemos todo el tiempo de invierno la atendemos esa, o sea. En invierno los tenemos los plantines...y a partir de septiembre.....la plantamos, a la tierra para que haga el bulbo y de mediado de enero....de enero hasta febrero por ahí...este...ya la cosechamos para tener para....para tener para este tiempo....o sea se la planta en marzo y algunos...para hacer el...la...la cabecita, o sea yo...pongo este semilla. Que de esta misma saco pero, o sea que yo me hago mi semilla de cebolla. Como ser ahora, ves, ya saqué en....en octubre coseché la....porque de este año voy dejando para el otro, así voy renovando" (Bonicatto, 2010c. Entrevista a BV-renglón 16) "dejo...o sea unos dos surcos de verdeo, dejo dos surcos de verdeo, que haga la flor, en septiembre hace la flor, hace en septiembre y yo cosecho en noviembre, en diciembre la estoy sacando" (Bonicatto, 2010c. Entrevista a BV-renglón 25) "como son tan caras las semillas esas, de choclo por ejemplo, digamos....este año saqué, digamos, me lo guardé. Te sirve para los otros, digamos, por lo menos ya paso un año...La tengo que volver a comprar, digamos, para otro año, porque más o menos un año podes poner de la misma...la de choclo. Como ser la de acelga no....esa la seguís guardando...si es buena tu semilla la seguís guardando, digamos, esa no hay problema, podes continuar nomás con esa y el verdeo sí también, el verdeo si, vos seguís sacando año a año... Podes ir sacando y te sirve igual, te viene bien" (Bonicatto, 2011a. Entrevista a BV-renglón 16) "a comprando digamos, por ahí guardo para un año y para el otro de vuelta compro. Ya digamos con ese dinero que no compré este año ya voy ya teniendo para comprar para el otro año, y después vuelta así" (Bonicatto, 2011a. Entrevista a BV-renglón 33) "que esté buena digamos... que sea buena digamos, que estén las plantas lindas, las mas lindas las más grandes, no que estén pequeñitas....bueno el verdeo no, siempre se ve que hace toda su semilla igual, el verdeo.....el choclo también voy eligiendo los que son más lindos, más parejitos, los dientes más parejitos...y así" (Bonicatto, 2011a. Entrevista a BV-renglón 37)

B Técnicas de recolección, limpieza y secado de semillas para conservar

"cuando más calor hace la estoy sacando la, la flor, ya está madura, ya botando las semillitas ya. La saco, la pongo a secar al sol, y después la...la con alguna cosa la voy golpeando así para que se disuelvan las semillitas. Después para sacarla bien limpiecita la lavo, la lavo, es un trabajo bárbaro pero igual la lavo, y la pongo al sol, y la estoy ahí siempre desparramando con algún palito, o hago algún como dientitos y con eso voy removiendo para que se seque todo, bien así como si fuera comprada (Bonicatto, 2010c. Entrevista a BV-renglón 27) "tenés que poner a secar las chauchas o que esté bien sequita y le doy de golpe con un palo, pongo una lona, y le golpeo y ahí se abren las vainas y salen las semillas" (Bonicatto, 2010c. Entrevista a BV-renglón 188)

\section{Acondicionamiento y guardado}

"pero eso depende de, que cuidarla, mirá hay un.....el.....como se llama ¿el que le entra a la semilla? Un negrito...ese, ese, tenés que ponerle... algo a la semilla para que no......yo le pongo las pelotitas esa que es para....eh... (Naftalina) le hace efecto para la chaucha o el choclo, esa no le entra el bicho, hay que poner varias, varias...de esas pelotitas y ese olor es fuerte. [...] en una bolsa de plástico (lo guardo) una de plástico para que salga afuera el olor de la pastilla esta y el bicho no entre" (Bonicatto, 2010c. Entrevista a BV-renglón 165) "por ahí tengo semillas por ahí en esos tachos y yo les pongo para que no le entre el bicho esto nastalina que es la bolita blanca, eso le pongo y las mantiene igual ...no le deja entrar el bicho, porque sino enseguida le entra un bichito negrito, pero y con esto le mantiene, los corre, no le deja que vengan a comer" (Bonicatto, 2011a. Entrevista a BV-renglón 112) "los ratones se comen las semillas, pero por suerte como tengo los gatos no hay ratones! (Bonicatto, 2011a. Entrevista a BV-renglón 121) "ahí tengo en esos tachitos con tapa justo saqué el otro día para sembrar y lo otro que tengo en el tacho es porque no está limpiecita" (Bonicatto, 2011a. Entrevista a BV-renglón 122) "después ya te muestro los choclos también que sacó mi marido, a esos le puso una pintura azul de un polvo, digamos de un veneno, le puso para que no le entre ...el nomás lo puso de esos ...Un polvo azul, no sé cómo se llama, digamos...no es que es tan fuerte pero el bicho yo creo, no le deja acercar. Tengo que ponerle cuando compre...nastalina, yo conservo así y sé que no le hace, como no es veneno tampoco me va a hacer nada" (Bonicatto, 2011a. Entrevista a BV-renglón 217)

\section{Dificultades para la conservación}

"cuando voy a verla estaba toda comida el corazón! O sea donde va a salir el brote tenía como cinco kilos y toda comida! Del bicho. Tuve que tirarla. Y en otra tenía como cuatro kilos, esta estaba un poco sana porque les había puesto...también...me quería morir porque cuesta nomas...el sacar la semilla te cuesta...pero por 
suerte como tengo los gatos ¡no hay ratones! (Bonicatto, 2010c. Entrevista a BV-renglón 182) "como ser de verdeo tuve este año una que no sé como que se me....como hubo mucha sequia se me calló mucha, o sea no llegaba a madurar bien, hace así pimpollo chiquito y ya se caían no se por la sequía me parece y ahí perdí mucha, saqué poca este año, en cambio los otros años sacaba como 5 kilos y así limpiecita y ahora no, ahora no tendré ni un kilo" (Bonicatto, 2011a. Entrevista a BV-renglón 126)

E Experimentación y mejoramiento de semillas

JV

A Cultivo y selección de plantas para obtener

"ahora vuelvo a sacar semilla para dos años, porque pierde la fuerza de germinación, yo saco mucha semilla, no termino poniendo...que se yo....5 kilos, 10 kilos por año, por ahí lo que pongo no me termino toda la bolsa, pero sí tengo que sobra" (Bonicatto, 2011f. Entrevista a JV-renglón 20) "así de tres, cuatro años hace que cada vez que saco las semillas elijo el más larguito, porque se degeneran, es un cherry perita que es así, pero cuando pasan 2, 3 años que vas sacando la semilla se van haciendo más redonditos, entonces vos tenés que ir seleccionando el fruto para......y ahora ya lo debo tener para tres o cuatro años (E1 96) sacamos en general, son para poner en el siguiente año. Tomate también te dura dos años después ya pierde el poder de germinación" (Bonicatto, 2011f. Entrevista a JV-renglón 87) "la berenjena también la hago semilla, hace unos 7 u 8 años hice semillas" (Bonicatto, 2011f. Entrevista a JVrenglón 20) (E1 179) "de ahí estuve guardando semilla de una acelga de penca verde, es el primer año que lo voy a hacer" (Bonicatto, 2011f. Entrevista a JV-renglón 254) "frecuentemente estoy dejando 2 rayas, 3 rayas es suficiente pero como tenía roto el tractor y ya que está" (Bonicatto, 2011f. Entrevista a JV-renglón 264)

B Técnicas de recolección, limpieza y secado de semillas para conservar

"así en un tiempo vos la juntas y la sacudís en un nylon sale toda la semillita, yo la sabía sembrar al lado del zapallito con el mismo viento, pero esto es lo más fácil de sacar, como te digo, ahora como está lo sacas y lo guardas y cuando se seca lo sacudís y casi ni la ves, pero la plantas" (Bonicatto, $2011 f$. Entrevista a JV-renglón 219) "esta semilla vino buena, acá la tengo y voy a ver si la saco, a ver como viene, de acá a 15 ,20 días más ya está para sacar" (Bonicatto, 2011f. Entrevista a JV-renglón 259)

C Acondicionamiento y guardado

"las pones en una bolsa de nylon o en una bolsa de tela, para que no traspire, que no entre mucho aire" (Bonicatto, 2011f. Entrevista a JV-renglón 402)

D Dificultades para la conservación

"para colmo no puedo mucho porque trabajamos yo y mi viejo y mi mamá" (Bonicatto, 2011f. Entrevista a JV-renglón 91) "semillas de antes tengo pero ya no germinan nada y la que tenía la perdí toda" (Bonicatto, 2011f. Entrevista a JV-renglón 97) "esa era la que cultivaba para comer, y después la perdí la semilla, un año me fue mal, va tuve problema en la quinta con el motor de riego....no lo puse....y al siguiente año no lo puse y ahora lo perdí. Y ponía...no ponía mucho, ponía unas 10, 20 plantas" (Bonicatto, 2011f. Entrevista a JV-renglón 109) "sobre la experiencia de guardar zapallito híbrido: no vienen, digamos vos queres guardar del espejo y al siguiente año se te hace la mayoría todo blanco, asique si, o si tenés que comprarle" (Bonicatto, 2011f. Entrevista a JV-renglón 124) "perdés casi un mes y medio, dos meses en hacer la semilla pone un poco más...esa ya está para juntarla, y si tenés que sacarla todo son como tres meses y no te conviene" (Bonicatto, 2011f. Entrevista a JV-renglón 298) "acá cuando llueve mucho aparece la laucha, que vienen del campo, sino no, a veces las agarra el gato, el perro" (Bonicatto, 2011f. Entrevista a JV-renglón 406)

\section{E Experimentación y mejoramiento de semillas}

"me dieron semilla de brócoli para este año que puse allá un surquito para hacer semilla" (Bonicatto, 2011f. Entrevista a JV-renglón 40) "no vienen (los híbridos) digamos vos queres guardar del espejo y al siguiente año se te hace la mayoría todo blanco, asique si, o si tenés que comprarle, para mí el único que viene es el cherry, porque el tomate tampoco, el tomate la haces y te viene menos carga que el ...la cosecha...es mucha complicación en la semilla" (Bonicatto, 2011f. Entrevista a JV-renglón124) "tenés allá un zapallito comprado, no es el espejo pero traje una variedad parecida, y bueno, voy a ver si este año saco semilla de este" (Bonicatto, 2011f. Entrevista a JV-renglón 161) "originalmente la comparaba, ah 
¿la que guardo? Si, una vuelta compré, hice semilla para ver como venía y venía bien" (Bonicatto, 2011f. Entrevista a JV-renglón 182) "la híbrida no la pude sacar semilla, esta semilla es la sacada, Esta semilla es la sacada ¿ves? Lo que pasa es que cuando va pasando el año, es igual como el tomate, se va cambiando el fruto, cuando yo lo compré era un fruto más parejo, y después se hace como una especie de pera, y bueno, ya tenés que ir eligiendo la semilla de vuelta para rescatarla" (Bonicatto, 2011f. Entrevista a JV-renglón 186) "este es el platense, este es el que me dio Lolo. Estas 6 . Y este lo conseguí en la experimental de Gorina" (Bonicatto, 2011f. Entrevista a JV-renglón 326)

S

A Cultivo y selección de plantas para obtener

"yo el año pasado saqué cherry, un cherry más o menos como este, ahora lo sembré, y dieron viste que da una rama, ¡me dieron dos! ahora de esa rama todo de cherry me salió otra rama. Y cantidad de cherry, son unas plantitas cuantas que puse" (Bonicatto, 2014i. Entrevista a S-renglón 24) "cuando ya es tiempo que se brota y esos se me quedaron ahí y dije no voy a tirarle, por ahí va a salir algo" (Bonicatto, 2014i. Entrevista a S-renglón 78) "este año le puse cherry solo para ella porque a ella le guasta ayudarme a cosechar" (Bonicatto, 2014i. Entrevista a S-renglón 96) "lo sembré todo porque me quedó una mazorquita y sembré todo" (Bonicatto, 2014i. Entrevista a S-renglón 125)

B Técnicas de recolección, limpieza y secado de semillas para conservar

"dos mazorcas o tres me guardo y ya está" (Bonicatto, 2014i. Entrevista a S-renglón 34) "si mi hermana si ellos también guardaban...si los abuelitos también sabían guardar en unas vasijas bien para que no le entre el bicho" (Bonicatto, 2014i. Entrevista a S-renglón 41)

\section{Acondicionamiento y guardado}

D Dificultades para la conservación

"le entra la polilla" (Bonicatto, 2014i. Entrevista a S-renglón 34) "porque como no es de nosotros no podemos poner mucho" (Bonicatto, 2014i. Entrevista a S-renglón 58)

\section{E Experimentación y mejoramiento de semillas}

"en el pepino igual, cuando se nos hace así una cosa verde y amarilla y le sacamos, y ya para la próxima siembra le sembramos" (Bonicatto, 2014i. Entrevista a S-renglón 16) "yo un año puse, no viene la papa lisa, creo que es el clima no va" (Bonicatto, 2014i. Entrevista a S-renglón 87) "cuando voy a visitar (a Bolivia) me traía, o cuando vienen los abuelos de ella, ellos también se llevan para allá, de remolacha, morrón, tomate" (Bonicatto, 2014i. Entrevista a S-renglón 103)

\section{NA}

A Cultivo y selección de plantas para obtener

"dejamos el fruto para hacer semilla porque otra no queda, porque vos lees, escuchas y decís tenemos que hacer la semilla, lleva su tiempo hacer la semilla digamos hay que regar la planta cuidarla, que no se te caiga la semilla, cosechar cuando hay que cosechar" (Bonicatto, 2009d. Entrevista a NA-renglón 202) "después como hacemos con el orégano nosotros cuando el orégano esta en flor, esta lista para cosechar" (Bonicatto, 2009d. Entrevista a NA-renglón 206) "es la cebolla blanca que dejamos para hacer semilla, la primera vez, y este dará semilla en primavera" (Bonicatto, 2009d. Entrevista a NA-renglón 338)

B Técnicas de recolección, limpieza y secado de semillas para conservar

"los morrón chiquitos los que son picantes, todo eso, son semillas que hicimos nosotros acá, que ya vendrían a ser orgánicos no son semillas mejoradas" (Bonicatto, 2009d. Entrevista a NA-renglón 49)

\section{Acondicionamiento y guardado}

"acá en frasquitos hasta cuando corresponde la temporada y hacemos almácigos" (Bonicatto, 2009d. Entrevista a NA-renglón 65) "solo en papel, lo secamos bien seco, diario y después en frasquitos, guardado a lo oscuro nomas" (Bonicatto, 2009d. Entrevista a NA-renglón 75) "lo curamos con tierra de diatomeas y con eso y chau se conserva lo mas bien, nada de venenos viste que las semillas vienen todas con colores" (Bonicatto, 2009d. Entrevista a NA-renglón 81)

D Dificultades para la conservación 
"si es hibrido no podes guardar" (Bonicatto, 2009d. Entrevista a NA-renglón 41) "si es bastante complejo tratar de conseguirlas también pero de a poquito y si porque ya está muy mercantilizado todo" (Bonicatto, 2009d. Entrevista a NA-renglón 57) "el maíz nos duró como 3 años y la echamos por fin porque la estaban comiendo...claro, el gorgojo, y lo curamos ¿cómo se llama el polvito? tierra de diatomeas" (Bonicatto, 2009d. Entrevista a NA-renglón 77) "yo decía esas las que fracasaron podían haber sido semillas para San Juan, esa zona no para acá, porque acá llovió mucho, mucha humedad y por eso puede ser que no dieron acá, pero el nabo dio" (Bonicatto, 2009d. Entrevista a NA-renglón 95) "¡ojalá pudiésemos hacer de todo! De todas las verduras que tenemos acá, de hoja y de que no sea de hoja tampoco pero a veces viste de todo no se puede hacer, hay cosas que no podes hacer, y del....hay que ver del repollo como vienen" (Bonicatto, 2009d. Entrevista a NA-renglón 109) "cuando estábamos en la otra quinta también, y después cuando estuvimos acá fuimos una vez intercambiamos algunas, si, si...pero no es....porque tenés que tener mucha suerte o no sé que para...hay algunas que no vienen...no salen" (Bonicatto, 2009d. Entrevista a NA-renglón 139) "es mucho y somos poquitos" (Bonicatto, 2009d. Entrevista a NA-renglón 370) "la rúcula es más complicada, la variedad de la semilla es chiquita es mucho más trabajo, es más fácil, pero lo que guarda mas es lo mas grande, el tomate, la albahaca, el morrón el zapallito, ahora este año no se si se va a hacer porque lo atacó el pulgón, el anco también que quedó en la nada se te va de las manos y te quedaste sin semilla, te quedaste sin morrón casero, por hacer toda se quedó sin semilla, el año pasado es lindo hicimos del ají vinagre, del morrón todo casero no eran plantas compradas" (Bonicatto, 2009d. Entrevista a NA-renglón 374)

E Experimentación y mejoramiento de semillas

"estos como eran tomates ya orgánicos, eran mejoradas las semillas entonces guardamos, hicimos semilla de ese tomate" (Bonicatto, 2009d. Entrevista a NA-renglón 41) "constantemente con todo probamos...en cantidad no...si por ejemplo ahora de los tomates hicimos tomate, morrón hicimos, de los picantes de todo eso vamos haciendo un puchito de cada cosa porque acá siempre se trabaja con poquito, dos bandejas, tres bandejas entonces para el año se va dejando de vuelta" (Bonicatto, 2009d. Entrevista a NA-renglón 192) "¡hacíamos de todo! Zanahoria, arveja, hinojo, hacía de todo en otras épocas, en los últimos años ya no porque $\mathrm{N}$ no daba abasto, y hacía todo incluso el otro día encontramos semillas de hinojo pero ya no germina, ya no probé y no germina más" (Bonicatto, 2009d. Entrevista a NA-renglón 216) "para hacer semilla (el tomate largo), este también vino de orgánico (un cherry) nos dio una clienta este año que viene de familia casera" (Bonicatto, 2009d. Entrevista a NA-renglón 286) "yo te decía el primer año encontré una plantita y la dejé, van a ser dos años porque el primer año dio tres tomates más o menos y sacamos las semillas y lo volvimos a hacer y ahora vamos a...hacer, vos sabes que no tienen mucha semilla, y acá allá hay de todo porque soy la loca de las plantas" (Bonicatto, 2009d. Entrevista a NA-renglón 300) "vamos a hacer a ver si sale porque es muy difícil de conseguir la blanca, la inflada, vamos aprobar" (Bonicatto, 2009d. Entrevista a NA-renglón 344)

CV

A Cultivo y selección de plantas para obtener

"todo por allá atrás, en pedazos porque había que armarlo, no es que le tirabas cualquier semilla en cualquier lugar. Y a la vez tenías que mantener la semilla pura, porque sino el año que viene que ¿haces con esto? claro por otro lado manteníamos la semilla pura, y la pudimos mantener pura porque la separamos de ciclo y ya está. ¿O sea quien me va a polinizar el maíz que estuvo floreciendo hace veinte días?

Mira ese que esta ahí lo cortamos el otro día y fijate que esta blanquito mira" (Bonicatto, 2011j. Entrevista a CV-renglón 91) "fíjate este está húmedo si lo tocas, entonces los puros los mantenemos y lo tenemos acá inclusive en la chacra. Estos están puros, entonces vamos a poder hacer lo mismo de nuevo" (Bonicatto, 2011j. Entrevista a CV-renglón 101) "tenemos 9 variedades de ají, que las rescatamos de la feria. Éramos medio, muy específicos con ese tema, o sea, buscábamos lo que queríamos" (Bonicatto, 2011j. Entrevista a CV-renglón 136) "mirá acá arranca por el girasol rojo que hay ahí que es una experiencia" (Bonicatto, 2011j. Entrevista a CV-renglón 271) "o que pasa que el maíz es medio concreto, no es tan complicado, siempre que estés en los parámetros de siembra va, no es que tienen específicamente" (Bonicatto, 2011j. Entrevista a CV-renglón296)

B Técnicas de recolección, limpieza y secado de semillas para conservar

C Acondicionamiento y guardado 
"y zapallos tenemos varios, lo que pasa es que nosotros tenemos un depósito en Capital que es el sótano de un edificio, entonces sabemos que ahí no lo comen las ratas, no se llena de agua, y están ahí" (Bonicatto, 2011j. Entrevista a CV-renglón 149)

D Dificultades para la conservación

"esto lo que tratamos es de adaptarlos y no se adaptaron. También hay maíces que no se adaptaron directamente, hay maíces que están las plantas ahí, después te los muestro, que de la manera que lo rebotaron esta" (Bonicatto, 2011j. Entrevista a CV-renglón 171) "los maíces esos los sembramos y muchos no se adaptaron directamente, no dieron nada" (Bonicatto, 2011j. Entrevista a CV-renglón 176) "yo te diría que si falló, falló un 10 \% (de las semillas traídas de intercambios) porque los maíces hay unos que no se adaptaron, hay unos zapallos que no los pudimos adaptar, o sea, se adaptaron pero poquito, capaz que si volviéramos a sembrar otro año eso se adaptan, pero no se adaptaron" (Bonicatto, 2011j. Entrevista a CV-renglón 281) "el arroz tampoco funcionó, lo trajimos de Catamarca" (Bonicatto, 2011j. Entrevista a CV-renglón 285)

\section{E Experimentación y mejoramiento de semillas}

"tomamos por ejemplo este blanco, este y algún amarillo....ahí está el amarillo mira...yo les muestro acá, bueno...empezamos a averiguar cómo era, de esto hace dos años, lo hicimos, y no dio resultado ¿Por qué? Porque estas plantitas, yo no sé si sucede alguna pero...estas plantitas son las que producen este maicito, este el negro ¿ves? y estas (señalando otras) son las que producen esto o esto. Entonces lo primero que tuvimos que hacer es averiguar el tiempo de floración de estas...de estas...y de estas (señalando tres) y hacerlo coincidir, hay 15 días de diferencia, entonces sembramos esto 15 días después de esto...y florecieron juntas y recién ahí se cruzaron. Antes la habíamos sembrado el primer año juntos y no se cruzaron ¿entendes lo que nos paso? ¡No coincidía la floración! Entonces tuvimos que buscarle la vuelta a ver el tiempo de floración, a ver en cuanto floreció, cuanto tardó esta, cuanto tardó aquella, y recién lo pudimos hacer. Por acá hay algunas, ¿ves lo que iban saliendo? Mira esta...y por ahí vas a encontrar las chiquitas (mazorcas chiquitas). Mira las chiquitas ¿ves? entonces este era el color morado, el blanco lo sacábamos de este y el amarillo de aquel que les mostré. Entonces ahí les queda una cosa vista que más fácil que lo vean que contarles....por lo menos ya lo vieron acá" (Bonicatto, 2011j. Entrevista a CV-renglón 23) "yo supongo que va a pasar como en las razas y va a terminar dominando el negro" (Bonicatto, 2011j. Entrevista a CV-renglón 107) "el que no acepta combinación es este, Pero no se cruza por ciclo. Este es así de este color y no quiere cruzarse, pero porque le erramos en el ciclo no conocíamos el ciclo de este, tienen que quedar de este color, con blanco, así queda bonito (haciendo referencia a un maíz de grano color rojo). Pero ves que podes mantener a la línea pura. Pero, lo tenés que sacar de ciclo, si lo dejas ahí chau. Y esto era el descarte de lo que se vendió, están las mazorquitas que se nos habían cortado las hojas" (Bonicatto, 2011j. Entrevista a CV-renglón 109) 